\title{
(1)
}

UNIVERSIDAD PERUANA DE CIENCIAS APLICADAS

FACULTAD DE INGENIERÍA

CARRERA DE INGENIERÍA CIVIL

\section{CONTRIBUCIÓN DEL ASFALTO ESPUMADO EN EL APORTE ESTRUCTURAL DE PAVIMENTOS EN ALTURA COMO SOLUCIÓN PARA EL PROYECTO DE CONSERVACIÓN VIAL TACNA - PUNO, TRAMO CAPAZO - MAZOCRUZ}

\author{
Tesis \\ Para optar el título de Ingeniero Civil por: \\ Narro Vásquez, Piero Ricardo (0000-0003-0322-9102) \\ Morales Gazco, Enzo Aníbal (0000-0003-3395-3599) \\ Asesor: \\ MSc. Guillermo Lazo Lázaro
}

Lima, 09 de abril del 2018 


\section{Dedicatoria}

A Dios, por permitirme culminar esta importante etapa de mi vida y darme las fuerzas necesarias para nunca darme por vencido. A mis padres, Silvia Marisol Vásquez Garay y Ricardo César Narro García, por todo el apoyo que me brindaron a lo largo de mi carrera, por los consejos que me dieron en momentos decisivos y por su amor incondicional. Todo esto es gracias a ustedes.

A mi abuela Ela Garay Miranda, quien siempre fue testigo de las tantas noches de estudio que tuve. Gracias por apoyarme en todo y por cuidar de mí siempre.

A nuestro asesor MSc. Ing. Guillermo Lazo Lázaro, por todos los conocimientos, facilidades y experiencias que nos brindó a lo largo de esta investigación.

\section{Piero Narro}

A mis padres, Porfirio Morales y Carmen Gazco, por nunca dejar de apoyarme y de creer en mí.

A mis hermanos, por los consejos y el apoyo a lo largo de toda mi vida. A nuestro asesor MSc. Ing. Guillermo Lazo por la confianza, el soporte y las experiencias transmitidas gracias a los cuales pudimos realizar este trabajo de investigación.

Enzo Morales 


\section{RESUMEN}

La presente investigación plantea como solución novedosa, desde el punto de vista técnico y económico, la pavimentación de vías con materiales granulares estabilizados con asfalto espumado ante el gran porcentaje de vías que tiene el Sistema Nacional de Carreteras (SINAC) sin pavimentar. Dicha investigación se llevó a cabo en el Proyecto "Servicio de Gestión, Mejoramiento y Conservación Vial por Niveles de Servicio del Corredor Vial: Dv. Humajalso

- Desaguadero y Tacna - Tarata - Capazo - Mazocruz", específicamente en el tramo VIII (Capazo - Mazocruz).

A medida que se profundiza en la investigación, se realiza una extensa revisión bibliográfica sobre la Tecnología del Asfalto Espumado, en donde se explica la definición e historia del asfalto espumado, para luego desarrollar su producción y sus aplicaciones. Se da pase a la Descripción del Proyecto, en donde se muestran sus antecedentes, ubicación, características principales y, estudio de suelos y canteras. A continuación, se explica el Diseño de Mezcla con Asfalto Espumado en laboratorio, allí se mencionan las características de los materiales granulares a ser mezclados, las características de los ligantes a usar y la calidad de espumación. Se desarrolla el Análisis Estructural del Pavimento en donde se lleva a cabo el método de diseño de pavimentos flexibles AASHTO 93, encontrando el número estructural requerido y el número estructural propuesto de los diseños con la finalidad de compararlos. Finalmente, se realiza la comparación estructural de un pavimento sin estabilización contra un pavimento estabilizado con asfalto espumado, con la finalidad de observar en qué medida aumentó el aporte estructural de este último.

Palabras clave: Asfalto espumado, estabilización con asfalto espumado, pavimento flexible 


\section{ABSTRACT}

The present investigation proposes as a novel solution, from the technical and economic point of view, the paving of roads with granular materials stabilized with foamed bitumen before the great percentage of roads that the National Road System (SINAC) has unpaved. This investigation was carried out in the Project "Servicio de Gestión, Mejoramiento y Conservación Vial por Niveles de Servicio del Corredor Vial: Dv. Humajalso - Desaguadero y Tacna - Tarata - Capazo - Mazocruz ", specifically in section VIII (Capazo - Mazocruz).

As the investigation is deepened, an extensive literature review is made on the Foam Asphalt Technology, where the definition and history of foamed bitumen is explained, in order to later develop its production and its applications. The description of the Project is given, where its antecedents, location, main characteristics and, study of soils and quarries are shown. Next, the Mixing Design with Foamed Asphalt in the laboratory is explained, there are mentioned the characteristics of the granular materials to be mixed, the characteristics of the binders to be used and the quality of foaming. The Structural Analysis of the Pavement is developed where the AASHTO 93 flexible pavements design method is carried out, finding the required structural number and the proposed structural number of the designs in order to compare them. Finally, the structural comparison of a pavement without stabilization against a stabilized pavement with foamed bitumen is carried out, in order to observe the extent to which the structural contribution of the latter increased.

Keywords: Foamed asphalt, stabilization with foamed bitumen, flexible pavement 


\section{TABLA DE CONTENIDO}

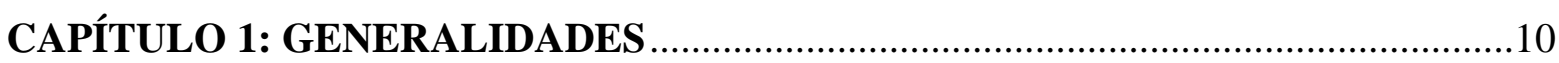

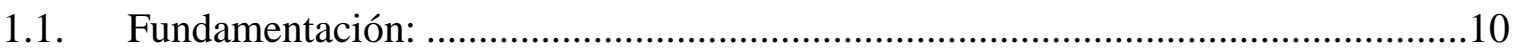

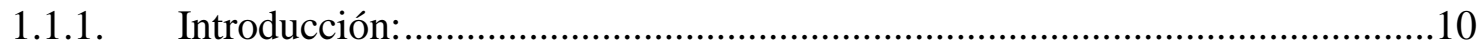

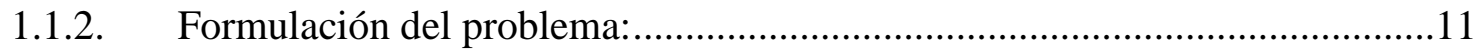

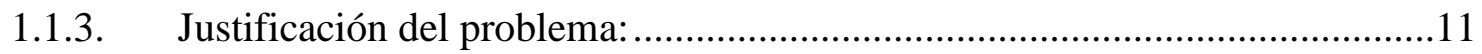

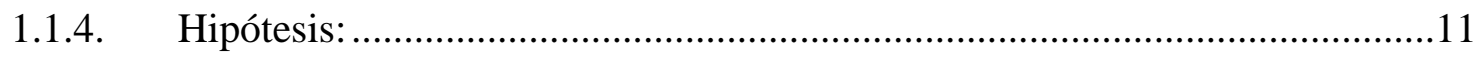

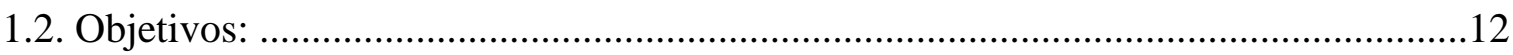

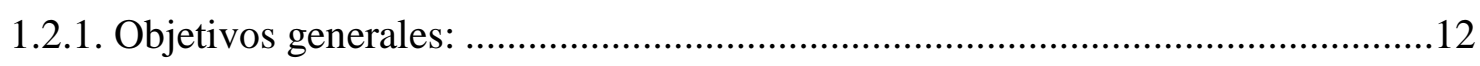

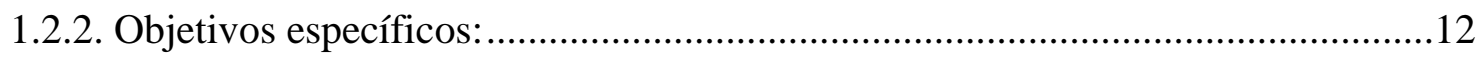

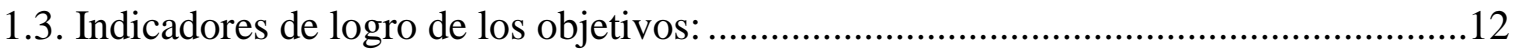

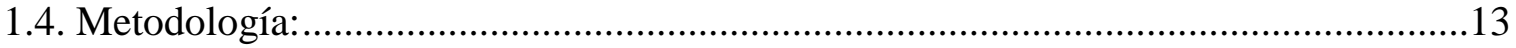

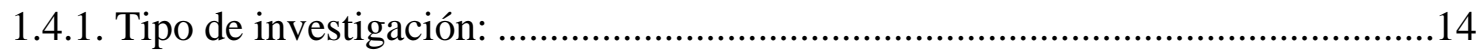

CAPÍTULO 2: DEFINICIONES Y CONCEPTOS BÁSICOS ...................................15

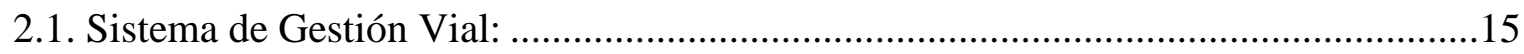

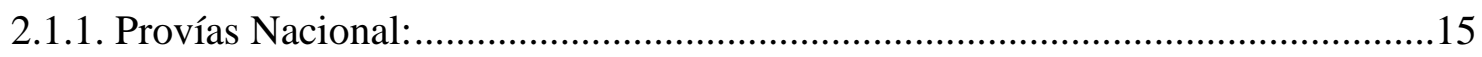

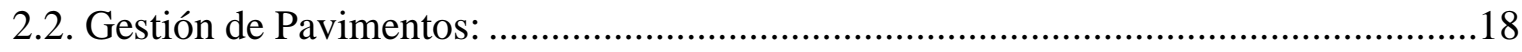

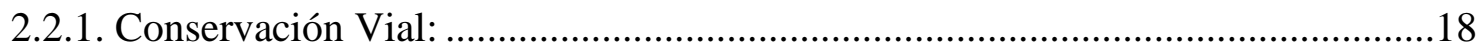

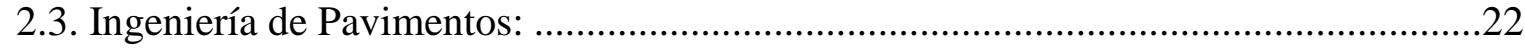

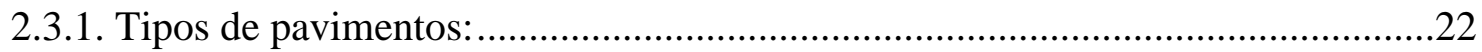

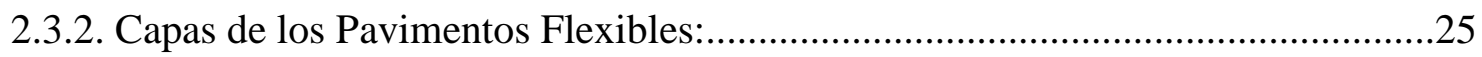

2.3.3. Métodos de diseño de Pavimentos Flexibles:...................................................27

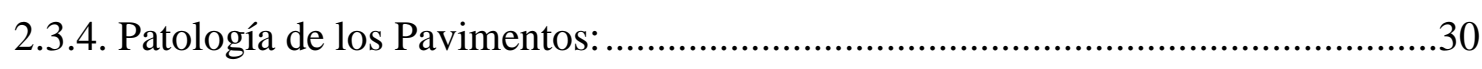

CAPÍTULO 3: MARCO REFERENCIAL Y TEÓRICO ................................................

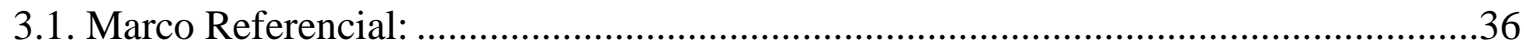

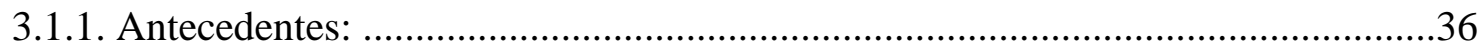

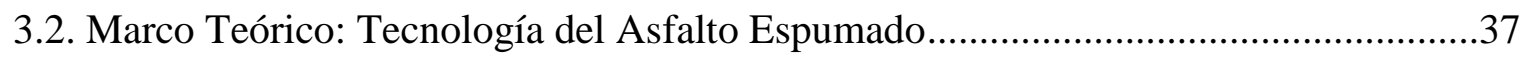

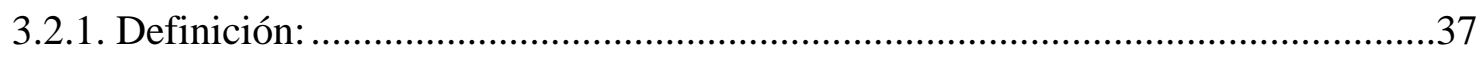

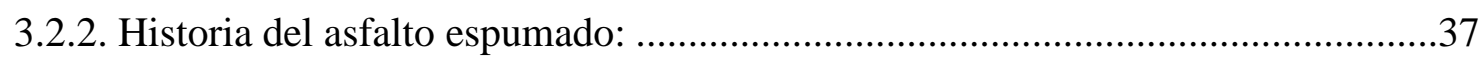

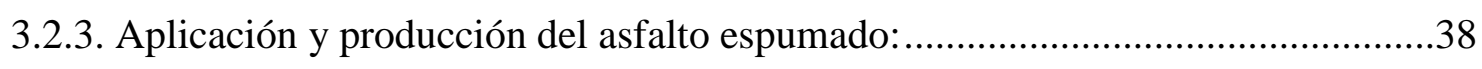

3.2.4. Caracterización geotécnica de los áridos para el Asfalto Espumado: ..................48 


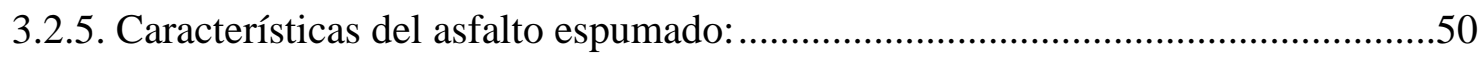

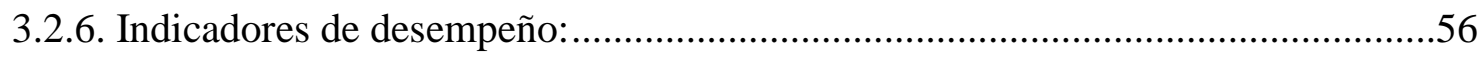

3.2.7. Diseño de la capa estabilizada con asfalto espumado: ......................................58

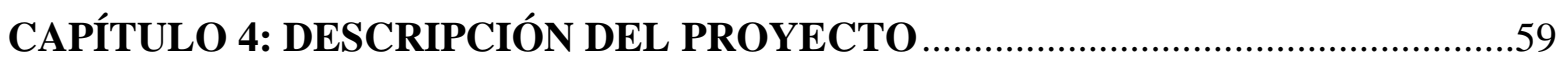

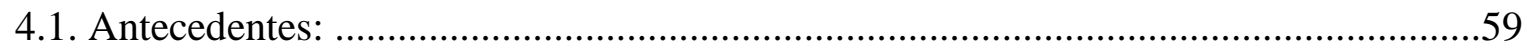

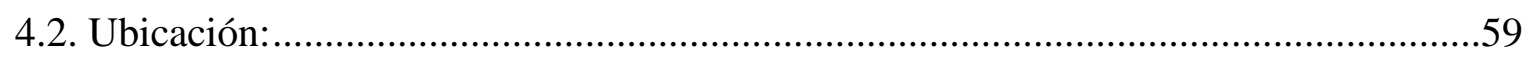

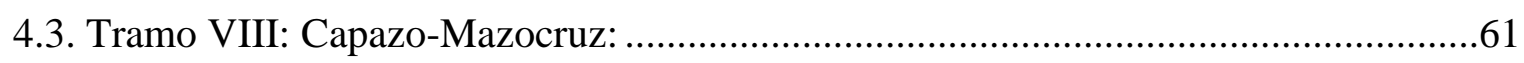

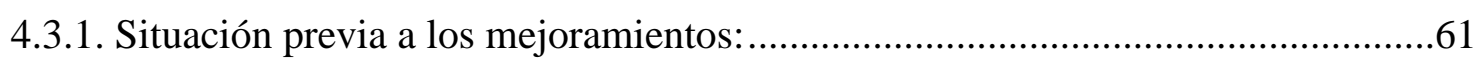

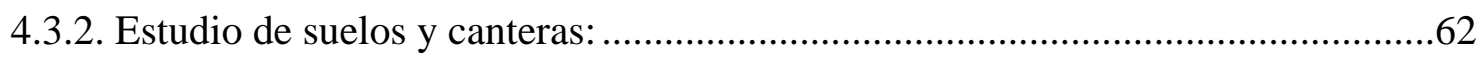

CAPÍTULO 5: DISEÑO DE MEZCLA DE ASFALTO ESPUMADO …......................65

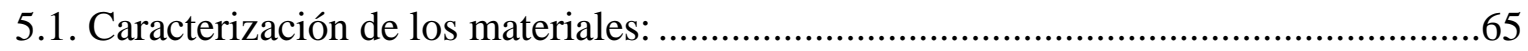

5.1.1. Caracterización de los agregados geotécnicos: ...............................................65

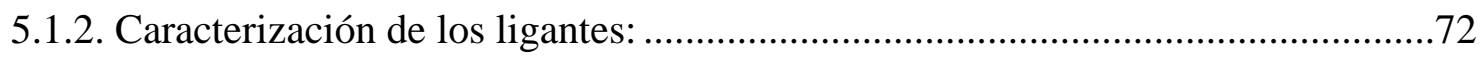

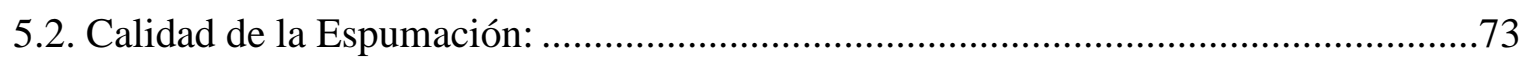

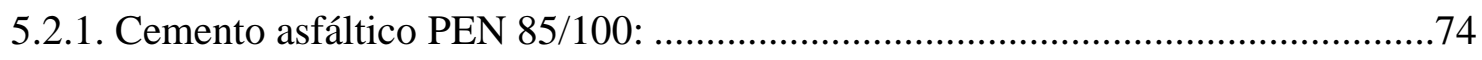

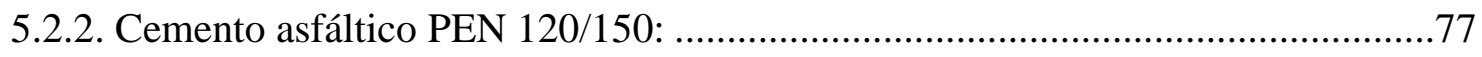

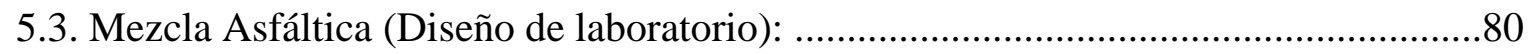

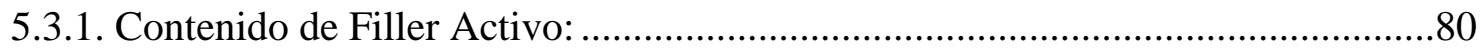

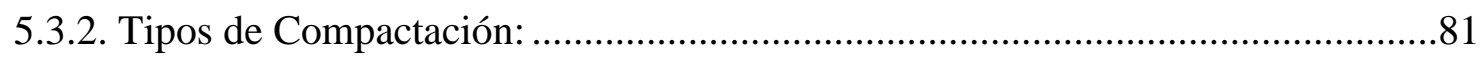

5.3.3. Ensayo de Tracción Indirecta (ITS): ............................................................. 83

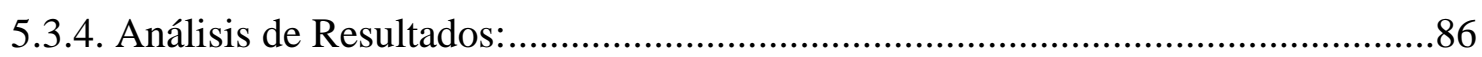

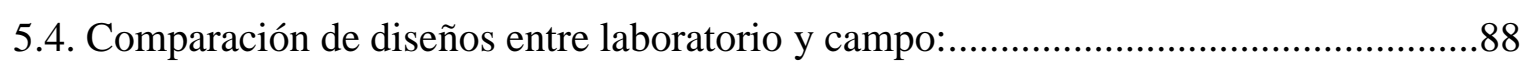

CAPÍTULO 6: DISEÑO ESTRUCTURAL DEL PAVIMENTO ..................................91

6.1. Método de Wirtgen para hallar el coeficiente de aporte estructural (a): .....................91

6.1.1. Coeficiente de aporte estructural para el Diseño 1 (2.0\% - PEN 85/100):...........93

6.1.2. Coeficiente de aporte estructural para el Diseño 2 (1.5\% - PEN 120/150):..........94

6.1.3. Coeficiente de aporte estructural para el Diseño 3 (2.0\% - Pen 120/150): ..........95

6.2. Método de diseño de pavimentos flexibles AASHTO 93: ........................................96

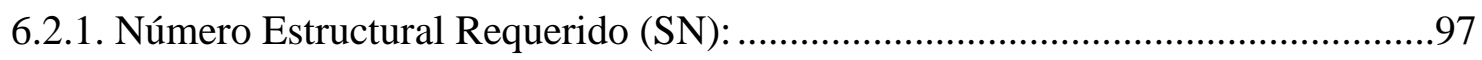

6.2.2. SN's Propuestos para los diseños realizados:...................................................... 101

6.3. Comparación estructural entre un pavimento sin estabilizar y un pavimento estabilizado con asfalto espumado: 106 


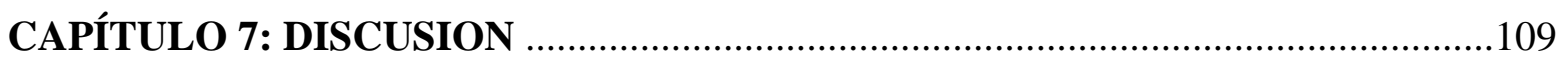

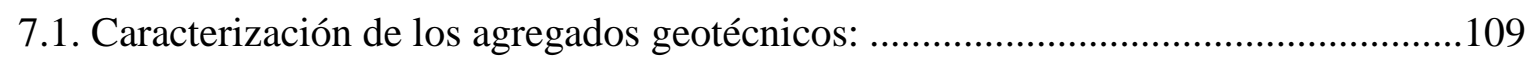

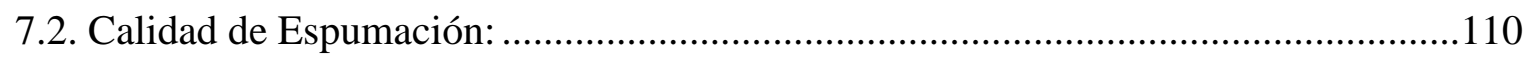

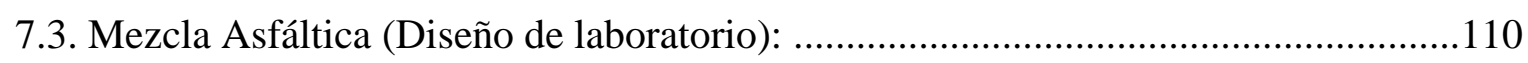

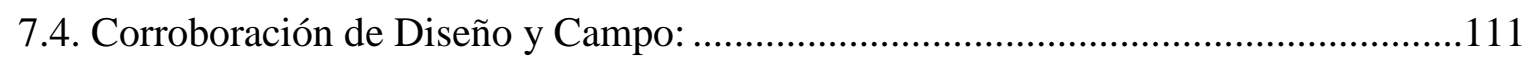

7.5. Coeficientes de aporte estructural (Método de Wirtgen): .........................................112

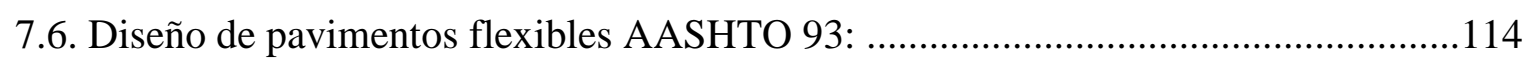

CAPÍTULO 8: CONCLUSIONES Y RECOMENDACIONES ...................................115

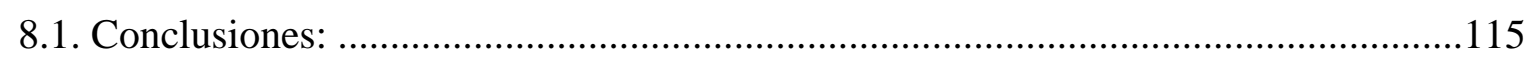

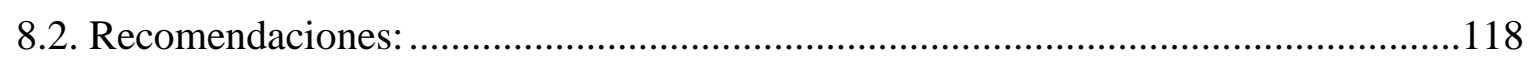

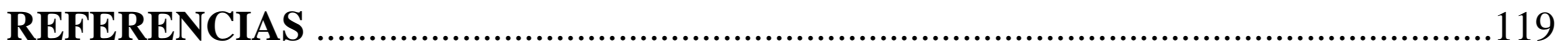

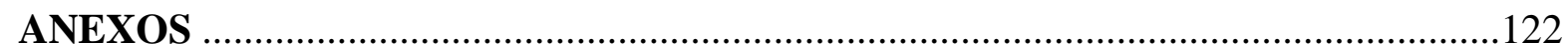




\section{ÍNDICE DE FIGURAS}

Fig. 2.1: Integración de los corredores económicos a lo largo del Perú .................................16

Fig. 2.2: Corredores Viales del Proyecto Perú 2 .................................................................17

Fig. 2.3: Desarrollo del concepto de conservación vial en el Perú ........................................19

Fig. 2.4: Etapas de un Contrato de Conservación Vial por Niveles de Servicio ....................21

Fig. 2.5: Distribución de los esfuerzos a través del pavimento rígido. .................................23

Fig. 2.6: Sección transversal de un pavimento semi-rígido.................................................23

Fig. 2.7: Sección transversal de un pavimento semi flexible. ............................................24

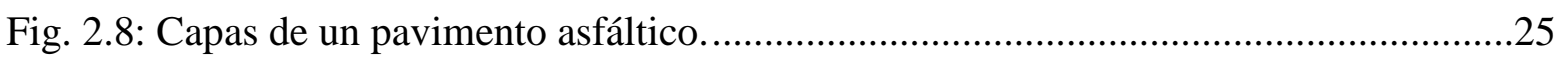

Fig. 2.9: Ecuación AASHTO para diseño de pavimentos flexibles. ......................................28

Fig. 2.10: Modelos utilizados en el diseño mecanístico empírico de pavimentos .................29

Fig. 2.11: Ecuación para la determinación del PSI....................................................................31

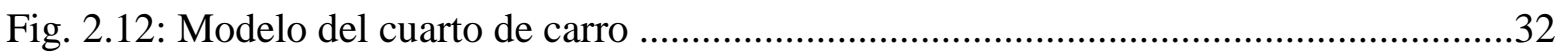

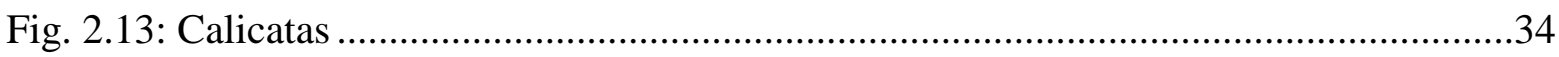

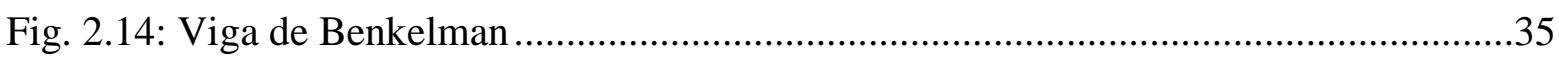

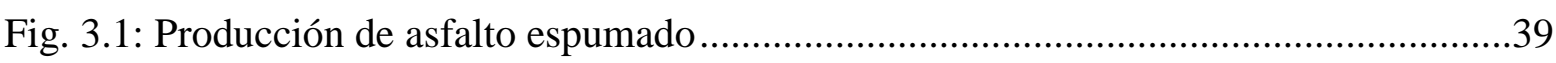

Fig. 3.2: Dispersión del asfalto espumado en la matriz de finos ..........................................40

Fig. 3.3: Equipo fresador-mezclador e inyección de asfalto espumado................................43

Fig. 3.4: Tren reciclador con mezclador de lechada y camión de asfalto...............................43

Fig. 3.5: Mezcladora móvil de reciclado en frío KMA 220 .................................................44

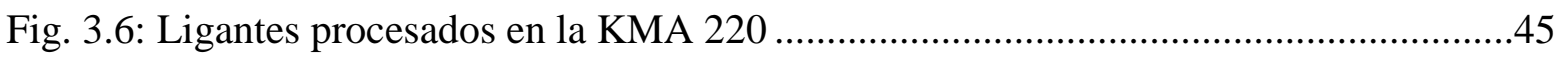

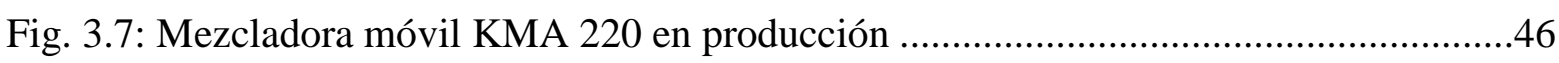

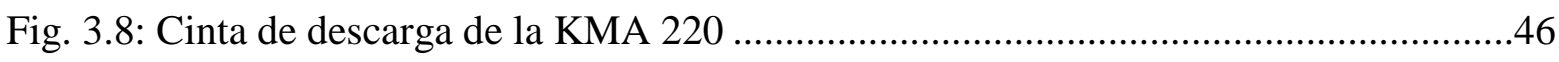

Fig. 3.9: Mezcladora móvil preparada para el transporte .................................................47

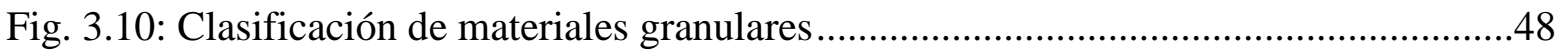

Fig. 3.11: Burbuja de asfalto espumado aislada ....................................................................50

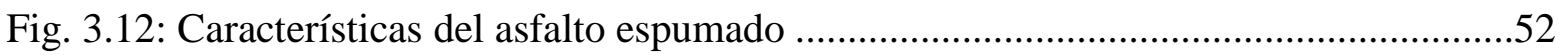

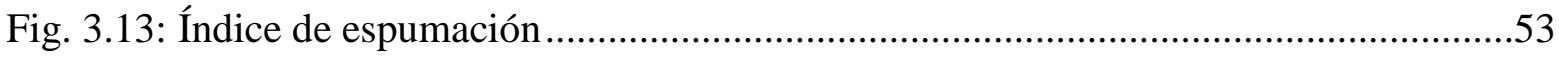

Fig. 3.14: Relación entre Razón de expansión y Vida media...............................................54

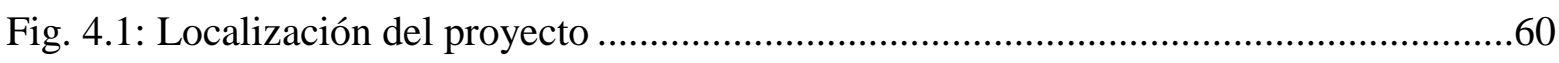

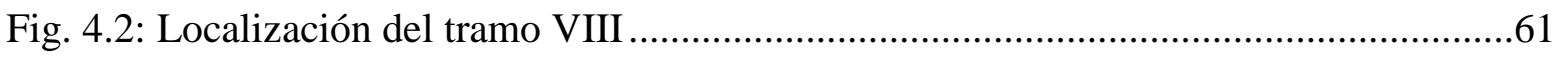




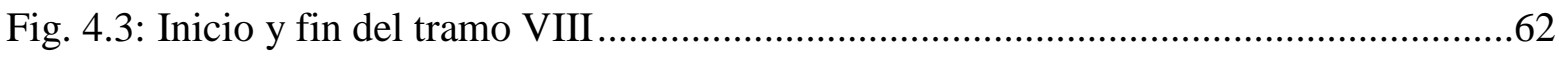

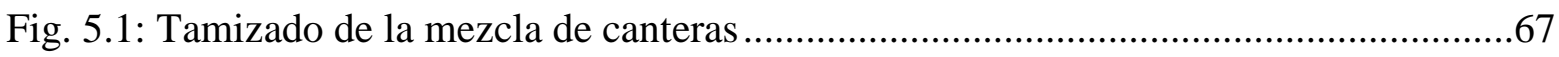

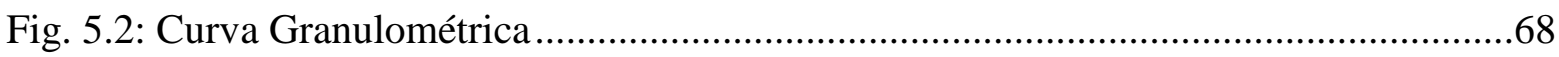

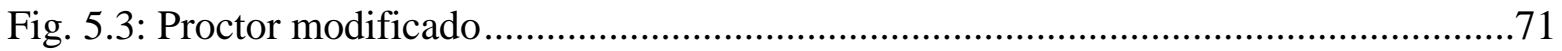

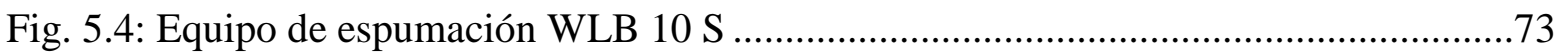

Fig. 5.5: Índice de espumación: Razón de expansión vs. Tiempo de vida media ..................75

Fig. 5.6: Determinación del óptimo contenido de agua para espumación para $\mathrm{T}=160^{\circ} \mathrm{C} \ldots . . .76$

Fig. 5.7: Índice de espumación: Razón de expansión vs. Tiempo de vida media ..................78

Fig. 5.8: Determinación del óptimo contenido de agua para espumación para $\mathrm{T}=180^{\circ} \mathrm{C} \ldots . . .79$

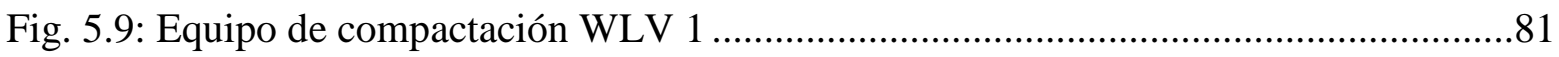

Fig. 5.10: Briquetas desmoldadas y dejadas en reposo ........................................................84

Fig. 5.11: Máquina de compresión para ensayo de Tracción Indirecta ..................................85

Fig. 5.12: Material disperso en campo y recolección para elaboración de briquetas .............88

Fig. 6.1: Coeficiente de aporte estructural sugerido para capas estabilizadas con asfalto

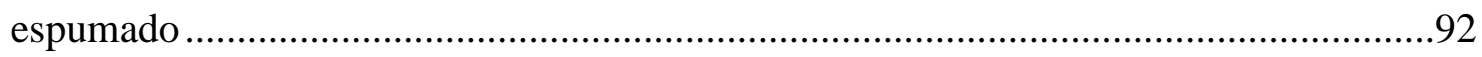

Fig. 6.2: Coeficiente de aporte estructural para Diseño 1 (2.0\% - PEN 85/100) ...................93

Fig. 6.3: Coeficiente de aporte estructural para Diseño 2 (1.5\% - PEN 120/150) .................94

Fig. 6.4: Coeficiente de aporte estructural para Diseño 3 (2.0\% - PEN 120/150) .................95

Fig. 6.5: Ecuación para el diseño estructural de pavimentos Método AASHTO 93 _.............96

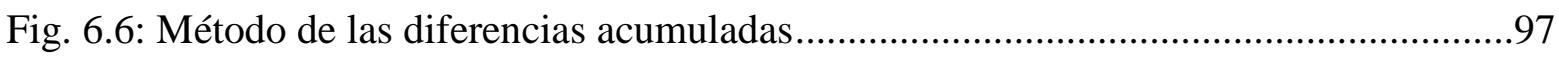

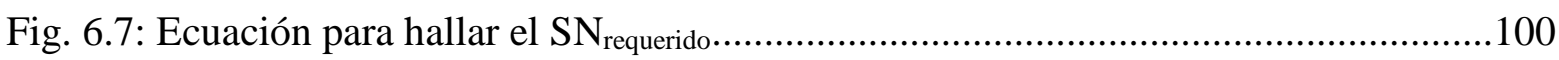

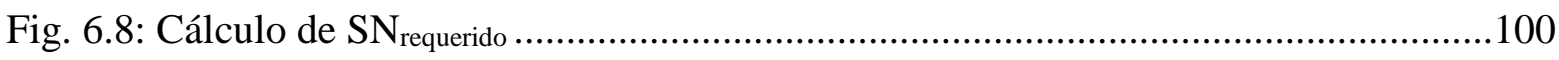

Fig. 6.9: Ecuación para el diseño estructural de pavimentos Método AASHTO 93 ............101

Fig. 6.10: Ábaco para hallar el coeficiente de aporte estructural de la sub-base...................102

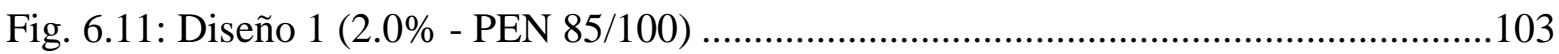

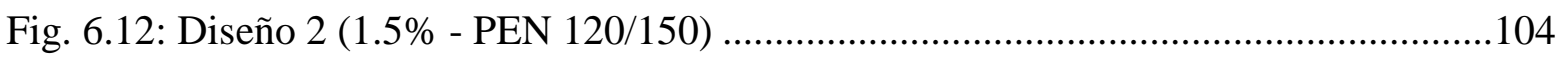

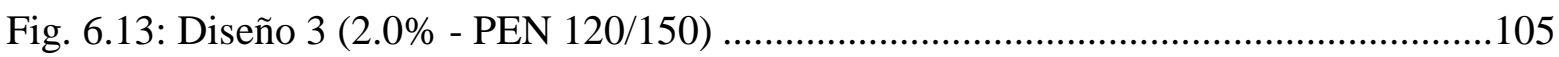

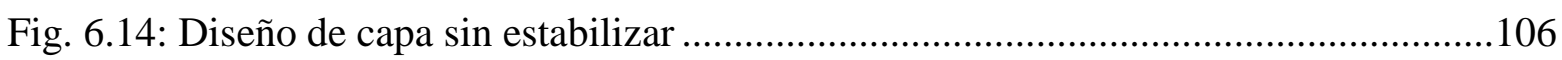

Fig. 6.15: Configuración de pavimento con capa sin estabilizar........................................108

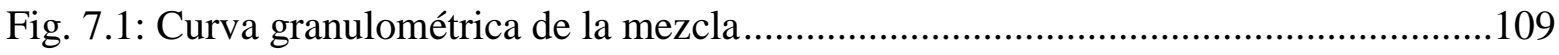

Fig. 7.2: Producción de mezcla asfáltica y recolección de material para ensayo de Tracción Indirecta 


\section{ÍNDICE DE TABLAS}

Tabla 3.1: Incorporación de cemento a la mezcla con asfalto espumado.............................49

Tabla 4.1: Canteras identificadas para el tramo VIII.........................................................64

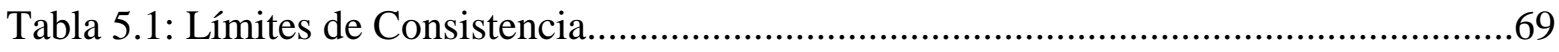

Tabla 5.2: Resumen de ensayo de límites de consistencia ...............................................69

Tabla 5.3: Peso específico y absorción de los agregados .....................................................70

Tabla 5.4: Resumen de ensayos de espumación PEN 85/100 .............................................74

Tabla 5.5: Resumen de condiciones óptimas de espumación...............................................77

Tabla 5.6: Resumen de ensayos de espumación PEN 120/150 ...........................................77

Tabla 5.7: Resumen de condiciones óptimas de espumación...............................................80

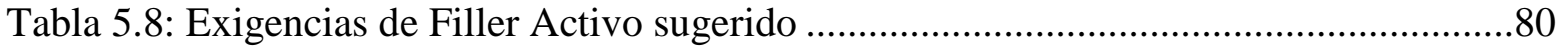

Tabla 5.9: Resultados del ensayo de ITS para cemento asfáltico PEN 85/100 .....................86

Tabla 5.10: Resultados del ensayo de ITS para cemento asfáltico PEN 120/150 .................87

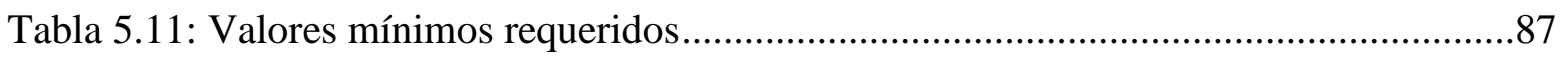

Tabla 5.12: Resultados del ensayo de resistencia a la Tracción Indirecta (ITS) ...................89

Tabla 5.13: Resultados del ensayo de ITS de la muestra realizada en laboratorio.................90

Tabla 6.1. Tabla resumen de los resultados de ITS de los diseños de mezcla propuestos.....91

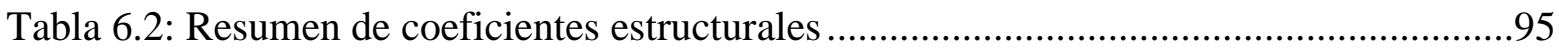

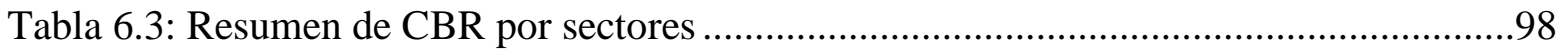

Tabla 6.4: Confiabilidad estadística y desviación estándar...............................................99

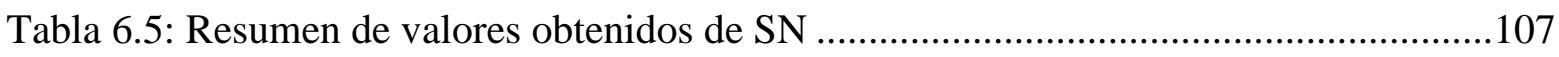

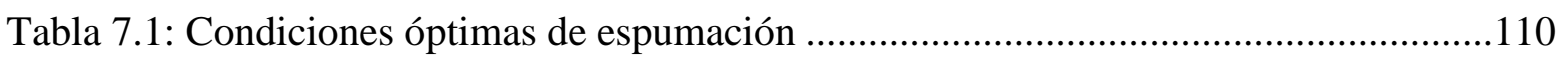

Tabla 7.2: Resumen de resultados del ensayo de Tracción Indirecta (ITS) ........................111

Tabla 7.3: Resumen de resultados del ensayo de Tracción Indirecta (ITS) ........................112

Tabla 7.4: Valores que cumplieron los valores mínimos requeridos .................................112

Tabla 7.5: Resumen de Coeficientes de Aporte Estructural ...............................................113

Tabla 7.6: Comparación de números estructurales $(\mathrm{SN})$..................................................114 


\section{CAPÍTULO 1: GENERALIDADES}

\subsection{Fundamentación:}

\subsubsection{Introducción:}

En la actualidad, la mayor parte de los principales corredores nacionales se encuentran pavimentados; sin embargo, hay un gran porcentaje de vías que están en un estado deficitario, lo cual ocasiona que los usuarios se vean afectados directamente, ya que el tiempo de transporte es mayor y por consecuencia se generan costos extras.

El Sistema Nacional de Carreteras (SINAC), que está compuesta por la Red Vial Nacional, Departamental y Distrital, según el Decreto Supremo que se encuentra en la página web oficial del Ministerio de Transportes y Comunicaciones (MTC), tiene una extensión de 140,672.36 km, de los cuáles, el 86\% se encuentra sin pavimentar. Además, del total de kilómetros que se encuentran sin pavimentar, el 91.9\% pertenecen a la Red Vial Departamental y Distrital. ${ }^{1}$

Frente a esta situación, se requiere una solución viable para pavimentar estos caminos. Es por ello que los pavimentos diseñados con materiales granulares son una alternativa, ya que, a diferencia de un pavimento flexible estándar, no contienen una carpeta asfáltica como última capa estructural, sino que debido a las menores cargas de tráfico a las que será sometido, su carpeta estructural está compuesta por una capa sub-base granular y una base granular estabilizada. Esta última es la que tiene un mayor aporte a la estructura del pavimento.

En la presente edición del Manual de Carreteras RD N²2-2013-MTC/14, existe un capítulo dedicado a afirmados, en la cual se habla de suelos estabilizados con emulsión asfáltica. No obstante, existe un método constructivo que se viene utilizando en otras partes del mundo y que ha demostrado mejores resultados desde el punto de vista técnico y económico. Se trata de la estabilización de suelos con asfalto espumado.

\footnotetext{
${ }^{1}$ D.S.No $012-2013-\mathrm{MTC}$
} 
Sin embargo, en nuestras normas técnicas no se ha desarrollado este tema, por lo que existe una falta de conocimiento de cuan eficiente puede llegar a ser este método constructivo, teniendo en cuenta las condiciones de nuestro país, tanto climáticas como topográficas.

Asimismo, no sabemos con certeza en qué medida contribuirá estructuralmente en todo el paquete del pavimento, teniendo en cuenta las condiciones ya mencionadas.

\subsubsection{Formulación del problema:}

Para las condiciones del Proyecto de Conservación Vial Tarata - Capazo - Mazocruz, las cuales son el tráfico proyectado y una vida útil de 6 años. ¿En qué medida, una estabilización con asfalto espumado contribuirá en el aporte estructural del pavimento en altura y cumplirá con los requisitos estructurales, analizando el porcentaje de asfalto inyectado y el grado de penetración hasta alcanzar el diseño óptimo, con la finalidad de ser una solución viable en el aspecto técnico?

\subsubsection{Justificación del problema:}

Es importante tratar esta problemática, pues el uso de asfaltos espumados es relativamente nuevo en el Perú. En el marco de los nuevos contratos de conservaciones viales, en los que el contratista conservador puede proponer su solución constructiva, el uso de asfalto espumado es una beneficiosa alternativa, pues viene siendo utilizado en otros países en donde los resultados han sido satisfactorios desde el punto de vista técnico y económico. Por esta razón, la investigación planteada contribuirá al conocimiento de estabilizaciones con asfalto espumado en el Perú y su comportamiento frente a variables inherentes a la de nuestra geografía, específicamente en el aporte estructural de pavimentos en altura.

\subsubsection{Hipótesis:}

Los pavimentos diseñados con materiales granulares estabilizados con asfalto espumado a una altura de más de 4500 m.s.n.m., en atención a las condiciones termodinámicas del lugar y para los materiales existentes, son una solución para aumentar la resistencia estructural del pavimento, cumpliendo con los requisitos estructurales del proyecto. 


\subsection{Objetivos:}

\subsubsection{Objetivos generales:}

Comprobar la efectividad en el aumento de la resistencia estructural del pavimento a más de 4500 m.s.n.m. en el Perú utilizando la tecnología de asfaltos espumados para las condiciones de diseño requeridas en el Tramo VIII del proyecto "Servicio de Gestión, Mejoramiento y Conservación Vial por Niveles de Servicio del Corredor Vial: Dv. Humajalso - Desaguadero y Tacna - Tarata - Capazo - Mazocruz"; analizando las propiedades fundamentales del ligante, inherentes a la mezcla con asfalto espumado.

\subsubsection{Objetivos específicos:}

- Evaluar las características/propiedades de los elementos que se encuentran en disposición del proyecto que componen la mezcla del asfalto espumado; como son los agregados, el agua y el asfalto.

- Asegurar la calidad de espumación óptima a través de los valores de razón de expansión y tiempo de vida media, variando la temperatura del asfalto y el porcentaje de agua presurizada, considerando asfaltos con diferentes grados de penetración.

- Evaluar a través del Ensayo de Tracción Indirecta (ITS) diferentes diseños de mezcla de laboratorio de la capa estabilizada con asfalto espumado, variando el contenido de asfalto inyectado y el grado de penetración del asfalto, y validarlos con lo realizado en campo.

- Analizar el desempeño del pavimento, validando la necesidad de estabilizar una capa con asfalto espumado, de manera tal que satisfaga las condiciones estructurales del proyecto, según el método de diseño AASHTO 93.

\subsection{Indicadores de logro de los objetivos:}

- Aumentar el conocimiento con respecto al diseño de los pavimentos con bases espumadas.

- Incrementar la eficiencia de las bases estabilizadas con asfalto espumado a partir de los diferentes diseños realizados.

- Comprobar las propiedades del pavimento diseñado utilizando una base espumada contra otra base sin espumar. 


\subsection{Metodología:}

La presente investigación se divide en cuatro etapas con la finalidad de satisfacer los objetivos planteados y justificar la hipótesis planteada.

\section{Etapa: Recolección de información teórica}

Se realizó una exhaustiva revisión bibliográfica en bibliotecas y sitios webs que tengan fuentes de información referente al tema con el fin de determinar los principales factores que afectan al aporte estructural de un pavimento.

\section{Etapa: Visita al lugar de estudio}

Se visitó la Carretera Desvío Humajalso - Desaguadero y Tacna - Tarata - Capazo -Mazocruz con la finalidad de observar, evaluar y poder recopilar material fotográfico acerca de la situación actual en el que se encuentra el proyecto. Asimismo, se tomaron muestras de los agregados de las distintas canteras de donde se sacó material granular para realizar la mezcla asfáltica con asfalto espumado y el diseño estructural del pavimento para las condiciones de tráfico del proyecto a tratar.

\section{Etapa: Análisis, diseño y comparación de la información obtenida}

Una vez recopilada la información y los materiales y/o muestras pertenecientes al proyecto, se procede a analizar los diferentes factores que implicarán un impacto en el desempeño del pavimento. Por otro lado, se realizaron diseños de mezcla junto a todos los ensayos requeridos para la misma. Para ello, se definen variables dependientes para medir el aporte estructural de la estabilización y de su aporte en la estructura del pavimento. Estas variarán según los parámetros que se definan más adelante.

\section{Etapa: Conclusiones y recomendaciones}

A partir de los resultados obtenidos y del análisis realizado se obtuvieron conclusiones de cómo varía el aporte estructural de los pavimentos con asfalto espumado, bajo las condiciones ya mencionadas. Asimismo, se realizan recomendaciones consideradas pertinentes para futuras investigaciones. 


\subsubsection{Tipo de investigación:}

- Por el tipo de análisis:

Es cuantitativo, debido a que se trabaja con aspectos observables y medibles a la realidad. En la presente investigación se definen dos variables relacionadas entre sí (asfalto espumado y aporte estructural del pavimento), en donde el asfalto espumado a su vez está compuesto por el porcentaje de asfalto inyectado y grado de penetración del asfalto, variables que intervienen y aterrizan como parámetros medidos con metodologías a fin de interpretar sus resultados y compararlos con valores admisibles.

\section{- Por el nivel de complejidad o alcance:}

Es correlacional, debido a que se evalúa el grado de vinculación que se tiene entre las dos variables definidas (asfalto espumado y aporte estructural del pavimento) y se sabrá cómo es el comportamiento de una de las variables (aporte estructural del pavimento) con respecto a la variación de la otra (asfalto espumado). Además, contiene un valor explicativo parcial, ya que sólo por el hecho de saber cómo dos variables se relacionan aporta cierta información explicativa.

\section{- Según la fuente de información:}

Investigación de campo y de laboratorio.

\section{- Según el tiempo:}

Es transversal, debido a que los resultados fueron medidos inmediatamente después de realizar los ensayos respectivos. 


\section{CAPÍTULO 2: DEFINICIONES Y CONCEPTOS BÁSICOS}

\subsection{Sistema de Gestión Vial:}

La Gestión Vial es un acuerdo entre el organismo vial y una empresa, que conlleva al traspase de la gestión de una o varias vías. En dicha Gestión Vial se determinará qué medidas deben de tomarse para poder alcanzar las condiciones de conservación y desarrollo que se hayan definido como convenientes e incluye la ejecución física de las actividades y obras de conservación y construcción necesarias (Bull A., 2003). En base a la definición de Gestión Vial y con la finalidad de promover la conservación y desarrollo de la infraestructura vial en nuestro país, se crea el Proyecto Perú 1, en donde los nuevos proyectos de corredores viales implementan un nuevo Sistema de Gestión Vial, que tiene como alcance: la construcción, rehabilitación, mejoramiento, conservación, atención de emergencias viales y control en las operaciones de la red vial nacional.

\subsubsection{Provías Nacional:}

Proyecto especial del Ministerio de Transportes y Comunicaciones que está encargado de la ejecución de proyectos de construcción, mejoramiento, rehabilitación y mantenimiento de la Red Vial Nacional, con el fin de brindar a los usuarios un medio de transporte eficiente y seguro, que contribuya a la integración económica y social del país. ${ }^{2}$ Incluye la preparación, gestión, administración y ejecución de proyectos inversión, conservación y seguridad de las carreteras y puentes de la red no concesionada.

\subsubsection{Proyecto Perú 1:}

Programa de infraestructura vial creado por el Ministerio de Transportes y Comunicaciones en el año 2007, a través de Provías Nacional, con la finalidad de mejorar las vías de integración de corredores económicos en la Red Vial Nacional, Red Vial Departamental y Red Vial

\footnotetext{
2 PROVIAS NACIONAL, Ministerio de Transporte y Comunicaciones, http://www.proviasnac.gob.pe/frmNosotros.aspx?idmenu=1
} 
Vecinal.

A continuación, en la Fig. 2.1 se muestran las vías de integración a lo largo de nuestro país:

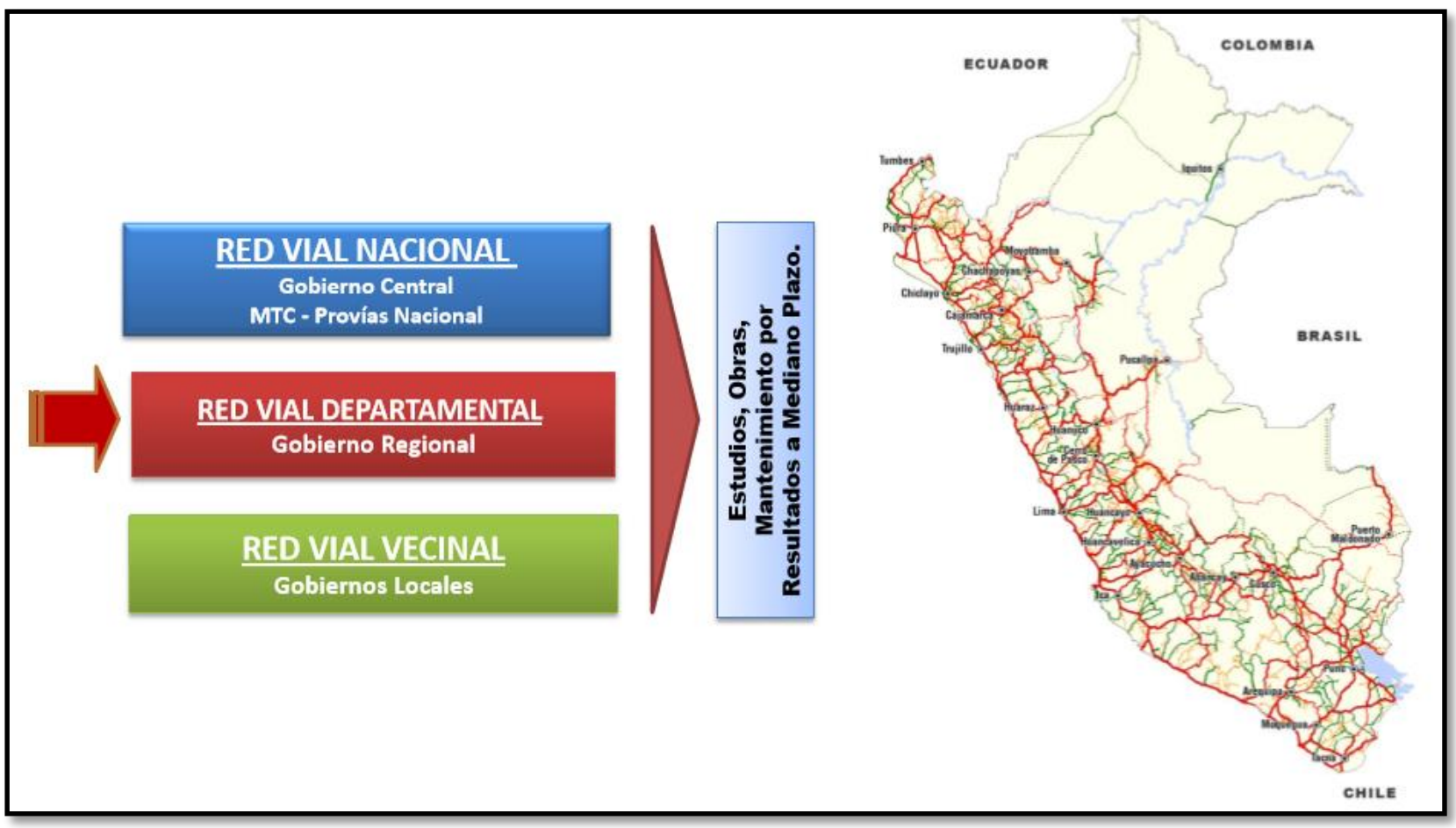

Fig. 2.1: Integración de los corredores económicos a lo largo del Perú

Fuente: MTC M. d., 2013

Dicho proyecto busca establecer un sistema de contratación de las actividades de conservación de la infraestructura vial, a través de contratos, en donde el traspaso de la gestión sea controlado por niveles de servicio y se pueda aplicar el concepto de "transferencia de riesgos" al contratista conservador.

Además, da un mayor énfasis a la Conservación Vial, lo que conllevaría a realizar menos intervenciones en rehabilitaciones.

Cabe resaltar también que dentro del Proyecto Perú 1 se llevan a cabo Contratos de Conservación Vial por Niveles de Servicio, los cuáles se explicarán más adelante dentro de la investigación.

\subsubsection{Proyecto Perú 2:}

En este programa continúan las características del Proyecto Perú 1, pero con actualizaciones en ciertos aspectos en lo que respecta a los Contratos de Conservación Vial por Niveles de Servicios. 
A continuación, en la Fig. 2.2 se muestran los corredores viales a lo largo de nuestro país:

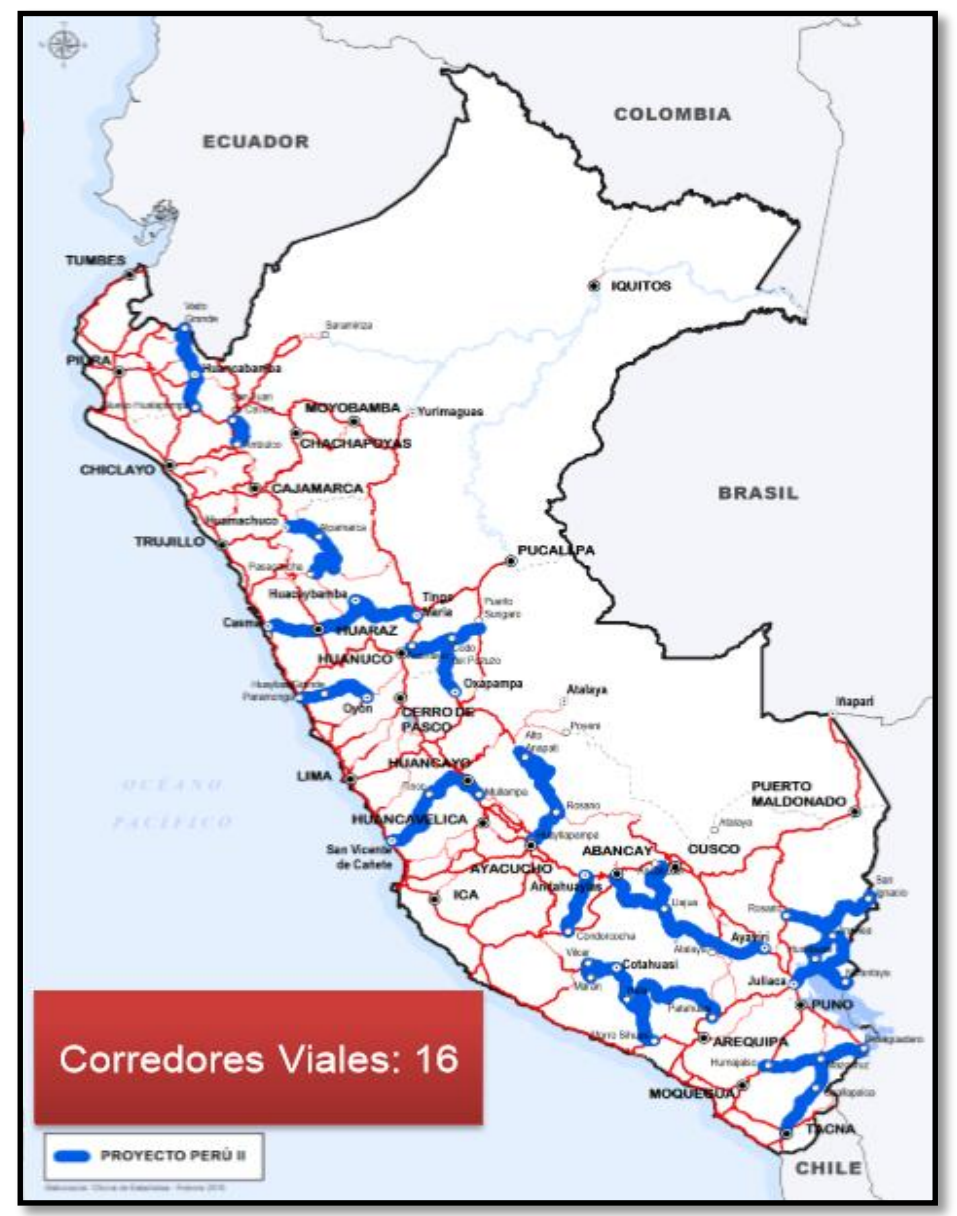

Fig. 2.2: Corredores Viales del Proyecto Perú 2

Fuente: MTC M. d., 2013

Las principales diferencias que tiene el Proyecto Perú 2 con respecto al Proyecto Perú 1 son las siguientes:

- Los Contratos de Conservación Vial por Niveles de Servicios en el Proyecto Perú 2 no sólo durarán los cinco años que se esté en obra, sino que se agregará un año más de garantía, garantizando que todos los meses se cumplan con los niveles de servicio que se requieran.

- Los Gastos Corrientes pasaron a ser Gastos de Capital (Inversión)

- Los costos se elevaron y pasaron de $\$ 100$ 000/km a $\$ 220000 / \mathrm{km}$. 
- Se incluyen ensanches y mejoras de obras de arte. En el Proyecto Perú 1 solo se realizaban ensanches en zonas críticas.

\subsection{Gestión de Pavimentos:}

Un sistema de gestión de pavimentos comprende un conjunto coordinado de actividades relacionadas con la planificación, diseño, construcción, conservación, evaluación, e investigación de todos los elementos que constituyen la infraestructura vial. Su objetivo principal es establecer la metodología para el seguimiento y continua evaluación del estado de los pavimentos, para proporcionar así seguridad, confort y economía al transporte, obteniendo la mayor rentabilidad posible por el dinero invertido sujeto a las restricciones económicas, técnicas, políticas y ambientales. ${ }^{3}$

\subsubsection{Conservación Vial:}

La Conservación Vial es un conjunto de actividades que se realizan, de forma continua y sostenida, periódica o permanente, para mantener en buen estado las condiciones físicas de los diferentes elementos que constituyen la vía y de esta manera garantizar que el transporte terrestre sea cómodo, seguro y económico. ${ }^{4}$

En nuestro país, el propósito de la Conservación Vial en la Red Vial Nacional, es evitar los deterioros prematuros en las vías, apoyándose en intervenciones rutinarias y periódicas. Lo que se busca es crear una cultura de conservación vial para evitar la realización de rehabilitaciones o reconstrucciones en las vías, lo que conlleva a un ahorro importante en los recursos del Estado.

La importancia de la conservación radica, especialmente por los elevados costos que representa al país el no intervenir oportunamente, en asegurar el uso permanente de las carreteras. Una de las dificultades se origina en la drástica separación de los gastos en rehabilitación y mejoramiento, con los gastos en conservación, considerando a los primeros como inversión y a los segundos como gastos corrientes.

\footnotetext{
${ }^{3}$ Montoya Goicochea, J.E. (2007). Implementación del Sistema de Gestión de Pavimentos con Herramienta HDM-4 para la Red Vial Nro. 5 Tramo Ancón-Huacho-Pativilca.

4 PROVIAS NACIONAL, Ministerio de Transporte y Comunicaciones, http://www.proviasnac.gob.pe/frmPreguntasFrecuentesDetalle.aspx?idPreg=16
} 
Por tal motivo es que se propone la categoría de Desarrollo Vial continuo para comprender y ejecutar mejor las intervenciones en la Red Vial Nacional, mediante los determinados contratos por niveles de servicios, en donde las intervenciones estén justificadas siempre que los resultados sean mayores o mejores, o ambos, sin importar que se originen en el ámbito de la conservación, de la operación o del mejoramiento, o que algunas categorías se mezclen entre sí.

A continuación, en la Fig. 2.3 se muestra el esquema de cómo pasó a desarrollarse el concepto de construir carreteras en nuestro país, además de la aplicación del Desarrollo Vial Continuo:

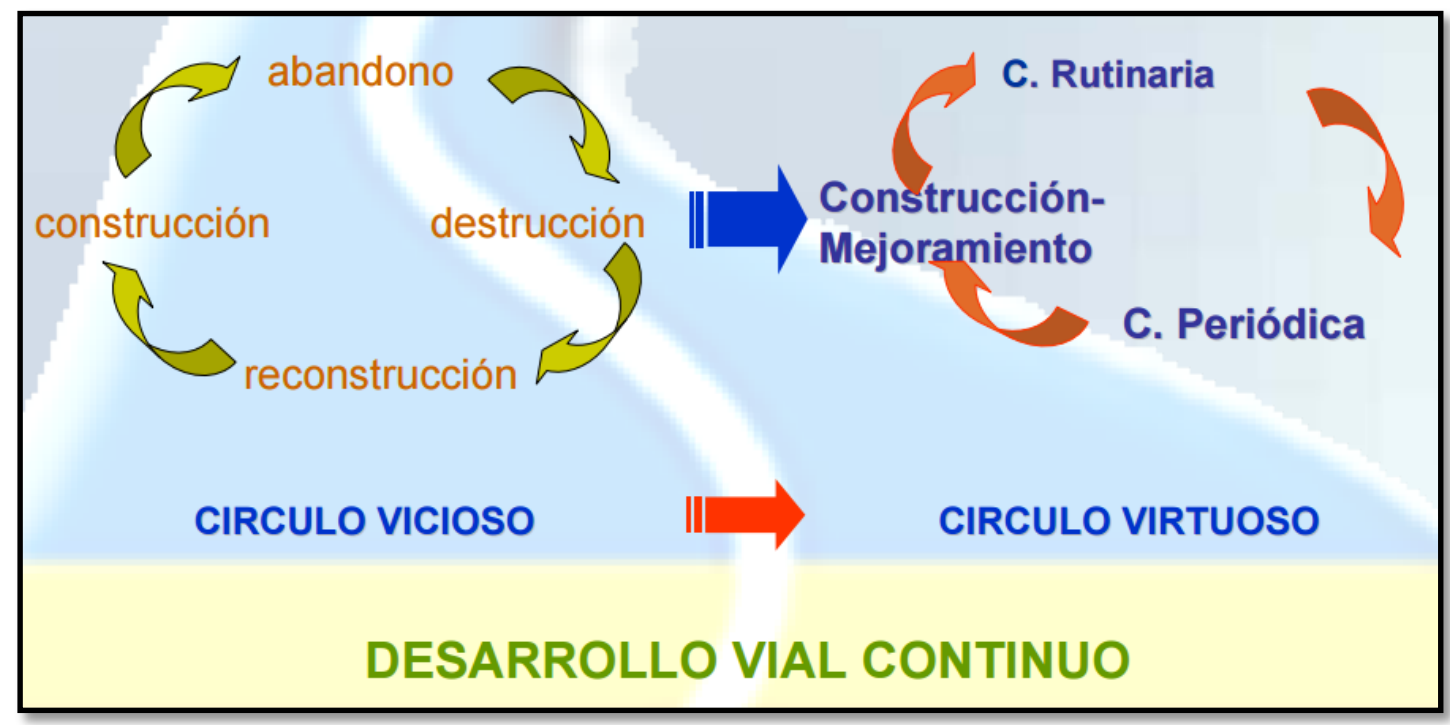

Fig. 2.3: Desarrollo del concepto de conservación vial en el Perú Fuente: MINCETUR (2008)

Lo novedoso dentro de lo que respecta a la Conservación Vial son los Contratos de Servicios de Gestión y Conservación Vial. Cabe resaltar que dichos contratos celebrados se avocan principalmente a Conservación Vial, Atención de Emergencias viales y Relevamiento de información, debido a que estos se encuentran por debajo de los estándares internacionales.

La característica principal en estos contratos es el riesgo que se le transfiere al Contratista Conservador, ya que, durante la vigencia del contrato, el Contratista es quien propone la solución tecnológica, ejecuta dicha solución y se encarga de la conservación de la vía tratada, 
la cual es controlada a través de niveles de servicio por parte del Estado y se atribuyen penalizaciones de no sostener el estándar predeterminado.

\subsubsection{Nivel de Servicio:}

Normalmente en el ámbito de la ingeniería vial, se le conoce a Nivel de Servicio como un indicador de volumen de tránsito y capacidad de las carreteras. Sin embargo, también desde inicio de la década de los 90, es un indicador de desempeño en la gestión de la conservación de las carreteras. Un nivel de servicio de conservación vial podemos resumirlo como un indicador de la calidad de la carretera (Obando, 2014).

En la conservación vial por niveles de servicio el trabajo se realiza para cumplir los estándares admisibles y no por el volumen de trabajo ejecutado. Es obligación del ejecutor de la conservación vial tener la carretera en perfectas condiciones los 365 días del año, en tal sentido el criterio de pago es el buen estado de las vías, de esta manera se asegura la preservación del buen estado de las vías 5 .

\subsubsection{Contratos de Conservación Vial por Niveles de Servicio:}

La gestión de conservación vial de carreteras en el Perú, comenzó a ser medida por Niveles de Servicio, por primera vez hace 18 años, a través de concesiones viales (Obando, 2014).

A partir del año 2007, como parte de la estrategia del MTC, se vienen entregando Contratos de Conservación de carreteras por Niveles de Servicio, con la finalidad de que se tome mayor relevancia el contar con un mayor número de parámetros de medición acordes a la necesidad de los usuarios y realidad de nuestro país.

Desde el año 2007, a través del Proyecto Perú 1, los Contratos de Conservación Vial por Niveles de Servicio vinieron evolucionando en la gestión de Niveles de Servicio y se decide tercerizar la conservación de las carreteras en nuestro país.

En la Fig. 2.4 se muestran las etapas y los tipos de conservación que existen dentro del contrato por un período de cinco años:

\footnotetext{
5 Dirección General de Caminos y Ferrocarriles, Ministerio de Transporte y Comunicaciones, http://transparencia.mtc.gob.pe/idm_docs/P_recientes/4877.pdf
} 


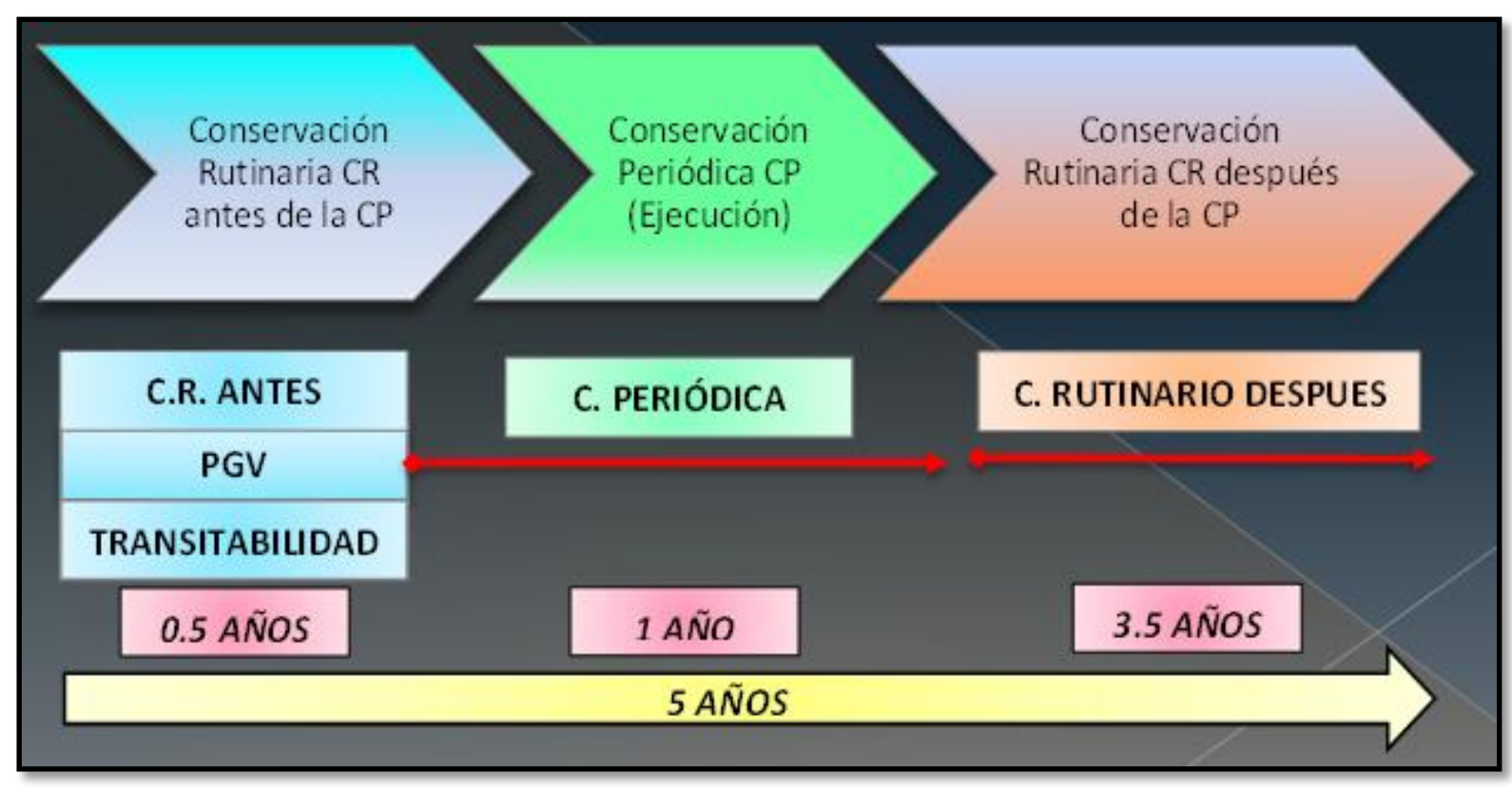

Fig. 2.4: Etapas de un Contrato de Conservación Vial por Niveles de Servicio

Fuente: Ing. Guillermo Lazo

Los Contratos de Conservación Vial por Niveles de Servicio se dividen en etapas y tipos de conservación. Dentro de los cinco años que se está en obra, existirán evaluaciones antes de la Conservación Periódica, las cuales no serán tan exigentes, debido a que aún no se realiza la ejecución de la obra. También evaluaciones después de la Conservación Periódica, las cuales tendrán un nivel de exigencia mayor que se debe de cumplir.

Los Contratos de Conservación Vial por Niveles de Servicio que se llevan a cabo en el Proyecto Perú 2, disponen de los cinco años en obra y luego el Contratista debe garantizar por un año la conservación de la carretera tratada, con la finalidad de que se asegure que todos los meses se cumplan con los niveles de servicio que se requieran.

El Contratista durante el transcurso de ese año de garantía no está en la obligación de estar en obra. Sin embargo, para no poner en riesgo las evaluaciones mensuales dispone de personal y maquinaria en obra para cualquier emergencia, pero en una cantidad mucho menor, con la finalidad de reducir sus gastos operativos.

Si bien falta mejorar en algunos aspectos como: uniformización de parámetros, objetividad en las mediciones y los criterios de medición, se puede decir con seguridad que los Contratos de Conservación Vial por Niveles de Servicio forma un nuevo rumbo en la gestión de 
conservación vial en donde el Estado y las empresas han aprendido a manejarse mutuamente, lo que ha mejorado sustancialmente el estado actual de las carreteras en nuestro país.

\subsection{Ingeniería de Pavimentos:}

\subsubsection{Tipos de pavimentos:}

Existen diferentes formas de clasificar los pavimentos. Una de estas, es según la manera en la que los pavimentos transmiten las cargas a la sub rasante. Estos pueden ser: pavimentos rígidos, pavimentos semi-rígidos, pavimentos semi-flexibles y pavimentos flexibles.

\subsubsection{Pavimentos Rígidos:}

Son pavimentos en los cuales su capa superior está compuesta por una losa de cemento hidráulico, la cual puede estar apoyada sobre la sub rasante o sobre una capa de material seleccionado, denominada sub-base del pavimento rígido. En cuanto a la transmisión de las cargas dinámicas a la sub rasante, debido a la alta rigidez del concreto hidráulico y a su elevado coeficiente de elasticidad, los esfuerzos se distribuyen en una zona muy amplia, como se puede apreciar en la Fig. 2.5. Es así, que casi todos los esfuerzos se distribuyen en la losa de concreto, por lo tanto, el apoyo de las capas subyacentes ejerce poca influencia en el diseño del pavimento. ${ }^{6}$

\footnotetext{
${ }^{6}$ Fonseca, A. M. (2002). Ingeniería de Pavimentos para carreteras Tomo I. Colombia: Ediciones y Publicaciones
} Universidad Católica de Colombia. 


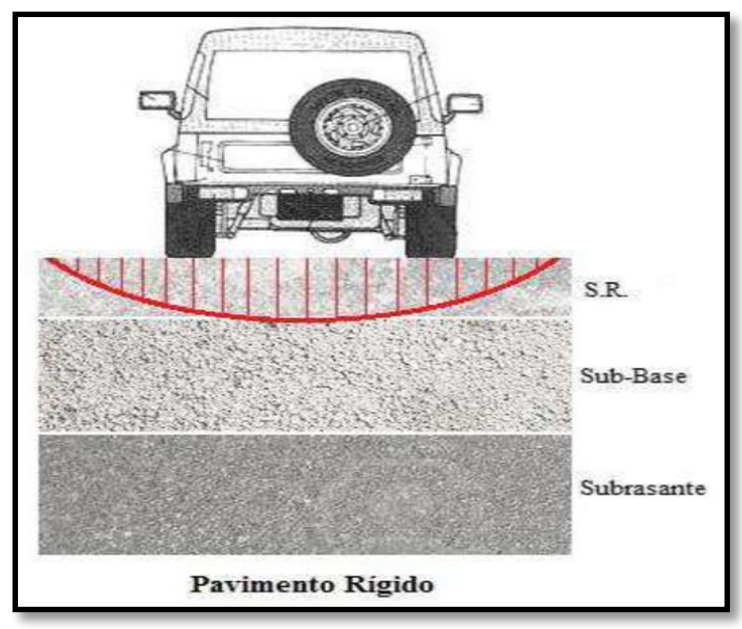

Fig. 2.5: Distribución de los esfuerzos a través del pavimento rígido.

Fuente: Bardales y Cheng (2013)

\subsubsection{Pavimentos Semi-rígidos:}

Contiene la misma estructura de un pavimento flexible, con la variación que una de sus capas se le agrega un aditivo para rigidizarla artificialmente. Este pude ser asfalto, cal, cemento, emulsión o químicos; los cuales permitan incrementar la capacidad portante del suelo. ${ }^{7}$ En la Fig. 2.6 se puede apreciar la estructura de un pavimento semi-rígido.

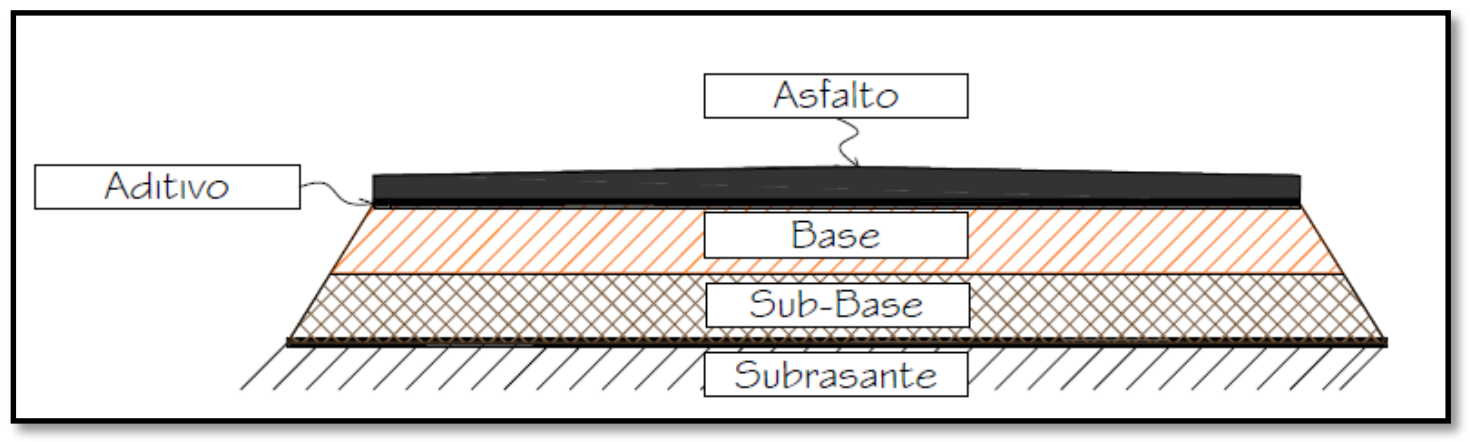

Fig. 2.6: Sección transversal de un pavimento semi-rígido.

Fuente: Armijos (2009)

\subsubsection{Pavimentos Semiflexibles, Articulados o Adoquinados:}

Son pavimentos cuyas capas de rodadura se encuentran conformadas por bloques prefabricados de concreto, que se denominan adoquines, son iguales entre sí y de un espesor

\footnotetext{
${ }^{7}$ Fonseca, A. M. (2002). Ingeniería de Pavimentos para carreteras Tomo I. Colombia: Ediciones y Publicaciones Universidad Católica de Colombia.
} 
uniforme y se colocan sobre una capa delgada de arena, la cual se encuentra sobre una capa granular o la sub rasante. ${ }^{8}$

En la Fig. 2.7 se muestra la estructura de un pavimento semiflexible.

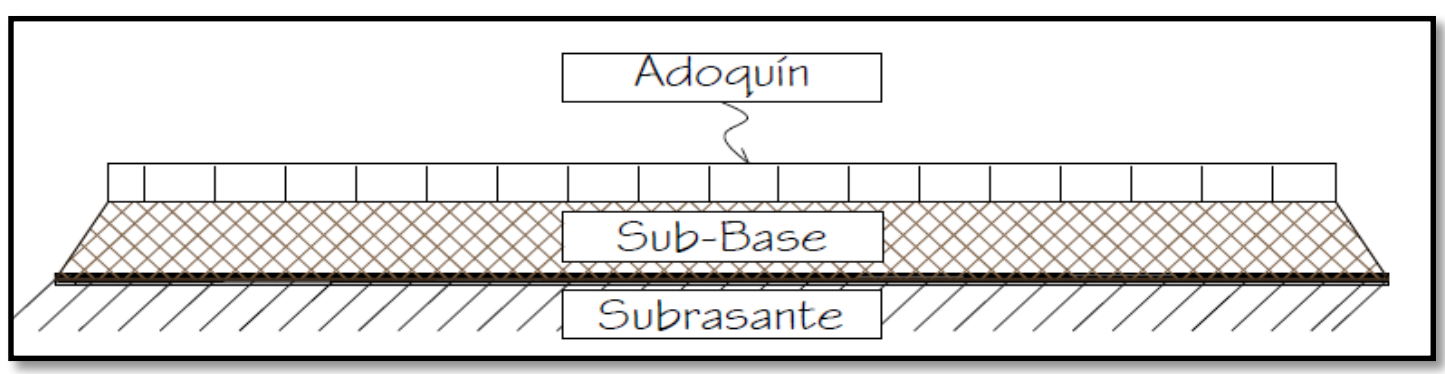

Fig. 2.7: Sección transversal de un pavimento semi flexible.

Fuente: Armijos (2009)

\subsubsection{Pavimentos Flexibles:}

Son aquellos que tienen un revestimiento asfáltico sobre una capa base granular. La distribución de tensiones y deformaciones generadas en la estructura por las cargas de rueda del tráfico, se da de tal forma que las capas de revestimiento y base absorben las tensiones verticales de compresión del suelo de fundación por medio de la absorción de tensiones cizallantes. En este proceso ocurren tensiones de deformación y tracción en la fibra inferior del revestimiento asfáltico, que provocará su fisuración por fatiga por la repetición de las cargas de tráfico. Al mismo tiempo la repetición de las tensiones y deformaciones verticales de compresión que actúan en todas las capas del pavimento producirán la formación de hundimientos en la trilla de rueda, cuando el tráfico tiende a ser canalizado, y la ondulación longitudinal de la superficie cuando la heterogeneidad del pavimento fuera significativa. ${ }^{9} \mathrm{En}$ la Fig. 2.8 se aprecia la distribución de esfuerzos en pavimentos flexibles.

\footnotetext{
${ }^{8}$ ARMIJOS, Christian (2009) Evaluación superficial de algunas calles de la ciudad de Loja.

${ }^{9}$ UMSS Facultad de Ciencias y Tecnología (2008) Manual Completo Diseño de Pavimentos
} 


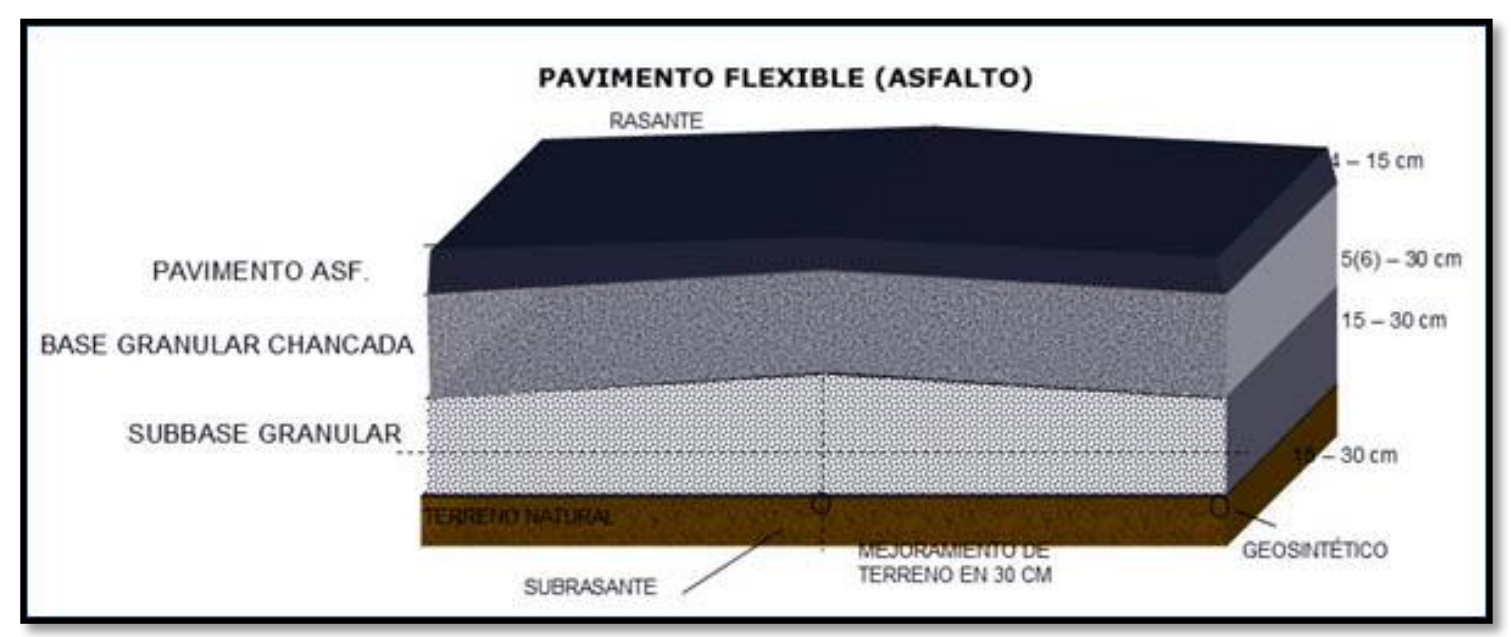

Fig. 2.8: Capas de un pavimento asfáltico.

Fuente: Modelo de evaluación técnica del desempeño del mantenimiento de pavimentos flexibles.

\subsubsection{Capas de los Pavimentos Flexibles:}

Los pavimentos flexibles, generalmente están conformados por 3 capas: Sub base, base y carpeta asfáltica (capa de rodadura).

\subsubsection{Sub-base:}

La función de la sub-base, en un pavimento flexible, es puramente económica, buscando así obtener un espesor utilizando el material más barato posible. Podría construirse dicho espesor con materiales de alta calidad como en el caso de la base, pero usualmente se hace aquella más delgada y se sustituye en parte por la sub-base que es de menor calidad, trayendo como resultado un aumento en el espesor total del pavimento, pues es un hecho que cuando menor es la calidad del material utilizado, mayor será el espesor necesario para soportar los esfuerzos transmitidos.

Otra función de la sub-base es la de servir de transición entre la base y la sub-rasante; ya que el material de la base es granular más o menos grueso y el de la sub-base es más fino que el anterior, de esta manera sirve como filtro para evitar que el material de la base se incruste en la sub-rasante. Sirve también para absorber las deformaciones que provienen de la sub-rasante y que pueden ser perjudiciales para el pavimento en general. 
De las funciones mencionadas anteriormente, la estructural y la económica son las que más se proyectan en la construcción de pavimentos, el resto dependen de las circunstancias y de los materiales con los que se cuente para la sub base.

\subsubsection{Base:}

Su función primordial es la de proporcionar un elemento resistente que transmita los esfuerzos producidos por el tránsito hacia la sub-base y sub-rasante en una intensidad adecuada. Esta también reduce el espesor de la carpeta más costosa.

Básicamente el material que constituye a la base, en el pavimento flexible, debe ser friccionante y provisto de vacíos.

La primera garantizará la resistencia adecuada y la permanencia de dicha resistencia con la variación de las condiciones que se puedan presentar, como podría ser el contenido de agua. Es lógico que no basta sólo con emplear material friccionante para garantizar la resistencia deseada, es necesaria también una compactación adecuada, necesaria para adquirir la compacidad y trabazón estructural requerida para una buena base.

Los materiales utilizados para la base suelen someterse a procesos exigentes para su aprobación como lo es la trituración, produciendo efectos favorables para la resistencia y deformabilidad de la estructura a construir, ya que se obtienen partículas con formas convenientes para un reacomodo adecuado; además de esto, se deben llenar otras especificaciones por lo que es necesario tamizar dicho material.

Los espesores de las bases son muy variables de acuerdo con el proyecto de que se trate, pero suele considerarse que 12 o 15 centímetros son espesores mínimos que conviene construir.

\subsubsection{Carpeta asfáltica:}

Es la capa que se coloca sobre la base. Su objetivo principal es proteger la estructura de pavimento, impermeabilizando la superficie, para evitar filtraciones de agua de lluvia que podrían saturar las capas inferiores. Evita la desintegración de las capas subyacentes a causa del tránsito de vehículos. La capa de rodadura también contribuye a aumentar la capacidad soporte del pavimento, absorbiendo cargas, si su espesor es apreciable (mayor de 4 centímetros). 


\subsubsection{Métodos de diseño de Pavimentos Flexibles:}

Para realizar el diseño de pavimentos flexibles, será necesario revisar los distintos métodos de diseño, con la finalidad de aplicar el que más se ajuste al proyecto. A continuación, se mencionan algunos métodos:

\subsubsection{Método AASHTO 93:}

El método de diseño AASHTO 93 se fundamenta en la ecuación empírica obtenida del ensayo vial AASHO realizado en Ottawa, Illinois. Desde su publicación en 1958 la ecuación de diseño ha sido modificada en varias ocasiones, 1973, 1986 y 1993. Todas las versiones están soportadas en la pérdida de serviciabilidad y en el cálculo del número estructural necesario para lograr un periodo de vida útil adoptado por el diseñador (AASHTO, 1993). La primera modificación en 1972 se realizó con el fin de poder emplear la ecuación AASHTO de manera generalizada en sitios donde no fue obtenida, esta publicación ingresa un factor R empírico a la ecuación para ajustar el número estructural y un factor de soporte del suelo S. ${ }^{10}$

La modificación de 1986 realizó una caracterización más racional de la subrasante y los materiales granulares, de esta manera, se incluye el módulo resiliente para la caracterización de la sub rasante y correlacionarlo con los coeficientes estructurales, de igual manera, en esta publicación se incluyen los coeficientes de drenaje y el concepto de confiabilidad y variabilidad. La modificación de 1993 estuvo enfocada a la rehabilitación de pavimentos y la utilización de ensayos no destructivos para el retro cálculo de la estructura. (Barry R et al., 2006).

La ecuación AASHTO que actualmente se utiliza para el diseño de pavimentos flexibles se presenta en la ecuación mostrada en la Fig. 2.9:

\footnotetext{
${ }^{10}$ Saldaña Marulanda, D. (2013). Estudio comparativo de la sensibilidad de la metodología de diseño estructural de pavimentos flexibles: método AASHTO 93 y ME-PDG V 1.1.
} 


$$
\begin{aligned}
& \log _{10}\left(W_{18}\right)=Z_{R} \times S_{0}+9.36 \times \log _{10}(S N+1)-0.20+\frac{\log _{10}\left(\frac{p_{i}-p_{f}}{4.2-1.5}\right)}{0.40+\frac{10.949}{(S N+1)^{5.19}}}+2.32 \times \\
& \log _{10}(M r)-8.07 \\
& \qquad N=a_{1} D_{1}+a_{2} D_{2} m_{2}+a_{3} D_{3} m_{3}
\end{aligned}
$$

Fig. 2.9: Ecuación AASHTO para diseño de pavimentos flexibles.

Fuente: Modelo de evaluación técnica del desempeño del mantenimiento de pavimentos flexibles.

Donde:

- W18: Ejes equivalentes de diseño

- $\mathrm{SN}$ : Numero Estructural (in)

- Pi: Indicie de Serviciabilidad Inicial

- Pf: Indicie de Serviciabilidad Final

- ai: Coeficiente estructural.

- Mr: Modulo Resiliente.

- Z: Nivel de Confiabilidad.

- So: Desviación Estándar Combinada.

- mi: Coeficiente de drenaje.

\subsubsection{Método AASHTO 2008:}

La guía de Diseño Mecanístico-Empírico de Pavimentos AASHTO 2008 (MEPDG 2008) refleja el estado del arte de las metodologías empleadas en el diseño de pavimentos nuevos y en la rehabilitación de pavimentos existentes.

Las variaciones climáticas y las cargas de tráfico son consideradas en el análisis para evaluar si la estructura de pavimento propuesta tiene la capacidad de soportar las cargas actuantes y cumplir con los niveles de servicio exigidos. Asimismo, el diseño con el método AASHTO 2008 requiere un proceso iterativo de enfoque práctico por el diseñador ya que se debe seleccionar un diseño de ensayo y luego analizar el diseño en detalle para determinar si cumple 
con los criterios de desempeño establecidos. Si el diseño del ensayo no cumple con los criterios de rendimiento, el diseño se debe modificar y volver a analizar.

El daño acumulado por acción de las cargas a través del tiempo en la estructura de pavimento propuesta es anticipado con modelos de predicción del desempeño. Si el diseño de pavimento propuesto no supera los límites máximos tolerables de servicio establecidos, entonces se considera que es una alternativa técnicamente viable.

La Fig. 2.10 muestra esquemáticamente la relación de los modelos utilizados en diseño mecanistico empírico de pavimentos:

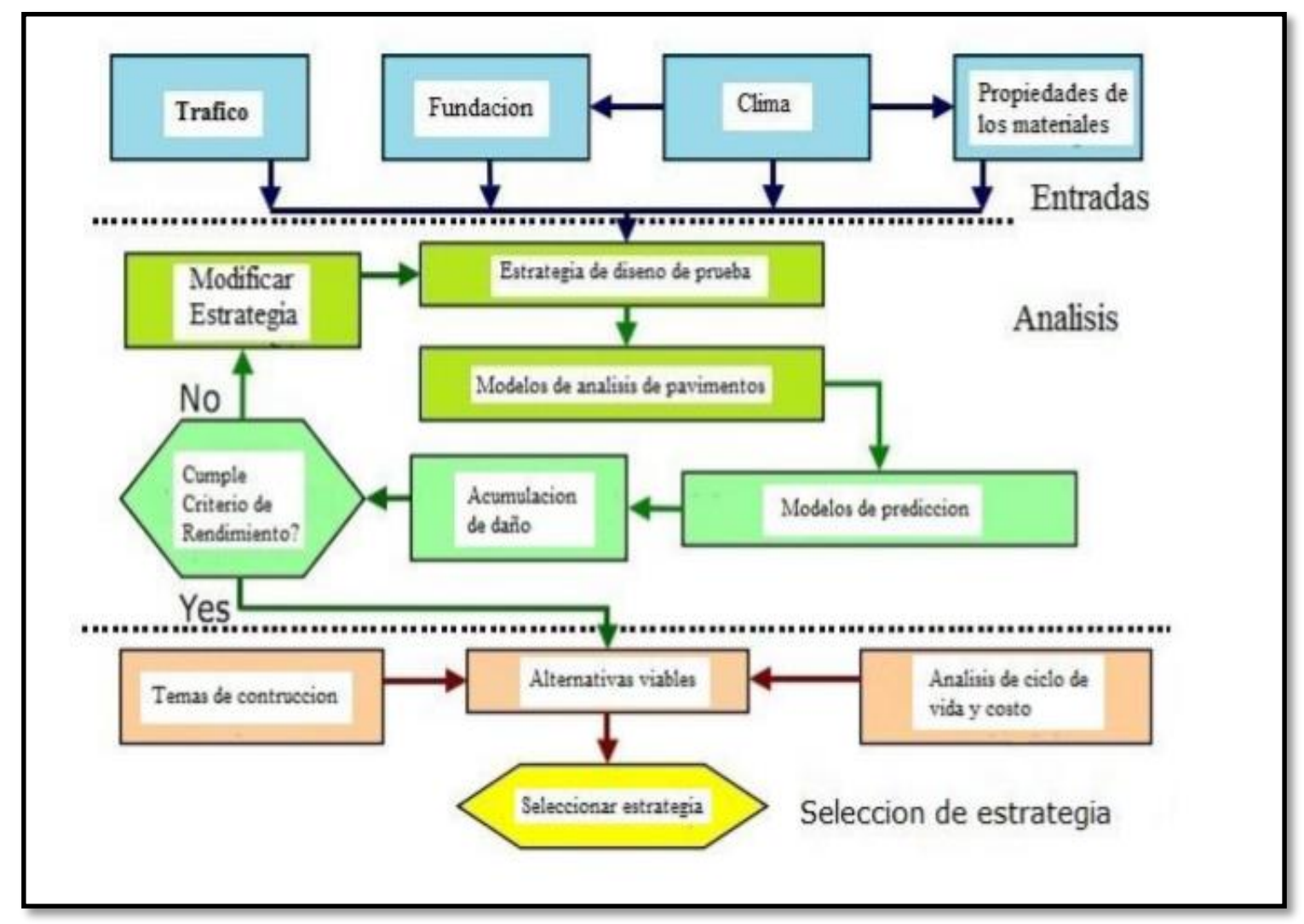

Fig. 2.10: Modelos utilizados en el diseño mecanístico empírico de pavimentos Fuente: Análisis del método AASHTO 2008 (MEPDG) en pavimentos flexibles

Para el diseño de pavimentos flexibles los modelos de desempeño consideran:

- Fisuramiento Longitudinal

- Fisuramiento Piel de Cocodrilo 
- Fisuramiento Transversal

- Ahuellamiento o deformación permanente

- Índice Internacional de Rugosidad (IRI)

Sin embargo, en la mayoría de los países Latinoamericanos no se han realizado esfuerzos significativos para la implementación del MEPDG. También se ha mencionado que el método del MEPDG no es usado en la práctica diaria de diseño porque los modelos de predicción (especialmente el climático) no han sido adaptados a cada país. Otro limitante para realizar este diseño es el limitado acceso al software del MEPDG 2008, falta de información climática detallada horaria, falta de apoyo de las entidades gubernamentales para incluir el método como requisito en nuevos proyectos de diseño y rehabilitación.

\subsubsection{Patología de los Pavimentos:}

La patología de los pavimentos se encarga de identificar las fallas que posee un pavimento y determinar por qué es que se han producido. Se debe de identificar el tipo, severidad y magnitud de cada falla que se produzca mediante las evaluaciones que se desarrollarán a continuación.

\subsubsection{Evaluación Superficial:}

La evaluación superficial está ligada con la serviciabilidad de los pavimentos, que puede determinarse a partir del promedio de las evaluaciones de todos los usuarios, puesto que el confort y la calidad de rodado es un aspecto subjetivo o de opinión del usuario. ${ }^{11}$

Este promedio da como origen al Present Serviciability Rating (PSR), el cual tiene carácter subjetivo.

Además, existen características físicas del pavimento que pueden determinarse mediante mediciones objetivas y que pueden relacionarse con las evaluaciones subjetivas. Dicha relación permite obtener un índice objetivo llamado Present Serviciability Index (PSI). ${ }^{12}$

\footnotetext{
${ }^{11}$ Montoya Goicochea, J. E. (2007). Implementación del Sistema de Gestión de Pavimentos con Herramienta HDM-4 para la Red Vial Nro. 5 Tramo Ancón-Huacho-Pativilca.

12 Miquel, M. P. (2006). Análisis de Regularidad Superficial en caminos pavimentados. Editor Responsable, 16.
} 


\subsection{Present Serviciability Index (PSI):}

Tal como su nombre lo indica, se refiere a la condición actual del pavimento. Se trata de un parámetro que, mediante análisis de regresión matemática, correlaciona:

- La opinión de un panel de expertos en lo referente a la calidad del rodaje, la cual sirvió para generar el concepto de Pavement Serviciability Rating (PSR) basado en encuestas.

- La condición superficial definida en términos de la rugosidad del pavimento utilizando rugosímetros o perfilómetros.

- Evaluaciones visuales que reportan sobre la presencia de grietas, baches y ahullamiento.

La ecuación original AASHO para la determinación del PSI en pavimentos flexibles se muestra en la Fig. 2.11:

$$
P S I=5.03-1.9 \log (1+S V)-1.38 R D^{2}-0.01(C+P)^{0.5}
$$

Fig. 2.11: Ecuación para la determinación del PSI

Fuente: Manual de evaluación de pavimentos (2009)

En donde:

- SV: variancia de las deformaciones de la pendiente longitudinal cada $30 \mathrm{~cm}$.

- RD: promedio aritmético de las deformaciones transversales o ahuellamiento en ambas huellas, medido con regla de $3 \mathrm{~m}$.

- C: grietas mayores a $1000 \mathrm{pie}^{2}$

- P: baches reparados en 1000 pie $^{2}$ 


\subsubsection{2. Índice de Rugosidad Internacional (IRI):}

Es un indicador estadístico de la irregularidad superficial del pavimento; representa la diferencia entre el perfil longitudinal teórico $(I R I=0)$ y el perfil longitudinal real existente en el instante de la medida. ${ }^{13}$

Con el fin de estandarizar el valor de la rugosidad superficial, el Banco Mundial propuso el Índice Internacional de Rugosidad (IRI) que se basa en un modelo matemático denominado cuarto de carro normalizado (Golden Quarter Car), mostrado en la Fig. 2.12, circulando a 80 $\mathrm{km} / \mathrm{h}$. Dicho índice se obtiene a partir de la acumulación del desplazamiento relativo entre las masas de las carrocerías y la suspensión del modelo, cuando el vehículo circula por el perfil del camino estudiado ${ }^{14}$.

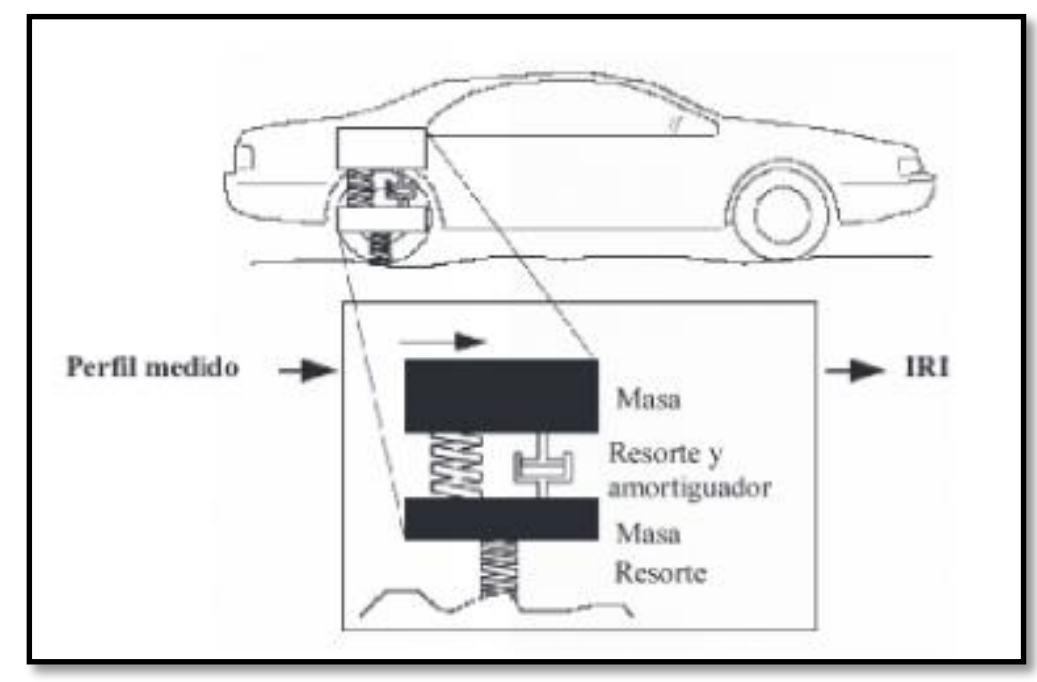

Fig. 2.12: Modelo del cuarto de carro

Fuente: Análisis de regularidad superficial en caminos pavimentados (2006)

La finalidad de este índice es establecer sus características de regularidad superficial en la red vial en estudio por segmentos de $1 \mathrm{~km}$. y se expresa generalmente en $\mathrm{m} / \mathrm{km}$ o in/mi.

\footnotetext{
${ }^{13}$ Miquel, M. P. (2006). Análisis de Regularidad Superficial en caminos pavimentados. Editor Responsable, 16.

14 OROZCO Y OROZCO, J. M., TELLEZ GUTIERREZ, R., SOLORIO MURILLO, R., PEREZ SALAZAR, A., SANCHEZ LOO, M. A., \& TORRAS ORTIZ, S. (2004). SISTEMA DE EVALUACION DE PAVIMENTOS: VERSION 2.0.PUBLICACION TECNICA, (245).
} 


\subsubsection{Evaluación Estructural:}

La evaluación del pavimento existente tiene como objetivo el análisis y estimación del valor estructural remanente, adicionalmente esta evaluación debe proporcionar la información necesaria para la investigación de las causas que originaron la falla del pavimento a rehabilitar, es decir, debe aportar los elementos de juicio necesarios con la finalidad de definir que accionar tomar según las deficiencias encontradas. ${ }^{15}$

\subsection{La deflexión:}

Se denomina deflexión al desplazamiento en sentido vertical en magnitudes muy pequeñas (centésimas o milésimas de milímetro) provenientes del pavimento al ser sometido por una determinada solicitación.

Su propósito es hallar la capacidad estructural de los pavimentos en campo, y dentro de la tecnología de pavimentos, particularmente en la evaluación estructural de los mismos existen diversas metodologías y equipos para tales propósitos. ${ }^{16}$

\subsection{Ensayos destructivos:}

Este tipo de evaluación se fundamenta en la toma de muestras representativas de los materiales que conforman las diferentes capas del pavimento en una vía.

El muestreo se realiza mediante diferentes tipos de sondeo, entre los cuales se encuentra las calicatas como se muestran en la Fig. 2.13.

\footnotetext{
${ }^{15}$ Manual de Evaluación de Pavimentos (2009).

${ }^{16}$ Montoya Goicochea, J. E. (2007). Implementación del Sistema de Gestión de Pavimentos con Herramienta HDM-4 para la Red Vial Nro. 5 Tramo Ancón-Huacho-Pativilca.
} 


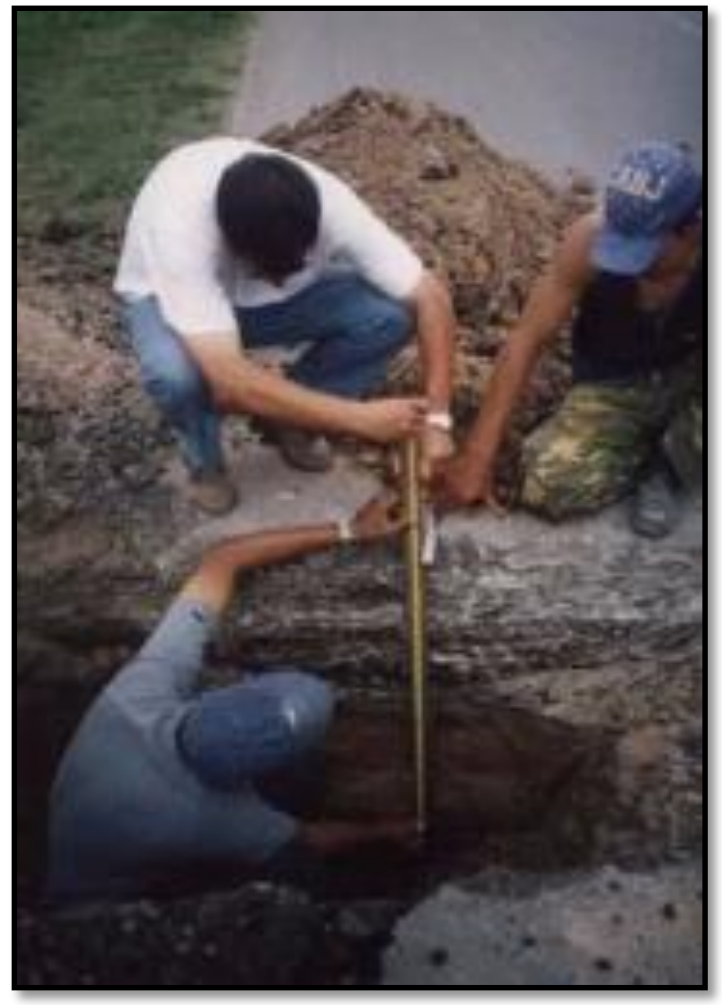

Fig. 2.13: Calicatas

Fuente: Manual de evaluación de pavimentos (2009)

\subsection{Ensayos no destructivos (NDT):}

El concepto de los Ensayos no destructivos fue establecido en los años 50, a través de los ensayos de placa de carga y desarrollo de la Viga de Benkelman. La principal aplicación de los Ensayos no destructivos fue el dimensionamiento del refuerzo del pavimento.

\subsection{1. Viga de Benkelman:}

Equipo desarrollado en 1952 durante el ensayo de la "Western Association of State Highway Organizations". Se trata de un dispositivo bastante simple, como se muestra en la Fig. 2.14, que funciona aplicando la Regla de la Palanca. Se usa junto con un camión; el ensayo se realiza colocando el extremo de la viga entre las dos ruedas gemelas del camión, midiendo la recuperación vertical de la superficie del pavimento cuando el camión avanza y se retira. ${ }^{17}$

\footnotetext{
${ }^{17}$ Montoya Goicochea, J. E. (2007). Implementación del Sistema de Gestión de Pavimentos con Herramienta HDM-4 para la Red Vial Nro. 5 Tramo Ancón-Huacho-Pativilca.
} 


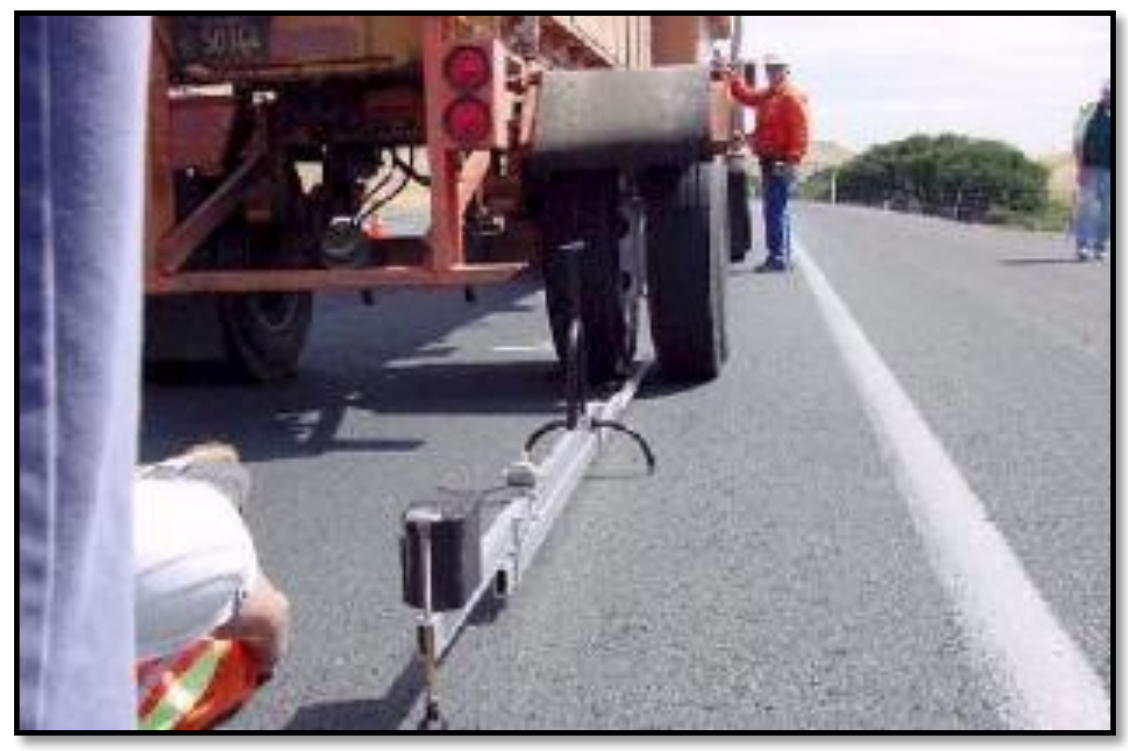

Fig. 2.14: Viga de Benkelman

Fuente: Manual de evaluación de pavimentos (2009) 


\section{CAPÍTULO 3: MARCO REFERENCIAL Y TEÓRICO}

\subsection{Marco Referencial:}

\subsubsection{Antecedentes:}

Paper A: Tecnología de asfalto espumado y diseño de mezcla (Thenoux G., 2002).

Dicho paper proporcionó datos importantes para nuestra investigación, ya que los diseños de mezcla desarrollados contienen distintos tipos y distintos porcentajes de inyección de cemento asfáltico, los cuales modifican las propiedades más importantes de la espumación. Por otro lado, la caracterización de los agregados con una correcta distribución de gruesos y finos consigue una base estabilizada con una mayor resistencia al esfuerzo cortante. Los tipos de cemento asfáltico, la caracterización de los agregados, la determinación del contenido óptimo de humedad de la mezcla y la determinación del contenido óptimo de asfalto mencionados en este paper, serán utilizados como referencia en esta tesis.

Paper B: Propiedades mecánicas y comportamiento de mezclas estabilizadas con asfalto espumado

(Halles

Felipe, 2010).

Este paper contiene datos importantes que tomaremos en cuenta para desarrollar el marco teórico. El autor enfatiza el mejoramiento de las propiedades mecánicas en bases estabilizadas, no solo utilizando asfalto espumado, sino también en conjunto con un filler activo, el cual es el cemento. Dentro de la base estabilizada (mezcla), el asfalto aporta capacidad de flexión sin fractura, mientras que el cemento aporta material fino y resistencia mecánica.

Paper C: Desempeño de pavimentos estabilizado con asfalto espumado en una prueba de pavimentos a escala real $y$ carga acelerada (Gonzalez et. al., 2012). El presente artículo nos presenta el desempeño de pavimentos estabilizados con asfalto espumado en el CAPTIF (Canterbury Accelerated Pavement Testing Indoor Facility), laboratorio de escala real ubicado en Nueva Zelanda. Contiene 6 secciones de pavimentos con distintas dosificaciones de asfalto espumado y cemento. Los resultados obtenidos, a pesar de 
tratarse de evaluaciones superficiales, nos indican que las secciones con asfalto espumado y cemento tienen mejores resultados. Esto nos da información importante a tomar en cuenta en esta tesis y nos da a entender que el asfalto espumado, junto con el cemento, tienden a mejorar significativamente los pavimentos, no sólo superficialmente, sino también estructuralmente.

\section{Paper D: The structure foamed bitumen mixture and effect of process parameters on $\begin{array}{lllll}\text { production } & \text { (Pelicilã } & \text { et. } & \text { al., } & \text { 2011). }\end{array}$} El presente paper nos muestra la importancia que se le debe de dar a los agregados, previo a la mezcla con asfalto espumado. Una cantidad menor de finos impactará de manera negativa en la mezcla, debido a que las pequeñas partículas de asfalto durante la mezcla no podrán actuar como conectores entre las partículas del agregado grueso. Sin embargo, una cantidad mayor de finos hará perder resistencia y estructura a la base estabilizada. Por otra parte, es importante poder encontrar la dosificación óptima de asfalto a mezclar, ya que la base estabilizada deberá cumplir con ciertos requisitos estructurales.

\subsection{Marco Teórico: Tecnología del Asfalto Espumado}

\subsubsection{Definición:}

"El asfalto espumado es una técnica relativamente nueva en su uso que permite utilizar mezclas asfálticas de un modo muy diferente a los sistemas tradicionales" Thenoux Z. (2002). Las mezclas producidas con asfalto espumado tienen un comportamiento estructural similar a una mezcla tradicional, pero difieren de su composición interna. (Macarrone et. al., 1993).

Además, la tecnología de asfalto espumado es una estrategia constructiva en la que se busca optimizar recursos, aprovechando las propiedades físicas del asfalto y el agua para producir el efecto de espumado y realizar la mezcla con áridos a temperatura ambiente.

\subsubsection{Historia del asfalto espumado:}

La primera persona en darse cuenta del potencial de usar asfalto espumado como agente estabilizador fue el profesor Ladis Csanyi en la Estación Experimental de Ingeniería (Engineering Experiment Station) en la Universidad Estatal de Iowa (Iowa State University) 
en 1956. Esta tecnología fue refinada más tarde por la organización Mobil Oil que desarrolló la primera cámara de expansión para mezclar agua con asfalto para generar espuma. ${ }^{18}$

A pesar de que la aplicación del asfalto espumado se descubrió en los años '50, se han construido pocos proyectos aplicando esta tecnología. Esta situación se mantuvo hasta que Wirtgen Group Company entró al mercado con sus sistemas y equipos a mediados de los años $90 .{ }^{19}$

Con respecto al último párrafo mencionado, si bien el uso de la tecnología recién cobró interés a mediados de los años 90, éste no fue ajeno en Sudamérica. Desde hace aproximadamente unos 20 años, el asfalto espumado ha sido utilizado en distintos países de Sudamérica (Chile y Brasil), situación que no ocurre en nuestro país, debido a que el uso del asfalto espumado como agente estabilizador de suelos aún se viene insertando lentamente y requiere de mayor investigación para poder conocer mejor sus propiedades físicas y mecánicas.

Con el paso del tiempo, las propiedades y comportamientos del asfalto espumado evidentemente se diferenciaban del asfalto tradicional, por tal motivo los ensayos de estabilidad y fluencia de Marshall fueron reemplazados gradualmente por los ensayos de Tracción Indirecta (ITS), los cuales siguen vigentes hasta el día de hoy.

\subsubsection{Aplicación y producción del asfalto espumado:}

El asfalto caliente $\left(160-180{ }^{\circ} \mathrm{C}\right)$ se transforma en asfalto espumado cuando se mezcla con una pequeña cantidad de agua atomizada (típicamente $2 \%$ en masa del asfalto) en una cámara de expansión especial. En el estado espumado (un estado temporalmente de baja viscosidad), el asfalto puede ser añadido y mezclado con los agregados a temperatura ambiente y con contenidos de humedad in-situ. El proceso de espumado del asfalto es dependiente del cambio de estado del agua de líquido a vapor, un proceso que está acompañado de una expansión de unas 1500 veces el volumen original del líquido a una presión atmosférica normal. Cuando las partículas de agua entran en contacto con el asfalto caliente, la energía calorífica del asfalto se transfiere en agua. Tan pronto como el agua alcanza su punto de ebullición, cambia de

\footnotetext{
${ }^{18}$ Wirtgen GmbH, (2004), Manual de reciclado en frío, Windhagen, Alemania.

${ }^{19}$ Wirtgen GmbH, (2004), Manual de reciclado en frío, Windhagen, Alemania.
} 
estado y, al hacerlo, se generan burbujas llenas de vapor de agua que son rodeadas con una delgada película de asfalto. ${ }^{20}$

En la Fig. 3.1 se muestra el proceso de producción del asfalto espumado.

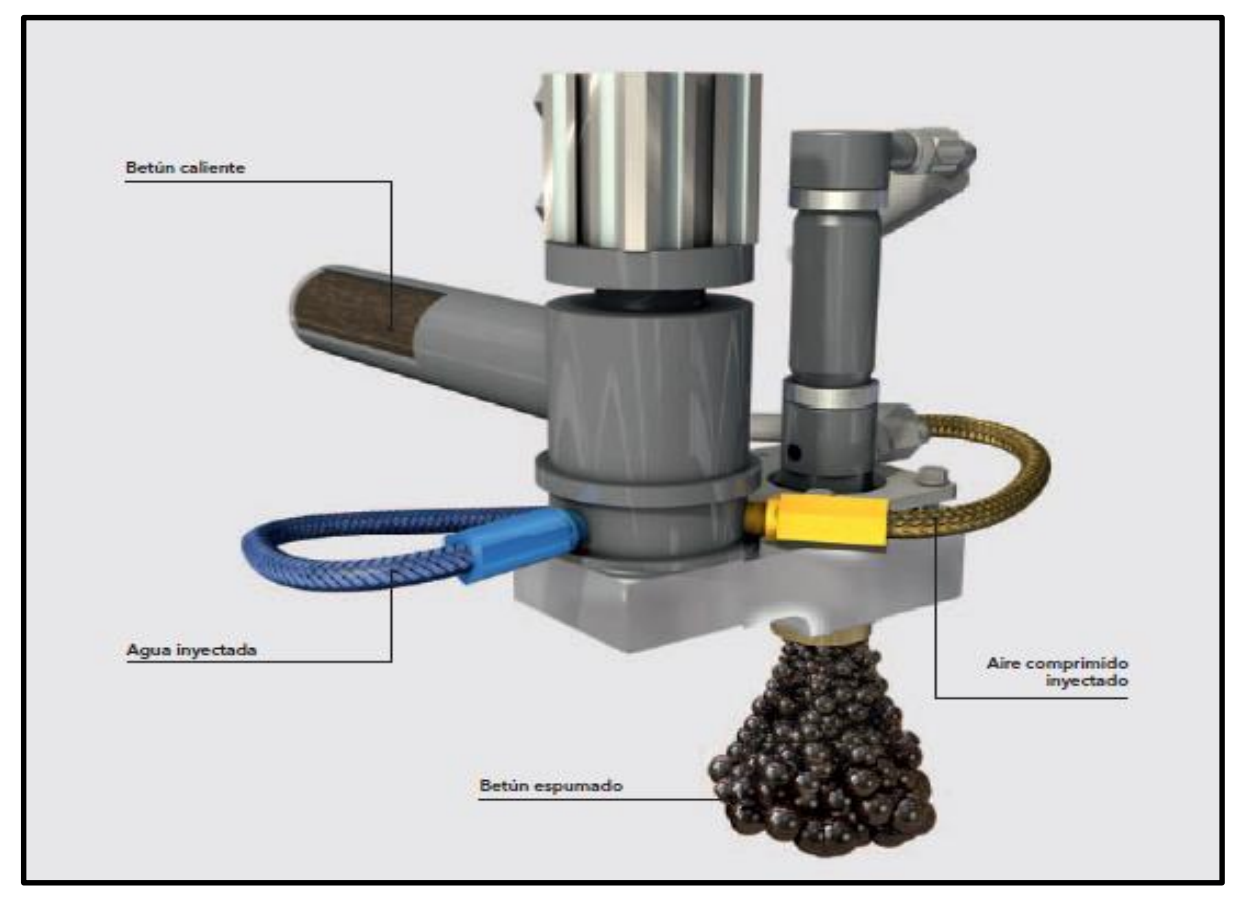

Fig. 3.1: Producción de asfalto espumado

Fuente: Manual de reciclado en frío, Wirtgen 2004

Además, Thenoux Z. (2002) afirma lo siguiente:

"Debido a la baja conductividad térmica del asfalto y del agua, las burbujas pueden mantener el equilibrio por pocos segundos (10 - 30 segundos). Este proceso ocurre para una gran cantidad de burbujas. A medida que la masa coloidal (gas/asfalto) se enfría a temperatura ambiente, el vapor en las burbujas se condensa causando el colapso y la desintegración de la espuma. La desintegración de la burbuja produce miles de gotitas de asfalto las cuales al unirse recuperan su volumen inicial sin alterar significativamente las propiedades reológicas de éste."

${ }^{20}$ Wirtgen GmbH, (2004), Manual de reciclado en frío, Windhagen, Alemania. 
Durante la mezcla entre los agregados (finos y gruesos) y el asfalto espumado, las gotas de asfalto se unen a los finos y la capa estabilizada tendrá una propiedad visco elástica, producto de los conectores que se encuentran entre los finos. En la Fig. 3.2 se puede ver la dispersión de asfalto dentro de la matriz de finos.
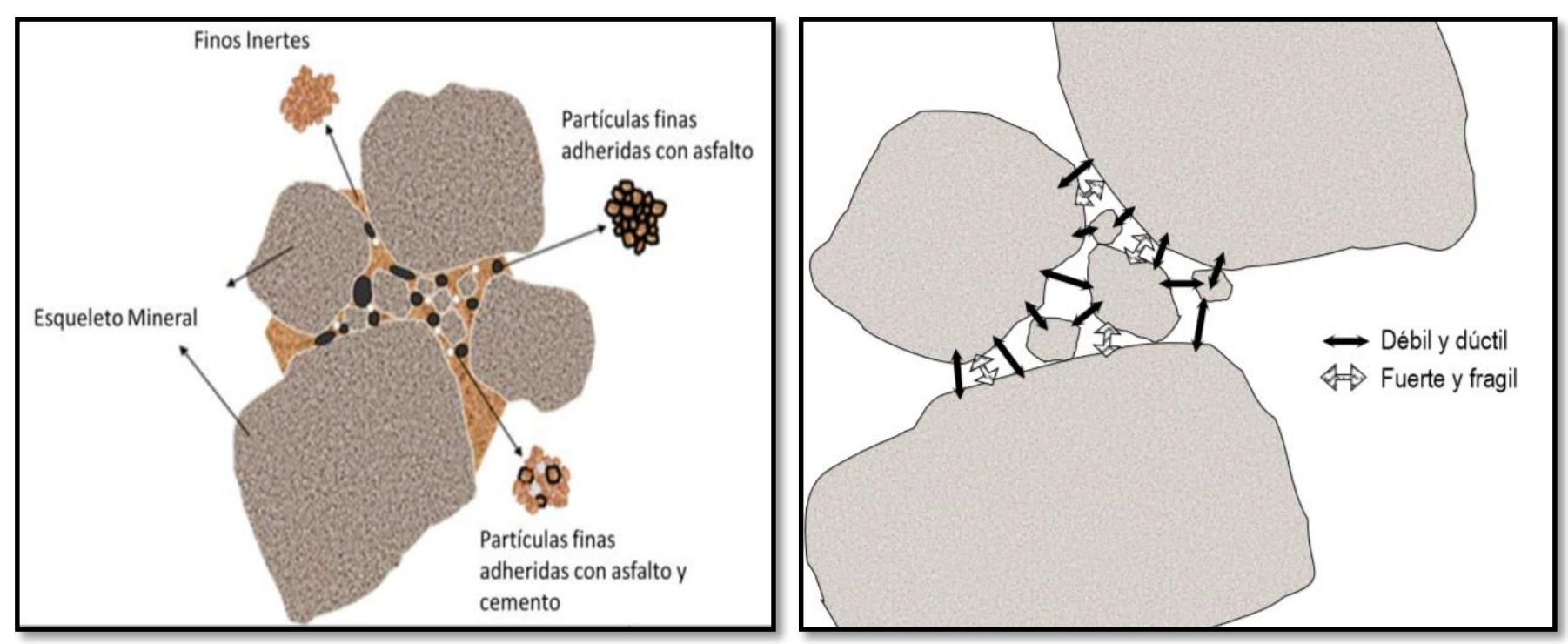

Fig. 3.2: Dispersión del asfalto espumado en la matriz de finos Fuente: Felipe Halles

Existen dos tipos de conectores: uno es el principal y le corresponde al residuo asfáltico que quedó después del proceso de espumación y el otro conector corresponde al cemento portland (condición dúctil y rígida respectivamente).

Durante la mezcla también se generan distintas fases, por lo que es importante entender el comportamiento de cada una, ya que se ven afectadas en el curado (Fu et al, 2009). Estas fases se pueden conceptualizar como una microestructura (Fig. 3.2) de la mezcla de agregados, cemento y asfalto espumado: 1. Esqueleto de agregado: formado por grandes partículas de piedras (agregado grueso). 2. Masillas de asfalto: partículas de agregado fino enlazadas mediante gotas de asfalto espumado. 3. Relleno mineral: partículas de agregado fino no enlazadas con asfalto durante la mezcla.

Si bien en estas fases no se menciona el cemento (filler activo), es debido a que su contenido dentro de la mezcla generalmente se encuentra entre el $1 \%$ y $2 \%$, por lo que no genera una fase independiente. Al no generar una fase independiente, se dispersa en la fase del relleno mineral, lo que le contribuye fuerza y resistencia a temprana edad. Cuando una grieta se 
propaga a través de una mezcla de asfalto espumado con cemento en el ensayo de tracción indirecta (ITS), se debe a: la rotura a través del relleno mineral con el cemento, rotura a través de la masilla de asfalto, o rotura en la interface entre la masilla de asfalto y el esqueleto de agregado. Sin embargo, la mezcla puede ser idealizada como un material compuesto:

- Partículas finas adheridas al asfalto (masilla de asfalto): esta fase posee un comportamiento dúctil.

- Relleno mineral adherido al filler activo (fase FA): esta fase posee un comportamiento rígido y frágil.

En una determinada carga, la rotura se genera primero en la "fase FA", debido a que tiene una condición frágil y continúa a través de la masilla de asfalto. Dicha masilla al tener una condición dúctil, posee una mayor deformabilidad que varía en función al contenido de asfalto inyectado. Esta variación guarda relación directa e importante con los resultados del ensayo de tracción indirecta, cuando estos no cumplen la resistencia mínima requerida y se debe a:

- Falta de asfalto espumado entre partículas finas: si una fracción importante de partículas finas no está recubierta por asfalto espumado, el módulo elástico y la fuerza de la masilla de asfalto será menor en comparación con una masilla de asfalto en donde las partículas finas estén recubiertas con un "contenido óptimo" de asfalto espumado.

- Exceso de asfalto espumado entre partículas finas: así mismo, la masilla de asfalto presentará un módulo elástico y una fuerza menor si el contenido de asfalto espumado supera el óptimo, ya que dicho asfalto, al no mezclarse y al no actuar como conector entre las partículas finas, se comportará como lubricante haciendo que la masilla pierda rigidez y resistencia.

\subsubsection{Aplicaciones del asfalto espumado:}

Existen principalmente dos tipos de aplicaciones del asfalto espumado, el reciclado en frío de pavimentos asfálticos y la estabilización de suelos con materiales vírgenes (Thenoux y Jamet, 2002). 
- Reciclado en frío de pavimentos asfálticos:

Consiste en la recuperación del material de un pavimento asfáltico existente, el cual es mezclado con asfalto espumado, adiciones (cemento o cal) y agregados vírgenes (si es necesario) para formar la base asfáltica que será colocada en el mismo lugar o en otro distinto. La recuperación puede ejecutarse mediante un equipo fresador capaz de disgregar el material o mediante métodos convencionales donde el proceso de disgregación ocurre con posterioridad a la recuperación. En general el material recuperado está formado no sólo por concreto asfáltico disgregado, sino también por agregados aportados por la base y sub-base granular existente.

- Estabilización de suelos:

Esta aplicación consiste en la estabilización de suelos de relativa baja plasticidad (IP<16) con asfalto espumado en donde los suelos están conformados por materiales vírgenes. Estos materiales vírgenes (agregados finos y agregados gruesos) son extraídos de una cantera con una proporción específica, con la finalidad de que su mezcla cumpla con los requisitos granulométricos.

\subsubsection{Producción del asfalto espumado:}

La producción del asfalto espumado se puede realizar mediante dos tecnologías: en sitio o en planta.

\subsection{Producción en sitio:}

La tecnología en sitio requiere de un equipo fresador-mezclador. Existen varios modelos y configuraciones para este tipo de equipos, pero en general todos poseen un tambor fresadormezclador, en el cual el material es removido desde la superficie, triturado, mezclado con el asfalto espumado y extendido. La inyección del asfalto espumado en el agregado se realiza simultáneamente a través de varias cámaras de expansión individuales. Dependiendo de los aditamentos del equipo de reciclado de mezcla puede quedar acordonada, extendida o extendida y nivelada. En este último caso se puede prescindir de una motoniveladora.

La Fig. 3.3 muestra la forma de trabajo del equipo fresador-mezclador aplicando asfalto espumado, mientras que la Fig. 3.4 nos muestra el tren de trabajo que se lleva a cabo para la aplicación del asfalto espumado. 


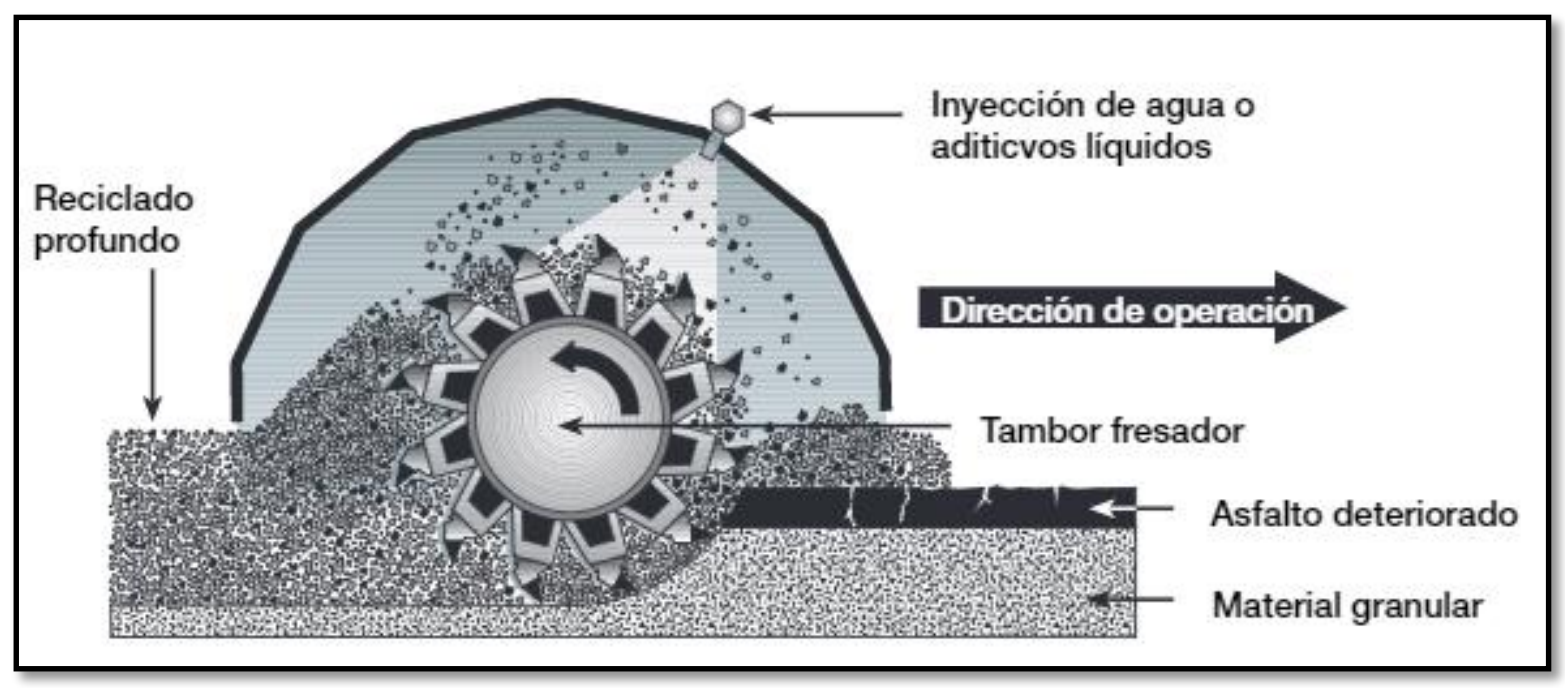

Fig. 3.3: Equipo fresador-mezclador e inyección de asfalto espumado.

Fuente: Manual de reciclado en frío, Wirtgen 2004

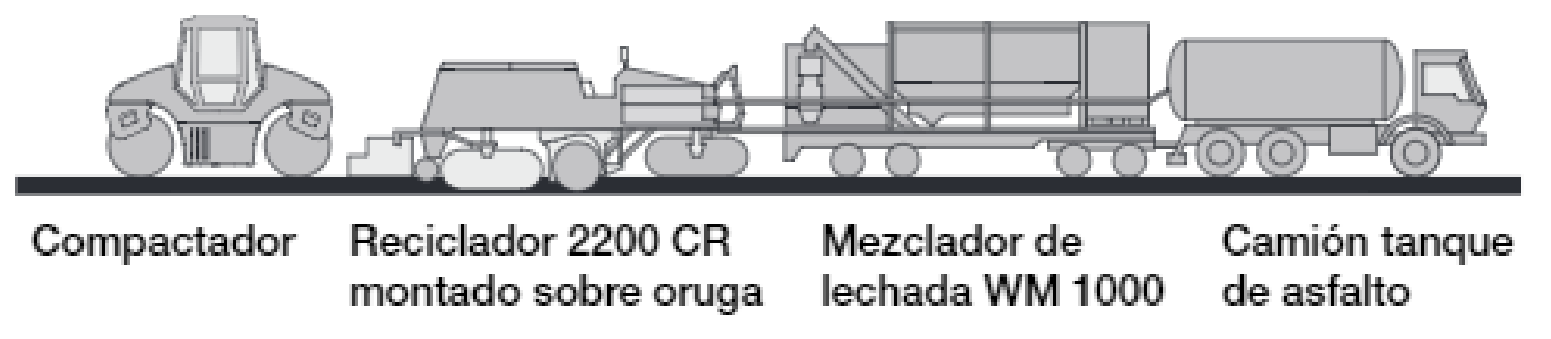

Fig. 3.4: Tren reciclador con mezclador de lechada y camión de asfalto

Fuente: Manual de reciclado en frío, Wirtgen 2004

\subsection{Producción en planta:}

\section{Planta Móvil KMA 220:}

Como se mencionó anteriormente en la investigación, para lograr una base estabilizada con asfalto espumado, no sólo es necesario fresar y utilizar el material existente, sino que también se pueden utilizar materiales vírgenes en una proporción adecuada para su mezcla.

Además de la producción de asfalto espumado con tecnología en sitio, en la actualidad se utiliza la tecnología de planta móvil cuyo equipo más avanzado es la mezcladora móvil de reciclado en frío KMA 220. 


\section{Características de la KMA 220:}

1. Una de las características más importantes de la mezcladora móvil es que puede ser transportada con total facilidad y rapidez a la cercanía del lugar en donde se realiza la obra, lo que ahorra tiempo, capacidad de los camiones y reduce el impacto sobre el medio ambiente. En la Fig. 3.5 se muestra la mezcladora móvil KMA 220.

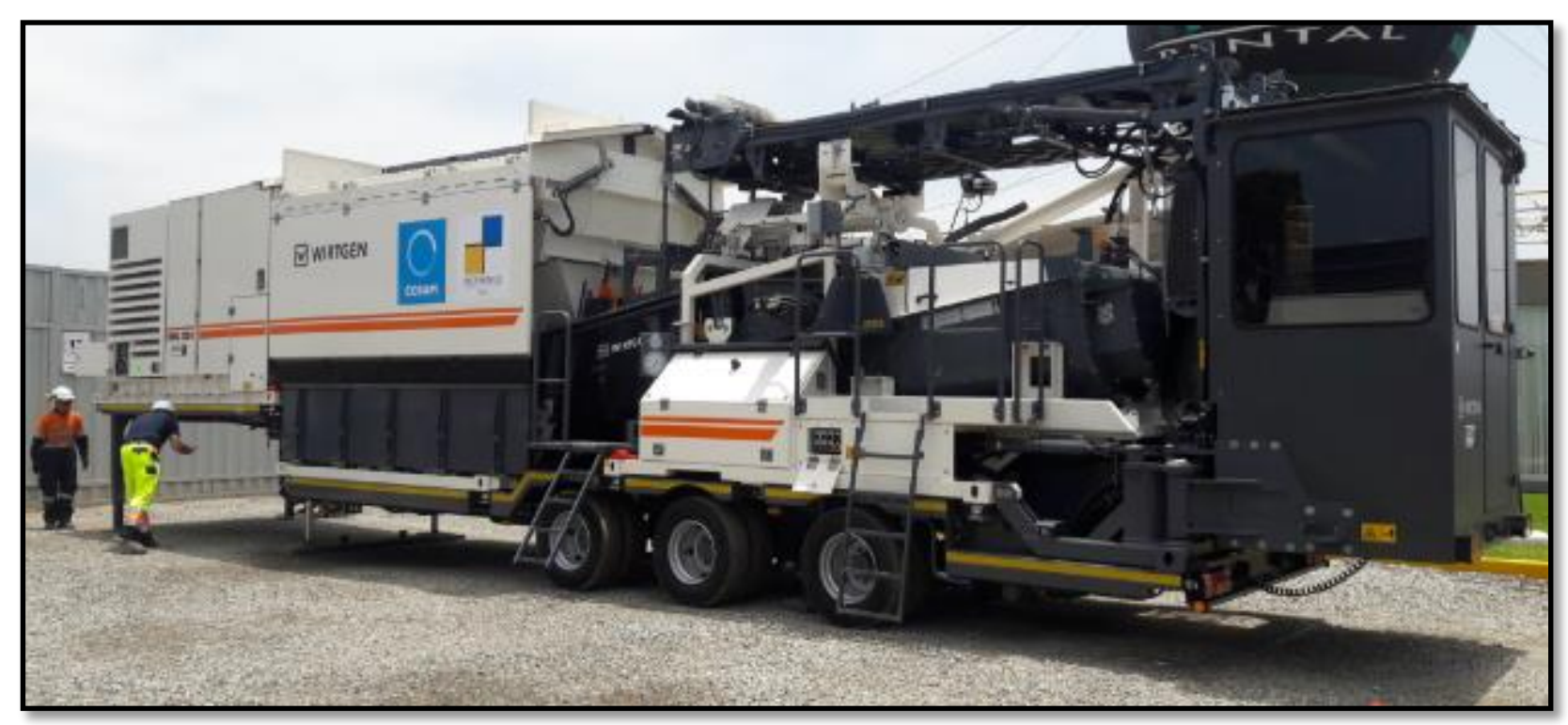

Fig. 3.5: Mezcladora móvil de reciclado en frío KMA 220

Fuente: PERUVIAS, Revista Especializada 
2. Tiene una impresionante capacidad de procesar muchos materiales diferentes no ligados, siendo posible así producir mezclas a base de las más variadas mezclas nuevas de granos (materiales vírgenes), de materiales de construcción fresados (reciclados) y de ligantes. El asfalto es uno de los ligantes ideales y se suministra a la mezcladora móvil desde camiones-tanque especiales. En la Fig. 3.6 se muestran todos los agentes estabilizadores con los que puede trabajar la mezcladora móvil KMA 220.

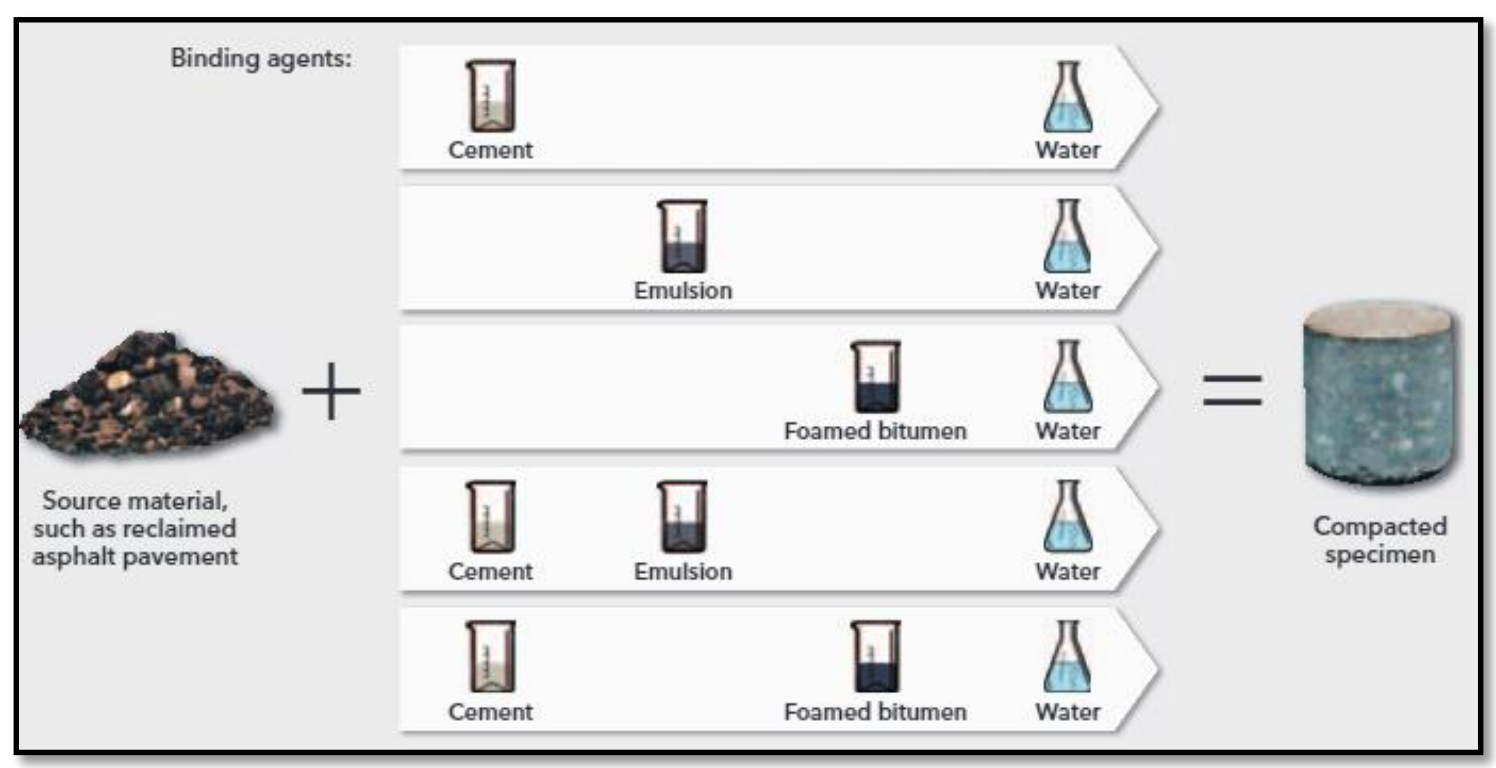

Fig. 3.6: Ligantes procesados en la KMA 220

Fuente: Wirtgen Group Company

3. La mezcladora móvil es sumamente eficaz comparada con mezclas producidas en planta, ya que tiene la capacidad de producir 220 ton/h de aglomerado de primera calidad. Su capacidad de producción se complementa con el sistema de suministro continuo de material en la obra. Es por eso que la mezcladora móvil cuenta con una cinta de descarga que gira en ángulos muy amplios lo que la convierte en un equipo completo.

En la Fig. 3.7 se muestra la facilidad y el espacio reducido con que la mezcladora móvil trabaja. También se puede apreciar en la Fig. 3.8 la cinta de descarga disponible para trabajar a distintos ángulos, de acuerdo a la posición de los camiones. 


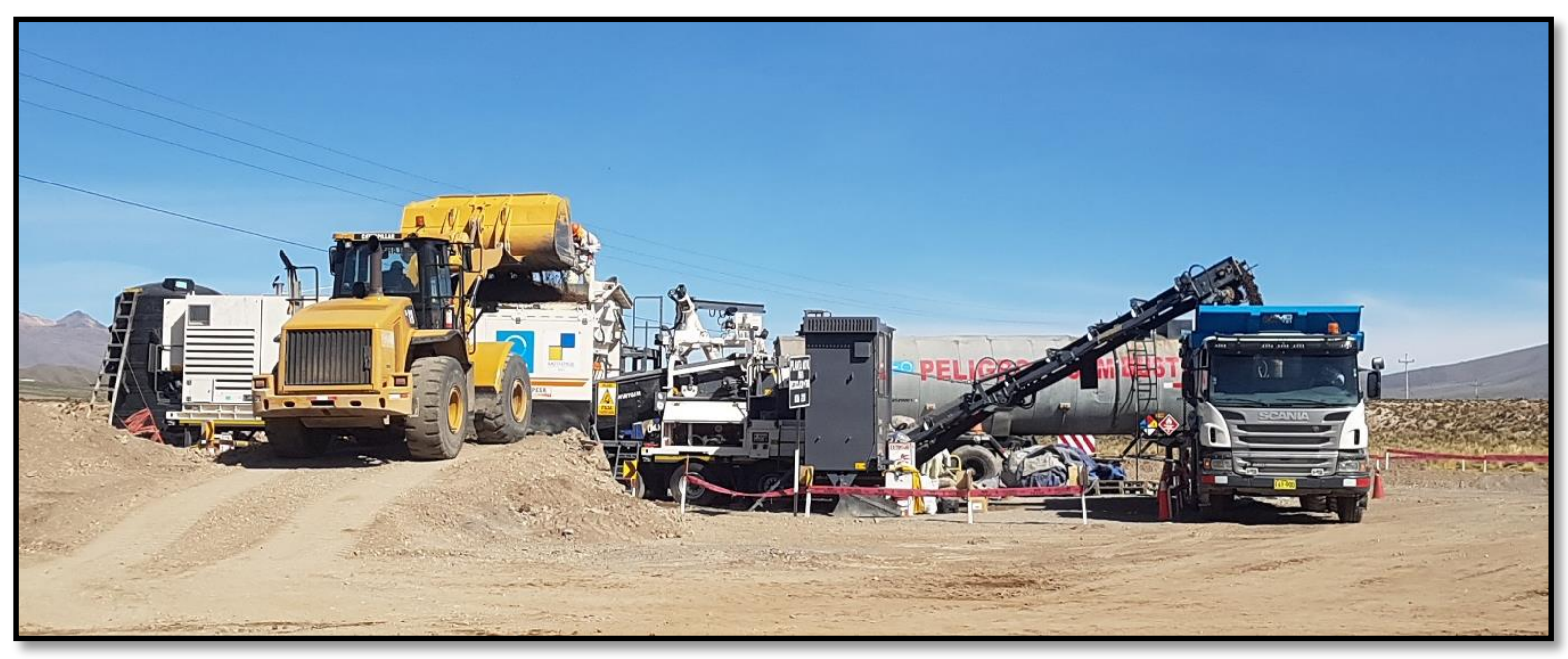

Fig. 3.7: Mezcladora móvil KMA 220 en producción

Fuente: Propia

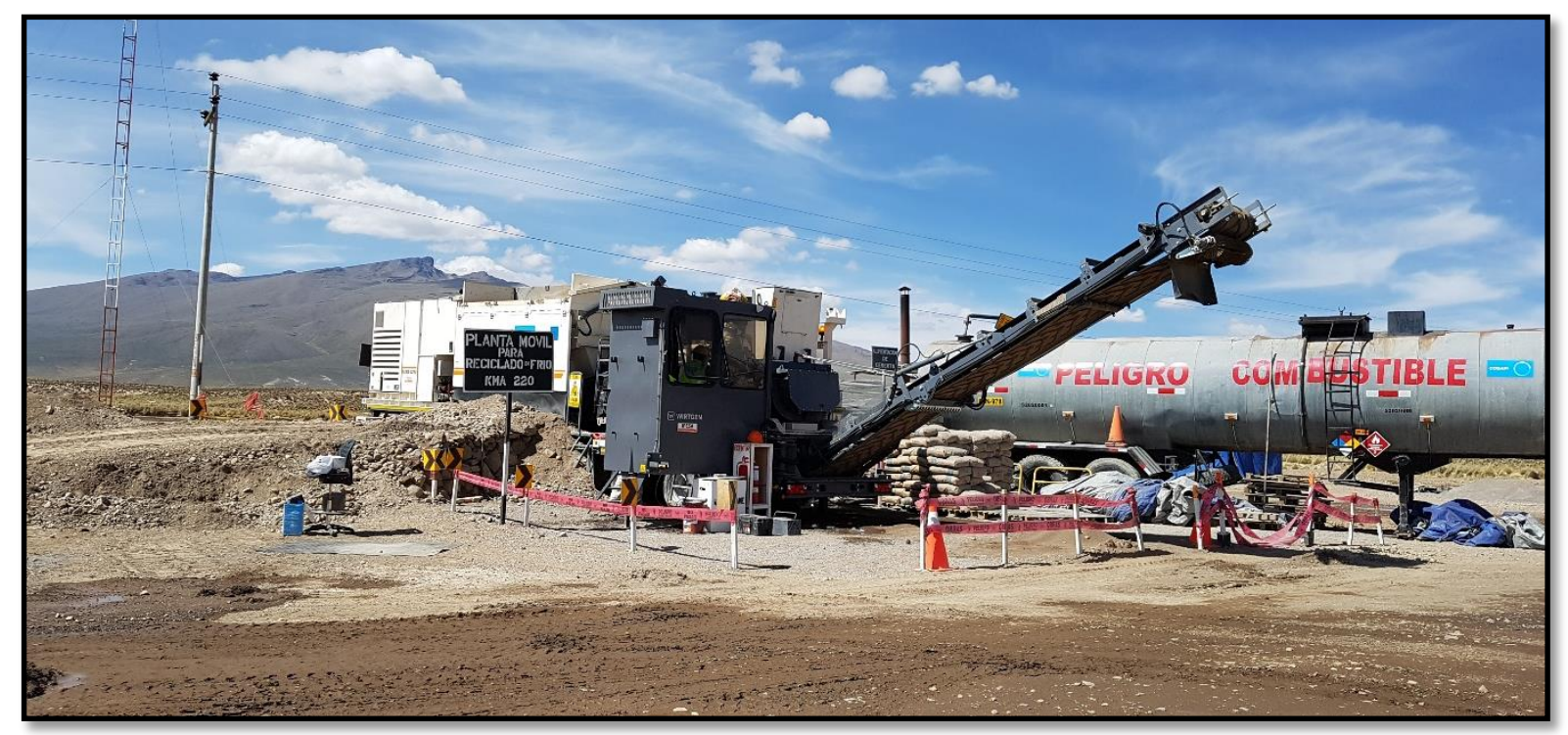

Fig. 3.8: Cinta de descarga de la KMA 220

Fuente: Propia 
4. El transporte de la mezcladora móvil es sumamente fácil, debido a que tiene una estructura que permite empacar la instalación y transportarla hacia lugares cercanos a la obra rápidamente. La mezcladora es sujetada a la plataforma del camión, lo que permite un viaje seguro y rápido. Las partes que componen la mezcladora móvil se muestran en la Fig. 3.9.

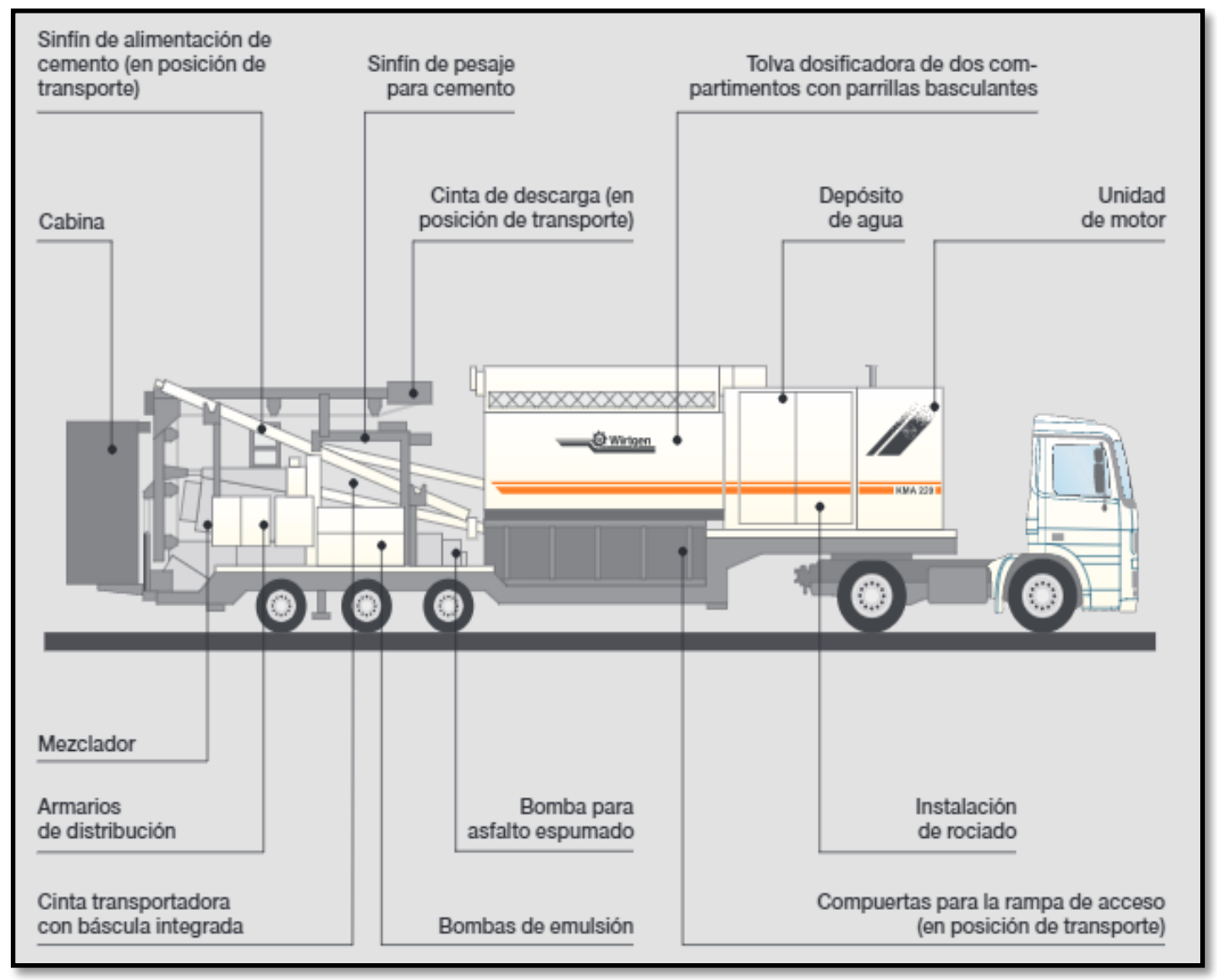

Fig. 3.9: Mezcladora móvil preparada para el transporte

Fuente: Wirtgen Group Company

Como se ha visto, esta mezcladora móvil de reciclado en frío es un equipo muy completo y potente desde cualquier punto de vista, debido a que da muchas facilidades en el lugar de la construcción y posee un gran rendimiento pese a no tener un gran tamaño. Además, permite reciclar asfaltos para producir nuevos tipos de mezclas de forma económica y cuidando del medio ambiente. 


\subsubsection{Caracterización geotécnica de los áridos para el Asfalto Espumado:}

Desde el inicio en el uso de asfalto espumado, una amplia gama de resultados ha sido tratada con éxito para su uso en la construcción. Los agregados de fuentes tanto vírgenes como reciclados se han utilizado en el proceso. ${ }^{21}$

\subsubsection{Propiedades de los agregados:}

Mobil Oil a partir de su experiencia con el proceso de asfalto espumado, usando diferentes tipos de materiales, estableció las directrices de gradaciones adecuadas de los agregados que se pueden utilizar para la estabilización de la espuma. Akeroyd y Hicks (1988), desarrollaron la curva granulométrica del agregado como muestra en la Fig. 3.10:

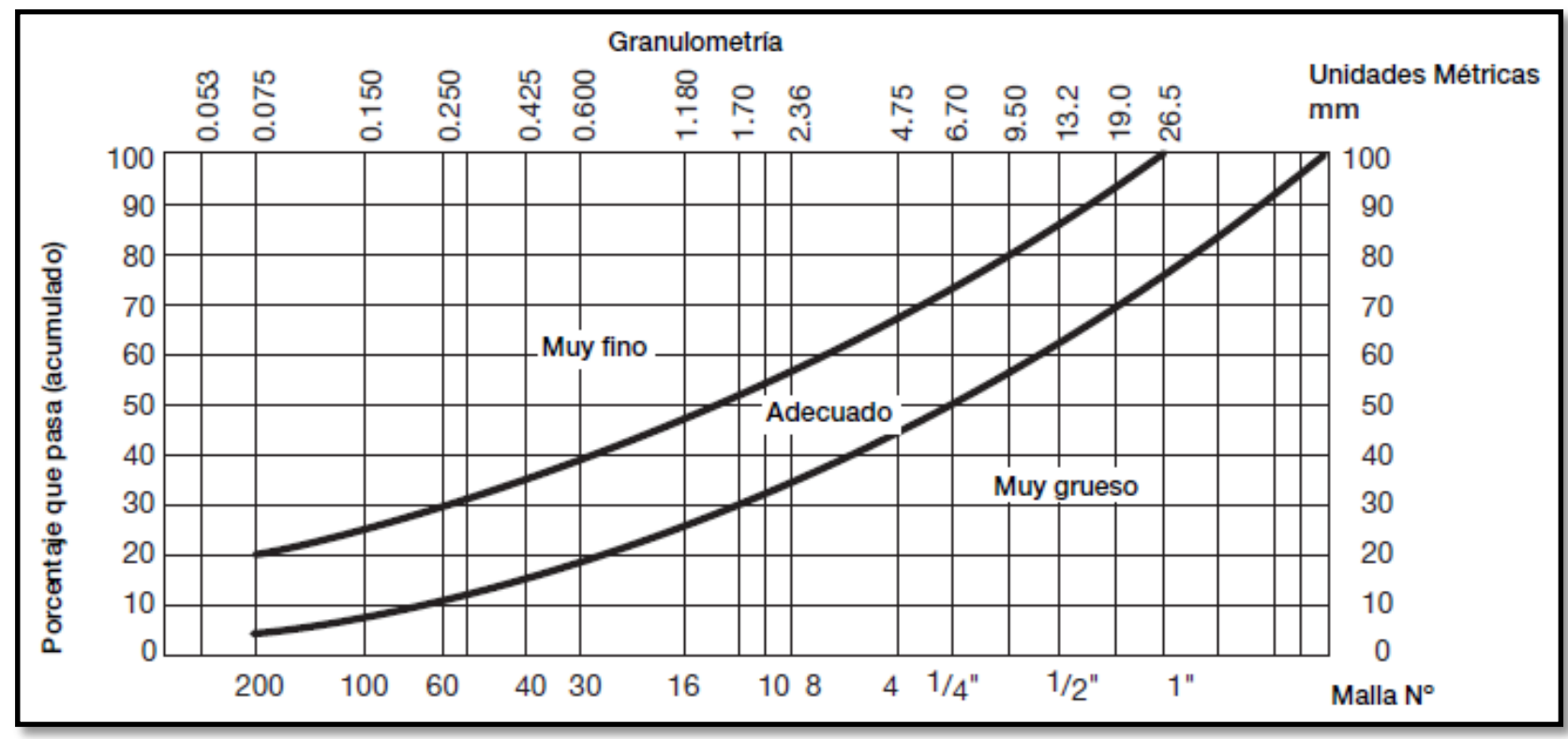

Fig. 3.10: Clasificación de materiales granulares

Fuente: Manual de reciclado en frío, Wirtgen 2004

De la Fig. 3.11 se puede afirmar que los materiales que se encuentran dentro de los husos granulométricos (Adecuado), son los apropiados para ser empleados en carreteras con tráfico pesado. Los materiales que se encuentran en la parte superior de los husos granulométricos (Muy fino), son apropiados para tráfico liviano, pero su comportamiento puede ser mejorado mediante la adición de fracciones gruesas. Los materiales que se encuentran en la parte inferior

\footnotetext{
${ }^{21}$ Jenkins, K. J. (2000). Mix design considerations for cold and half-warm bituminous mixes with emphasis of foamed bitumen (Doctoral dissertation, Stellenbosch: Stellenbosch University).
} 
de los husos granulométricos (Muy grueso), son deficientes en finos y no son apropiados para la estabilización de suelos a menos que sean mejorados mediante la adición de finos.

Además, se puede apreciar que el porcentaje mínimo de finos requeridos es de 5\%, considerando como finos la fracción de material que pasa la malla $\mathrm{N}^{\circ} 200(0.075 \mathrm{~mm}$.).

\subsubsection{Contenido de Filler:}

El filler es un material que se utiliza en las mezclas asfálticas, con la finalidad de complementar la granulometría de los agregados finos cuyas características no cumplen las especificaciones técnicas correspondientes.

Pese a la definición anterior, en esta investigación se hace uso del filler activo (cemento), con la finalidad de agregarle resistencia a la base estabilizada, mas no para complementar la granulometría de agregados finos, ya que el porcentaje de éste último, que se tiene luego de la mezcla entre agregado fino y grueso, es el necesario para poder cumplir con el 5\% mínimo de finos que se requiere. Además, se debe tener en cuenta que la dosificación del filler activo no debe de excederse del $3 \%$, debido a que un porcentaje mayor producirá una pérdida de flexibilidad en la base estabilizada.

La dosis del filler activo guarda relación con el Índice de Plasticidad, que es un indicador de la capacidad que tienen los finos para ser mezclados con la espuma de asfalto. Dependiendo de los valores que enlace este índice, se recomienda el uso de pequeñas cantidades de cemento de acuerdo con la clasificación mostrada en la Tabla 3.1.

\begin{tabular}{|c|c|}
\hline Indice de Plasticidad & Cantidad de Cemento (\% en peso del agregado) \\
\hline $\mathrm{IP}<10$ & $1 \%$ \\
\hline $10<\mathrm{IP}<16$ & $1.5 \%$ \\
\hline $\mathrm{IP}>16$ & $3 \%$ \\
\hline
\end{tabular}

Tabla 3.1: Incorporación de cemento a la mezcla con asfalto espumado

Fuente: Tecnología del asfalto espumado y diseño de mezcla (2002) 


\subsubsection{Tipo de Material:}

Los tipos de materiales adecuados para el tratamiento mediante el proceso de asfalto espumado han tenido más importancia por su gradación y propiedades que por el tipo de material. $^{22}$

Ruckel et al. (1983), lista a materiales adecuados para el tratamiento de la espuma como la piedra chancada, roca, grava, arena, arena limosa, grava arena, escoria, agregados reciclados, de colas de mineral y otros.

\subsubsection{Características del asfalto espumado:}

\subsubsection{Propiedades físicas del asfalto espumado:}

\subsection{Volumen de expansión:}

Se debe de entender cómo es que se produce el intercambio energético dentro del sistema agua-asfalto-recipiente para poder calcular el volumen de expansión teórico de la espuma del asfalto en el laboratorio. Normalmente se puede utilizar la ley universal de los gases $(\mathrm{P} * \mathrm{~V}=\mathrm{R} * \mathrm{~T} * \mathrm{n})($ Thenoux Z., 2002).

\subsection{Tamaño y espesor de la burbuja de asfalto:}

Para explicar la interacción física entre el vapor y el asfalto, se analiza una burbuja aislada de asfalto espumado. ${ }^{23}$ La Fig. 3.11 representa una burbuja aislada de asfalto espumado:

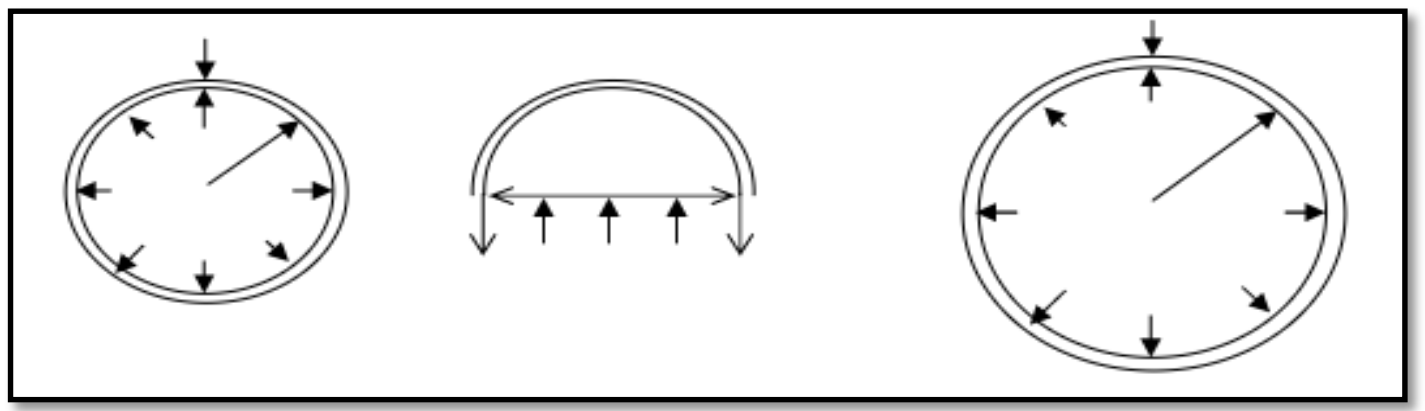

Fig. 3.11: Burbuja de asfalto espumado aislada

Fuente: Tecnología del asfalto espumado (2002)

\footnotetext{
22 Jenkins, K. J. (2000). Mix design considerations for cold and half-warm bituminous mixes with emphasis of foamed bitumen (Doctoral dissertation, Stellenbosch: Stellenbosch University).

${ }^{23}$ Thenoux Zeballos, G. A. (2002). Tecnología del asfalto espumado= Foamed asphalt technology.
} 
Jenkins (1999) afirma que los esfuerzos de tracción se mantienen constantes a medida que la burbuja se expande. Sin embargo, existen una serie de factores que limitan la expansión de las burbujas y por ende de la espuma.

Heukelom (1973) estableció una relación entre la elongación y el módulo de rigidez de los asfaltos con diferentes grados de penetración. Usando esta relación como un indicador de la elongación de la película de asfalto que forma las burbujas, se puede estimar la máxima elongación de la burbuja. Utilizando el monograma de Heukelom y la relación establecida entre el Módulo de Rigidez y elongación, se obtiene una elongación igual a 100 veces el valor del perímetro de la circunferencia.

\subsubsection{Propiedades empíricas del asfalto espumado:}

\subsection{Estabilidad del asfalto espumado: ${ }^{24}$}

Se determina por medio del estudio del tiempo que requiere la espuma para colapsar. Dichos efectos son estudiados en el laboratorio. El quiebre en las pruebas de laboratorio ocurre cuando uno de los dos efectos ocurre primero:

- Reducción en la temperatura del vapor, debido al contacto de la película de asfalto con el aire o el recipiente que se encuentra a una temperatura menor. Las burbujas más grandes, aunque posean teóricamente la misma tensión superficial que sus contrapartes más pequeñas, tienen una mayor área superficial y por lo tanto experimentarían una mayor disminución de la temperatura lo que las hará colapsar primero.

- Superación del límite de elongación de la película de asfalto. Cuando la presión del vapor al interior de la burbuja es demasiado grande, la película de asfalto se expandirá más allá de su límite de elongación, resultando en su quiebre antes de lograr el equilibrio.

${ }^{24}$ Thenoux Zeballos, G. A. (2002). Tecnología del asfalto espumado= Foamed asphalt technology. 


\subsection{Razón de expansión: ${ }^{25}$}

Es una medida de la viscosidad de la espuma y va a determinar qué tan bien se va a dispersar el asfalto en la mezcla. Se calcula como la razón entre el máximo volumen de la espuma relativo a su volumen original.

\subsection{Vida media: ${ }^{26}$}

Medida de estabilidad de la espuma y provee una indicación de la tasa de colapso de la espuma. Se calcula como el tiempo, en segundos, que transcurre para que la espuma colapse a la mitad de su volumen máximo.

En la Fig. 3.12 se muestran las propiedades de razón de expansión y vida media mencionadas:

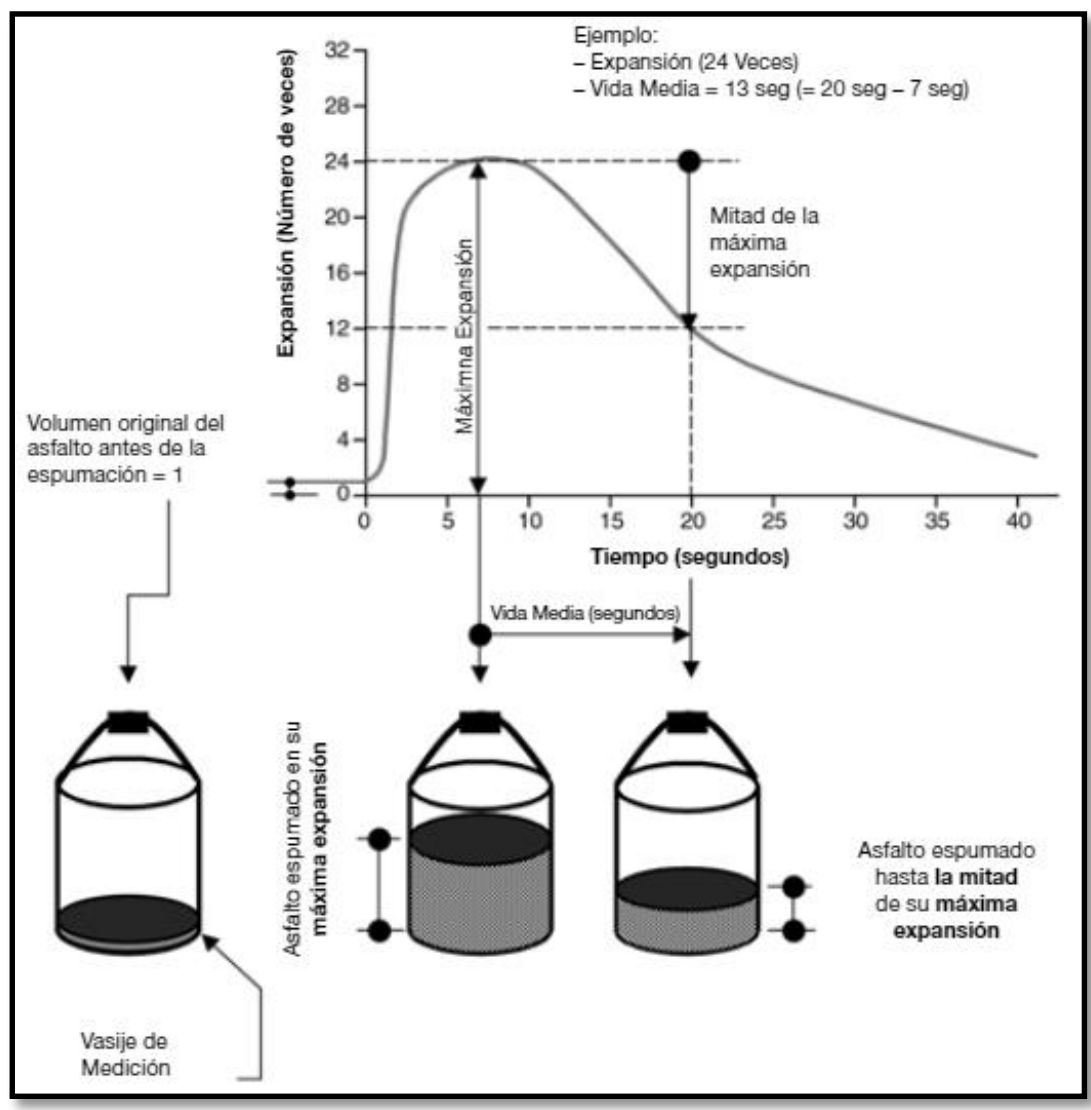

Fig. 3.12: Características del asfalto espumado

Fuente: Manual de reciclado en frío, Wirtgen 2004

\footnotetext{
${ }^{25}$ Wirtgen GmbH, (2004), Manual de reciclado en frío, Windhagen, Alemania.

${ }^{26}$ Wirtgen GmbH, (2004), Manual de reciclado en frío, Windhagen, Alemania.
} 


\subsubsection{4. Índice de Espumación:}

El Índice de Espumación se define como el área bajo la curva de la Razón de Expansión y el Tiempo de Colapso (Jenkins et al., 1999). La curva que se obtiene corresponde a la curva de colapso, la cual es un indicador del tiempo disponible para el mezclado. En la Fig. 3.13 se muestra el Índice de Espumación:

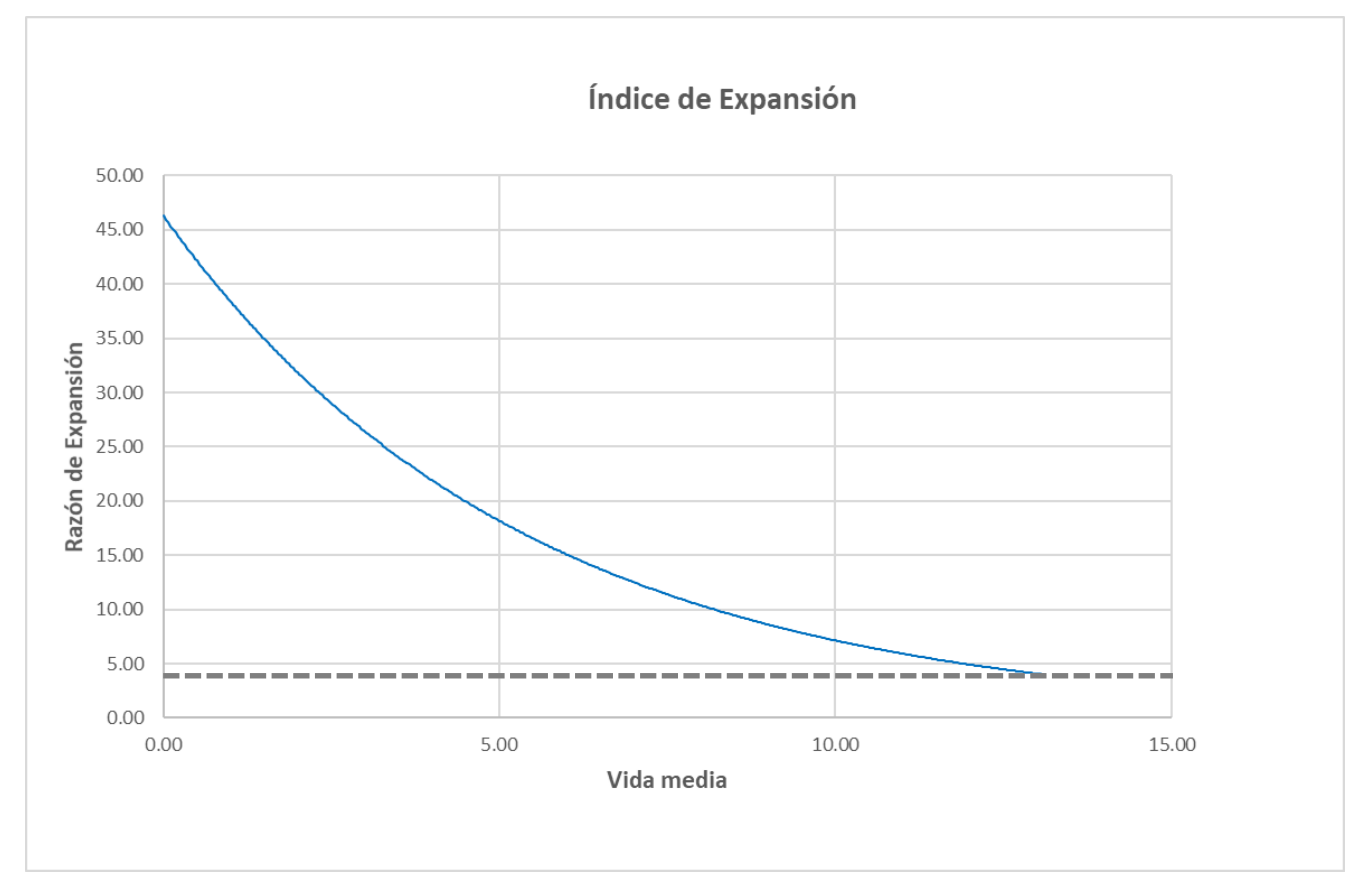

Fig. 3.13: Índice de espumación

Fuente: Tecnología del asfalto espumado (2002)

\subsubsection{Factores que influyen en la espuma: ${ }^{27}$}

Las características de expansión y vida media del asfalto espumado se ven afectados por:

${ }^{27}$ Wirtgen GmbH, (2004), Manual de reciclado en frío, Windhagen, Alemania. 
- Adición de agua: Al aumentar cantidad de agua que es inyectada en el asfalto aumenta efectivamente el volumen de la espuma por un factor multiplicador de 1500. Así, al aumentar la cantidad de agua añadida aumenta el tamaño de las burbujas creadas, causando que se aumenta la tasa de expansión. Sin embargo, al aumentar el tamaño individual de las burbujas reduce el espesor de la película del asfalto que las rodea, haciéndolas menos estables y resultando en una reducción de la vida media. Es por tal motivo que se busca el porcentaje de agua que mantenga en equilibrio estas dos características como se muestra en la Fig. 3.14.

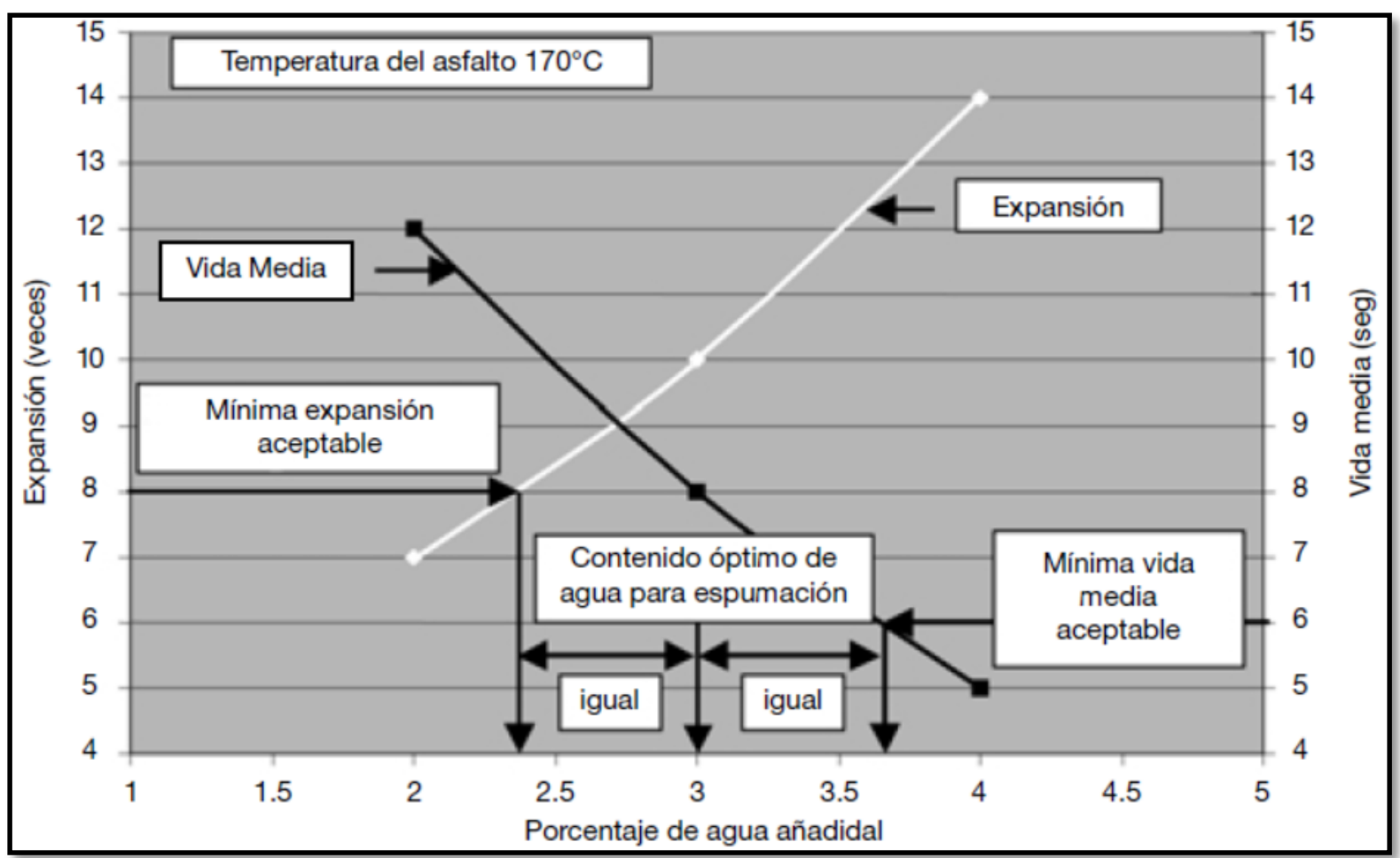

Fig. 3.14: Relación entre Razón de expansión y Vida media

Fuente: Manual de reciclado en frío, Wirtgen 2004

- $\quad$ Tipo de asfalto: Generalmente se utilizan asfaltos con valores de penetración entre 80 y 150 para espumar. Por razones prácticas, los asfaltos más rígidos son generalmente evitados ya que producen una espuma de peor calidad, generando una dispersión más pobre. Los asfaltos blandos también son evitados, ya que son más susceptibles al envejecimiento prematuro. 
- Fuente del asfalto: Algunos asfaltos espuman mejor que otros debido a su composición. En Venezuela, las propiedades espumantes de los asfaltos exceden enormemente a aquellas que tienen otras fuentes.

- Aditivos: Existen productos que varían las propiedades espumantes del asfalto, tanto negativamente (agentes anti-espumantes) como positivamente (espumantes). Los espumantes son usualmente requeridos cuando el asfalto utilizado ha sido tratado con un agente anti-espumante durante su proceso de refinado. Los espumantes son muy sensibles a la temperatura, por lo que tiene una vida efectiva bastante corta. Si se desea tener beneficios al utilizar un espumante, el asfalto debe de utilizarse en pocas horas.

\subsection{Factores Termodinámicos:}

Dentro de todos los factores, mencionados anteriormente, que influyen en la espumación, también existen factores termodinámicos a los que se les dará más importancia, debido a que el proyecto, sobre el cuál se realiza la investigación, se encuentra ubicado a una altura de más 4500 m.s.n.m. y, además, se encuentra bajo condiciones críticas como son las bajas temperaturas y distintas presiones. Dichos factores, que se mencionarán a continuación, afectan tanto en la efectividad de la espuma como en la efectividad de la espuma trabajando sobre los áridos. Por tal razón, es muy importante realizar los estudios y ensayos necesarios en estas condiciones climáticas para poder tener conocimiento de cómo es que estos factores afectan finalmente la base espumada a diseñarse.

- Temperatura del asfalto: La viscosidad del asfalto goza una relación inversa con la temperatura; a medida que la temperatura aumenta, la viscosidad se reduce. Lógicamente, mientras más baja es la viscosidad, mayor será el tamaño de las burbujas que se formarán cuando el agua cambie de estado en el proceso de espumado. Debido a que este proceso saca energía del asfalto, la temperatura antes de espumar debe de exceder los $160^{\circ} \mathrm{C}$ para obtener un producto satisfactorio. Debido a las muy bajas temperaturas que se tienen en el lugar del proyecto, se tendrá que buscar una solución para que la temperatura del asfalto no sea inferior a la requerida $\left(160^{\circ} \mathrm{C}-180^{\circ} \mathrm{C}\right)$ para poder realizar una espumación de buena calidad.

- Presión de asfalto y agua: El asfalto y el agua son inyectados en la cámara de expansión a través de pequeñas aberturas. El aumentar la presión en las tuberías de suministro causa 
que el flujo que pasa a través de las aberturas se disperse (atomice). Mientras más pequeñas son las partículas individuales, mayor es el área de contacto disponible, mejorando así la uniformidad de la espuma. Además de la presión con la cual el asfalto y el agua son inyectados dentro de la cámara de expansión, la presión atmosférica es un factor desconocido en los diseños de mezcla con asfalto espumado, ya que no se ha realizado un diseño de mezcla con asfalto espumado para un proyecto a más de 4500 m.s.n.m.

\subsubsection{Características aceptables de la espuma: ${ }^{28}$}

No existen límites en lo que respecta a las propiedades del asfalto espumado y el objetivo siempre será producir la mejor espuma para la estabilización.

Por experiencia se sabe que la dispersión adecuada de la espuma y la estabilización efectiva son posible cuando la razón de expansión y la vida media son tan bajas como 8 veces y 6 segundos respectivamente, para estabilizar un material a $25^{\circ} \mathrm{C}$; sin embargo, existen otros factores que influyen, tal como la temperatura del material granular.

En la presente investigación se considerarán los siguientes valores mínimos para la razón de expansión y la vida media:

- Razón de expansión: 10 veces

- Vida media: 8 segundos

\subsubsection{Indicadores de desempeño:}

Uno de los factores de desempeño de la capa estabilizada con asfalto espumado es la resistencia a la tracción indirecta. (ITS).

\subsubsection{Determinación de la resistencia a la tracción indirecta (ITS):}

El ensayo de resistencia a la tracción indirecta (ITS) se realiza sobre briquetas de mezclas con asfalto espumado compactadas.

${ }^{28}$ Wirtgen GmbH, (2004), Manual de reciclado en frío, Windhagen, Alemania. 
Antes de realizar dicho ensayo, las briquetas se deben de elaborar, extraer y curar, y su procedimiento se explica a continuación:

Se elaboran seis briquetas y se compactan con el equipo WLV 1. Después de la elaboración y compactación de las briquetas, se debe considerar que algunos materiales carecen de cohesión, por lo que es necesario dejarlas en el molde durante 24 horas para que desarrollen la resistencia antes de la extracción. Se desmoldan sobre una bandeja plana y se curan en un horno con circulación de aire forzado a $40{ }^{\circ} \mathrm{C}$ durante 72 horas.

Pasadas las 72 horas, las briquetas se retiran del horno y se dejan a temperatura ambiente para luego medir la altura de cada una en cuatro puntos uniformemente espaciados, con la finalidad de calcular una altura promedio en metros (L). De la misma manera, se mide su diámetro en metros (D).

Se realizan los ensayos de gravedad específica (masa seca, masa saturada y masa sumergida), con la finalidad de hallar el volumen y la densidad de las briquetas.

Luego de obtener las densidades de las seis briquetas, tres pasan al ensayo de tracción indirecta y las otras tres se colocan en Baño María a $25{ }^{\circ} \mathrm{C}$ durante 24 horas, para luego ser ensayadas.

Finalmente se realiza el ensayo de tracción indirecta y su procedimiento se explica a continuación:

Las briquetas se colocan en el dispositivo de carga y posición de la muestra debe ser tal, que las bandas de apoyo estén paralelas y centradas sobre el plano vertical diametral. Se coloca entonces la placa de transferencia sobre la banda superior y se acomoda el conjunto de manera que quede centrado bajo el pistón de carga de la máquina de compresión.

Se aplica carga a la briqueta sin impactos a una velocidad de avance de $50.8 \mathrm{~mm} /$ minuto hasta alcanzar la máxima carga, registrando esta última $(\mathrm{P})$ con precisión de $0.1 \mathrm{kN}$.

La resistencia a la tracción indirecta de cada briqueta se calcula con la siguiente expresión, debiendo redondearse el resultado al entero de kilo pascal más cercano:

$$
I T S=\frac{2 P}{\pi \cdot L \cdot D}
$$


Siendo:

- $\quad$ ITS = resistencia a la tracción indirecta $(\mathrm{kPa})$

- $\mathrm{P}=$ máxima carga aplicada $(\mathrm{kN})$

- $\quad \mathrm{L}=$ altura de la briqueta $(\mathrm{m})$

- $\quad \mathrm{D}=$ diámetro de la briqueta $(\mathrm{m})$

\subsubsection{Diseño de la capa estabilizada con asfalto espumado:}

Para el diseño de mezcla utilizaremos la guía de diseño AAHSTO 93, para la cual ingresaremos con un coeficiente de aporte estructural teniendo en cuenta los factores que influyen en el asfalto espumado, mencionados en este capítulo, que afectan a la efectividad de la espuma y la efectividad de la espuma mezclado con los áridos.

Estos se factores se evaluarán teniendo en cuenta las características del proyecto para poder encontrar en laboratorio los contenidos óptimos de mezcla que cumplan los requerimientos de número estructural del proyecto.

Dichos coeficientes estructurales se hallarán a través del ábaco de Wirtgen, colocando como datos los resultados de los ensayos de tracción indirecta (ITS), tanto en estado seco como húmedo.

Cabe resaltar también que los coeficientes de aporte estructural de la sub-base granular se hallarán a través del ábaco ubicado en la Guía de diseño de pavimento AASHTO 93 y se mantendrán constantes para cada uno de los diseños. 


\section{CAPÍTULO 4: DESCRIPCIÓN DEL PROYECTO}

\subsection{Antecedentes:}

El Consorcio Conservador Vial Santa Rosa para la ejecución del Proyecto "Servicio de Gestión, Mejoramiento y Conservación Vial por Niveles de Servicio del Corredor Vial: Dv. Humajalso - Desaguadero y Tacna - Tarata - Capazo - Mazocruz" está enmarcado dentro de los departamentos de Tacna, Puno y Moquegua, comprendiendo las provincias de Tacna, Tarata, El Collao, Chucuito Candarave y Mariscal Nieto.

La envergadura de las obras proyectadas durante un período de 5 años pretende mejorar la transitabilidad y seguridad en el corredor de $400 \mathrm{~km}$, el cual reposa sobre un relieve cuya elevación varía entre $4900 \mathrm{msnm}$ y $5000 \mathrm{msnm}$, con temperaturas extremas (bajo cero) y compleja diversidad geológica y geotécnica.

\subsection{Ubicación:}

El corredor se desarrolla entre los departamentos de Moquegua, Tacna y Puno. El corredor se divide en dos ejes, el primer eje inicia en el Dv. Humajalso hasta el distrito de Desaguadero en Puno que forma parte de la ruta Binacional, localizado en las provincias de Mariscal Nieto, Candarave, El Collao y Chucuito, pasando por los departamentos de Moquegua, Tacna y Puno; y el segundo eje inicia en la ciudad de Tacna hasta la intersección con el primer eje en Mazocruz, pasando por las localidades de Tacna, Tarata y El Collao, en los departamentos de Tacna y Puno.

El corredor divide en 2 ejes y se ha subdividido en 8 tramos según el tipo de intervención.

Para fines de la investigación, se evaluará el Tramo VIII que se encuentran en el eje número dos, correspondiente a Capazo - Mazocruz respectivamente. En la Fig. 4.1 se muestra la ubicación de los dos ejes del proyecto. 

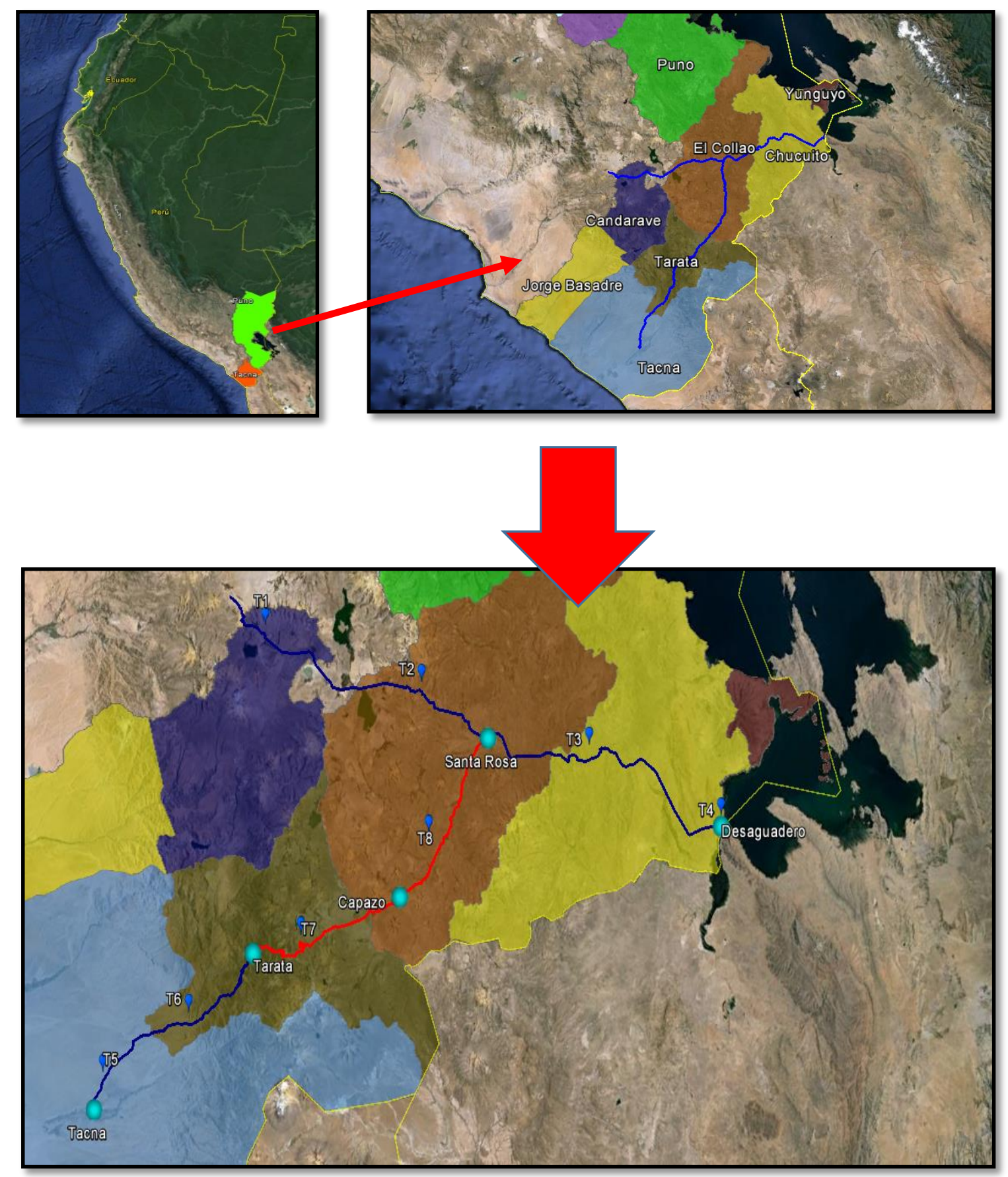

Fig. 4.1: Localización del proyecto

Fuente: Consorcio Conservación Vial Santa Rosa 


\subsection{Tramo VIII: Capazo-Mazocruz:}

Inicia en la población de Capazo, abarca desde los 4450 m.s.n.m. a los 4000 m.s.n.m, el recorrido del tramo se realiza por una zona en su mayoría plana, inundable, con presencia de bofedales; en la que se encuentran con cierta regularidad badenes en concreto que permiten el paso de un sin número de quebradas, al igual que se pueden evidenciar puentes de mediana longitud.

El tramo, en general, carece de una estructura de pavimento definitiva; en su mayoría presenta una capa granular como superficie de rodadura; tiene una sección transversal con ancho promedio de 5m; evidencia deficiencias tales como drenaje inadecuado en el borde de plataforma, corrugaciones, hundimientos, encalaminado, baches, surcos, material granular suelto y abundancia de finos. A continuación, se muestra la localización del tramo VIII en la Fig. 4.2.

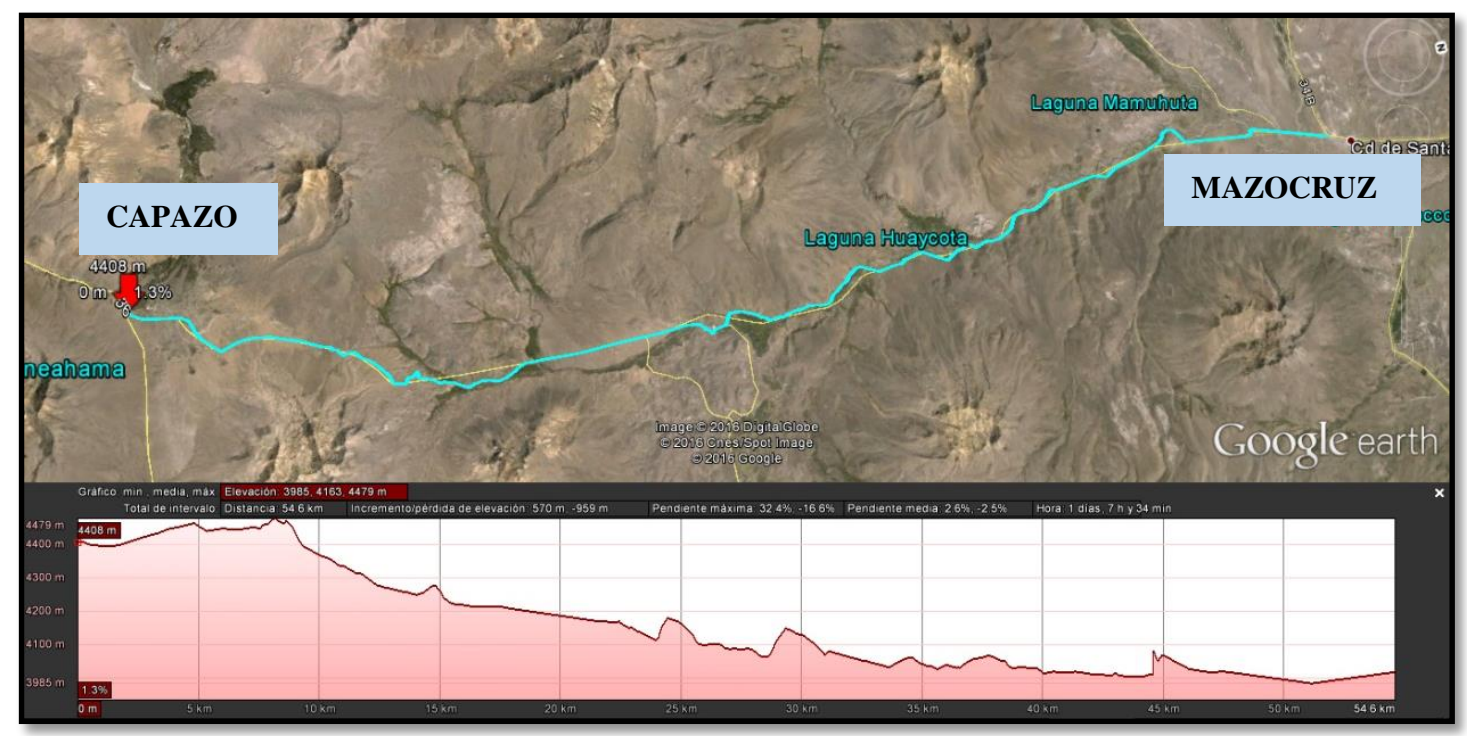

Fig. 4.2: Localización del tramo VIII

Fuente: Google Earth

\subsubsection{Situación previa a los mejoramientos:}

El tramo en general se encuentra sin pavimentar, en su mayoría presenta una capa granular como rasante. Tiene una mejor sección transversal que el tramo VII. Se presentan daños como drenaje inadecuado en el borde de carretera, corrugaciones, hundimientos, encalaminado, 
polvo, baches, surcos y agregado suelto. Los valores de PCI obtenidos se encuentran en un nivel muy bueno.

En la Fig. 4.3 se aprecia la situación actual en que se encuentra el tramo VIII desde el inicio (lado derecho) hasta el final (lado izquierdo).
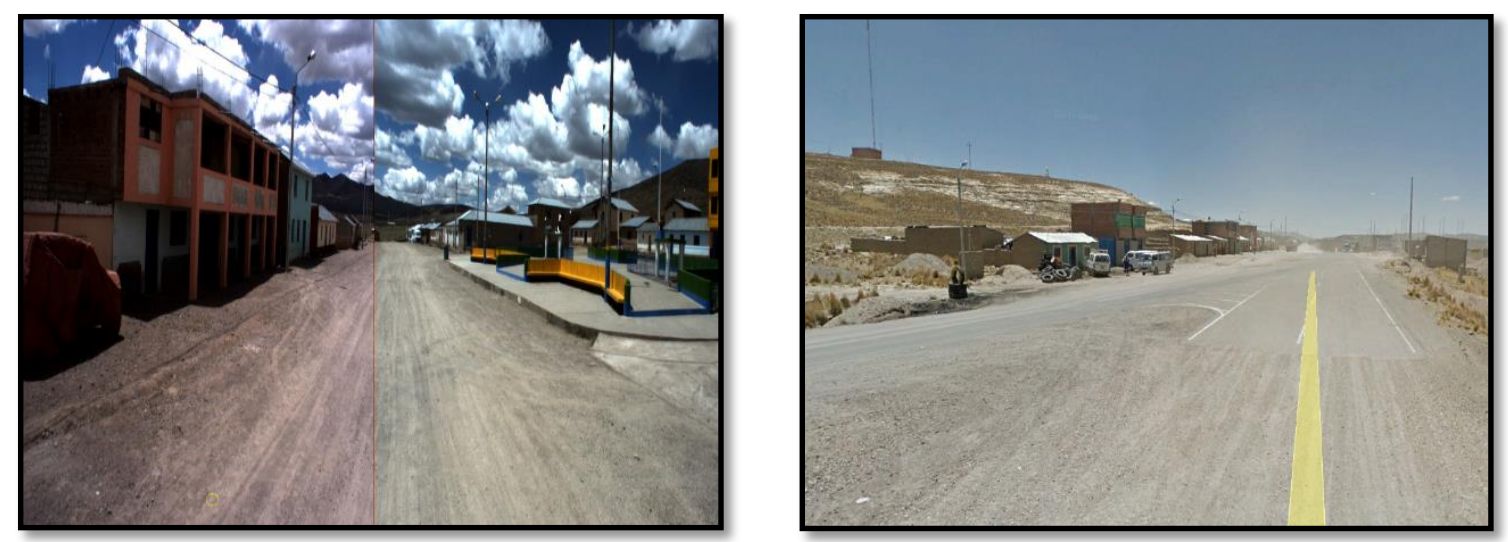

Fig. 4.3: Inicio y fin del tramo VIII

Fuente: Consorcio Conservación Vial Santa Rosa

\subsubsection{Estudio de suelos y canteras:}

\subsubsection{Exploración geotécnica de la subrasante y capas granulares de pavimento:}

De acuerdo con las necesidades propias del proyecto en ejecución, se ha llevado a cabo una campaña de prospección de suelos que incluyó la ejecución de 107 pozos, para todos estos, su ubicación y cantidad están en concordancia con los términos de referencia, que establecen 2 calicatas por kilómetro en sectores de mejoramiento. Se requiere una exploración adicional cuando entre progresivas se identifican estratos de características diferentes. La profundidad considerada de las calicatas aludidas fue de $1,5 \mathrm{~m}$.

A continuación, se listan de acuerdo con la normativa vigente los ensayos estándar efectuados:

- Análisis Granulométricos por tamizado ASTM D 422, MTC E 107 - 2000

- Clasificaciones SUCS

- Clasificaciones AASHTO

- Límites de Atterberg, (Límite Líquido y Límite Plástico) (ASTM D 4318, MTC E 110, $111-2000)$ 
- Humedad Natural (ASTM D 2216, MTC E 108 - 2000)

- Proctor Modificado (ASTM C 1557-C, MTC E 115 - 2000)

- California Bearing Ratio (CBR) (ASTM D 1883, MTC E 132 - 2000)

Las excavaciones se realizaron mecánicamente con retroexcavadora, de manera adyacente al borde del pavimento, siempre buscando la mayor representatividad de cada una de las capas, y el menor impacto a la operación normal de las vías. Campaña siempre acompañada de personal calificado encargado de la extracción de las muestras y del mapeo estratigráfico.

\subsubsection{Descripción de las canteras:}

Dentro del área del proyecto se disponen de canteras de cauce de rio y depósitos coluviales. Bajo estas consideraciones en la primera identificación y evaluación preliminar de reconocimiento se identificaron 9 canteras de origen fluvial y 34 canteras de cerro. En la primera entrega preliminar se presentó dentro de los planes de conservación y mejoramiento los planos de canteras con la delimitada del área estimada de explotación, ubicando los vértices y calicatas efectuadas con sus respectivas coordenadas UTM de esta primera identificación de canteras.

Luego, se ejecutaron los ensayos de las muestras obtenidas de esta primera identificación; una vez obtenido los resultados de las mismas, y tomando los criterios de elección de las canteras, que posteriormente se presentaran; finalmente se obtuvo como conclusión 4 canteras para el tramo 8.

Se tomaron los siguientes principales criterios para la elección de una cantera:

- Calidad

- Potencia y Rendimiento

- Accesibilidad y estado de las vías de acceso

- Situación legal

A continuación, se presentan las canteras definidas para el tramo VIII en la Tabla 4.1: 
Tabla 4.1: Canteras identificadas para el tramo VIII

Fuente: Consorcio Conservación Vial Santa Rosa

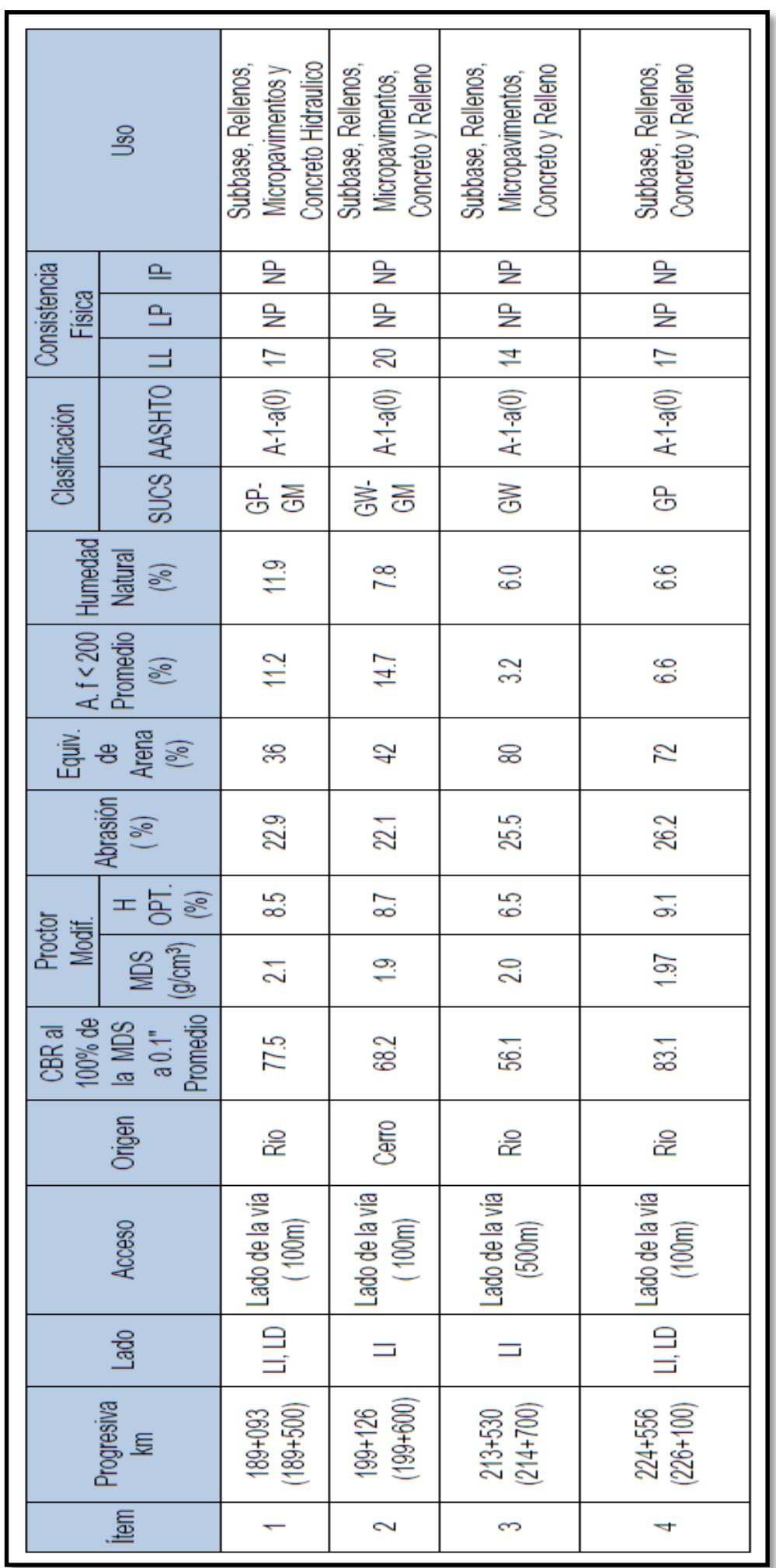




\section{CAPÍTULO 5: DISEÑO DE MEZCLA DE ASFALTO ESPUMADO}

El presente capítulo tiene la finalidad de alcanzar la dosificación de los componentes que se usarán en la preparación de la base estabilizada con asfalto espumado para el tramo VIII del proyecto "Servicio de Gestión, Mejoramiento y Conservación Vial por Niveles de Servicio del Corredor Vial: Dv. Humajalso - Desaguadero y Tacna - Tarata - Capazo - Mazocruz". Es necesario tener en cuenta tres componentes importantes en este capítulo, los cuales son:

- Caracterización de los materiales

- Calidad de la espumación

- Mezcla Asfáltica

\subsection{Caracterización de los materiales:}

Los principales materiales que forman parte de la mezcla son los agregados geotécnicos, el ligante y el filler activo (cemento).

\subsubsection{Caracterización de los agregados geotécnicos:}

La caracterización de los agregados es un parámetro importante para el diseño de mezcla de asfalto espumado, por tal motivo que se realizarán los ensayos necesarios para obtener una buena mezcla.

Los ensayos por realizar se muestran a continuación:

- Análisis granulométrico de suelos por tamizado: Norma MTC E107

- Límites de consistencia de suelos (Malla N 40): Norma MTC E110 y MTC E111

- Peso específico y absorción de los agregados gruesos: Norma MTC E206

- Compactación de suelos en laboratorio (proctor modificado): Norma MTC E115 
Para cubrir las condiciones del proyecto, se ensayarán los agregados de las canteras seleccionadas.

Cabe resaltar que los ensayos mostrados a continuación, fueron llevados a cabo en los laboratorios del lugar del proyecto.

\subsubsection{Análisis granulométrico de suelos por tamizado:}

Se realizaron los ensayos granulométricos de la Cantera Mazocruz km. 225+650 y los resultados obtenidos indicaron que el contenido de finos (material pasante de la malla $\mathrm{N}^{\circ} 200$ ) era menor al 5\% (Ver Anexo 1.9).

Por tal motivo, se recurrió a utilizar agregados finos de la Cantera km. 217+000 y realizar una mezcla en una proporción de $85 \%$ y $15 \%$ (grueso y fino respectivamente), con la finalidad de obtener una curva granulométrica que se encuentre dentro de los husos establecidos.

Luego de realizar la mezcla entre las dos canteras mencionadas, con sus respectivos porcentajes, se procede a tamizar el material con la finalidad de hallar el porcentaje mínimo de material pasante de la malla $\mathrm{N}^{\circ} 200$ y así corroborar que la mezcla de los materiales granulares y finos se realizó correctamente. En la Fig. 5.1 se muestra el proceso de tamizado. 


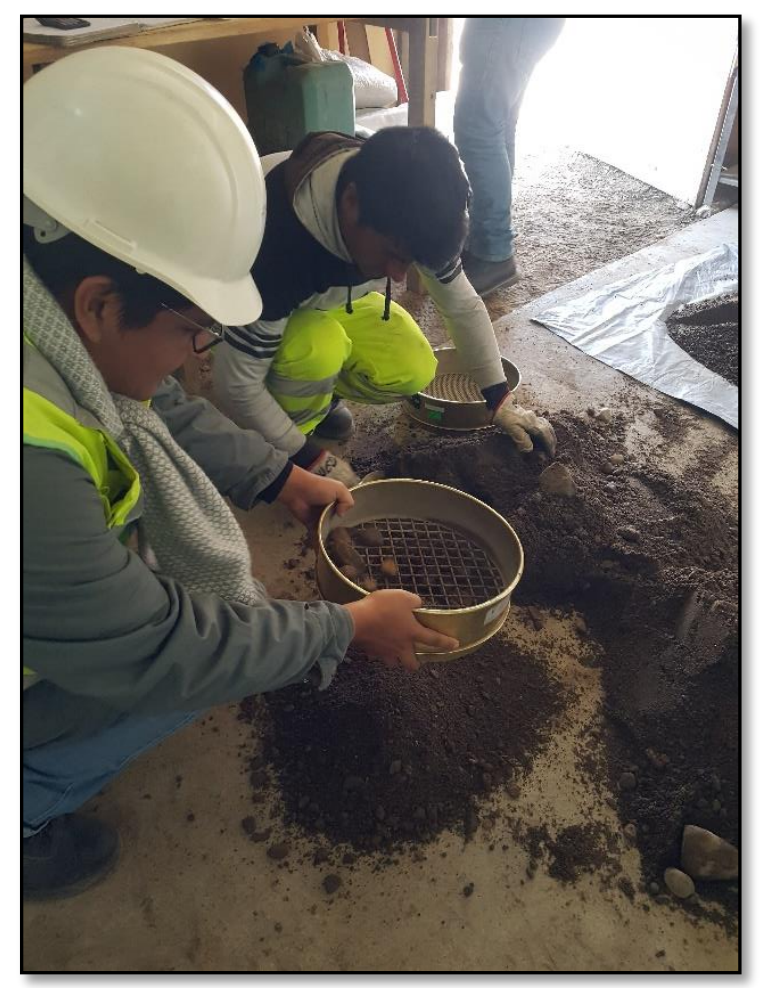

Fig. 5.1: Tamizado de la mezcla de canteras Fuente: Propia

A continuación, se muestra la curva granulométrica de la mezcla entre el agregado grueso de la Cantera Mazocruz km. 225+650 (85\%) y el agregado fino de la Cantera km. 217 (15\%) en la Fig. 5.2: 


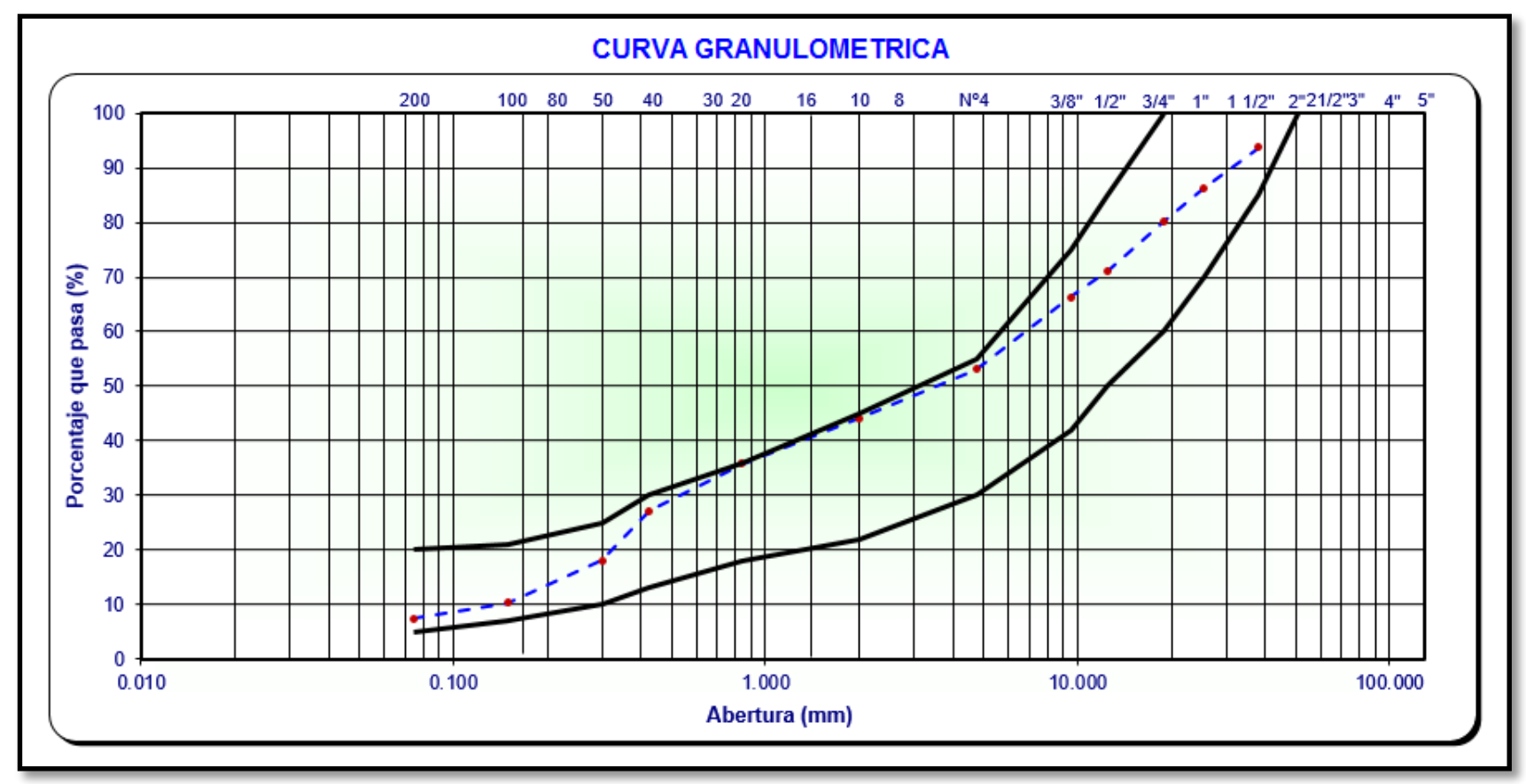

Fig. 5.2: Curva Granulométrica

Fuente: Propia

Como se puede apreciar en la Fig. 5.2, la curva granulométrica de la mezcla mencionada cumple con los husos establecidos que se encuentran graficados de color negro. Además, cumple también con el porcentaje mínimo de material fino pasante de la malla N²00 (5\%). 


\subsubsection{Límites de Consistencia de Suelos:}

Se realizaron los ensayos de límites de consistencia según el ASTM D4318-10 y se encontró que la muestra presenta límite líquido, pero no límite plástico (NP). En la Tabla 5.1 se muestran los resultados:

Tabla 5.1: Límites de Consistencia

Fuente: Propia

\begin{tabular}{|c|c|c|c|c|}
\hline \multicolumn{5}{|c|}{ LímITE LÍQUIDO (MTC E 110, AASHTO T 89) } \\
\hline$N^{\circ}$ DE TARA & & $\mathrm{T}-03$ & $\mathrm{~T}-04$ & $\mathrm{~T}-05$ \\
\hline PESO TARA + SUELO HÚMEDO & $(g r)$ & 35.24 & 35.54 & 35.45 \\
\hline PESO TARA + SUELO SECO & $(g r)$ & 32.12 & 32.22 & 31.98 \\
\hline PESO DEL AGUA & $(g r)$ & 3.12 & 3.32 & 3.47 \\
\hline PESO DE LA TARA & $(g r)$ & 13.97 & 14.00 & 13.90 \\
\hline PESO DE L SUELO SECO & $(g r)$ & 18.15 & 18.22 & 18.08 \\
\hline CONTENIDO DE HUMEDAD & $(\%)$ & 17.19 & 18.22 & 19.19 \\
\hline NÚMERO DE GOLPES & & 29 & 29 & 15 \\
\hline \multicolumn{5}{|c|}{ LímITE PLÁSTICO (MTC E 111, AASHTO T 90) } \\
\hline \multicolumn{5}{|l|}{$N^{\circ}$ DE TARA } \\
\hline PESO TARA + SUELO HÚMEDO & $(g r)$ & & & \\
\hline PESO TARA + SUELO SECO & $(g r)$ & & & \\
\hline PESO DE LA TARA & $(g r)$ & & & \\
\hline PESO DEL AGUA & $(g r)$ & & & \\
\hline PESO DE L SUELO SECO & $(g r)$ & & & \\
\hline CONTENIDO DE HUMEDAD & $(\%)$ & & & \\
\hline
\end{tabular}

En la Tabla 5.2 se muestran los valores finales del ensayo de límites de consistencia, en donde finalmente obtenemos un Índice de Plasticidad (IP) NP.

Tabla 5.2: Resumen de ensayo de límites de consistencia Fuente: Propia

\begin{tabular}{|lc|c|}
\hline \multicolumn{3}{|c|}{ CONSTANTES FISICAS DE LA MUESTRA } \\
\hline LIMITE LÍQUIDO & $(\%)$ & 18 \\
\hline LíMITE PLÁSTICO & $(\%)$ & NP \\
\hline INDICE DE PLASTICIDAD & $(\%)$ & NP \\
\hline
\end{tabular}




\subsubsection{Peso específico y absorción de los agregados gruesos:}

A continuación, se muestran los resultados de la gravedad específica y de la absorción de los agregados gruesos en la Tabla 5.3:

Tabla 5.3: Peso específico y absorción de los agregados

Fuente: Propia

\begin{tabular}{|c|c|c|c|c|}
\hline \multicolumn{4}{|c|}{ DATOS DE LA MUESTRA } & \\
\hline \multicolumn{4}{|c|}{ AGREGADO GRUESO } & \\
\hline & & $N^{\circ} 1$ & $\mathrm{~N}^{\circ} 2$ & \\
\hline A & Peso material saturado superficialmente seco (en aire ) (gr) & 2853.0 & 2907.8 & \\
\hline $\mathrm{B}$ & Peso material saturado superficialmente seco (en agua ) (gr) & 1704.4 & 1737.6 & \\
\hline $\mathrm{C}$ & Volumen de masa + volumen de vacíos $=A-B\left(\mathrm{~cm}^{3}\right)$ & 1148.6 & 1170.2 & \\
\hline $\mathrm{D}$ & Peso material seco en estufa $\left(105^{\circ} \mathrm{C}\right)(\mathrm{gr})$ & 2812.9 & 2862.4 & \\
\hline \multirow[t]{5}{*}{$\mathrm{E}$} & Volumen de masa $=C-(A-D)\left(\mathrm{cm}^{3}\right)$ & 1108.5 & 1124.8 & PROMEDIO \\
\hline & Pe bulk $($ Base seca $)=\mathrm{D} / \mathrm{C}$ & 2.449 & 2.446 & 2.448 \\
\hline & Pe bulk (Base saturada) $=\mathrm{AVC}$ & 2.484 & 2.485 & 2.484 \\
\hline & Pe Aparente $($ Base Seca $)=D / E$ & 2.538 & 2.545 & 2.541 \\
\hline & $\%$ de absorción $=((A-D) / D * 100)$ & 1.426 & 1.586 & 1.506 \\
\hline
\end{tabular}

Como se aprecia en la Tabla 5.3, las muestras $\mathrm{N}^{\circ} 1$ y N $\mathrm{N}^{\circ} 2$ nos dan resultados de porcentaje de absorción de $1.426 \%$ y $1.586 \%$ respectivamente, con un promedio de $1.506 \%$. 


\subsubsection{Compactación de suelos en laboratorio (proctor modificado):}

En la Fig. 5.3 se muestra la curva que une los puntos que relacionan densidad seca con contenido de humedad:

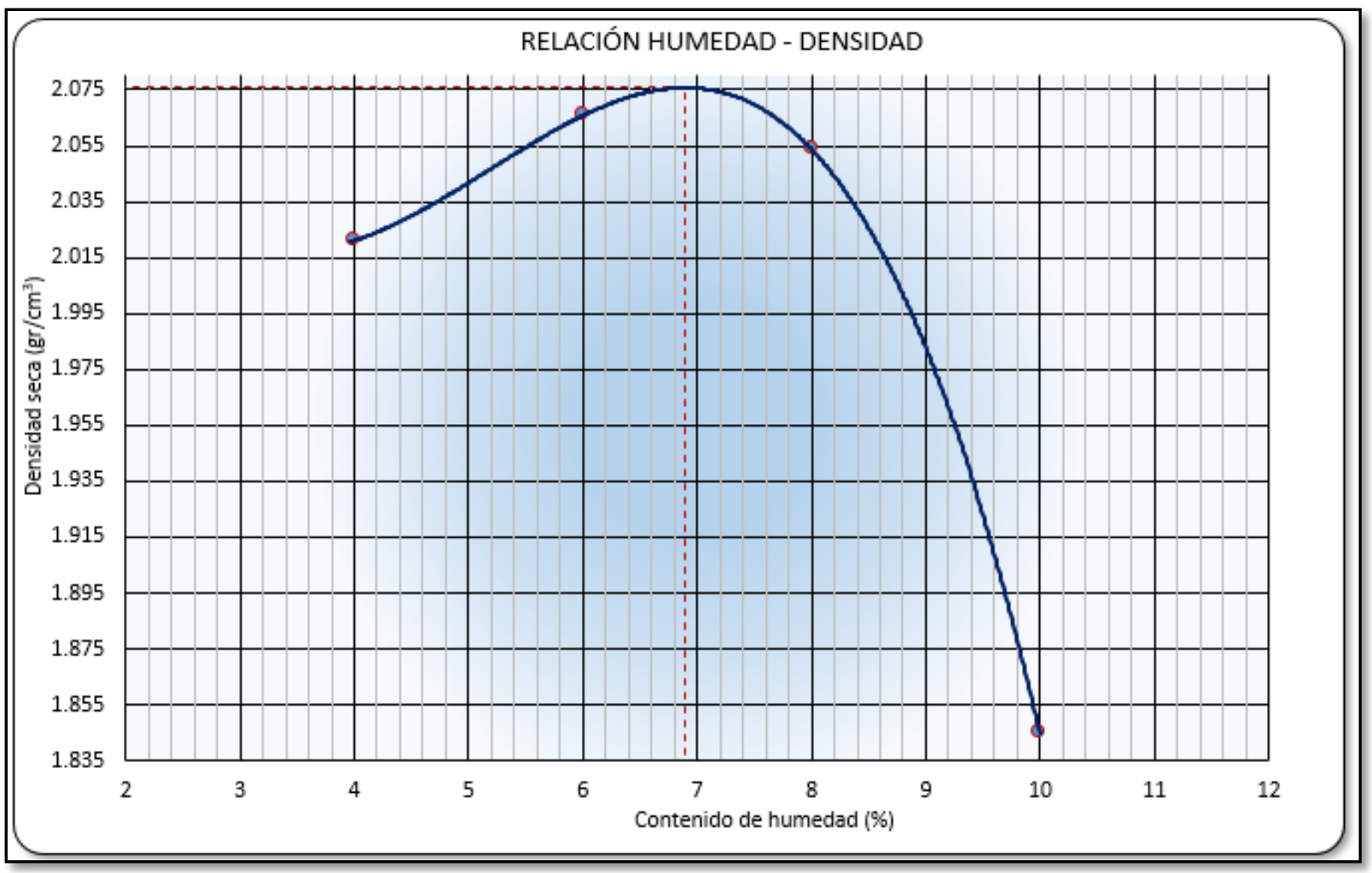

Fig. 5.3: Proctor modificado

Fuente: Propia

Como podemos apreciar en la Fig. 5.3, los puntos para poder realizar la curva que nos permite hallar la máxima densidad seca, corresponden a contenidos de humedad de 4\%, 6\%, $8 \%$ y $10 \%$, obteniendo una máxima densidad seca de $2.076 \mathrm{gr} / \mathrm{cm}^{3}$ con una humedad óptima de $6.9 \%$. 


\subsubsection{Caracterización de los ligantes:}

En el presente proyecto de investigación, se han utilizado cementos asfálticos con distintos grados de penetración:

\subsubsection{Cemento Asfáltico PEN 85/100:}

A continuación, se presentan las principales características del asfalto sólido PEN 85/100 de Petroperú (Ver Anexo 3.1):

- Volatilidad:

- Punto de inflamación Cleveland: $232{ }^{\circ} \mathrm{C}(\mathrm{ASTM}-\mathrm{D}$ 92)

- Ductilidad: $100 \mathrm{~cm}$ (ASTM D 113-99)

- Solubilidad en tricloroetileno: 99\% (ASTM D 2042)

\subsubsection{Cemento Asfáltico PEN 120/150:}

A continuación, se presentan las principales características del asfalto sólido PEN 120/150 de Petroperú (Ver Anexo 3.2):

- Volatilidad:

- Punto de inflamación Cleveland: $218{ }^{\circ} \mathrm{C}$ (ASTM-D 92)

- Ductilidad: 100 cm (ASTM D 113-99)

- Solubilidad en tricloroetileno: 99\% (ASTM D 2042) 


\subsection{Calidad de la Espumación:}

En el proceso de espumación intervienen el asfalto y el agua a altas temperaturas y a altas presiones respectivamente. La calidad de la espuma generada dependerá de las propiedades físicas de estos dos agentes, como son la temperatura y la presión. Para los ensayos realizados, se consideran constantes la presión del agua y la temperatura de agua $\left(25^{\circ} \mathrm{C}\right)$, por recomendación del Manual de Reciclado en frío de Wirtgen.

Con la finalidad de medir la calidad del espumado, se considerarán los valores mínimos aceptables de tiempo de vida media (8 segundos) y de razón de expansión (10 veces).

Por otra parte, es necesario tener en cuenta que todos los ensayos expuestos en este apartado se realizaron en el equipo de laboratorio WLB 10S para asfalto espumado que se muestra en la Fig. 5.4. Este equipo se encuentra en el lugar del proyecto, en el laboratorio habilitado por el Consorcio Vial Santa Rosa.

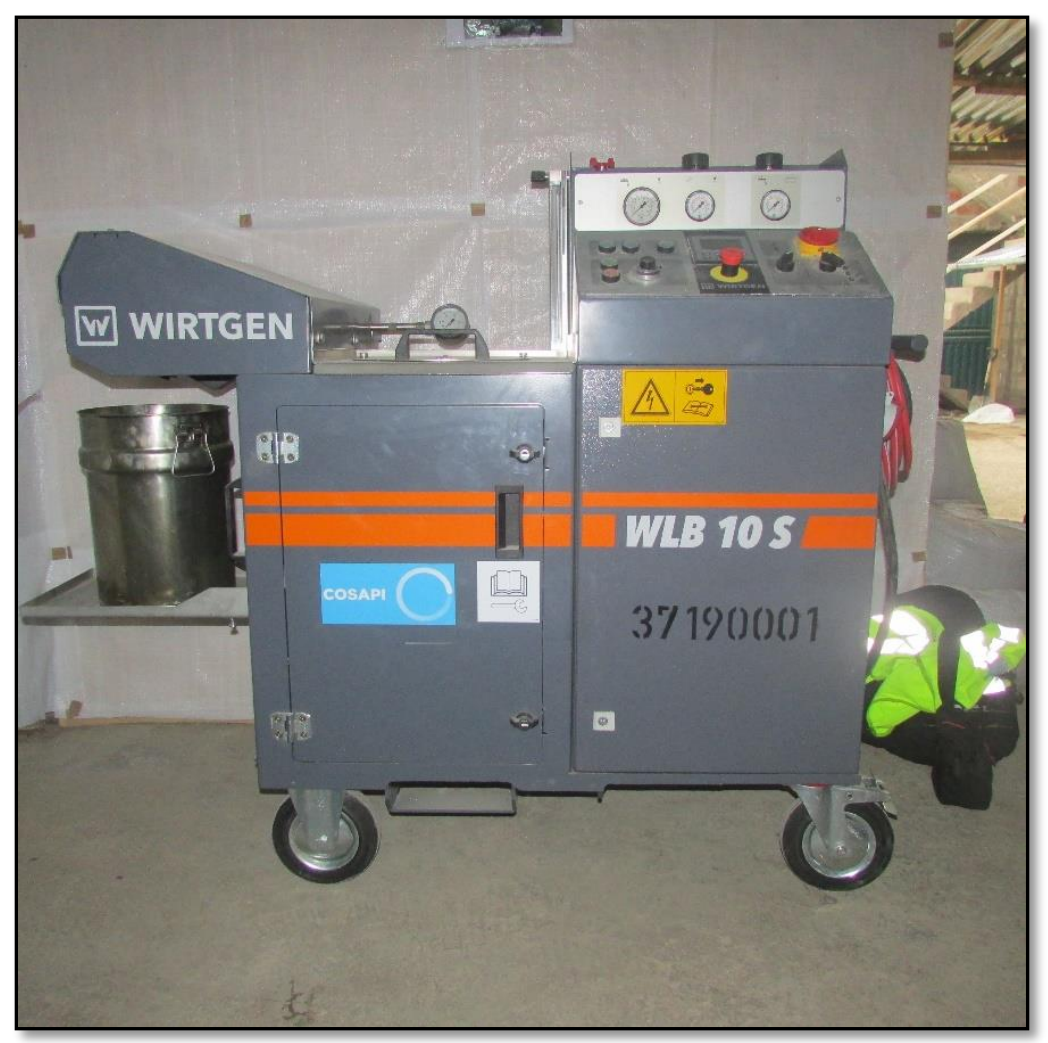

Fig. 5.4: Equipo de espumación WLB $10 \mathrm{~S}$

Fuente: Propia 
Con el fin de comparar la calidad de espumación, realizaremos ensayos con cemento asfáltico de distintos grados de penetración para observar cómo varían las propiedades de espumación.

\subsubsection{Cemento asfáltico PEN 85/100:}

Con el cemento asfáltico mencionado, se realizaron ensayos para determinar la calidad de espumación con las siguientes variables que se controlarán, las cuales son:

1. Temperatura (entre $160^{\circ} \mathrm{C}$. y $180^{\circ} \mathrm{C}$ )

2. Porcentaje de agua de espumación (entre $1 \%$ y $4 \%$ )

Cabe resaltar que estas variables son muy importantes en los ensayos mostrados, debido a que darán como resultado distintos tipos de valores para la Razón de Expansión y Vida Media, las propiedades más importantes de espumación desarrolladas en el Capítulo III.

En la Tabla 5.4 se muestra el resumen de resultados tomados de los 16 ensayos de espumación, que son producto de las combinaciones de las variables utilizadas entre temperatura y porcentaje de agua de espumación.

Tabla 5.4: Resumen de ensayos de espumación PEN 85/100

Fuente: Propia

\begin{tabular}{|c|c|c|c|c|c|c|}
\hline \multirow{2}{*}{$\begin{array}{c}\text { Contenido } \\
\text { de agua \% }\end{array}$} & \multicolumn{2}{|c|}{$\mathrm{T}=160^{\circ} \mathrm{C}$} & \multicolumn{2}{c|}{$\mathrm{T}=170^{\circ} \mathrm{C}$} & \multicolumn{2}{c|}{$\mathrm{T}=180^{\circ} \mathrm{C}$} \\
\cline { 2 - 7 } & Expansión & Vida Media & Expansión & Vida Media & Expansión & Vida Media \\
\hline 1.00 & 7.70 & 12.60 & 9.70 & 8.00 & 11.70 & 6.80 \\
\hline 2.00 & 11.70 & 9.40 & 13.30 & 7.00 & 14.70 & 6.30 \\
\hline 3.00 & 16.00 & 6.00 & 16.70 & 5.70 & 17.30 & 5.30 \\
\hline 4.00 & 19.70 & 4.50 & 21.00 & 4.00 & 23.30 & 4.00 \\
\hline
\end{tabular}

A partir de estos resultados se encontrará la temperatura óptima del asfalto y el porcentaje óptimo de agua de espumación, que serán los valores para los que la espuma de asfalto tendrá un mejor desempeño. 


\subsubsection{Temperatura del asfalto:}

A partir de la Tabla 5.4, se realiza la gráfica de las 3 temperaturas, considerando en el eje de las abscisas el tiempo de vida media y en el de las ordenadas la razón de expansión. A partir de este gráfico, se halla el índice de expansión, que es el área formada por la intersección de la curva con el eje de las ordenadas y la recta correspondiente a una razón de expansión igual a 4.0. En la Fig. 5.5 se muestra con detalle la composición del índice de expansión.

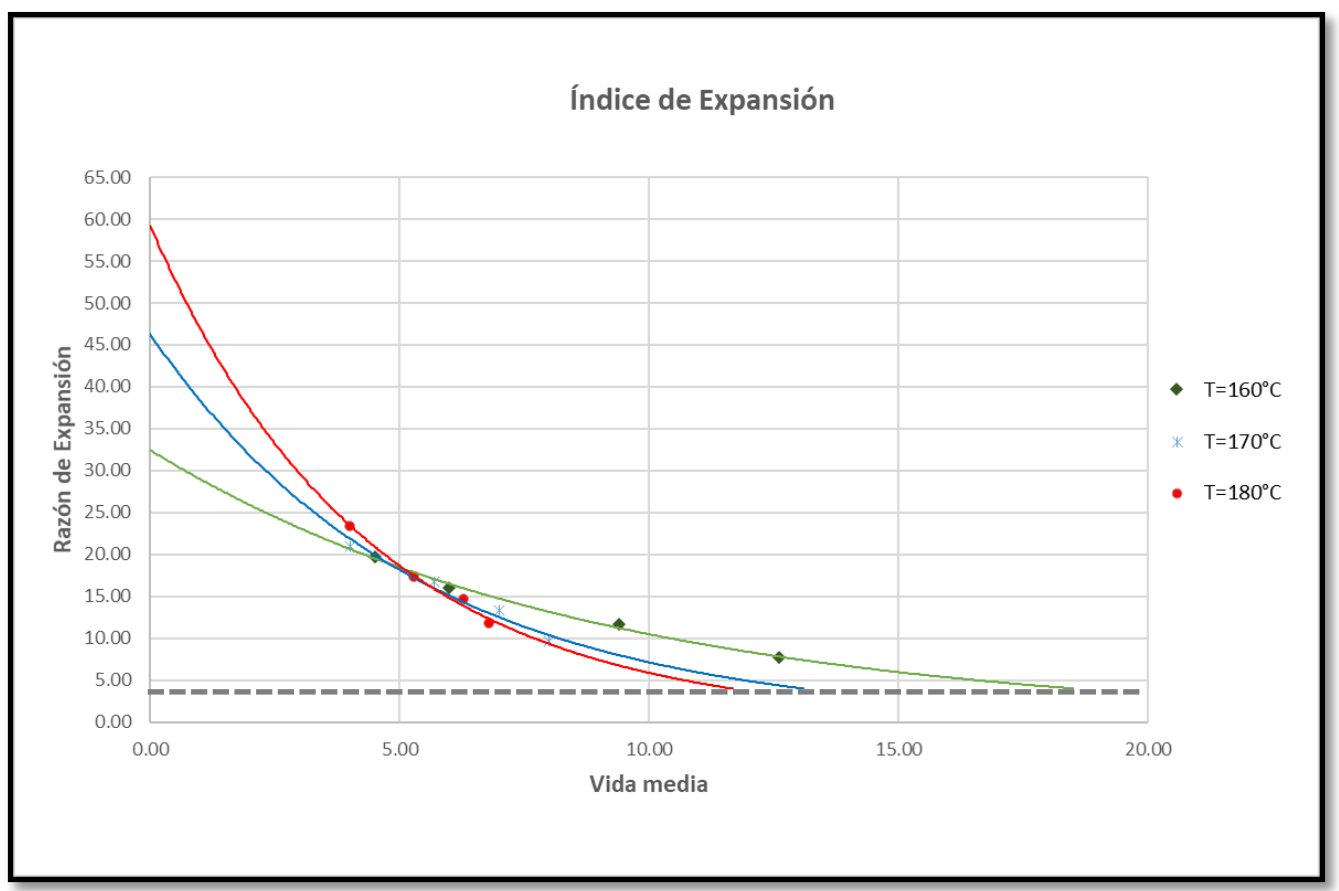

Fig. 5.5: Índice de espumación: Razón de expansión vs. Tiempo de vida media Fuente: Propia

Como se observa en la Fig. 5.5, la curva que representa a la temperatura $160^{\circ} \mathrm{C}$, es la que genera un mayor índice de espumación, por lo tanto, teniendo en cuenta todas las condiciones de estos ensayos, se considera como la temperatura óptima de espumación. 


\subsubsection{Contenido óptimo de agua de espumación:}

Una vez obtenida la temperatura del asfalto a utilizar en la espumación, tenemos que encontrar el contenido óptimo de agua de espumación. Para esto, se realizará un gráfico combinado los valores obtenidos para la temperatura $160^{\circ} \mathrm{C}$ de la vida media y la razón de expansión vs. el contenido óptimo de agua como se muestra en Fig. 5.6.

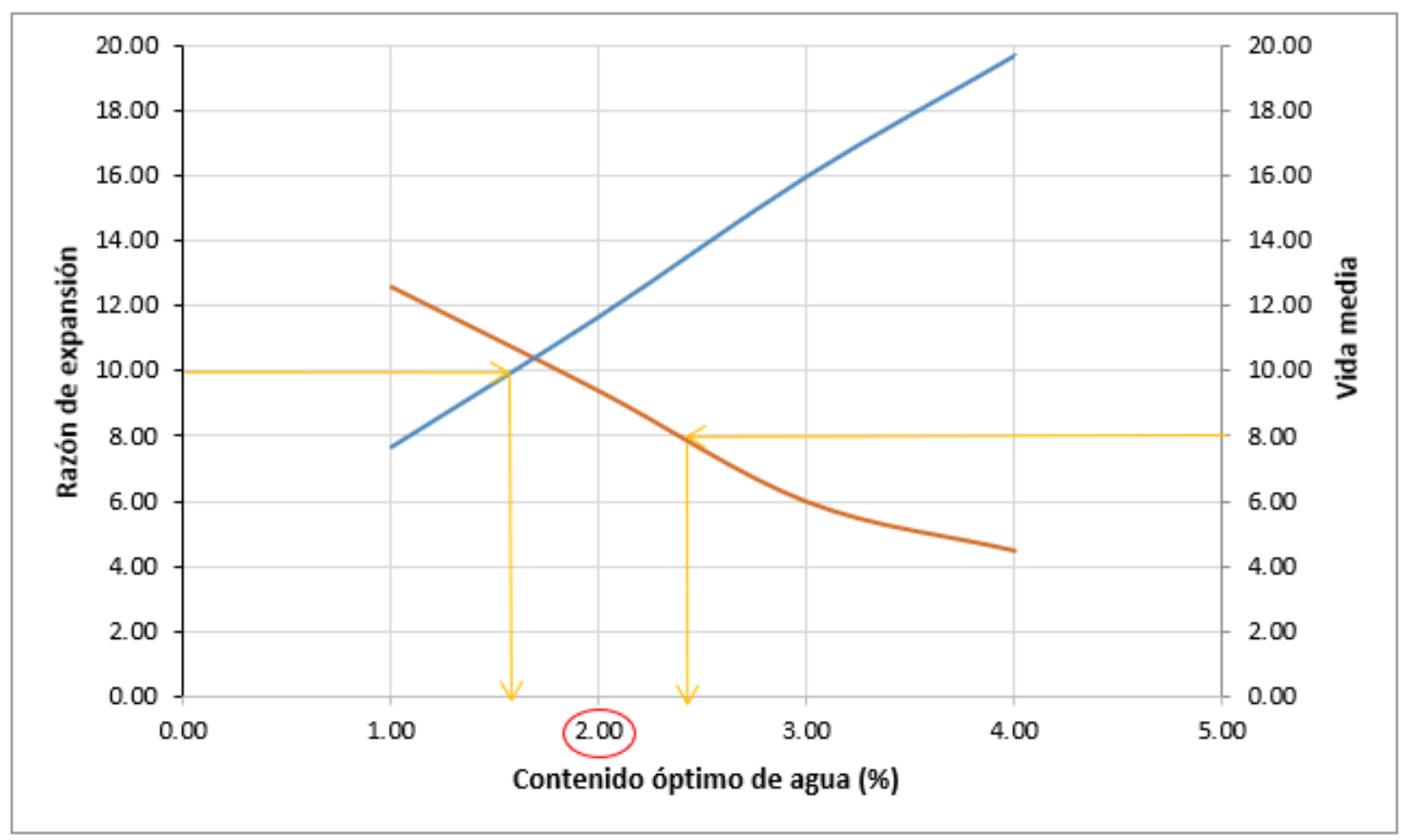

Fig. 5.6: Determinación del óptimo contenido de agua para espumación para $\mathrm{T}=160^{\circ} \mathrm{C}$. Fuente: Propia

A partir del gráfico encontramos que el contenido óptimo de agua de espumación para una temperatura de $160^{\circ} \mathrm{C}$ es de $2.0 \%$.

Finalmente, tenemos los resultados idóneos de espumación para el cemento asfáltico PEN $85 / 100$ que se muestran en la Tabla 5.5. 
Tabla 5.5: Resumen de condiciones óptimas de espumación

Fuente: Propia

\begin{tabular}{|c|c|}
\hline \multicolumn{2}{|c|}{ Condiciones óptimas de espumación } \\
\hline Asfalto & Petroperú PEN $85 / 100$ \\
\hline Temperatura & $160^{\circ} \mathrm{C}$ \\
\hline$\%$ Agua de espumación & $2.0 \%$ \\
\hline Razón de expansión promedio & $11.7>10$ veces \\
\hline Vida media promedio & $9.4>8$ segundos \\
\hline
\end{tabular}

\subsubsection{Cemento asfáltico PEN 120/150:}

Con este cemento asfáltico, se realizaron ensayos para determinar la calidad de la espumación con las siguientes variables que controlaremos, las cuáles son:

1. Temperatura (entre $160^{\circ} \mathrm{C} . \mathrm{y} 190^{\circ} \mathrm{C}$ )

2. Porcentaje de agua de espumación (entre 1\% y 4\%)

En la Tabla 5.6, se resumen los resultados tomados de los 16 ensayos de espumación, que son producto de las combinaciones de las variables utilizadas entre temperatura y porcentaje de agua de espumación.

A partir de estos resultados se encontrará la temperatura óptima del asfalto y el porcentaje óptimo de agua de espumación, que serán los valores para los que la espuma de asfalto tendrá un mejor desempeño.

Tabla 5.6: Resumen de ensayos de espumación PEN 120/150

Fuente: Propia

\begin{tabular}{|c|c|c|c|c|c|c|c|c|}
\hline \multirow{2}{*}{$\begin{array}{c}\text { Contenido } \\
\text { de agua \% }\end{array}$} & \multicolumn{2}{|c|}{$T=160^{\circ} \mathrm{C}$} & \multicolumn{2}{c|}{$\mathrm{T}$} & \multicolumn{2}{c|}{$\mathrm{T}=180{ }^{\circ} \mathrm{C}$} \\
\cline { 2 - 10 } & Expansión & Vida Media & Expansión & Vida Media & Expansión & Vida Media & Expansión & Vida Media \\
\hline 1.00 & 6.00 & 17.90 & 7.00 & 18.30 & 7.00 & 20.20 & 8.00 & 24.60 \\
\hline 2.00 & 12.00 & 14.20 & 14.00 & 16.20 & 14.00 & 18.50 & 15.00 & 19.60 \\
\hline 3.00 & 18.00 & 11.50 & 18.00 & 12.30 & 19.00 & 15.30 & 19.00 & 16.10 \\
\hline 4.00 & 20.00 & 10.10 & 22.00 & 11.20 & 23.00 & 12.30 & 25.00 & 12.90 \\
\hline
\end{tabular}




\subsubsection{Temperatura del asfalto:}

A partir de la Tabla 5.6, se realiza la gráfica de las 4 temperaturas, considerando en el eje de las abscisas la razón de expansión y en el de las ordenadas en tiempo de vida media. A partir de este gráfico, se haya el índice de expansión, que es el área formada por la intersección de la curva con el eje de las ordenadas y la recta correspondiente a una razón de expansión igual a 4.0. En la Fig. 5.7 se muestra con detalle la composición del índice de expansión.

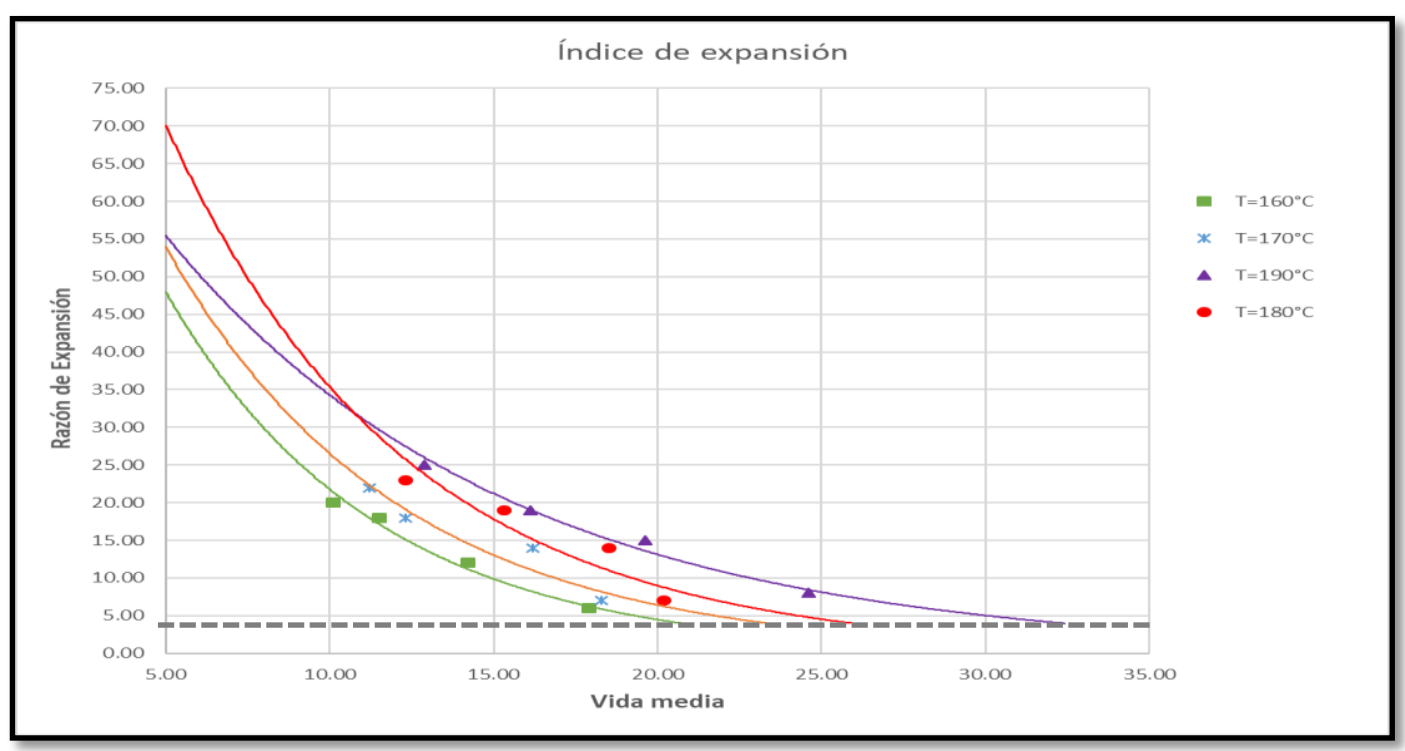

Fig. 5.7: Índice de espumación: Razón de expansión vs. Tiempo de vida media Fuente: Propia

Como se observa en la Fig. 5.7, la curva que representa a la temperatura $180^{\circ} \mathrm{C}$, es la que genera un mayor índice de espumación, por lo tanto, teniendo en cuenta todas las condiciones de estos ensayos, se considera como la temperatura óptima de espumación. 


\subsubsection{Contenido óptimo de agua de espumación:}

Una vez obtenida la temperatura del asfalto a utilizar en la espumación, tenemos que encontrar el contenido óptimo de agua de espumación. Para esto, se realizará un gráfico combinado los valores obtenidos para la temperatura $180^{\circ} \mathrm{C}$ de la vida media y la razón de expansión vs. el contenido óptimo de agua como se muestra en Fig. 5.8.

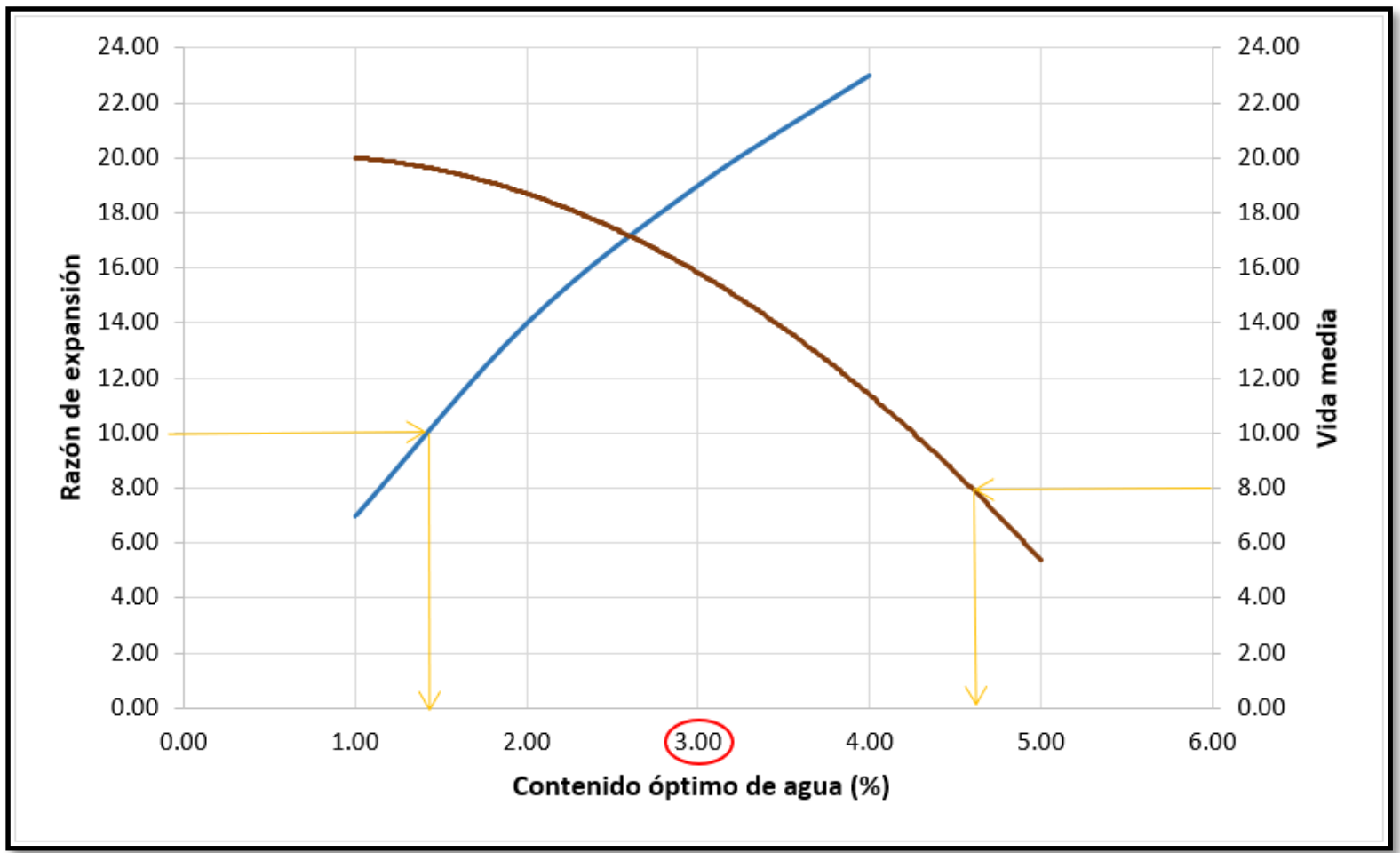

Fig. 5.8: Determinación del óptimo contenido de agua para espumación para $\mathrm{T}=180^{\circ} \mathrm{C}$. Fuente: Propia

A partir del gráfico encontramos que el contenido óptimo de agua de espumación para una temperatura de $180^{\circ} \mathrm{C}$ es de $3.0 \%$.

Finalmente, tenemos los resultados idóneos de espumación para el cemento asfáltico PEN 120/150 que se muestran en la Tabla 5.7. 
Tabla 5.7: Resumen de condiciones óptimas de espumación

Fuente: Propia

\begin{tabular}{|c|c|}
\hline \multicolumn{2}{|c|}{ Condiciones óptimas de espumación } \\
\hline Asfalto & Petroperú PEN $120 / 150$ \\
\hline Temperatura & $180^{\circ} \mathrm{C}$ \\
\hline$\%$ Agua de espumación & $3.0 \%$ \\
\hline Razón de expansión promedio & $19.0>10$ veces \\
\hline Vida media promedio & $15.3>8$ segundos \\
\hline
\end{tabular}

\subsection{Mezcla Asfáltica (Diseño de laboratorio):}

\subsubsection{Contenido de Filler Activo:}

Las estabilizaciones con asfalto espumado normalmente se realizan con una pequeña cantidad de filler activo (cemento Portland tipo IP). En la Tabla 5.8 se muestran las aplicaciones sugeridas para la incorporación del filler.

Tabla 5.8: Exigencias de Filler Activo sugerido

Fuente: Propia

\begin{tabular}{|c|c|c|}
\hline Indice de plasticidad $<10$ & Indice de plasticidad $10-16$ & Indice de plasticidad $>16$ \\
\hline $\begin{array}{c}\text { Agregar } 1.0 \% \text { de Cemento } \\
\text { Portland }\end{array}$ & $\begin{array}{c}\text { Agregar } 1.0 \% \text { de Cal } \\
\text { Hidratada }\end{array}$ & $\begin{array}{c}\text { Agregar } 2.0 \% \text { de Cal } \\
\text { Hidratada }\end{array}$ \\
\hline
\end{tabular}

De acuerdo con los resultados obtenidos en los ensayos de límites consistencia, indican que no presenta Índice Plasticidad (NP), por lo que se requiere incorporar $1.0 \%$ de cemento Portland tipo IP. El cemento y el agregado serán mezclados con la dosis de agua establecida, previo a la adición del asfalto espumado. 


\subsubsection{Tipos de Compactación:}

\subsubsection{Compactador Vibratorio WLV1:}

El WLV 1 es el nuevo equipo de compactación de la empresa Wirtgen que sirve especialmente para la producción de briquetas con material estabilizado con asfalto espumado. Dicho equipo posee un elemento central, el cual es el martillo vibrador que se desplaza de forma vertical fijado a una columna que sirve de guía vertical. Mediante su pata apisonadora robusta, el martillo vibrador transfiere una alta energía de impacto y simula una compactación real como es la que se realiza en el frente de trabajo. Además, la calibración de este equipo, que consiste en encontrar el tiempo de compactación óptimo, se realiza utilizando como input la máxima densidad seca obtenida del ensayo de proctor modificado. Se realizan varias pruebas con la finalidad de encontrar el tiempo requerido, llegando al valor de la máxima densidad seca. En la Fig. 5.9 se puede apreciar todas las partes completas de la máquina de compactación WLV 1.

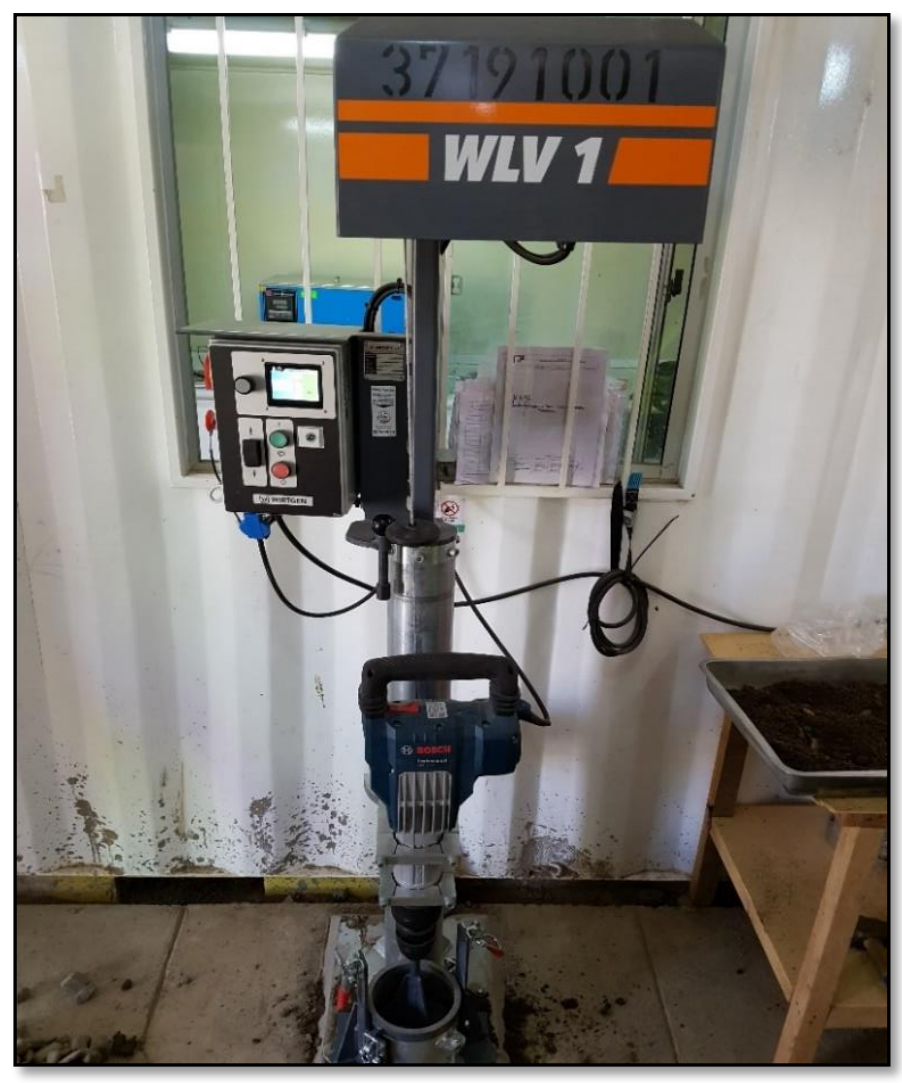

Fig. 5.9: Equipo de compactación WLV 1

Fuente: Propia 


\subsubsection{Compactación por el método Marshall:}

El método Marshall tiene como finalidad determinar el contenido óptimo de asfalto para una combinación de agregados. Se puede utilizar tanto para realizar el diseño en laboratorio como para hacer el respectivo control de calidad durante la pavimentación. Los aspectos principales que se realizan en muestras asfálticas compactadas son:

- Análisis densidad-vacíos

- Ensayo de estabilidad y flujo

Se fabrican briquetas normalizadas con una altura de $63.5 \mathrm{~mm}$. y un diámetro de $101.6 \mathrm{~mm}$. Dichas briquetas son preparadas siguiendo procedimientos especificados los cuales son: gradación, calentamiento, mezclado y compactación de la mezcla. Hondando en el procedimiento de compactación para la elaboración de briquetas, el número de golpes en cada cara está ligado al tipo de tránsito:

- Tránsito ligero: 35 golpes por cara

- Tránsito mediano: 50 golpes por cara

- Tránsito pesado: 75 golpes por cara

Una vez terminado el proceso para la elaboración de briquetas, estas son sacadas del molde para ser ensayadas en el Aparato Marshall y medir sus resistencias.

A partir de estas definiciones, ambos métodos de compactación tienen procedimientos distintos, por lo que cada uno tendrá sus ventajas y desventajas.

\section{Ventajas:}

La compactación con la máquina WLV 1 simula una compactación real, tal y como se realiza en el frente de trabajo con el rodillo vibratorio.

Una vez finalizado el proceso de compactación del WLV 1, el martillo vibrador se desplaza automáticamente a su posición inicial, lo que permite sacar la briqueta rápidamente abriendo el cierre, incrementando la productividad para la fabricación de varias briquetas. 
Se pueden producir especímenes de ensayo con diámetros de $152 \mathrm{~mm}$. y altura de $95 \mathrm{~mm}$. para ensayos de tracción indirecta (ITS) y diámetros de $152 \mathrm{~mm}$. y altura de $300 \mathrm{~mm}$. para ensayos triaxiales.

\section{Desventajas:}

La compactación por el método Marshall genera una gran cantidad de energía, lo que produce una fractura de los agregados pétreos. En esta investigación es importante evitar que se generen dichas fracturas, ya que se tendrían una incidencia alta en los resultados de los ensayos de tracción indirecta (ITS).

La compactación por el método de Marshall es limitada en la preparación de briquetas, ya que solo se producen briquetas de pequeñas dimensiones en comparación al método de compactación vibratoria con la WLV 1 que permite generar briquetas de mayores dimensiones.

\subsubsection{Ensayo de Tracción Indirecta (ITS):}

Una vez que el material se compactó en el equipo de compactación WLV 1, se desmoldan todas las muestras (briquetas) y se pesan con la finalidad de hallar su densidad.

Se realizaron 6 briquetas por cada porcentaje de asfalto inyectado, de las cuales 3 briquetas serán ensayadas para calcular su resistencia a la Tracción Indirecta en estado seco y 3 briquetas en estado saturado.

Los procedimientos para realizar el ensayo de tracción indirecta se detallaron en el apartado 3.2.6 del Capítulo III. 
En la Fig. 5.10 se puede apreciar el resultado final de las briquetas luego de terminado el ensayo de compactación vibratorio, para finalmente continuar con el ensayo de Tracción Indirecta (ITS).

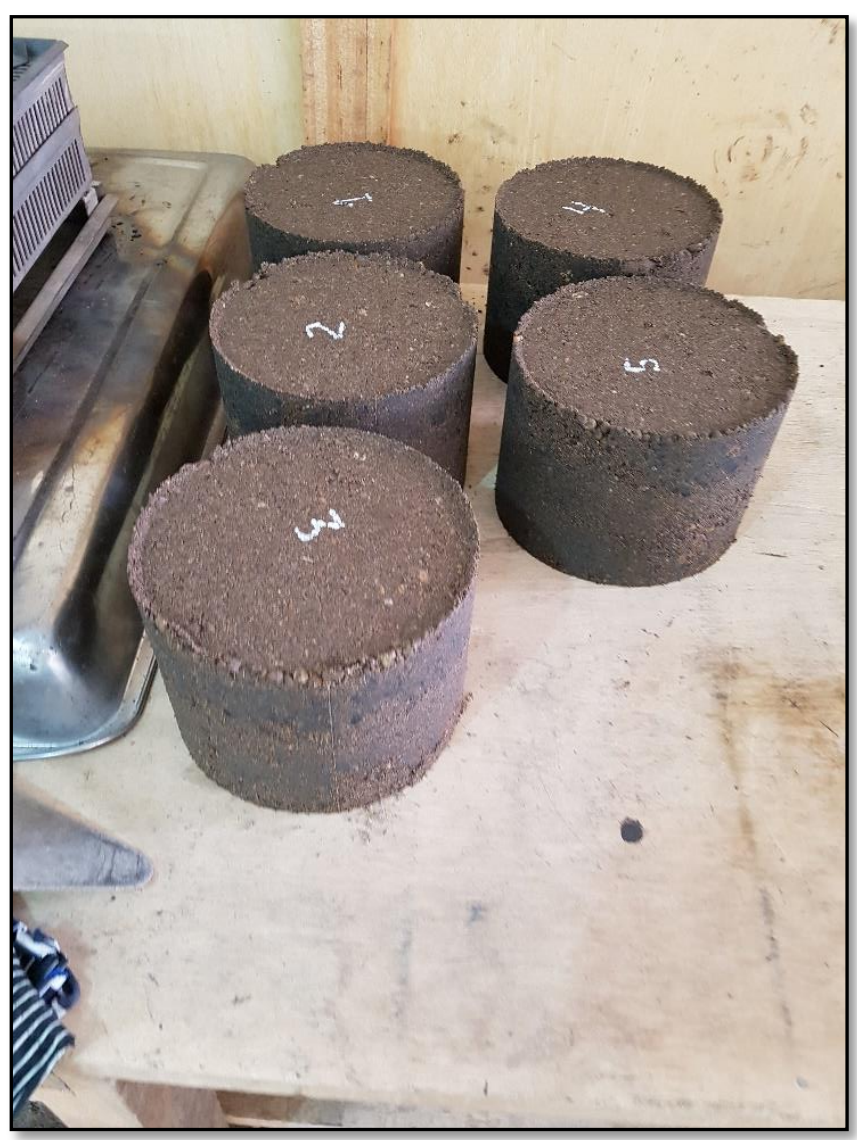

Fig. 5.10: Briquetas desmoldadas y dejadas en reposo Fuente: Propia 
En la Fig. 5.11 se muestra la máquina de compresión con el que se realiza el ensayo de Tracción Indirecta.

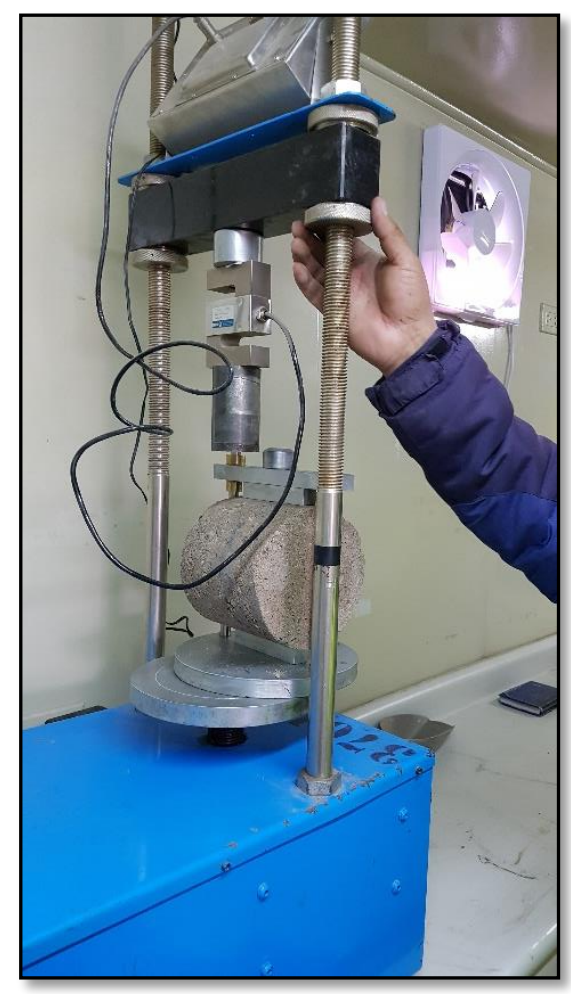

Fig. 5.11: Máquina de compresión para ensayo de Tracción Indirecta Fuente: Propia 


\subsubsection{Análisis de Resultados:}

Los resultados del ensayo de resistencia a la Tracción Indirecta para los 3 porcentajes de asfalto inyectado $(1.5 \%, 2.0 \%$ y $2.5 \%)$ y para el cemento asfáltico PEN 85/100, se muestran en resumen en la Tabla 5.9:

Tabla 5.9: Resultados del ensayo de ITS para cemento asfáltico PEN 85/100

Fuente: Propia

\begin{tabular}{|c|c|c|c|c|c|}
\hline \multicolumn{6}{|c|}{ RESUMEN TOTAL TRACCION INDIRECTA DE LA BASE ESPUMADA } \\
\hline MATERIAL & \multicolumn{5}{|c|}{ MEZCLA DE CANTERAS: MAZOCRUZ y KM 217+000 } \\
\hline TIPO DE ASFALTO & \multicolumn{3}{|c|}{ REPSOL - PEN 85/100 } & $\%$ RESISTENCIA CONSERVADA $>=$ & $50.00 \%$ \\
\hline TOASFALTO & \multicolumn{3}{|c|}{$160^{\circ} \mathrm{C}$} & $\%$ H2O DE ESPUMACION & $2.00 \%$ \\
\hline ITS SECO $>=$ & \multicolumn{3}{|c|}{$200 \mathrm{Koa}$} & \% ASFALTO ESPUMADO & $1.5 \%, 2.0 \%, 2.5 \%$ \\
\hline ITS HUMEDA $>=$ & \multicolumn{3}{|c|}{$100 \mathrm{Kpa}$} & \% CEMENTO PORTLAND TIPO IP & $1.00 \%$ \\
\hline \multirow{2}{*}{$\begin{array}{l}\text { \% ASFALTO } \\
\text { INYECTADO }\end{array}$} & \multicolumn{2}{|c|}{ RESISTENCIA T.I. (KPa) } & \multirow{2}{*}{$\begin{array}{c}\text { RESISTENCIA } \\
\text { CONSERVADA (\%) }\end{array}$} & & \\
\hline & SECA & HUMEDA & & & \\
\hline 1.5 & 198.251 & 118.945 & $60 \%$ & & \\
\hline 2.0 & 253.429 & 169.837 & $67 \%$ & & \\
\hline 2.5 & 160.880 & 101.042 & $63 \%$ & & \\
\hline
\end{tabular}


Así mismo, en la Tabla 5.10 se muestra el resumen de los resultados para los tres porcentajes de asfalto inyectado $(1.5 \%, 2.0 \%$ y $2.5 \%)$ y para el cemento asfáltico PEN 120/150.

Tabla 5.10: Resultados del ensayo de ITS para cemento asfáltico PEN 120/150

Fuente: Propia

\begin{tabular}{|c|c|c|c|c|c|}
\hline \multicolumn{6}{|c|}{ RESUMEN TOTAL TRACCION INDIRECTA DE LA BASE ESPUMADA } \\
\hline MATERIAL & \multicolumn{5}{|c|}{ MEZCLA DE CANTERAS: MAZOCRUZ y KM 217++000 } \\
\hline TIPO DE ASFALTO & \multicolumn{3}{|c|}{ REPSOL - PEN 120/150 } & $\%$ RESISTENCIA CONSERVADA $>=$ & $50.00 \%$ \\
\hline TOASFALTO & \multicolumn{3}{|c|}{$180^{\circ} \mathrm{C}$} & $\%$ H2O DE ESPUMACION & $3.00 \%$ \\
\hline ITS SECO $x=$ & \multicolumn{3}{|c|}{$200 \mathrm{Kpa}$} & \% ASFALTO ESPUMADO & $1.5 \%, 2.0 \%, 2.5 \%$ \\
\hline ITS HUMEDA $>=$ & \multicolumn{3}{|c|}{$100 \mathrm{Kpa}$} & \% CEMENTO PORTLAND TIPO IP & $1.00 \%$ \\
\hline \multirow{2}{*}{$\begin{array}{l}\% \text { ASFALTO } \\
\text { INYECTADO }\end{array}$} & \multicolumn{2}{|c|}{ RESISTENCIA T.I. (KPa) } & \multirow{2}{*}{$\begin{array}{l}\text { RESISTENCIA } \\
\text { CONSERVADA (\%) }\end{array}$} & & \\
\hline & SECA & HUMEDA & & & \\
\hline 1.5 & 202.049 & 106.890 & $53 \%$ & & \\
\hline 2.0 & 261.665 & 148.863 & $57 \%$ & & \\
\hline 2.5 & 191.203 & 101.520 & $53 \%$ & & \\
\hline
\end{tabular}

Los resultados de los ensayos de ITS, mostrados a continuación, satisfacen los valores mínimos requeridos que se muestran en la Tabla 5.11 y serán los porcentajes de asfalto inyectado que utilizaremos para posteriormente realizar los diseños de mezcla con cada uno de estos:

- PEN 120/150: porcentaje de asfalto inyectado de $1.5 \%$ y $2.0 \%$

- PEN 85/100: porcentaje de asfalto inyectado de $2.0 \%$

Tabla 5.11: Valores mínimos requeridos Fuente: Propia

\begin{tabular}{|c|c|}
\hline RESISTENCIA SECA : & $>200 \mathrm{Kpa}$ \\
\hline RESISTENCIA HUMEDA: & $>100 \mathrm{Kpa}$ \\
\hline ITR : & $>50.0 \%$ \\
\hline
\end{tabular}


Por otro lado, los resultados de los ensayos de ITS (en condición seca), mostrados a continuación, no llegan al valor mínimo indicado en la Tabla 5.11:

- PEN 120/150: porcentaje de asfalto inyectado de $2.5 \%$.

- PEN 85/100: porcentaje de asfalto inyectado de $1.5 \%$ y $2.5 \%$.

Una vez obtenidos los valores de dosificación de asfalto espumado que cumplen con los valores mínimos requeridos mostrados en la Tabla 5.11, debemos elegir cuál de estos resulta ser la más eficiente, en la que se optimice el asfalto para el Tramo VIII del proyecto "Servicio de Gestión, Mejoramiento y Conservación Vial por Niveles de Servicio del Corredor Vial: Dv. Humajalso - Desaguadero y Tacna - Tarata - Capazo - Mazocruz”.

\subsection{Comparación de diseños entre laboratorio y campo:}

Luego de obtener los resultados de los ensayos de Tracción Indirecta (ITS) y haber elegido los diseños de laboratorio que cumplieron con los valores mínimos requeridos, éstos se compararon con los ensayos de ITS de las briquetas elaboradas con el material disperso y recolectado en el frente de trabajo en campo como se aprecia en la Fig. 5.12.

Cabe resaltar que los resultados del ensayo de ITS mostrados a continuación representan al diseño realizado por la planta móvil KMA 220 para el cemento asfáltico PEN 120/150 con una dosificación de $2.0 \%$ de asfalto inyectado.
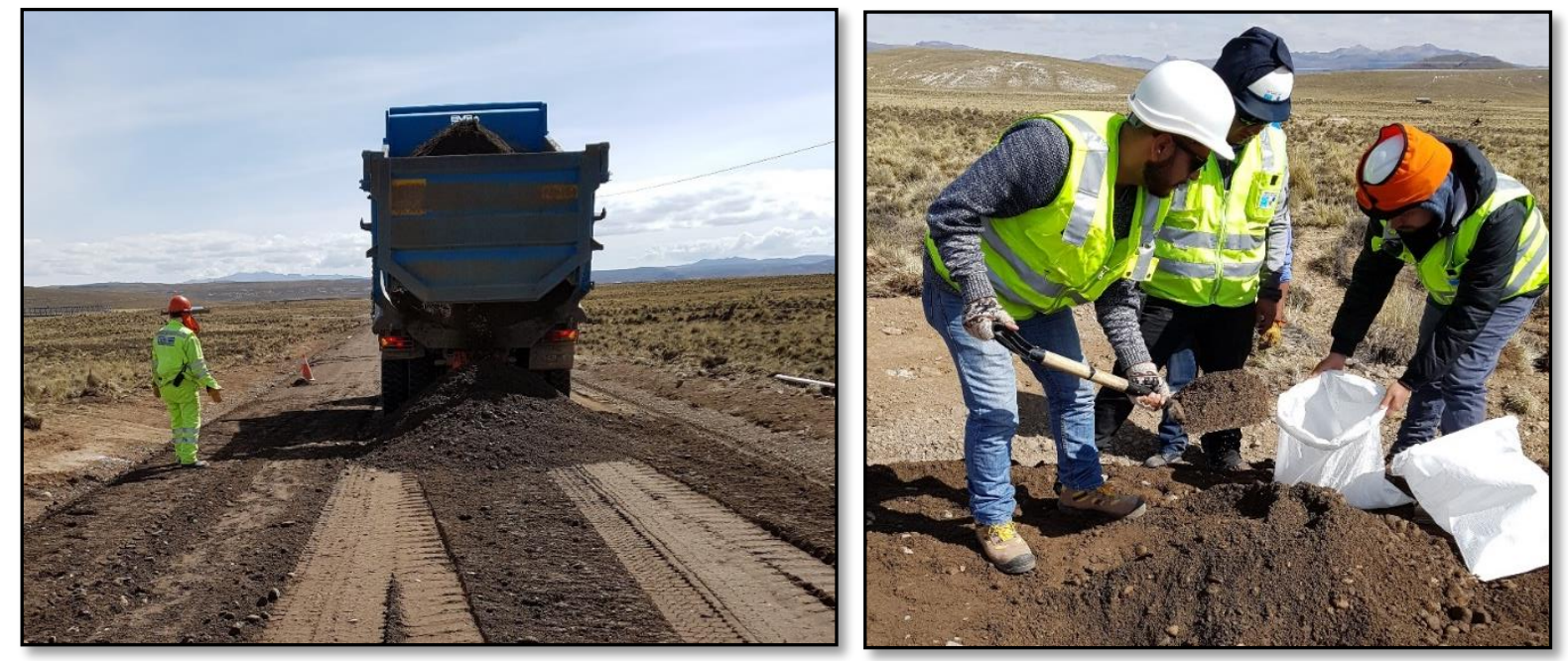

Fig. 5.12: Material disperso en campo y recolección para elaboración de briquetas Fuente: Propia 
Luego de la recolección de material para la elaboración de las briquetas, se repite el procedimiento de elaboración y ensayo de briquetas, detallado en la sección de ensayo de tracción indirecta (ITS) en laboratorio. A continuación, se muestran los resultados del ensayo de ITS en la Tabla 5.12:

Tabla 5.12: Resultados del ensayo de resistencia a la Tracción Indirecta (ITS) Fuente: Propia

\begin{tabular}{|c|c|c|c|c|c|c|c|}
\hline \multicolumn{8}{|c|}{ RESUMEN TOTAL TRACCION INDIRECTA DE LA BASE RECICLADA } \\
\hline MATERIAL & \multicolumn{7}{|c|}{ MEZCLA DE CANTERAS: MAZOCRUZ y km.: 217+000 } \\
\hline TIPO DE ASFALTO & \multicolumn{4}{|c|}{ REPSOL - PEN 120/150 } & \multicolumn{2}{|c|}{ \% RESISTENCIACONSERVADA > } & $50.00 \%$ \\
\hline T'ASFALTO & \multicolumn{4}{|c|}{$180^{\circ} \mathrm{C}$} & \multicolumn{2}{|c|}{$\%$ H2O DE ESPUMACION } & $3.00 \%$ \\
\hline$\%$ ITS SECO >= & \multicolumn{4}{|c|}{$200 \mathrm{Kpa}$} & \multicolumn{2}{|c|}{ \% ASFALTO ESPUMADO } & $2.00 \%$ \\
\hline$\%$ ITS HUMEDA $>=$ & \multicolumn{4}{|c|}{$100 \mathrm{Kpa}$} & \multicolumn{2}{|c|}{ \% CEMENTO PORT LAND TIPO IP } & $1.00 \%$ \\
\hline \multirow{2}{*}{$N^{\circ}$ DE PRODUCCION } & \multirow{2}{*}{$\begin{array}{l}\text { PROGRESIVA } \\
\text { INICIAL (Km.) }\end{array}$} & \multirow{2}{*}{$\begin{array}{l}\text { PROGRESINA } \\
\text { FINAL (Km.) }\end{array}$} & \multirow{2}{*}{$\begin{array}{l}\text { DENSIDAD } \\
\text { (Gr/cm3) }\end{array}$} & \multicolumn{2}{|c|}{ RESISTENCIA T.I. (KPa) } & \multirow{2}{*}{$\begin{array}{c}\text { RESISTENCIA } \\
\text { CONSERVADA (\%) }\end{array}$} & \\
\hline & & & & SECA & HUMEDA & & \\
\hline 1 & $226+860$ & $227+050$ & 2.016 & 254.8 & 142.3 & $55.8 \%$ & \\
\hline \multirow{2}{*}{2} & $226+360$ & $226+480$ & \multirow{2}{*}{2.024} & \multirow{2}{*}{233.2} & \multirow{2}{*}{141.1} & \multirow{2}{*}{$60.5 \%$} & \\
\hline & $226+660$ & $226+860$ & & & & & \\
\hline 3 & $225+695$ & $226+360$ & 2.017 & 258.546 & 142.9 & $55.3 \%$ & \\
\hline \multirow{2}{*}{4} & $223+243$ & $223+500$ & \multirow{2}{*}{2.022} & \multirow{2}{*}{263.2} & \multirow{2}{*}{143.8} & \multirow{2}{*}{$54.6 \%$} & \\
\hline & $225+580$ & $225+640$ & & & & & \\
\hline 5 & $223+520$ & $224+210$ & 2.066 & 232.8 & 145.7 & $62.6 \%$ & \\
\hline 6 & $224+210$ & $225+050$ & 2.066 & 231.8 & 139.7 & $60.3 \%$ & \\
\hline 7 & $225+050$ & $225+580$ & 2.041 & 223.0 & 143.6 & $64.4 \%$ & \\
\hline
\end{tabular}

Luego de obtener los resultados del ensayo de ITS con material recolectado en campo, se compararon con los resultados del ensayo de ITS de laboratorio para el cemento asfáltico PEN 120/150 con una dosificación de 2.0\% de asfalto inyectado como se indicó anteriormente (Diseño 3). En la Tabla 5.13 se muestra el resumen del ensayo de ITS de laboratorio: 
Tabla 5.13: Resultados del ensayo de ITS de la muestra realizada en laboratorio Fuente: Propia

\begin{tabular}{|c|c|c|c|}
\hline \multirow{2}{*}{$\begin{array}{c}\text { \% ASFALTO } \\
\text { INYECTADO }\end{array}$} & \multicolumn{2}{|c|}{ RESISTENCIA T.I. (KPa) } & RESISTENCIA \\
\cline { 2 - 3 } & SECA & HUMEDA & $\begin{array}{c}\text { CONSERVADA } \\
(\%)\end{array}$ \\
\hline 2.0 & 261.665 & 148.863 & $57 \%$ \\
\hline
\end{tabular}

Al comparar las Tablas 5.12 y 5.13, se puede ver que las resistencias en condición seca y húmeda de campo sobrepasan los valores mínimos requeridos de ITS (200 KPa para seca y $100 \mathrm{KPa}$ para húmeda) y la mayoría de ellas se encuentran cercanas a la resistencia encontrada en la muestra realizada en laboratorio.

Asimismo, de la Tabla 5.12, tenemos que el mínimo valor obtenido de ITS para condición seca y húmeda se obtuvo de la muestra $\mathrm{N}^{\circ}$ 6. El ITS obtenido para condición seca fue de 231.8 $\mathrm{KPa}$, que con respecto al ITS de la muestra desarrollada en laboratorio que fue de 261.665 $\mathrm{KPa}$ (tabla 5.13), representa el $88.5 \%$. Se tuvo una variación porcentual del $11.5 \%$ para la condición seca. El ITS obtenido para condición húmeda fue de $139.7 \mathrm{KPa}$, que con respecto al ITS de la muestra desarrollaada en laboratorio que fue de $148.863 \mathrm{KPa}$, representa el 93.8\%. Se tuvo una variación porcentual de $6.2 \%$ para la condición húmeda.

Lo que nos permite afirmar que los diseños realizados en la planta móvil KMA 220 tienen valores aceptables para continuar con los trabajos en campo. 


\section{CAPÍTULO 6: DISEÑO ESTRUCTURAL DEL PAVIMENTO}

\subsection{Método de Wirtgen para hallar el coeficiente de aporte estructural (a):}

En el Capítulo V, encontramos mediante el ensayo de Tracción Indirecta la resistencia seca, húmeda y conservada de los 6 diseños de mezcla propuestos. De estos diseños, se comprobó que tres cumplían con los valores mínimos requeridos sugeridos por el Manual de Wirtgen.

En la Tabla 6.1, se muestran los resultados obtenidos previamente y se resaltan cuáles son los diseños que satisfacen los requisitos mínimos de diseño.

Tabla 6.1. Tabla resumen de los resultados de ITS de los diseños de mezcla propuestos.

Fuente: Propia

\begin{tabular}{|c|c|c|c|c|c|c|}
\hline \multirow{3}{*}{$\begin{array}{l}\% \text { ASFALTO } \\
\text { INYECTADO }\end{array}$} & \multicolumn{3}{|c|}{ PEN 85/100 } & \multicolumn{3}{|c|}{ PEN 120/150 } \\
\hline & \multicolumn{2}{|c|}{ RESISTENCIA T.I. (KPa) } & \multirow{2}{*}{$\begin{array}{c}\text { RESISTENCIA } \\
\text { CONSERVADA } \\
(\%)\end{array}$} & \multicolumn{2}{|c|}{ RESISTENCIA T.I. (KPa) } & \multirow{2}{*}{$\begin{array}{c}\text { RESISTENCIA } \\
\text { CONSERVADA } \\
(\%)\end{array}$} \\
\hline & SECA & HUMEDA & & SECA & HUMEDA & \\
\hline 1.5 & 198.251 & 118.945 & $60 \%$ & 202.049 & 106.890 & $53 \%$ \\
\hline 2.0 & 253.429 & 169.837 & $67 \%$ & 261.665 & 148.863 & $57 \%$ \\
\hline 2.5 & 160.880 & 101.042 & $63 \%$ & 191.203 & 101.520 & $53 \%$ \\
\hline
\end{tabular}

Estos diseños se utilizarán como una capa del pavimento. El pavimento estará conformado por 2 capas con materiales granulares y con un micropavimento que fungirá como capa de rodadura. Sin embargo, para poder realizar el diseño del pavimento como estructura, es necesario saber cuánto aporta estructuralmente cada una de estas capas. Para ello, debemos encontrar el coeficiente de aporte estructural de cada una de estas.

En adelante y para fines de esta investigación se realizarán los cálculos para los 3 diseños que se muestran en la Tabla 6.1, como se detalla a continuación: 
- Diseño 1: 2.0\% de asfalto inyectado con grado de penetración 85/100.

- Diseño 2: 1.5\% de asfalto inyectado con grado de penetración 120/150.

- Diseño 3: 2.0\% de asfalto inyectado con grado de penetración 120/150.

En la Fig. 6.1 se muestra el ábaco de Wirtgen para encontrar este coeficiente a partir de los resultados de ITS. En este, entramos con los valores de ITS seca e ITS húmeda. Debemos de tener en cuenta que el coeficiente de aporte estructural (a) encontrado es por pulgada de capa.

A continuación, se realizará este procedimiento para los 3 diseños seleccionados.

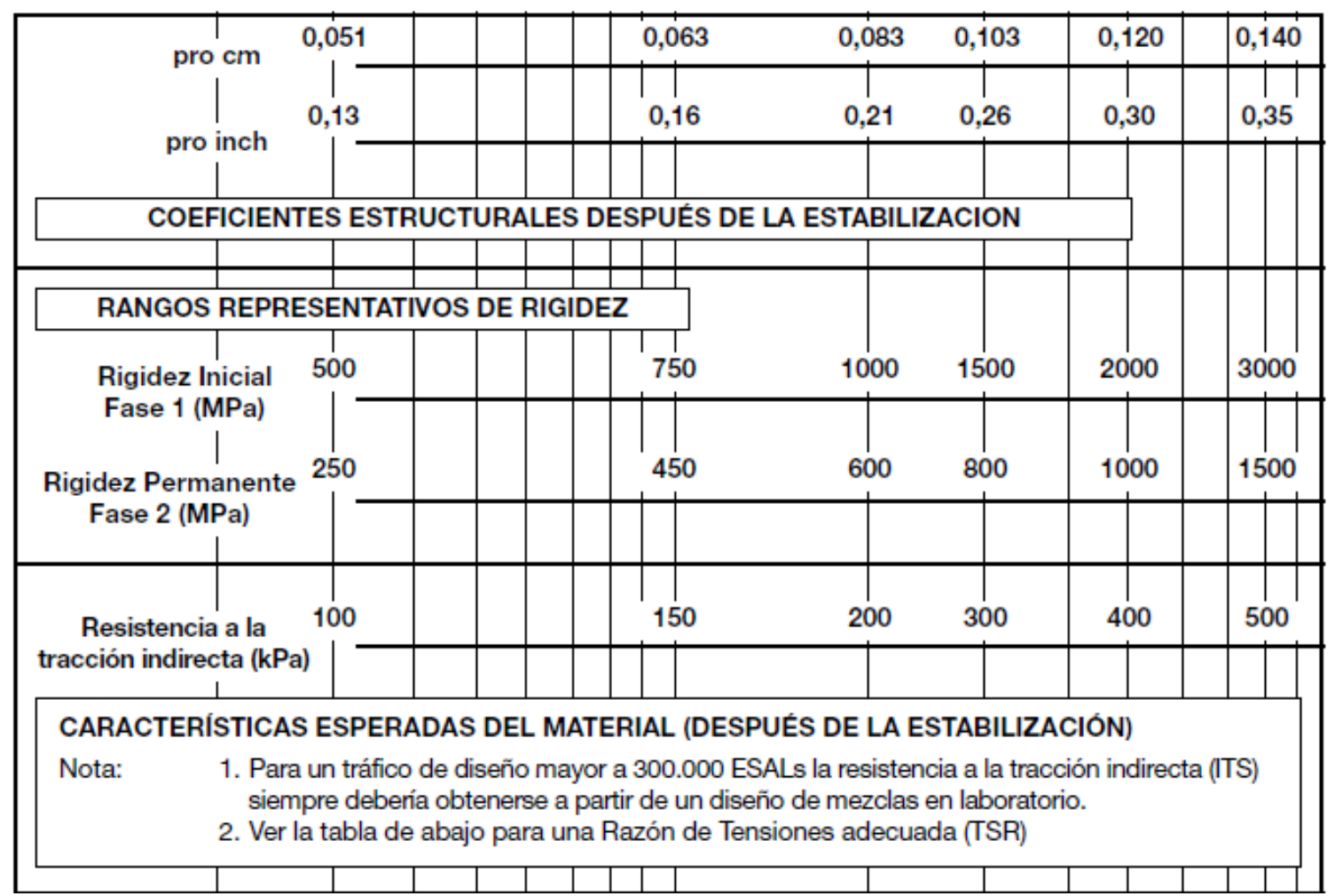

Fig. 6.1: Coeficiente de aporte estructural sugerido para capas estabilizadas con asfalto espumado

Fuente: Manual de Wirtgen 


\subsubsection{Coeficiente de aporte estructural para el Diseño $1(2.0 \%$ - PEN}

\section{5/100):}

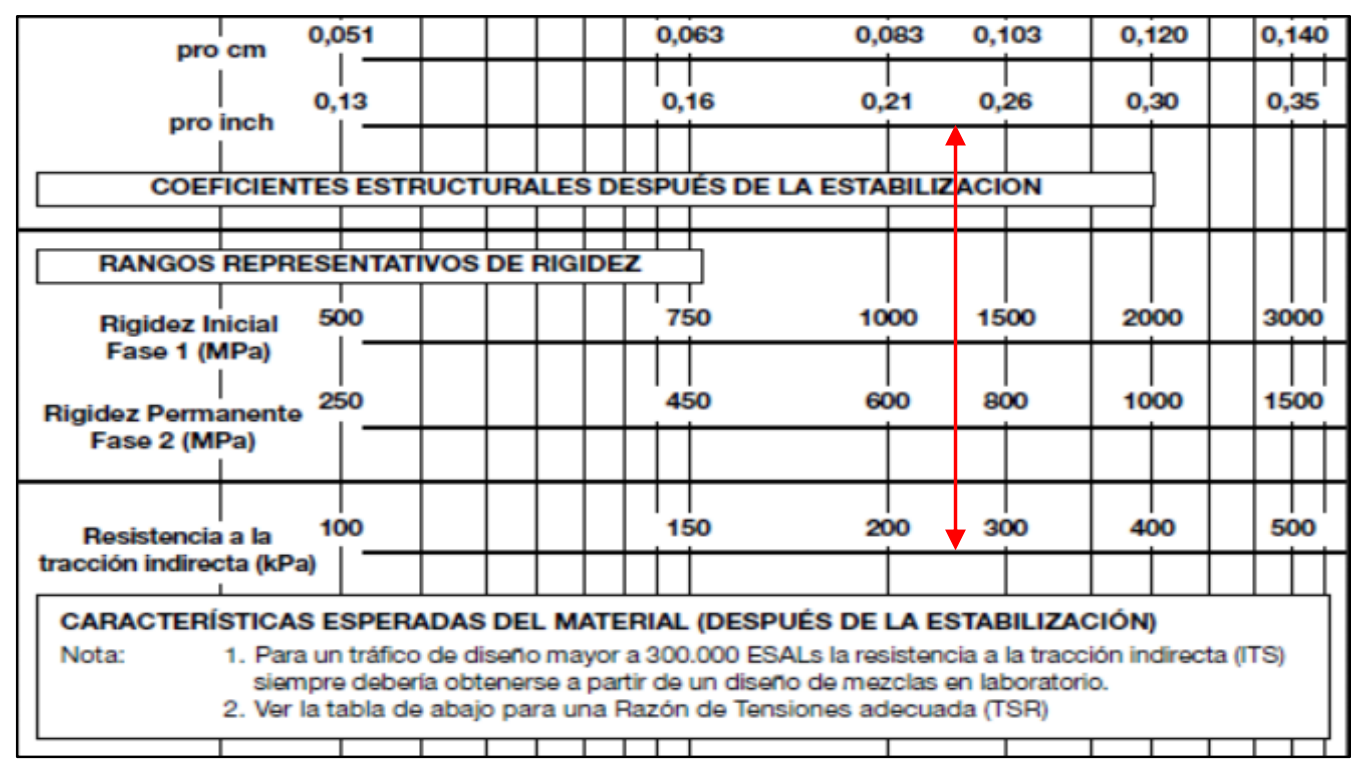

Fig. 6.2: Coeficiente de aporte estructural para Diseño 1 (2.0\% - PEN 85/100)

Fuente: Propia

Para el diseño 1 se obtuvo un ITS de $253.43 \mathrm{KPa}$. Con dicho valor ingresamos al ábaco de Wirtgen (Fig.6.1) para poder hallar el coeficiente de aporte estructural. Como se observa en la Figura 6.2 el valor obtenido es de $\mathbf{0 . 2 3 6}$. 


\subsubsection{Coeficiente de aporte estructural para el Diseño $2(1.5 \%$ - PEN}

\section{0/150):}

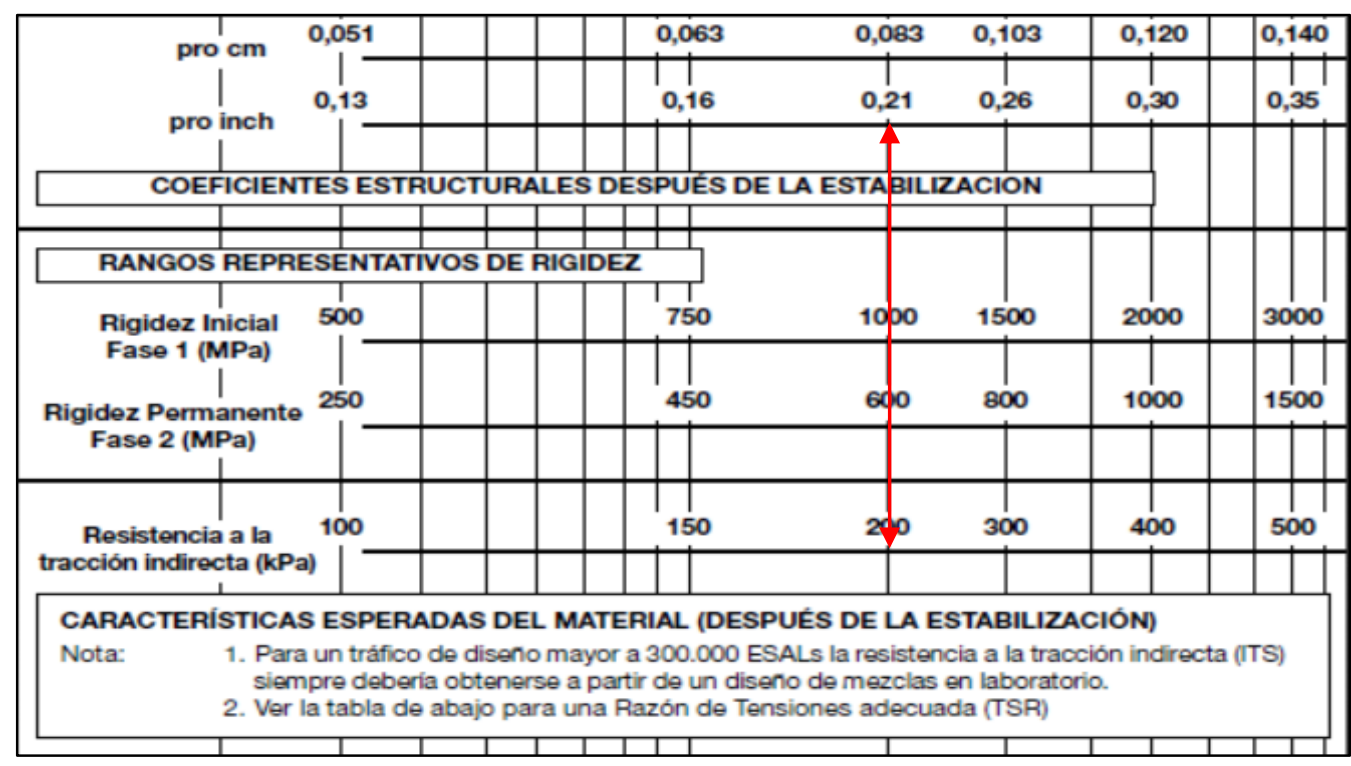

Fig. 6.3: Coeficiente de aporte estructural para Diseño 2 (1.5\% - PEN 120/150)

Fuente: Propia

Para el diseño 2 se obtuvo un ITS de $202.05 \mathrm{KPa}$. Con dicho valor ingresamos al ábaco de Wirtgen (Fig.6.1) para poder hallar el coeficiente de aporte estructural. Como se observa en la Figura 6.3 el valor obtenido es de $\mathbf{0 . 2 1 1}$. 


\subsubsection{Coeficiente de aporte estructural para el Diseño $3(2.0 \%$ - Pen}

\section{0/150):}

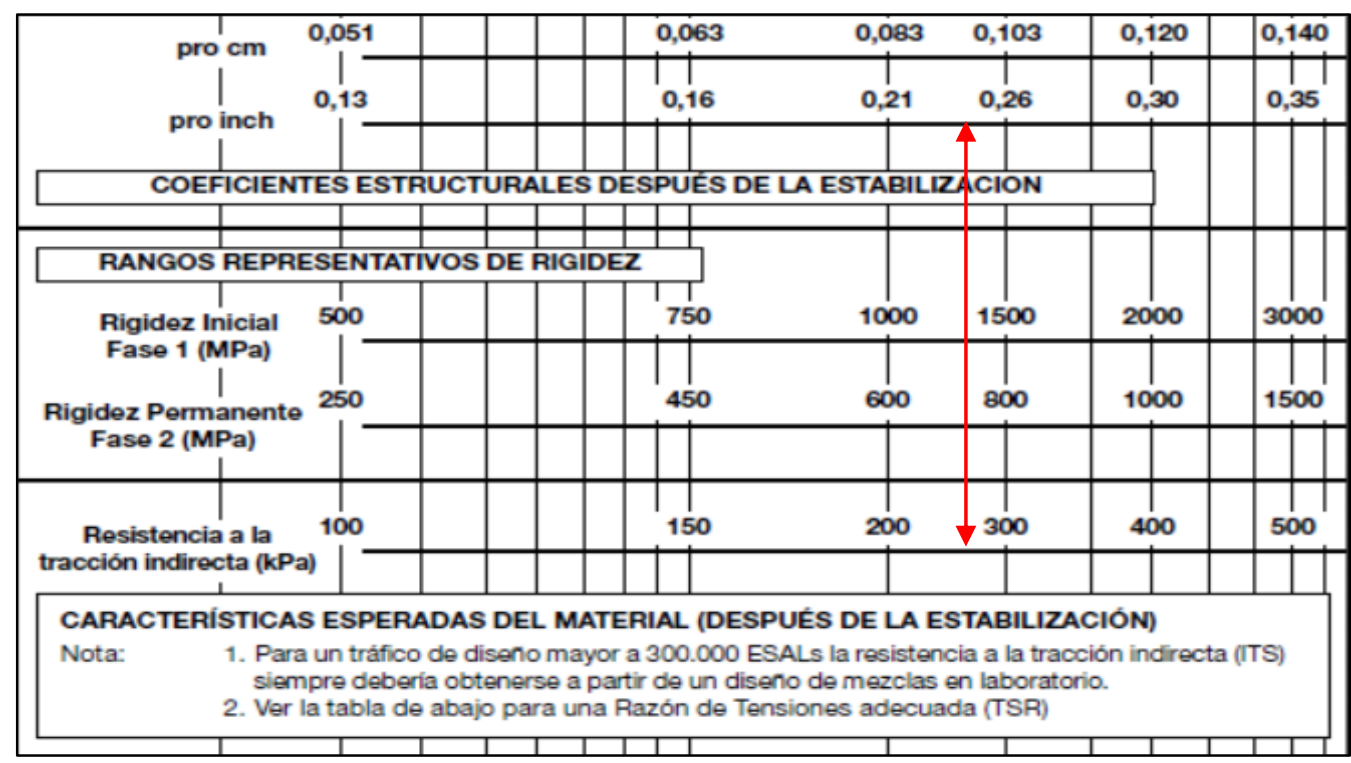

Fig. 6.4: Coeficiente de aporte estructural para Diseño 3 (2.0\% - PEN 120/150)

Fuente: Propia

Para el diseño 3 se obtuvo un ITS de $261.65 \mathrm{KPa}$. Con dicho valor ingresamos al ábaco de Wirtgen (Fig.6.1) para poder hallar el coeficiente de aporte estructural. Como se observa en la Figura 6.4 el valor obtenido es de $\mathbf{0 . 2 4 1}$.

Finalmente, podemos obtener un resumen en la Tabla 6.2:

Tabla 6.2: Resumen de coeficientes estructurales

Fuente: Propia

\begin{tabular}{|c|c|}
\hline Diseño & $\begin{array}{c}\text { Coeficiente Aporte } \\
\text { Estructural (a) }\end{array}$ \\
\hline Diseño 1 & 0.236 \\
\hline Diseño 2 & 0.211 \\
\hline Diseño 3 & 0.241 \\
\hline
\end{tabular}




\subsection{Método de diseño de pavimentos flexibles AASHTO 93:}

Para los 3 diseños de mezcla propuestos y que cumplen con los requisitos mínimos, se desarrollará el diseño del pavimento compuesto de una sub-base granular y una capa estabilizada con asfalto espumado. Según la metodología AASHTO 93 para diseño de pavimentos flexibles, en primer lugar, se debe realizar el cálculo del número estructural requerido. El cálculo de este valor depende de factores inherentes del proyecto como son el tráfico proyectado, la sub rasante y su valor de CBR, y la servicialidad prevista en el diseño. Asimismo, debemos encontrar el valor del número estructural propuesto, que depende de la suma del número de capas y cada capa está compuesta por: el coeficiente de aporte estructural, el espesor y la capacidad de drenaje de la capa. La ecuación para el diseño de pavimentos método AASHTO 93, se muestra en la Fig. 6.5:

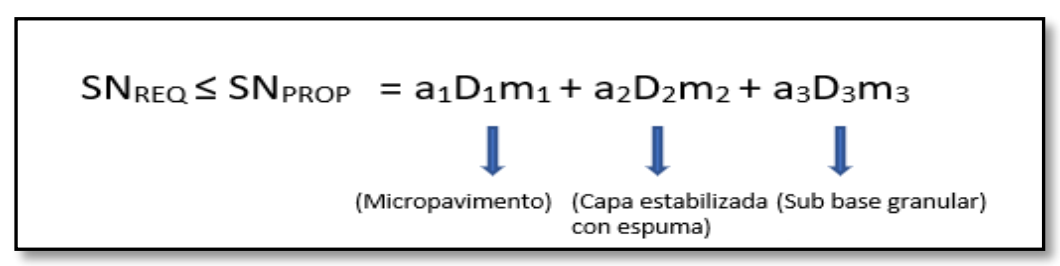

Fig. 6.5: Ecuación para el diseño estructural de pavimentos Método AASHTO 93 Fuente: Propia

Donde:

- $\quad \mathrm{SN}_{\text {req }}=$ Número estructural requerida

- $\mathrm{SN}_{\text {prop }}=$ Número estructural requerida

- $\mathrm{a} \quad=$ coeficiente de aporte estructural

- $\mathrm{D}$ = espesor de la capa

- $\mathrm{m}$ = capacidad de drenaje de la estructura

Para las condiciones del proyecto en el que se enmarca esta investigación, se encontrará un número estructural requerido. Este será constante y es para este número estructural requerido que debemos encontrar un número estructural propuesto que lo satisfaga. Para ello, desarrollaremos la ecuación del número estructural propuesto, en el que nuestra única variable 
será el coeficiente de aporte estructural de la capa estabilizada con asfalto espumado, obtenida anteriormente.

\subsubsection{Número Estructural Requerido (SN):}

Para encontrar el SN requerido, bajo la metodología de diseño de AASHTO 93, se deben considerar algunos datos inherentes del proyecto, en este caso del Tramo VIII CapazoMazocruz.

\subsubsection{CBR de la Subrasante:}

Para encontrar el CBR de la subrasante se realizaron ensayos de las calicatas extraídas a lo largo del tramo a diseñar (Prog. $174+000$ a Prog. $226+000$ ) y mediante el método de las diferencias acumuladas sectorizamos los subtramos homogéneos como se muestra en la Fig. 6.6:

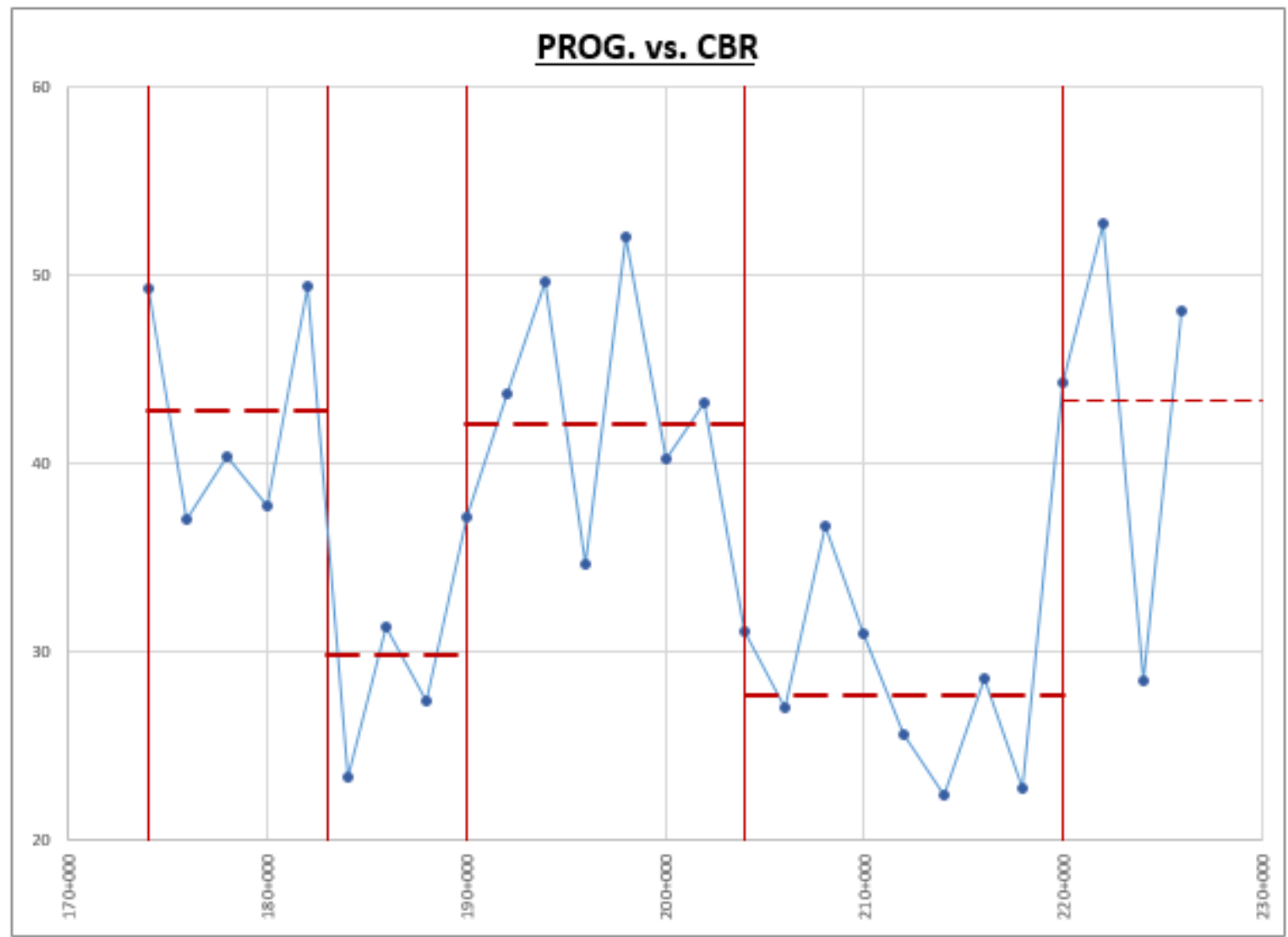

Fig. 6.6: Método de las diferencias acumuladas

Fuente: Propia 
A partir de la Fig. 6.6 obtenemos los siguientes valores mostrados en la Tabla 6.3 en los que se definieron dos subtramos homogéneos:

Tabla 6.3: Resumen de CBR por sectores

Fuente: Propia

\begin{tabular}{|c|c|c|c|}
\hline \multicolumn{2}{|c|}{ Sectores } & $\begin{array}{c}\text { CBR (\%) } \\
\text { Sectores }\end{array}$ & Sub Tramos \\
\hline $174+000$ & $184+000$ & 42.79 & Sub tramo Homogéneo 1 \\
\hline $184+000$ & $192+000$ & 29.79 & Sub tramo Homogéneo 2 \\
\hline $192+000$ & $208+000$ & 42.09 & Sub tramo Homogéneo 1 \\
\hline $208+000$ & $218+000$ & 27.71 & Sub tramo Homogéneo 2 \\
\hline $218+000$ & $226+000$ & 43.40 & Sub tramo Homogéneo 1 \\
\hline
\end{tabular}

De los 02 Sub Tramos Homogéneos, el Tramo Homogéneo 2 posee un coeficiente de soporte (CBR) menor de $27.71 \%$. Este será más crítico pues el número estructural requerido para este sub tramo será mayor. Por esta razón, realizamos el diseño del tramo VIII tomando como referencia este subtramo. 


\subsubsection{Confiabilidad estadística $(R)$ y desviación estándar $(Z r)$ :}

Para este diseño, teniendo en cuenta el periodo de diseño y los datos de análisis, se considerará una confiabilidad de $75 \%$ y un $\mathrm{Zr}$ de -0.674 mostrada en la Tabla 6.4:

Tabla 6.4: Confiabilidad estadística y desviación estándar

Fuente: Guía de Diseño de Pavimentos AASHTO 93

\begin{tabular}{|c|c|c|}
\hline \multicolumn{3}{|c|}{ DESVIACION ESTÁNDDAR NORMAL (Zr) } \\
\hline CONFIABILIDAD (R). \% & & \\
\hline 50 & & 0.000 \\
\hline 60 & & 0.253 \\
\hline 70 & & 0.524 \\
\hline 75 & & 0.674 \\
\hline 80 & & 0.841 \\
\hline 85 & & 1.037 \\
\hline 90 & & 1.282 \\
\hline 91 & & 1.340 \\
\hline 92 & & 1.405 \\
\hline 93 & & 1.476 \\
\hline 94 & & 1.555 \\
\hline 95 & & 1.645 \\
\hline 96 & & 1.751 \\
\hline 97 & & 1.881 \\
\hline 98 & & 2.054 \\
\hline 99 & & 2.327 \\
\hline 99.9 & & 3.090 \\
\hline 99.99 & & 3.750 \\
\hline
\end{tabular}

\subsubsection{Variabilidad o error normal combinado (So):}

La guía AASTHO recomienda un So entre 0.40 y 0.50 , para este caso se toma un valor de 0.45 .

\subsubsection{Ejes equivalentes:}

Los ESAL's (Equivalent Simple Axial Load) son el número acumulado de repeticiones de carga de eje equivalente (8.20 Ton) que circularía por la vía durante el periodo de su vida útil. Esta se hallará a través de un estudio de tráfico proyectado. Para el tramo VIII se estableció una estación de conteo y el tráfico proyectado a 7 años es 3.61 E+05.

Con estos datos, podemos resolver la ecuación para hallar el número estructural requerido según AASTHO 93 mostrado en la Fig. 6.7. En este caso se utilizó una hoja de cálculo para calcular este valor mostrado en la Fig. 6.8: 


$$
\log _{10}\left(W_{18}\right)=Z_{R} S_{0}+9.36 \log _{10}(S N+1)-0.20+\frac{\log _{10}\left[\frac{\Delta P S I}{4.2-1.5}\right]}{0.40+\frac{1094}{(S N+1)^{5.19}}}+2.32 \log _{10}\left(M_{R}\right)-8.07
$$

Fig. 6.7: Ecuación para hallar el $\mathrm{SN}_{\text {requerido }}$ Fuente: Guía de Diseño de Pavimentos AASHTO 93

\begin{tabular}{|llr|}
\hline \multicolumn{3}{|c|}{ DISEÑO DE PAVIMENTO FLEXIBLE (AASHTO 1993) } \\
\hline INSTITUCION & $:$ UPC & FECHA $: 25 / 05 / 2017$ \\
PROYECTO & $:$ CSV Santa Rosa & \\
TRAMO & : 8. Capazo - Mazocruz & \\
\hline
\end{tabular}

$$
\log _{10}\left(W_{18}\right)=Z_{R} S_{0}+9.36 \log _{10}(S N+1)-0.20+\frac{\log _{10}\left[\frac{\Delta P S I}{4.2-1.5}\right]}{0.40+\frac{1094}{(S N+1)^{5.19}}}+2.32 \log _{10}\left(M_{R}\right)-8.07
$$

$R=\quad 75 \% \quad$ Nivel de Confiabilidad para el periódo de análisis

$Z_{R}=-0.674 \quad$ Desviación Estandar Normal

$\mathrm{S}_{\mathrm{o}}=\quad 0.45 \quad$ Variabilidad

$\mathrm{W}_{18}=\quad 3.61 \mathrm{E}+05 \quad$ EAL para el periodo de diseño

$\mathrm{P}_{\mathrm{o}}=\quad 3.8 \quad$ Serviciabilidad inicial

$P_{t}=2 \quad$ Serviciabilidad final

$\triangle \mathrm{PSI}=\quad 1.8 \quad$ Perdida de serviciabilidad $\left(\mathrm{P}_{\mathrm{t}}-\mathrm{P}_{\mathrm{o}}\right)$

$$
\begin{array}{lll}
\text { CBR }= & 27.7 & \text { CBR de diseño } \\
M_{R}= & 21408.1 & \text { Modulo resiliente }
\end{array}
$$

$\mathrm{SN}_{\text {req }}=\quad 1.75 \quad$ Numero estructural requerido

Observación.- - Parámetros de diseño considerados de acuerdo a las recomendaciones del Manual de Carreteras de acuerdo al tráfico proyectado para cada tramo para el periodo de diseño.

- Periodo de diseño de 5 años (2017 - 2021)

- El ESAL fue considerado del estudio de tráfico descontando los E.E. del año 2016.

Fig. 6.8: Cálculo de $\mathrm{SN}_{\text {requerido }}$

Fuente: Propia 
Para el tramo homogéneo más crítico, el SN requerido es de 1.75. Para satisfacer este valor, se desarrollarán los diseños propuestos con los tres diseños de capa estabilizada con asfalto espumado seleccionados.

\subsubsection{SN's Propuestos para los diseños realizados:}

Para hallar los SN's propuestos, hacemos uso de la misma ecuación mostrada en la Fig. 6.9:

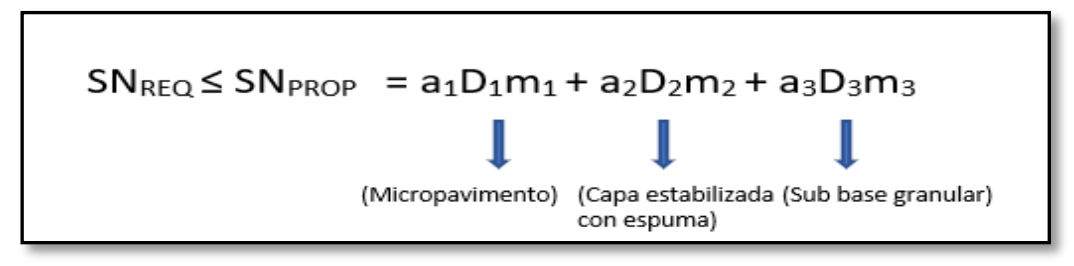

Fig. 6.9: Ecuación para el diseño estructural de pavimentos Método AASHTO 93

\section{Fuente: Propia}

Para la conformación de la estructura del pavimento se han considerado dos capas: una subbase granular y una base granular estabilizada con asfalto espumado, cada una con un espesor de $15 \mathrm{~cm}$. Por encima de estas dos capas se colocará un micropavimento con espesor de $1 \mathrm{~cm}$; sin embargo, el micropavimento no aporta estructuralmente al paquete estructural, ya que tiene un espesor pequeño.

Las condiciones de drenaje $(\mathrm{m})$ de la sub-base granular se consideró 0.95 y para la base granular estabilizada con asfalto espumado se consideró 1.0.

Asimismo, se considera un CBR mínimo de $40 \%$ para la sub-base granular, con la finalidad de encontrar su coeficiente de aporte estructural en el siguiente ábaco mostrado en la Fig. 6.10: 


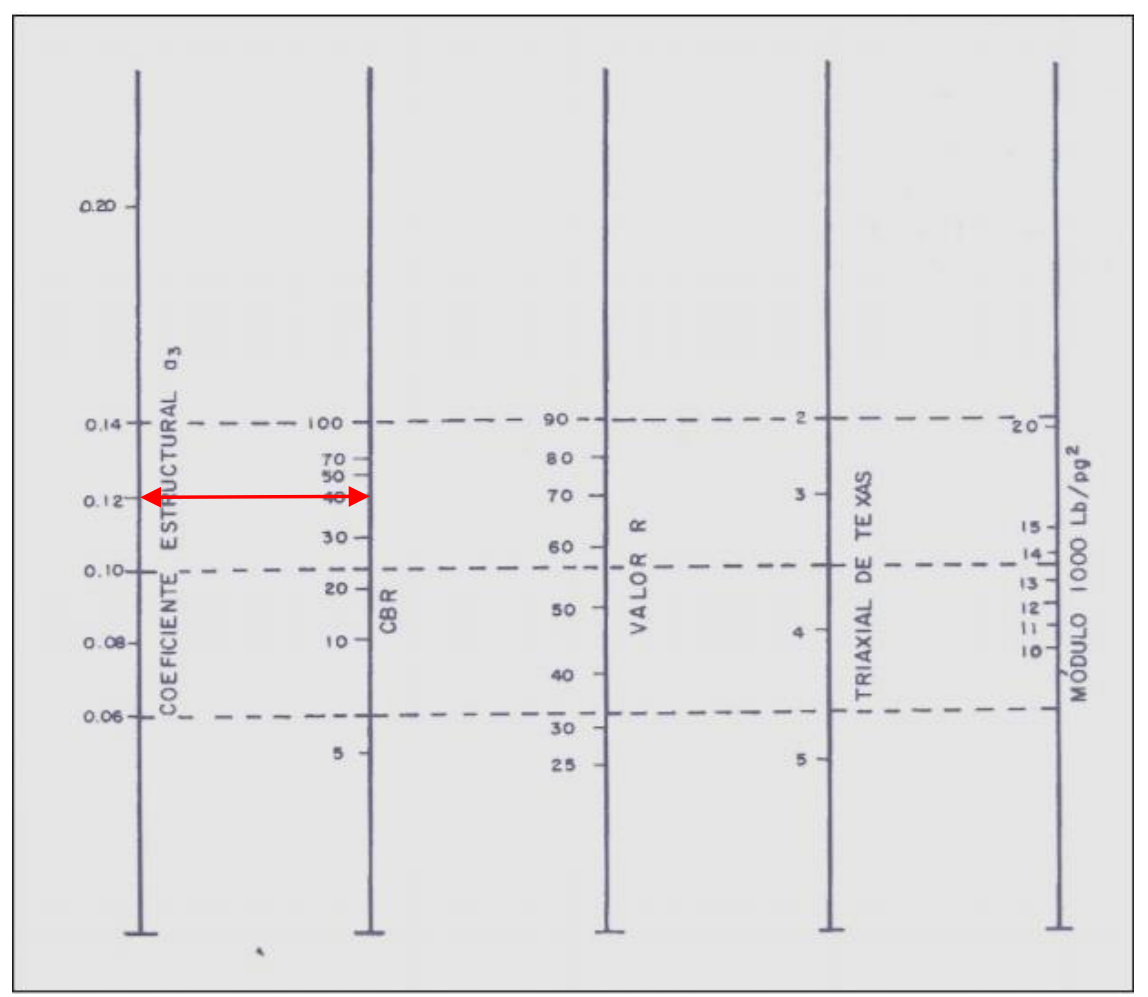

Fig. 6.10: Ábaco para hallar el coeficiente de aporte estructural de la sub-base Fuente: Guía de Diseño de Pavimentos AASHTO 93

De la Fig. 6.10 obtenemos un coeficiente estructural (a3) de 0.12 para la sub-base granular. 


\subsubsection{Diseño 1 (2.0\% - Pen 85/100):}

Este diseño tendrá la configuración del pavimento propuesto con una capa estabilizada de asfalto espumado, utilizando un cemento asfáltico con grado de penetración PEN 85/100 y un porcentaje de asfalto inyectado de 2.0\%. El diseño 1 se muestra en la Fig. 6.11 a continuación:

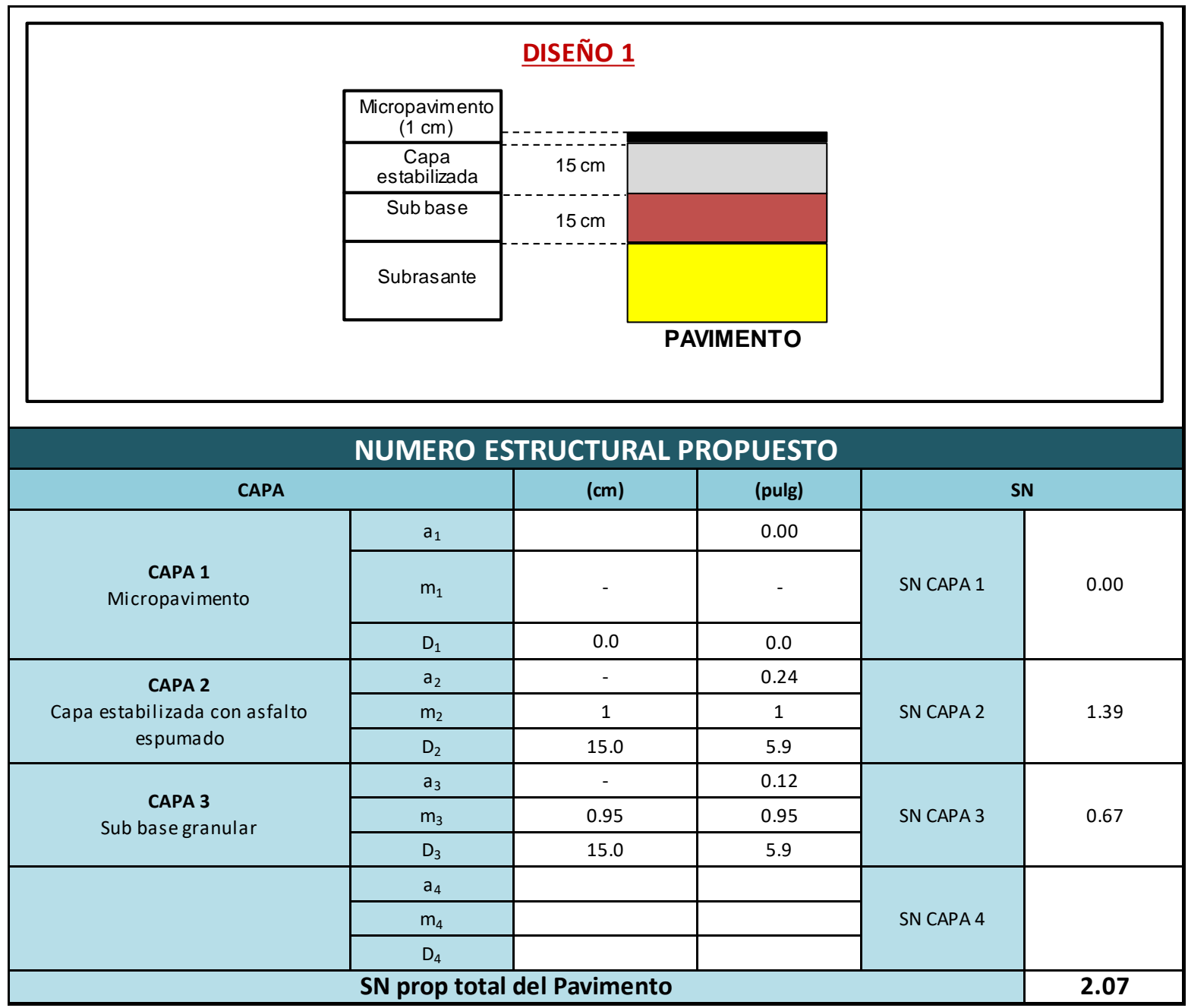

Fig. 6.11: Diseño 1 (2.0\% - PEN 85/100)

Fuente: Propia

Para el Diseño 1 obtenemos un $\mathrm{SN}_{\text {propuesto de } 2.07 .}$ 


\subsubsection{Diseño 2 (1.5\% - PEN 120/150):}

Este diseño tendrá la configuración del pavimento propuesto con una capa estabilizada de asfalto espumado, utilizando un cemento asfáltico con grado de penetración PEN 120/150 y un porcentaje de asfalto inyectado de 1.50\%. El diseño 2 se muestra en la Fig. 6.12 a continuación:

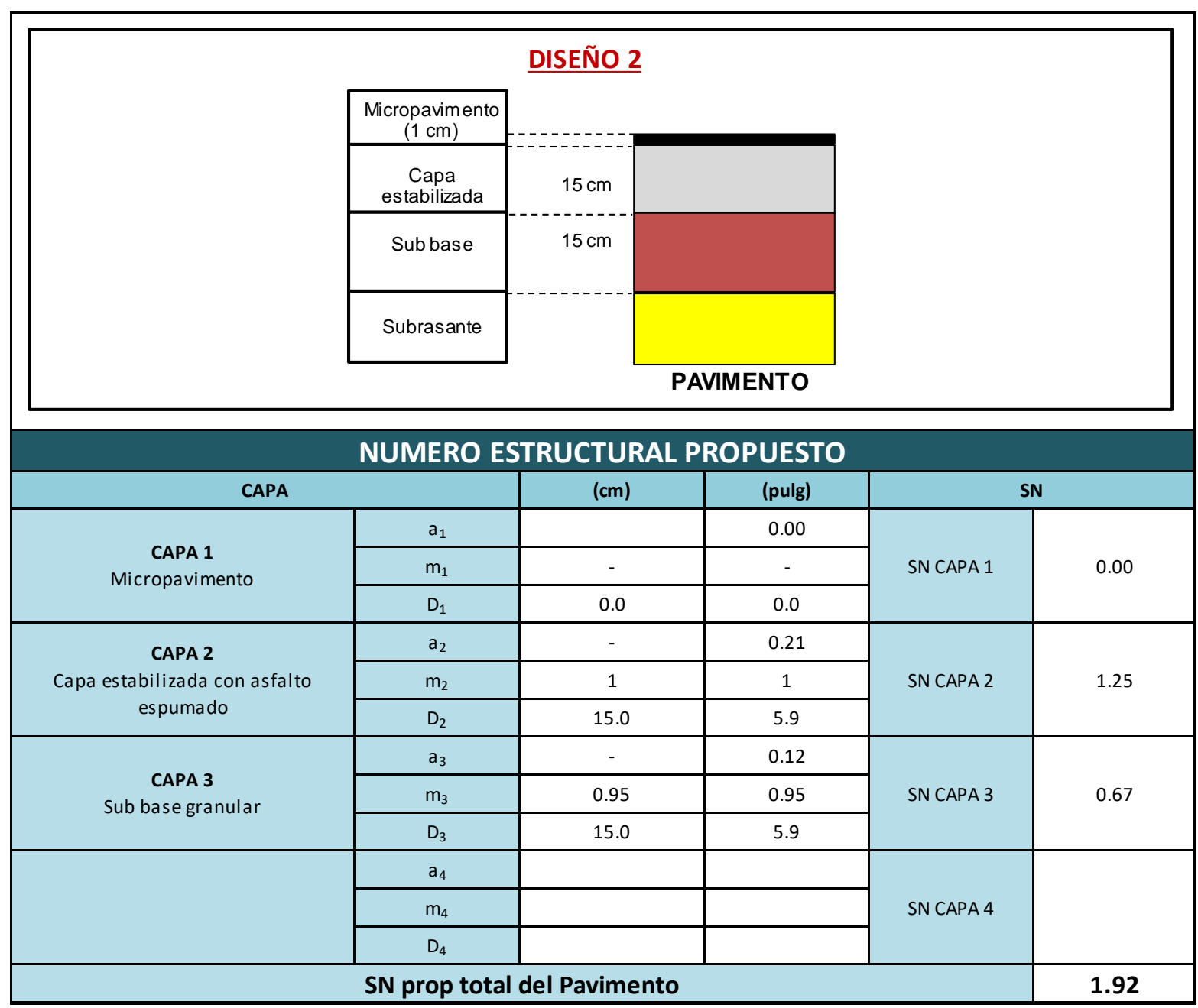

Fig. 6.12: Diseño 2 (1.5\% - PEN 120/150)

Fuente: Propia

Para el Diseño 2 obtenemos un $\mathrm{SN}_{\text {propuesto de } 1.92 .}$ 


\subsubsection{Diseño 3 (2.0\% - PEN 120/150):}

Este diseño tendrá la configuración del pavimento propuesto con una capa estabilizada de asfalto espumado, utilizando un cemento asfáltico con grado de penetración PEN 120/150 y un porcentaje de asfalto inyectado de 2.0\%. El diseño 3 se muestra en la Fig. 6.13 a continuación:

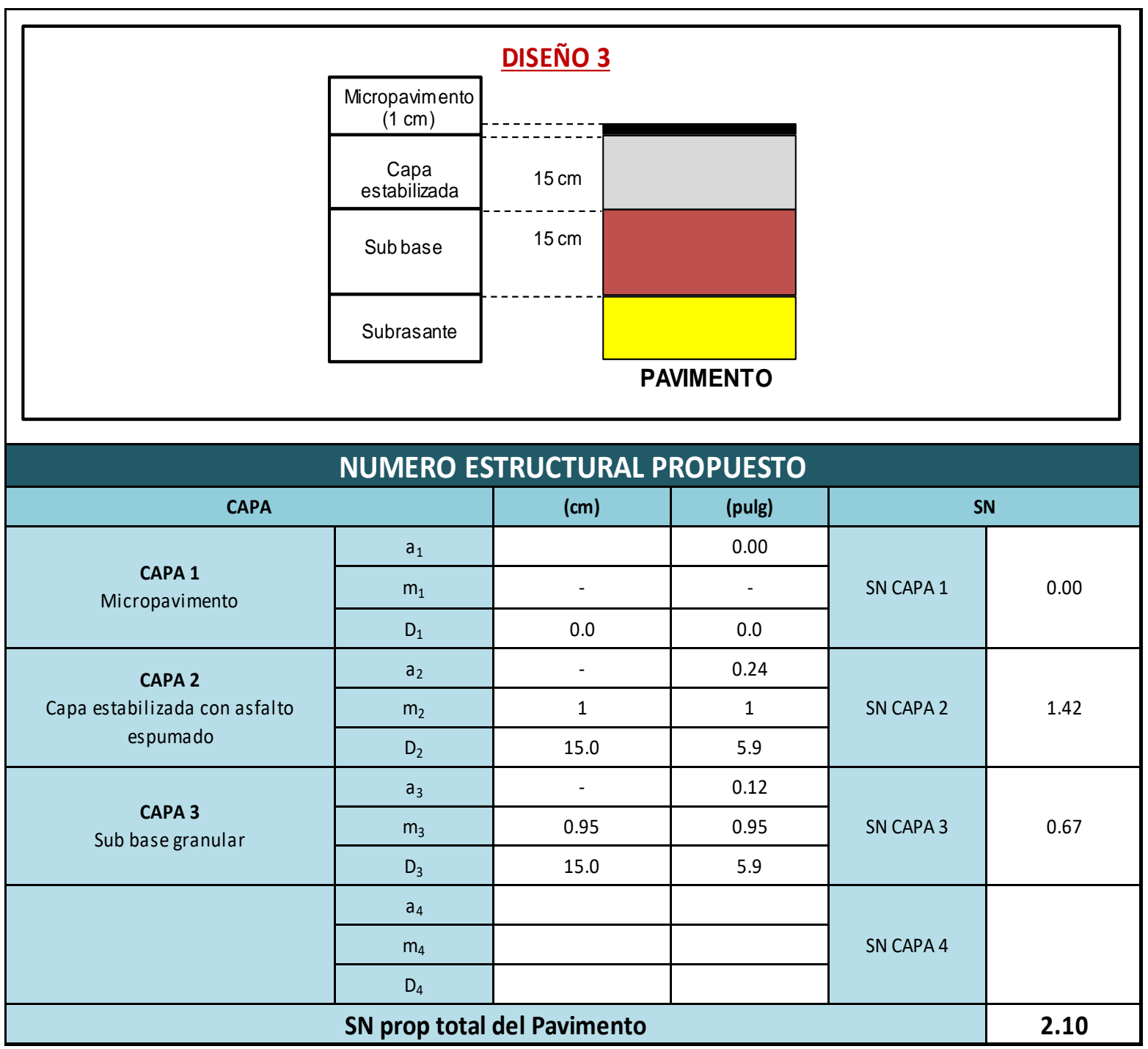

Fig. 6.13: Diseño 3 (2.0\% - PEN 120/150)

Fuente: Propia

Para el Diseño 3 obtenemos un $\mathrm{SN}_{\text {propuesto }}$ de 2.10 . 


\subsection{Comparación estructural entre un pavimento sin estabilizar y un pavimento estabilizado con asfalto espumado:}

Una vez diseñado nuestro pavimento con una capa estabilizada con asfalto espumado es necesario establecer en qué medida ha aumentado en el aporte estructural del pavimento. Esto se realizará a partir de la comparación de la estructura de pavimento estabilizado contra un pavimento en el que la primera capa no se haya estabilizado, teniendo como base la configuración de pavimento propuesta anteriormente (01 base/capa estabilizada de 15 m y 01 sub base de $15 \mathrm{~cm}$ ). El cálculo del Número Estructural (SN) del pavimento sin estabilizar se muestra en la Fig. 6.14:

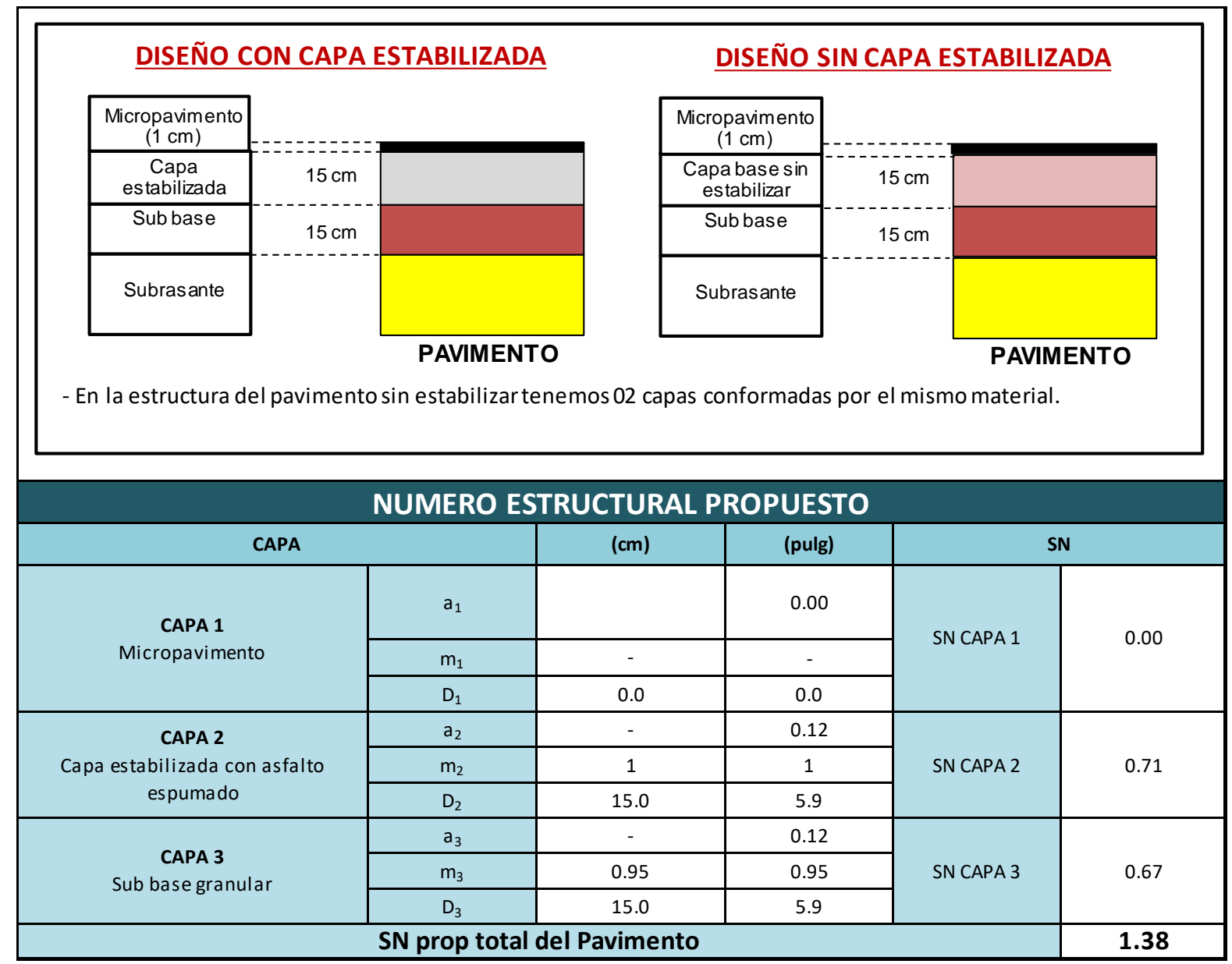

Fig. 6.14: Diseño de capa sin estabilizar

Fuente: Propia 
Como se puede observar, el $\mathrm{SN}_{\text {propuesto }}$ del pavimento sin estabilización con asfalto espumado es de 1.38. Este valor no cumple con el valor mínimo requerido de 1.75.

Por otra parte, este valor estructural obtenido es menor que los valores obtenidos en los diseños de pavimento en los que se utiliza una capa estabilizada con asfalto espumado, como se puede apreciar en la Tabla 6.5:

Tabla 6.5: Resumen de valores obtenidos de SN

Fuente: Propia

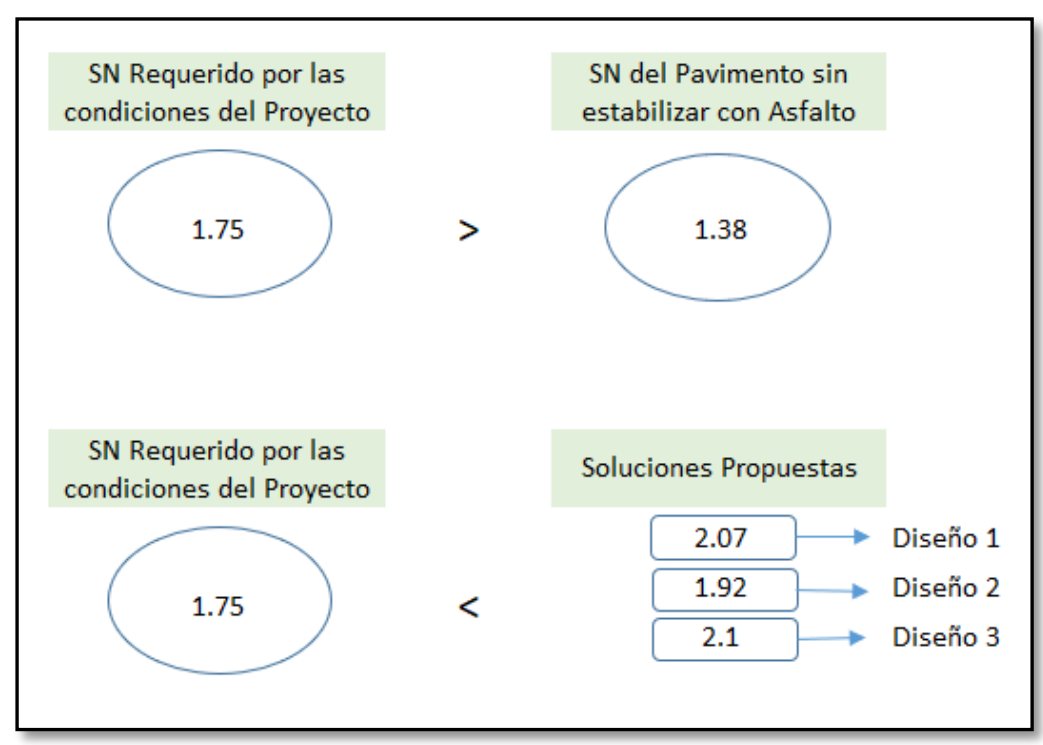

Asimismo, se calculará cuál es la configuración de un pavimento sin el uso de la estabilización con asfalto espumado que cumpla con los requerimientos estructurales del proyecto; en este caso superar el Número Estructural (SN) requerido que es de 1.75. Para esto, calcularemos el valor del Número Estructural conforme vayamos aumentando la altura de la base, hasta que superemos el valor de 1.75. Finalmente, con una base granular de $35 \mathrm{~cm}$ se satisface el requerimiento estructural del proyecto. Como se puede apreciar en la figura Fig. 6.15, obtenemos un SN de 1.82. 


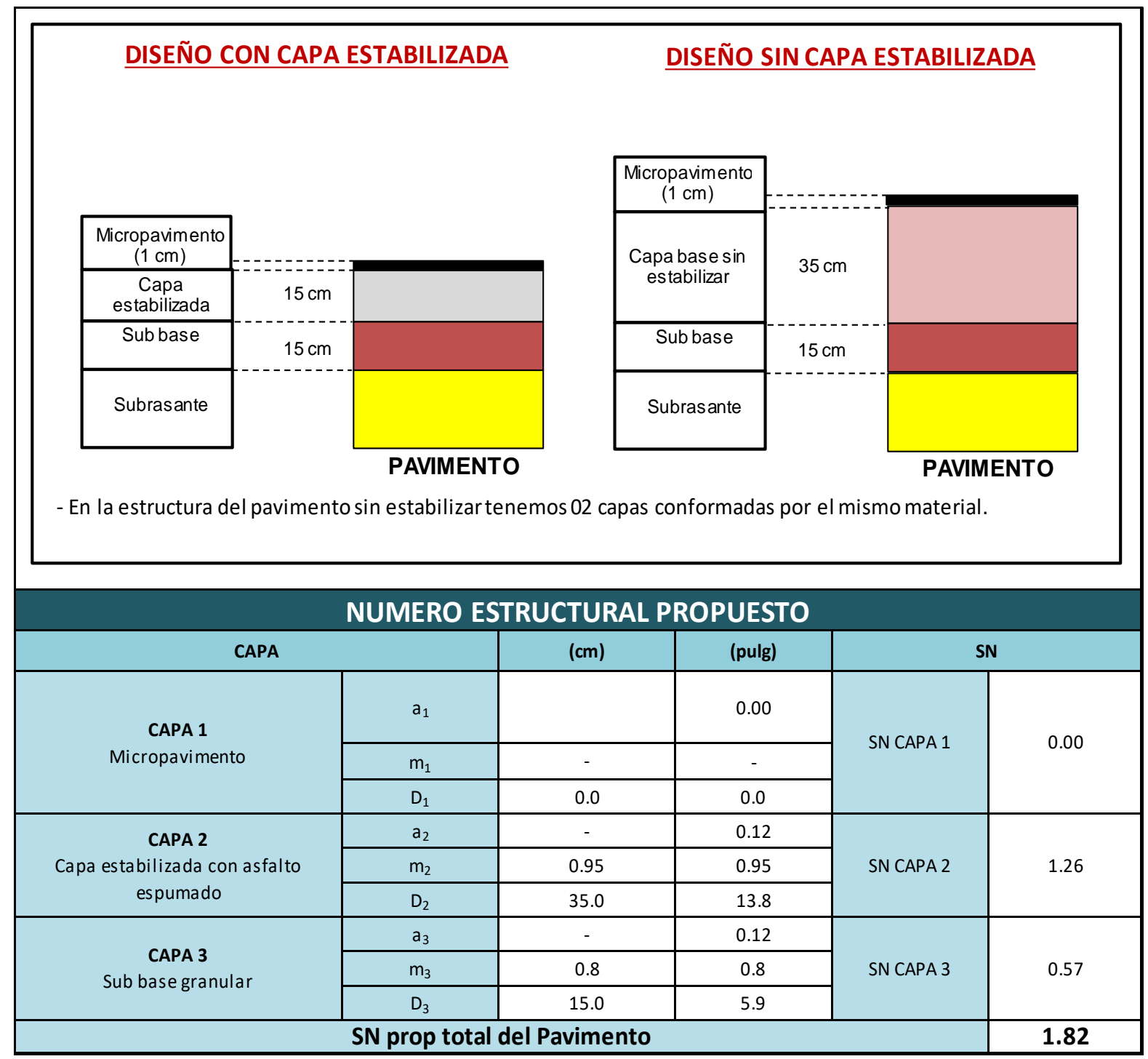

Fig. 6.15: Configuración de pavimento con capa sin estabilizar Fuente: Propia 


\section{CAPÍTULO 7: DISCUSION}

Luego de haber llevado a cabo los procedimientos de los capítulos de diseño de mezcla y evaluación estructural del pavimento, en este capítulo se analizarán e interpretarán los resultados obtenidos:

\subsection{Caracterización de los agregados geotécnicos:}

Se utilizaron agregados de dos canteras (Cantera Mazocruz km 225+650 y Cantera km 217+000), debido a que la primera mencionada no cumplía con el porcentaje mínimo de 5\% de material fino pasante de la malla $\mathrm{N}^{\circ} 200$. La proporción de la mezcla de ambas canteras fue de $85 \%$ y $15 \%$ respectivamente. En la Fig. 7.1 se puede apreciar la curva granulométrica de la mezcla. Este resultado es importante, debido a que luego de realizar el siguiente proceso de inyección de asfalto, éste actuará como conector entre los finos con una condición dúctil.

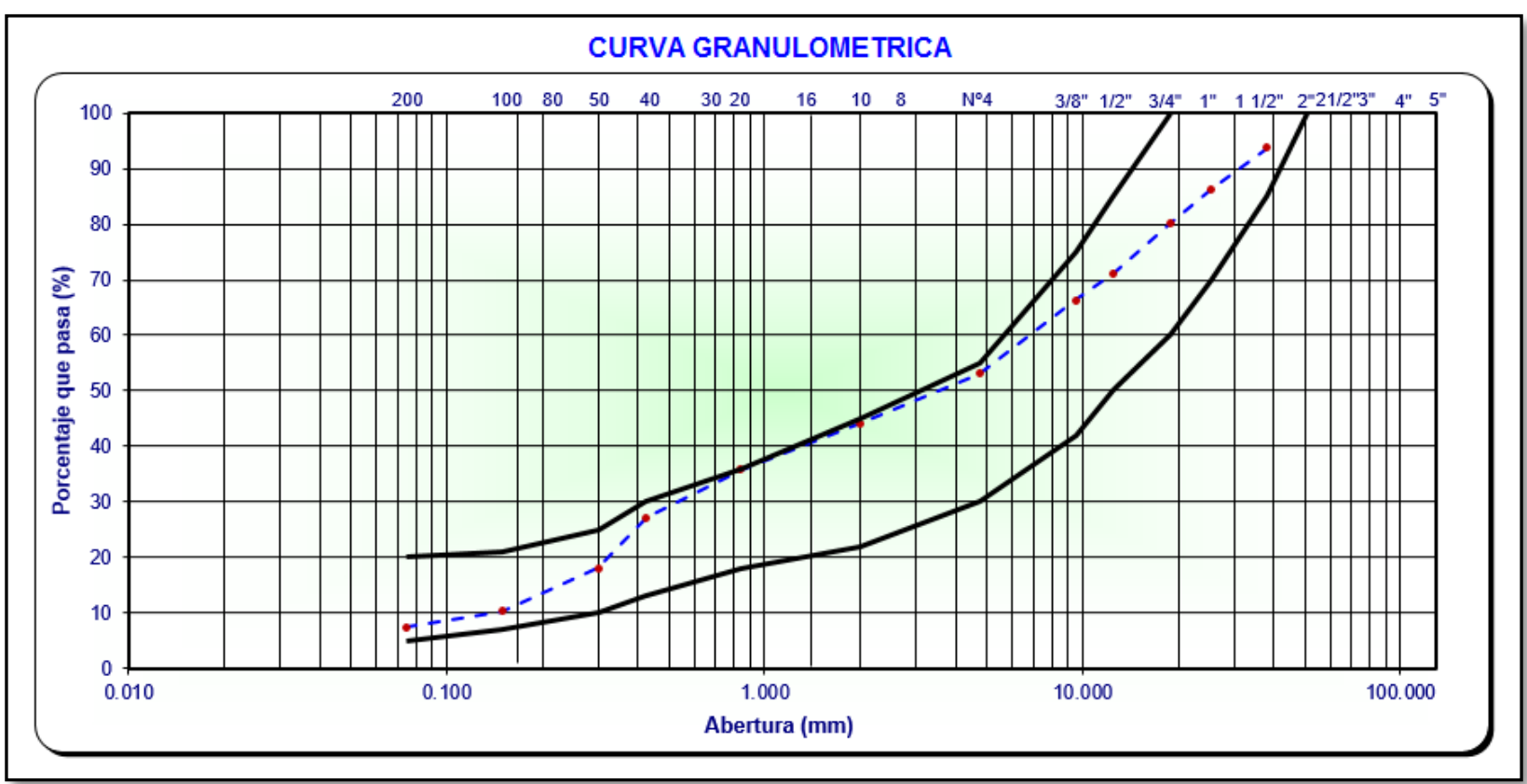

Fig. 7.1: Curva granulométrica de la mezcla

Fuente: Propia 


\subsection{Calidad de Espumación:}

En el proceso de espumación, dentro del equipo WLB 10S, se tuvieron 2 factores influyentes para poder llegar a las condiciones óptimas de espumación por cada cemento asfáltico (PEN $85 / 100$ y PEN $120 / 150)$ : la temperatura del asfalto $\left(160^{\circ} \mathrm{C}-190^{\circ} \mathrm{C}\right)$ y los porcentajes de agua de espumación (1\% - 4\%). Fue muy importante realizar los ensayos de espumación con estos rangos de temperatura y porcentaje de agua, ya que se tuvo un universo de resultados más amplio en donde se pudieron escoger los valores más altos de vida media y razón de expansión, y con éstos poder obtener las condiciones óptimas de espumación como se muestran en la Tabla 7.1. Se tuvieron limitaciones en la temperatura de $190^{\circ} \mathrm{C}$ para el cemento asfáltico PEN 85/100 por no llegar a los valores mínimos de vida media y razón de expansión.

Tabla 7.1: Condiciones óptimas de espumación

Fuente: Propia

\begin{tabular}{|c|c|c|}
\hline \multicolumn{3}{|c|}{ Condiciones óptimas de espumación } \\
\hline Cemento asfáltico & Petroperú PEN $85 / 100$ & Petroperú PEN $120 / 150$ \\
\hline Temperatura & $160^{\circ} \mathrm{C}$ & $180^{\circ} \mathrm{C}$ \\
\hline \% Agua de espumación & $2.0 \%$ & $3.0 \%$ \\
\hline Razón de expansión promedio & $11.7>10$ veces & $19.0>10$ veces \\
\hline Vida media promedio & $9.4>8$ segundos & $15.3>8$ segundos \\
\hline
\end{tabular}

\subsection{Mezcla Asfáltica (Diseño de laboratorio):}

Se realizó la mezcla con asfalto espumado para los dos cementos asfálticos (PEN 85/100 y PEN 120/150) y diferentes dosificaciones de asfalto inyectado (1.5\%, $2.0 \%$ y $2.5 \%)$. Los resultados del ensayo de Tracción Indirecta son mostrados en la Tabla 7.2 y sólo algunos sobrepasan los valores mínimos requeridos. 
Tabla 7.2: Resumen de resultados del ensayo de Tracción Indirecta (ITS)

Fuente: Propia

\begin{tabular}{|c|c|c|c|c|c|c|}
\cline { 2 - 7 } \multicolumn{1}{c|}{} & \multicolumn{3}{c|}{ PEN 85/100 } & \multicolumn{3}{c|}{ PEN 120/150 } \\
\hline$\%$ & ITS Seca & ITS Humeda & ITS Conservada & ITS Seca & ITS Humeda & ITS Conservada \\
\hline 1,5 & 198,25 & 118,9 & $60 \%$ & 202,05 & 106,9 & $53 \%$ \\
\hline 2,0 & 253,43 & 169,8 & $67 \%$ & 261,67 & 148,9 & $57 \%$ \\
\hline 2,5 & 160,88 & 101,0 & $63 \%$ & 191,20 & 101,5 & $53 \%$ \\
\hline
\end{tabular}

\subsection{Corroboración de Diseño y Campo:}

La mezcla asfáltica se realizó en la Planta Móvil KMA 220 y luego fue llevado mediante volquetes al frente de trabajo en campo. Se tomaron muestras y se realizaron los ensayos de Tracción Indirecta para el cemento asfáltico PEN 120/150 con un porcentaje de asfalto inyectado de $2.0 \%$ como está estipulado en el proyecto. En la Fig. 7.2 se muestra la producción de mezcla asfáltica en la KMA 220 y en la Tabla 7.3 se muestran los resultados del ensayo de Tracción Indirecta.
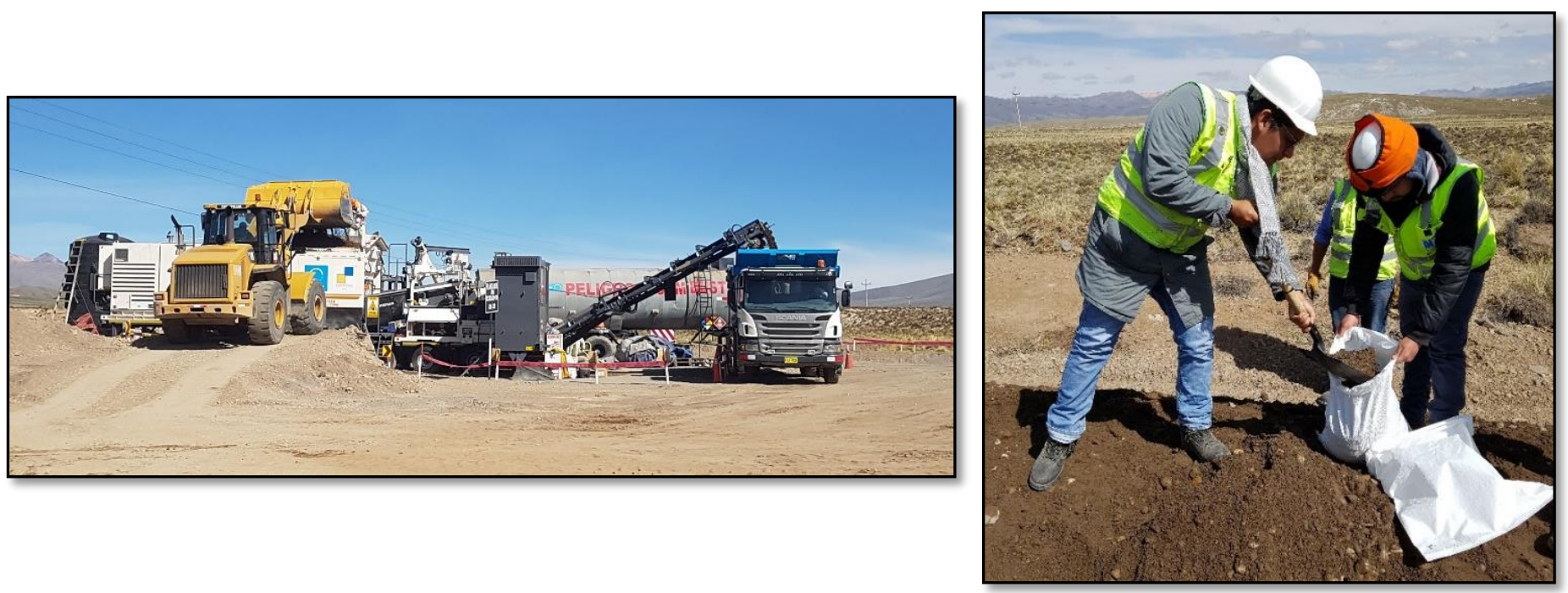

Fig. 7.2: Producción de mezcla asfáltica y recolección de material para ensayo de Tracción Indirecta

Fuente: Propia 
Tabla 7.3: Resumen de resultados del ensayo de Tracción Indirecta (ITS)

Fuente: Propia

\begin{tabular}{|c|c|c|c|c|c|c|}
\hline \multirow{2}{*}{$N^{\circ}$ DE PRODUCCION } & \multirow{2}{*}{$\begin{array}{l}\text { PROGRESIVA } \\
\text { INICIAL (Km.) }\end{array}$} & \multirow{2}{*}{$\begin{array}{l}\text { PROGRESIVA } \\
\text { FINAL (Km.) }\end{array}$} & \multirow{2}{*}{$\begin{array}{l}\text { DENSIDAD } \\
\text { (Gr/cm3) }\end{array}$} & \multicolumn{2}{|c|}{ RESISTENCIA T.I. (KPa) } & \multirow{2}{*}{$\begin{array}{c}\text { RESISTENCIA } \\
\text { CONSERVADA (\%) }\end{array}$} \\
\hline & & & & SECA & HUMEDA & \\
\hline 1 & $226+860$ & $227+050$ & 2.016 & 254.8 & 142.3 & $55.8 \%$ \\
\hline \multirow{2}{*}{2} & $226+360$ & $226+480$ & \multirow{2}{*}{2.024} & \multirow{2}{*}{233.2} & \multirow{2}{*}{141.1} & \multirow{2}{*}{$60.5 \%$} \\
\hline & $226+660$ & $226+860$ & & & & \\
\hline 3 & $225+695$ & $226+360$ & 2.017 & 258.546 & 142.9 & $55.3 \%$ \\
\hline \multirow{2}{*}{4} & $223+243$ & $223+500$ & \multirow{2}{*}{2.022} & \multirow{2}{*}{263.2} & \multirow{2}{*}{143.8} & \multirow{2}{*}{$54.6 \%$} \\
\hline & $225+580$ & $225+640$ & & & & \\
\hline 5 & $223+520$ & $224+210$ & 2.066 & 232.8 & 145.7 & $62.6 \%$ \\
\hline 6 & $224+210$ & $225+050$ & 2.066 & 231.8 & 139.7 & $60.3 \%$ \\
\hline 7 & $225+050$ & $225+580$ & 2.041 & 223.0 & 143.6 & $64.4 \%$ \\
\hline
\end{tabular}

\subsection{Coeficientes de aporte estructural (Método de Wirtgen):}

Con los resultados del ensayo de Tracción Indirecta de los diseños de laboratorio, se procedió a hallar los coeficientes de aporte estructural de los diseños que cumplieron los valores mínimos requeridos, mostrados en la Tabla 7.4, utilizando el ábaco de Wirtgen que se muestra en la Figura 6.1. Los coeficientes obtenidos de los diseños que cumplieron los valores mínimos requeridos se muestran en la Tabla 7.5:

Tabla 7.4: Valores que cumplieron los valores mínimos requeridos

Fuente: Propia

\begin{tabular}{|c|c|c|c|c|c|c|}
\hline \multirow{3}{*}{$\begin{array}{l}\% \text { ASFALTO } \\
\text { INYECTADO }\end{array}$} & \multicolumn{3}{|c|}{ PEN 85/100 } & \multicolumn{3}{|c|}{ PEN 120/150 } \\
\hline & \multicolumn{2}{|c|}{ RESISTENCIA T.I. (KPa) } & \multirow{2}{*}{$\begin{array}{c}\text { RESISTENCIA } \\
\text { CONSERVADA } \\
(\%)\end{array}$} & \multicolumn{2}{|c|}{ RESISTENCIA T.I. (KPa) } & \multirow{2}{*}{$\begin{array}{c}\text { RESISTENCIA } \\
\text { CONSERVADA } \\
(\%)\end{array}$} \\
\hline & SECA & HUMEDA & & SECA & HUMEDA & \\
\hline 1.5 & 198.251 & 118.945 & $60 \%$ & 202.049 & 106.890 & $53 \%$ \\
\hline 2.0 & 253.429 & 169.837 & $67 \%$ & 261.665 & 148.863 & $57 \%$ \\
\hline 2.5 & 160.880 & 101.042 & $63 \%$ & 191.203 & 101.520 & $53 \%$ \\
\hline
\end{tabular}


Tabla 7.5: Resumen de Coeficientes de Aporte Estructural Fuente: Propia

\begin{tabular}{|c|c|}
\hline Diseños & $\begin{array}{c}\text { Coeficiente de Aporte } \\
\text { Estructural (a) }\end{array}$ \\
\hline Diseño 1 & 0.236 \\
\hline Diseño 2 & 0.211 \\
\hline Diseño 3 & 0.241 \\
\hline
\end{tabular}




\subsection{Diseño de pavimentos flexibles AASHTO 93:}

Luego de hallar los coeficientes de aporte estructural para cada diseño, se halló el número estructural requerido y se comparó contra los números estructurales propuestos de los 3 diseños como se muestra en la Tabla 7.6. Como se puede apreciar, la base estabilizada con asfalto espumado eleva la resistencia estructural del pavimento, arrojándonos SNpropuestos mayores al SNrequerido. Por otro lado, se comparó un pavimento con una base sin estabilizar contra un pavimento con base estabilizada con asfalto espumado. Los resultados nos muestran que el pavimento sin estabilización posee un SNpropuesto menor al SNrequerido, lo cual es un indicativo y se cumple la hipótesis de que los pavimentos diseñados con materiales granulares estabilizados con asfalto espumado, son una solución para elevar la resistencia estructural del pavimento.

Tabla 7.6: Comparación de números estructurales (SN)

Fuente: Propia

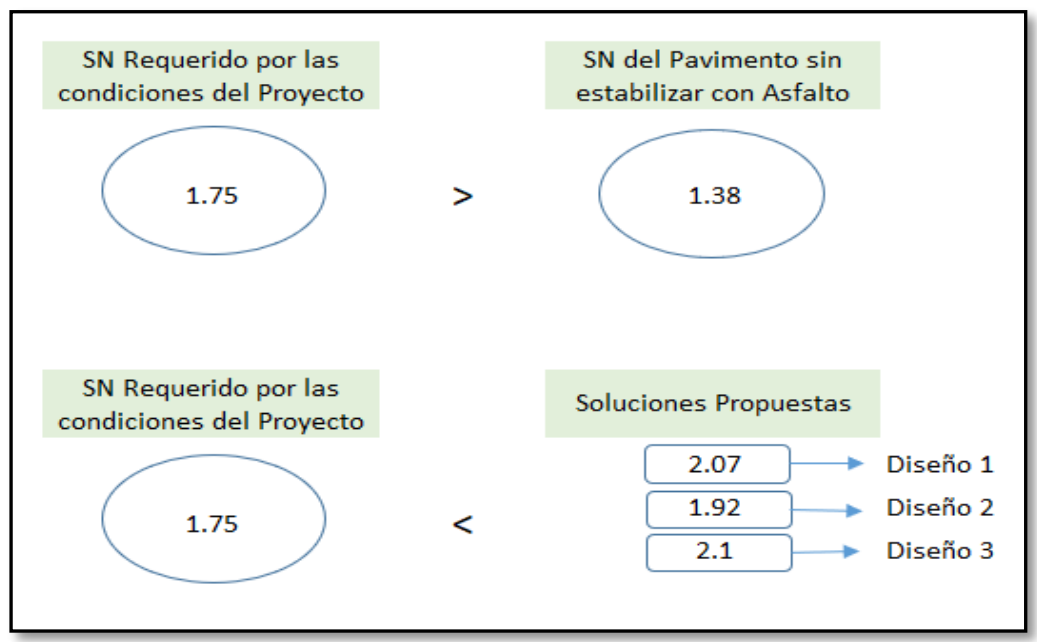




\section{CAPÍTULO 8: CONCLUSIONES Y RECOMENDACIONES}

\subsection{Conclusiones:}

En la presenta investigación se ha demostrado, a través de ensayos de Tracción Indirecta, el aumento de la resistencia de una capa estabilizada con asfalto espumado y se ha realizado el análisis comparativo de cómo su resistencia varía dependiendo de las propiedades del ligante (tipo de asfalto, temperatura, dosificación). Este aumento en la resistencia se traduce en un aumento en el aporte estructural de todo el pavimento. Asimismo, este estudio se realizó en el marco del proyecto "Servicio de Gestión, Mejoramiento y Conservación Vial por Niveles de Servicio del Corredor Vial: Dv Humajalso - Desaguadero y Tacna - Tarata - Capazo Mazocruz" - Tramo 8, teniendo en cuenta que todos los ensayos se realizaron en un laboratorio in situ.

La mezcla de los agregados de la Cantera Mazocruz y Cantera km. 217+000, en una proporción de $85 \%$ y $15 \%$ respectivamente, fue necesaria para poder cumplir con el requisito de tener el porcentaje mínimo de $5 \%$ de material fino pasante de la malla $\mathrm{N}^{\circ} 200$ y cumplir con el huso granulométrico para el diseño de mezcla con asfalto espumado. Cumplir este requisito es importante, debido a que las gotas de asfalto, que se mezclan entre los finos, actúan como conectores aumentando la resistencia de la capa estabilizada; por consiguiente, de la estructura del pavimento.

El tipo de asfalto influye directamente en las propiedades del asfalto espumado. Para las condiciones termodinámicas en las que se encuentra el proyecto, de las cuales la más crítica es la baja temperatura, el asfalto con mayor grado de penetración (PEN 120/150) tiene un mejor desempeño para realizar el asfalto espumado, específicamente en el proceso de espumación.

El uso del laboratorio de asfalto espumado WLB10S, que simula en su cámara de expansión el performance de la KMA220, y el compactador vibratorio WLV1, que simula la 
compactación vibratoria realizada en campo, nos sirve para que los resultados de las resistencias de los ensayos sean más parecidos a lo que se ejecutará en la realidad. Esto se debe a que los equipos de laboratorio fueron desarrollados y fabricados con este fin por Wirtgen, que es también el fabricante de la Planta Móvil KMA220

Aseguramos la calidad de espumación a partir de elegir una temperatura óptima $\left(180^{\circ} \mathrm{C}\right.$ para PEN $120 / 150$ y $160^{\circ} \mathrm{C}$ para PEN $85 / 100$ ) que tenga mayor índice de espumación. A partir de esta temperatura, se encontró un porcentaje óptimo de agua presurizada relacionándola con la razón de expansión y el tiempo de vida media.

Según los ensayos de ITS realizados, la resistencia tiende a aumentar conforme se aumenta el porcentaje de asfalto inyectado hasta encontrar el valor óptimo. Después de llegar a este valor, la resistencia disminuye. Como se describe en el punto 3.2.3, la masilla de asfalto presentará un módulo elástico y una fuerza menor si el contenido de asfalto supera el óptimo, ya que el exceso de asfalto al no mezclarse y no actuar como conectores entre las partículas finas, se comportará como lubricante haciendo que la masilla pierda rigidez y resistencia. Además, de los 6 diseños propuestos, 3 de estos cumplen con los valores mínimos requeridos de resistencia seca, húmeda y conservada.

Los valores de resistencia a la tracción indirecta (ITS) de las muestras obtenidas en el campo comparados con los valores de ITS de las muestras obtenidas en el laboratorio con las mismas características (2.0\% asfalto inyectado y PEN 120/150) poseen una variación porcentual máxima de $11.5 \%$ para la condición seca y de $6.3 \%$ para la condición húmeda, como se presenta en el punto 5.4. Debido a estas pequeñas variaciones encontradas, podemos validar que los ensayos realizados con las muestras obtenidas de campo (procesadas en la KMA220), bajo las condiciones descritas, guardan relación con las muestras realizadas en laboratorio.

Según el diseño de pavimentos flexibles AASTHO 93 para las condiciones del proyecto, como se muestra en la Tabla 7.6 para la misma conformación de pavimento (una (01) base/capa sin estabilizar de $15.00 \mathrm{~cm}$ y una (01) sub base de $15.00 \mathrm{~cm}$ ) se tiene un número estructural de 1.38; por lo tanto, el número estructural requerido de 1.75 no puede ser satisfecho y de esta manera se justifica el uso de la estabilización de una capa granular con asfalto espumado. De igual forma, si buscamos la conformación de un pavimento compuesta por 02 capas sin estabilizar que cumpla con el número estructural requerido, como se muestra en el punto 6.3 
(figura 6.15), obtenemos una configuración de una (01) sub base granular de $15.00 \mathrm{~cm}$ y una (01) base granular de $35.00 \mathrm{~cm}$. Una base granular con esta dimensión no es viable para un proyecto enmarcado en una conservación vial, tanto por dimensiones como por el costo adicional que implicaría.

Al analizar los 03 diseños de mezcla para la base estabilizada con asfalto espumado, seleccionados en el punto 5.3.4, como estructura de un pavimento junto a una (01) sub base granular de $15.00 \mathrm{~cm}$ y a un (01) micropavimento de $1.00 \mathrm{~cm}$, se logra satisfacer el número estructural requerido por el proyecto. Esto concuerda con la premisa propuesta en el punto 3.2 en el que se explica con mayor detalle que las gotas de asfalto, generados en la espumación, se mezclan entre los áridos rodeando los finos y actúan como conectores, haciendo que estos estén fuertemente ligados. Esto le proporciona una propiedad viscoelástica a la capa estabilizada, aportándole resistencia y durabilidad frente a las cargas dinámicas del tránsito. Finalmente, concluimos que el diseño óptimo de la capa estabilizada con asfalto espumada desde un punto de vista técnico-económico es el de $1.50 \%$ de asfalto inyectado y cemento asfáltico PEN 120/150. 


\subsection{Recomendaciones:}

Para analizar cómo se desempeña la estabilización con asfalto espumado en el tiempo se sugiere realizar, además de la evaluación funcional a través del IRI y la evaluación estructural a través de la deflectometría, ensayar núcleos representativos de la capa estabilizada.

Se recomienda evaluar el desempeño de la capa estabilizada y del pavimento considerando como variable el origen y el porcentaje de finos.

Es importante controlar la calidad de los procesos constructivos en las diferentes etapas de asfalto espumado, tanto en la espumación y mezcla, como en el colocado de la capa estabilizada.

Se recomienda analizar en qué medida impacta en la resistencia del pavimento la utilización de la KMA 220 o con una recicladora en frío, teniendo en cuenta que al utilizar la planta móvil se contará con un stock que está expuesto a las condiciones climáticas del proyecto. 


\section{REFERENCIAS}

- AASHTO. Guide For The Design Of Pavement Structures. American Association of State Highway and Transportation Officials Washington D.C., 1993.

- ATARAMA MONDRAGÓN, E. A. (2015). Evaluación de la transitabilidad para caminos de bajo tránsito estabilizados con aditivo PROES.

- BULL, A. (2003). Mejoramiento de la gestión vial con aportes específicos del sector privado. United Nations Publications.

- BULL, A. (2003). Un Nuevo Paradigma para la Conservación Vial de Hacer lo que se Puede, a Hacer lo que es Exigible. In División de Recursos Naturales e Infraestructura, CEPAL, Santiago, Chile, Primer congreso de fondos de conservación vial de Centroamérica.

- CAMACHO TUTA, J. F. (2016). Influencia de la velocidad en la medición de IRI con el equipo Perfilometro Laser.

- CORROS, M., URBAÉZ, E., \& CORREDOR, G. (2009). Manual de evaluación de pavimentos. Empresa MAYER, 97.

- DEL AGUILA RODRÍGUEZ, P. Experiencias y resultados obtenidos en la evaluación de la rugosidad de más de $3000 \mathrm{~km}$ de pavimentos en el Perú y otros países.

- DIARIO GESTION (2016). MTC priorizará pavimentación de 7,000 kilómetros de carreteras. Sitio web: http://gestion.pe/economia/mtc-priorizara-pavimentacion-7000-kilometros-carreteras-2169386

- ECHAVEGurEn, T., Civil, M. I., VARGAS, S., CONCHA, E., \& SOTO, A. (2003). Metodología de inspección visual para sistema de gestión de pavimentos urbanos Sigmap. Universidad de Concepción y Universidad Bio-Bio de Chile. Chile.

- EG-2013 Ministerio de Transportes y Comunicaciones del Perú. Especificaciones Técnicas Generales para Construcción de Carreteras. Capítulo 3 y 4. Diciembre de 2013. Lima - Perú.

- EM-2000 Ministerio de Transportes y Comunicaciones del Perú. Manual de Ensayos de Materiales para Carreteras. Volumen I. Agosto de 2003. Lima - Perú

- FAÚNDEZ CARVAJAL, R.A. (2011), Estimación del coeficiente estructural del asfalto espumado mediante el análisis de deflectometría (FWD). Departamento de Ingeniería Civil. Facultad de Ciencias Físicas y Matemáticas, Universidad de Chile. 2011. 
- GAMARRA, H., \& CATHERINE, J. (2015). Evaluación del sistema de gestión de pavimentos flexibles en el Perú.

- GUERRERO ABREGO, O. W., MARTÍNEZ RODRÍGUEZ, O. E., \& PORTILlO REVELO, J. M. (2014). Estabilización de material reciclado de carpeta asfáltica, utilizando asfalto espumado, mediante metodología Wirtgen, para ser empleado como base en pavimentos (Doctoral dissertation, Universidad de El Salvador).

- JENKINS, K. J. (2000). Mix design considerations for cold and half-warm bituminous mixes with emphasis of foamed bitumen (Doctoral dissertation, Stellenbosch: Stellenbosch University).

- MIQUEL, M. P. (2006). Análisis de Regularidad Superficial en caminos pavimentados.

- MONTOYA GOICOCHEA, J. E. (2007). Implementación del Sistema de Gestión de Pavimentos con Herramienta HDM-4 para la Red Vial Nro. 5 Tramo Ancón-HuachoPativilca.

- MONTOYA GOICOCHEA, J. E. (2014). Análisis del IRI para un proyecto de carretera sinuosa concesionada en el Perú.

- New Zealand Supplement to the Document, Pavement Design- A guide to the Structural Design of Road Pavements AUSTROADS, New Zealand, 2004.

- OBANDO, P. N. M., GÓMEZ, M. G. E., ARIZTÍA, F. E. D., \& MURUA, R. A. S. (2008). Definición de un índice de rugosidad intensivo de pavimentos orientado a mantenimiento.

- OBANDO, W. (2014). La conservación vial por niveles de servicio. Obtenido de https://www.academia.edu/6288437/LA_CONSERVACI\%C3\%93N_VIAL_PO R_NIVELES_DE_SERVICIO

- OROZCO Y OROZCO, J. M., TELLEZ GUTIERREZ, R., SOLORIO MURILLO, R., PEREZ SALAZAR, A., SANCHEZ LOO, M. A., \& TORRAS ORTIZ, S. (2004). Sistema de evaluacion de pavimentos: version 2.0.publicacion tecnica, (245).

- O'SUlliVAN, B. (2001). Is this the future? International Construction, 40(7), 15.

- PROVIAS NACIONAL. (2014). Programa de infraestructura vial proyecto Perú. Jueves 01 de Setiembre de 2016, de Ministerio de Transporte y Comunicaciones Sitio web: http://www.proviasnac.gob.pe/frmConservacion.aspx?idMenu=646 
- PETICILÃ, M., PHD, CAZACLIU, B., PHD., \& ROMANESCU, C., PHD. (2011). The structure foamed bitumen mixture and effect of process parameters on production. Bucharest: Technical University of Civil Engineering from Bucharest.

- REDDY, M. A., REDDY, K. S., \& PANDEY, B. B. (2014). EVALUATION OF REHABILITATED urban recycled asphalt pavement. Road Materials and Pavement Design, 15(2), 434-445.

- ROCO V., FUENTES C. \& VALVERDE S. (2002). Evaluación de la Resistencia al deslizamiento en Pavimentos Chilenos. In Proc VI Congreso Internacional PROVIAL, Chile.

- ROMANOSCHI S.A., HOSSAIN M., MICHAEL HEITZMAN M., GISI A.J. (2003) Foamed Asphalt Stabilized Base in Reclaimed Asphalt Pavement: A Promising Technology for Midwestern Roads. Mid-Continent Transportation Research Symposium, Ames, IA, August, 2003.

- RONDON A., REYES F.: Comportamiento Resiliente De Materiales Granulares En Pavimentos Flexibles: Estado Del Conocimiento. Revista de Ingenierías Universidad de Medellín, JulioDiciembre, año/vol. 6, número 011, Medellín, Colombia.[s.a.]

- RONDÓN QUINTANA, H., \& REYES LIZCANO, F. (2015). Metodologías de diseño de pavimentos flexibles: Tendencias, alcances y limitaciones. Ciencia E IngenieríA Neogranadina, 17(2), 41-65.

- SCHLIESSLER, A. (1992). Caminos: un nuevo enfoque para la gestión y conservación de redes viales.

- THENOUX, G. J., \& JAMET, A. (2002). A. “Tecnología del asfalto espumado y diseño de mezcla”. Revista Ingeniería de Construcción Pontificia Universidad Católica de Chile, (en imprenta), Santiago, Chile.

- THENOUX ZEBALLOS, G. A. (2002). Tecnología del asfalto espumado= Foamed asphalt technology.

- THENOUX ZEBALLOS, G. A. (2003). Aspectos constructivos del primer proyecto de reciclado en frío in-situ con asfalto espumado en Chile $=$ Constructive aspects of the first in place recycling project using foamed bitumen.

- Wirtgen GmbH. Manual de Reciclado en Frío. 2004. Windhagen - Alemania. 


\section{ANEXOS}

ANEXO 1: Características geotécnicas de los suelos

Anexo 1.1: Ensayo de análisis granulométrico de la sub rasante, Calicata C-01 (Km 174+000)

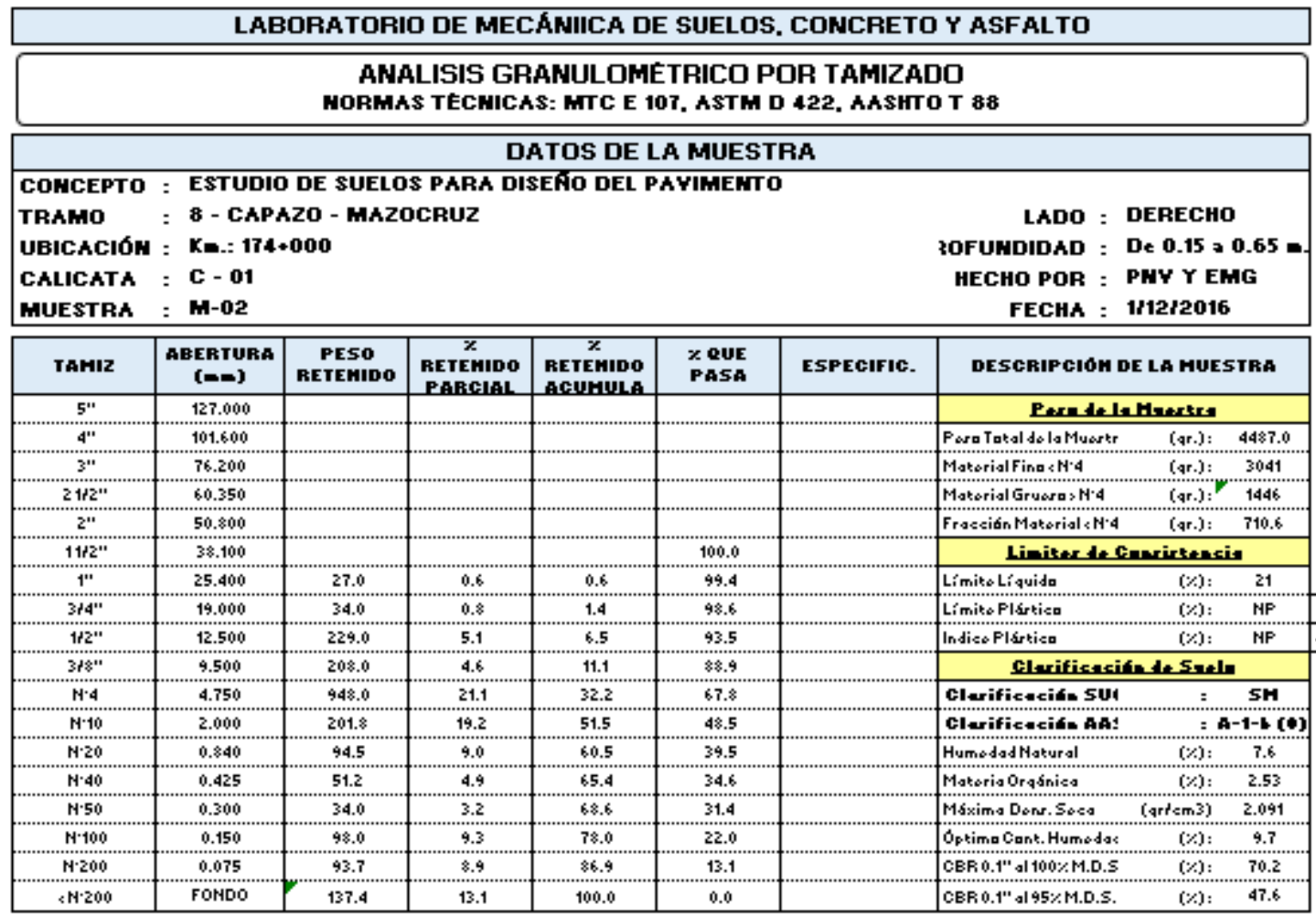

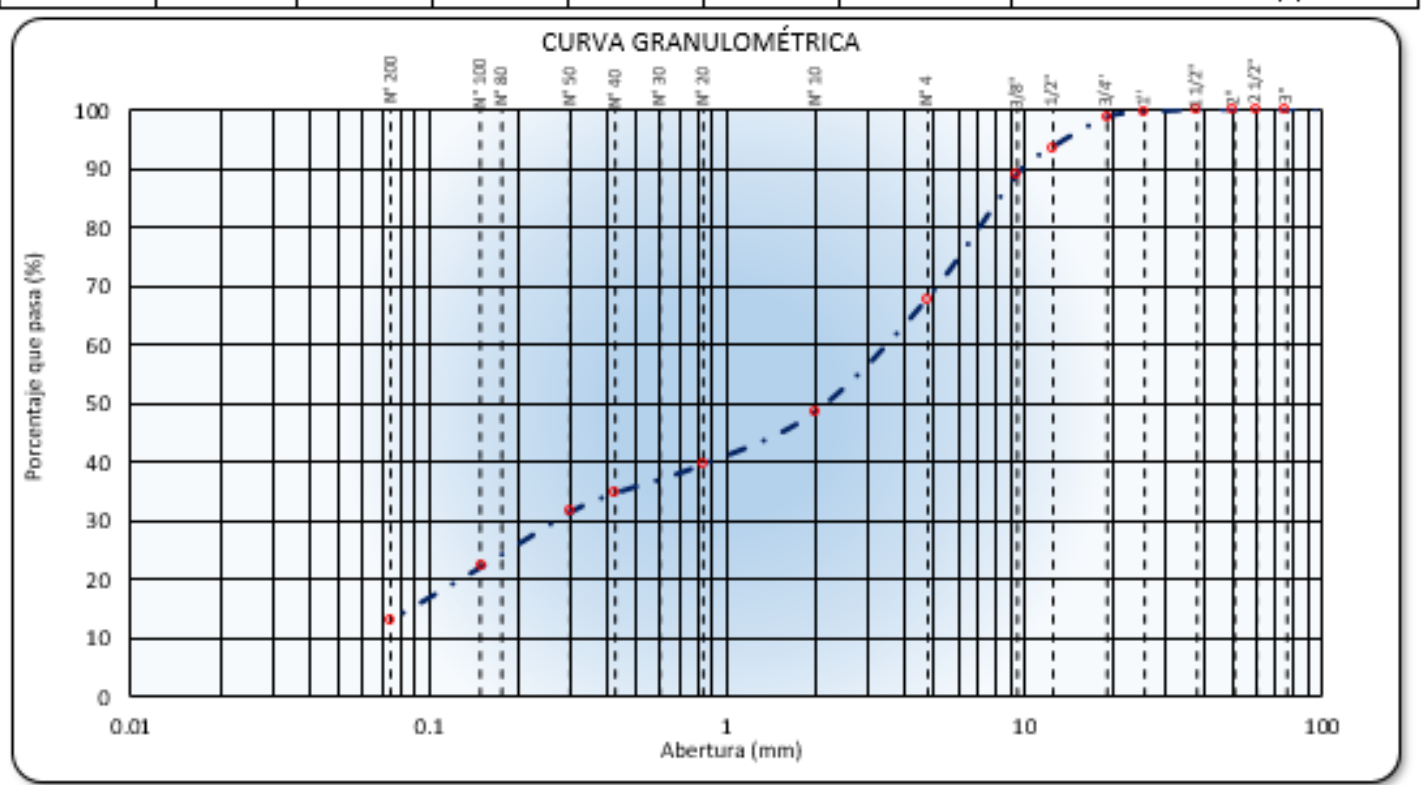


Anexo 1.2: Determinación de humedad natural de la sub rasante, Calicata C-01 (Km 174+000)

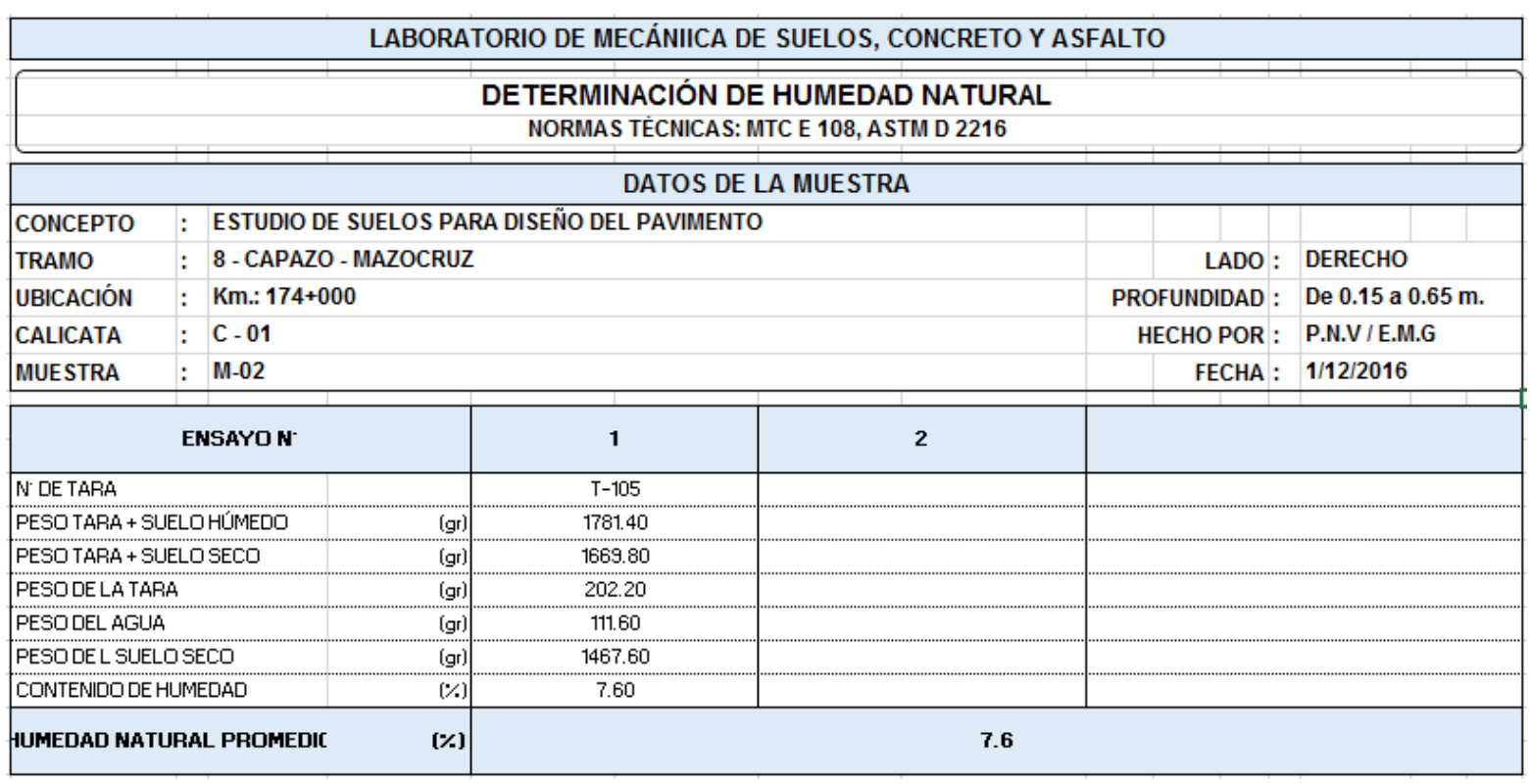

Anexo 1.3: Contenido de materia orgánica de la sub rasante, Calicata C-01 (Km 174+000)

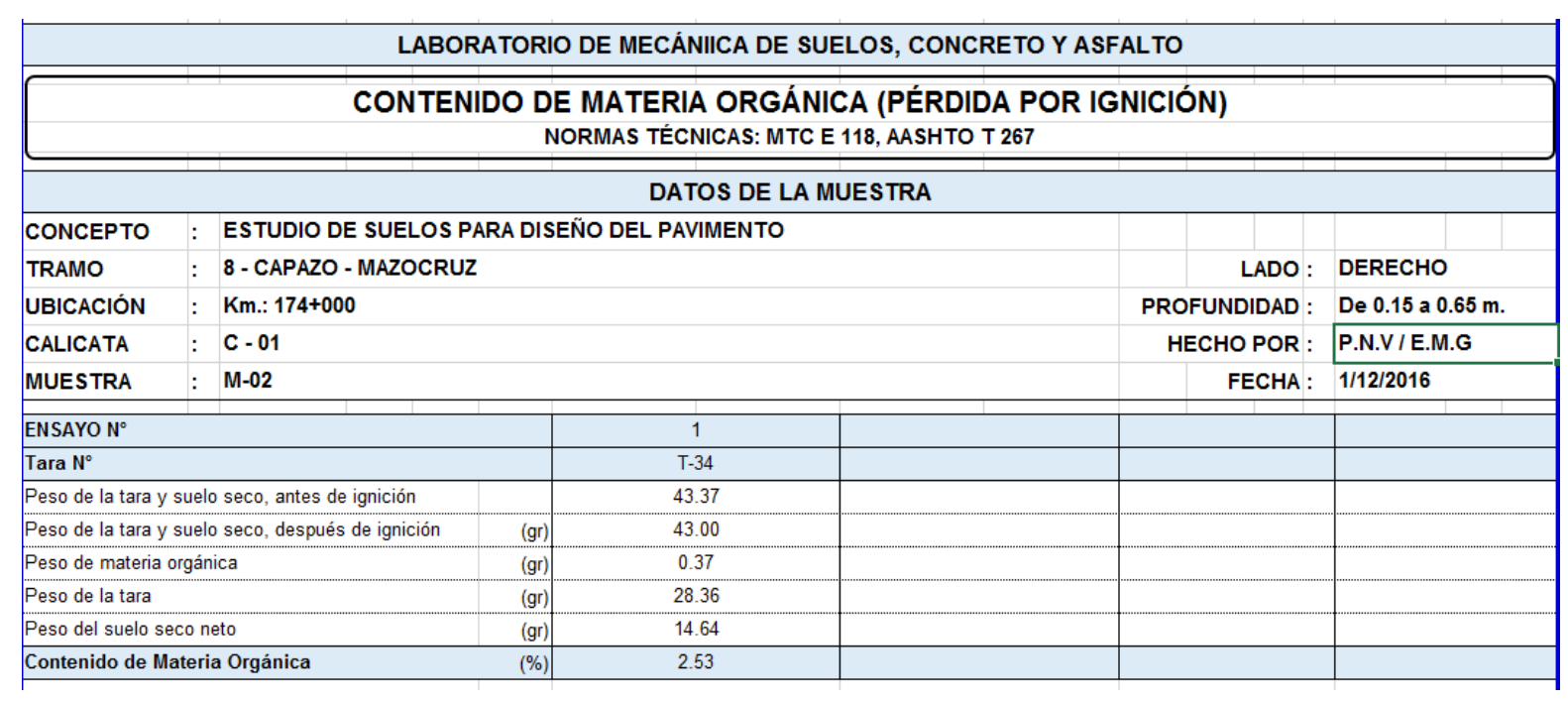


Anexo 1.4: Límites de consistencia de la sub rasante, Calicata C-01 (Km 174+000)

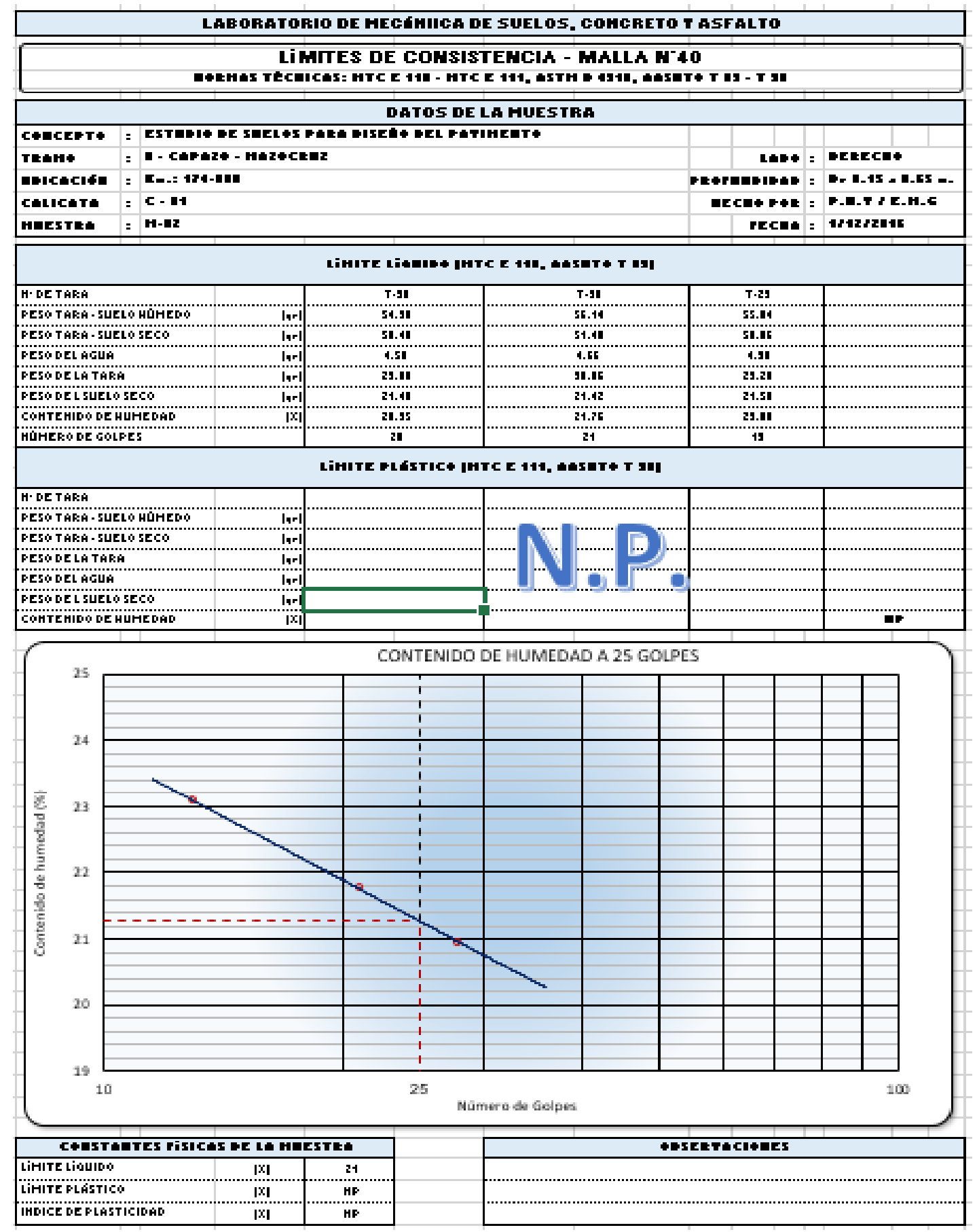


Anexo 1.5: Densidad máxima y humedad óptima de la sub rasante, Calicata C-01 (Km 174+000)

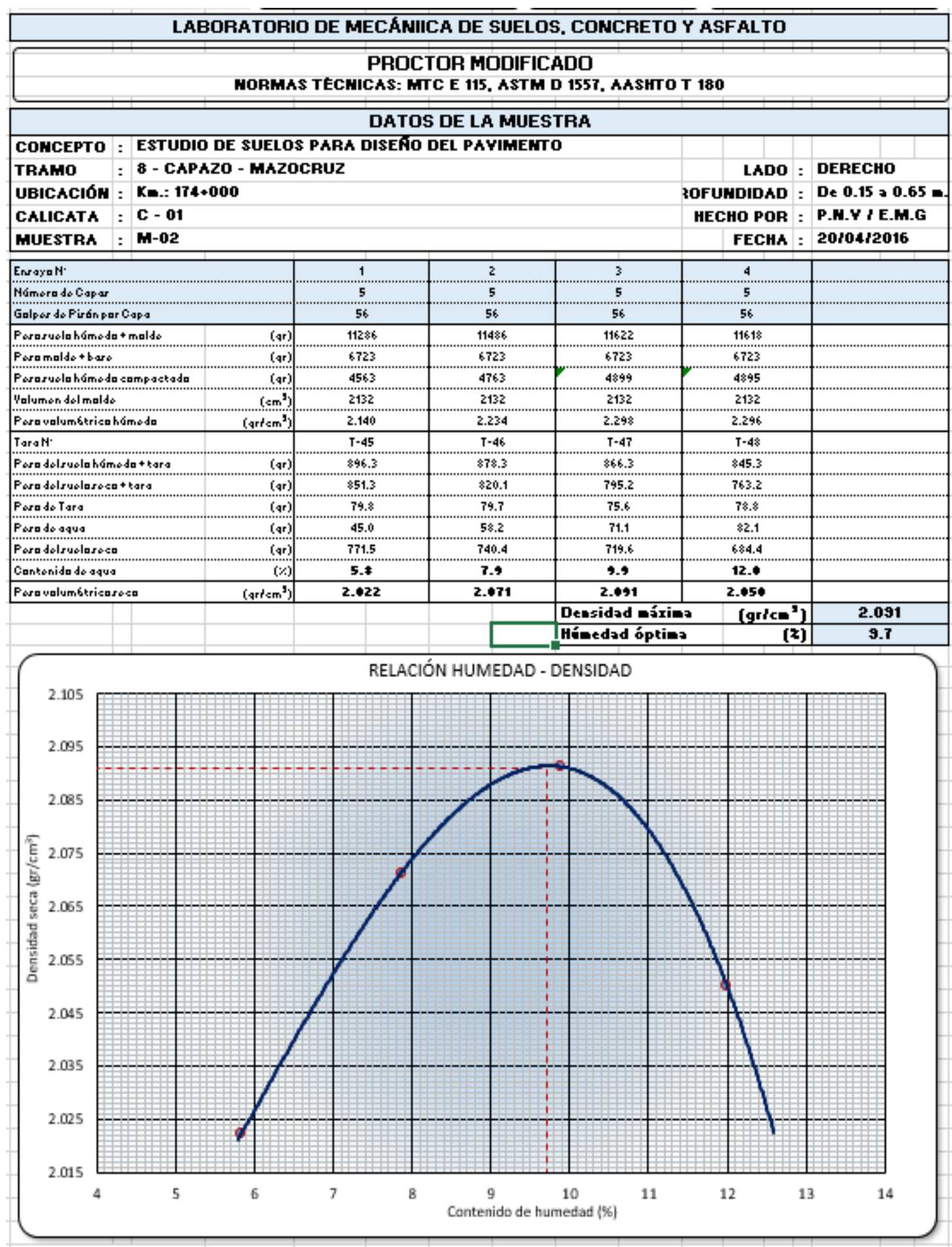


Anexo 1.6: CBR de la sub rasante, Calicata C-01 (Km 174+000)

\begin{tabular}{|c|c|c|c|c|c|c|c|c|}
\hline \multicolumn{9}{|c|}{ LABORA TORIO DE MECANHCA DE SUELOS, CONCRETO Y ASF ALTO } \\
\hline \multicolumn{9}{|c|}{ RELACION SOPORTE DE CALIFORNIA (C.B.R.) } \\
\hline \multicolumn{9}{|c|}{ HORHAS TECHICAS: MTC E 132. ASTM D 1883. AASHTO T 193} \\
\hline \multicolumn{9}{|c|}{ DATOS DE LA MUESTRA } \\
\hline COHCEPTO & \multicolumn{6}{|c|}{ ESTUDIO DE SUELOS PARA DISEFO DEL PAYIMEKTO } & & \\
\hline TRAMO & \multicolumn{6}{|c|}{ 8 - CAPAZO - HAZOCRUZ } & LADO & \multirow{3}{*}{$\begin{array}{l}\text { : DERECHO } \\
\text { : De 0.15 a } 0.65= \\
\text { : P.H.Y / E.H.G }\end{array}$} \\
\hline UBICACı́́N & \multicolumn{6}{|c|}{$K=.: 174 * 000$} & :OFUHDIDAD & \\
\hline CALICATA & \multicolumn{4}{|l|}{ C - 01} & & & HECHO POR & \\
\hline MUESTRA & \multicolumn{4}{|l|}{ M-02 } & & & FECHA & $: 20104 / 2016$ \\
\hline \multicolumn{9}{|c|}{ COMPACTACIOH } \\
\hline MaldoN & & & \multicolumn{2}{|c|}{22} & \multicolumn{2}{|c|}{23} & \multicolumn{2}{|r|}{24} \\
\hline N.Capar & & & \multicolumn{2}{|c|}{5} & \multicolumn{2}{|c|}{5} & \multicolumn{2}{|r|}{5} \\
\hline \multicolumn{3}{|l|}{ N. qolpes par eapas } & \multicolumn{2}{|c|}{56} & \multicolumn{2}{|c|}{25} & \multicolumn{2}{|r|}{12} \\
\hline \multicolumn{3}{|c|}{ Candisián de la muartra } & MOSATURADO & SATURADO & MOSATURADO & SATURADO & MOSATURADO & SATURADO \\
\hline \multicolumn{2}{|c|}{ Fora de malde + Suela hómeda } & $(a r)$ & 13408 & & 13196 & & 12896 & \\
\hline \multicolumn{2}{|c|}{ Porademalde+bare } & $(a r)$ & 8530 & & 8500 & & 8444 & \\
\hline \multicolumn{2}{|c|}{ Fora delruela hómeda } & $(a r)$ & $4 \$ 78$ & & 4696 & & 4452 & \\
\hline \multicolumn{2}{|l|}{ Valumen del malde } & $\left(\mathrm{cm}^{3}\right)$ & 2124 & & 2132 & & 2122 & \\
\hline \multicolumn{2}{|l|}{ Denridadhámeda } & $\left(a r t=m^{3}\right)$ & 2.247 & & 2.203 & & 2.098 & 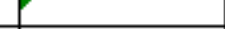 \\
\hline \multicolumn{2}{|l|}{ H.Tara } & & $T-54$ & & $T-55$ & & $T-56$ & \\
\hline \multicolumn{2}{|c|}{ Foraruelahómeda +tara } & $(a r)$ & 655.2 & & 675.3 & & 586.3 & \\
\hline Foraruelaresatt & sara & $(a r)$ & 604.0 & & 622.0 & & 541.6 & \\
\hline Pora détara & & $(q r)$ & 79.2 & & 79.6 & & 79.9 & \\
\hline Faradesqua & & (ar) & 51.2 & & 53.3 & & 44.7 & \\
\hline Pora desuelaresa & & $(a r)$ & 524.8 & & 542.4 & & 461.7 & \\
\hline Cantenida de hume & adad & $(\%)$ & 9.8 & & 9.8 & & 9.7 & L \\
\hline Denridadresa & & $\left(a r t=m^{2}\right)$ & 2.092 & & 2.006 & & 1.913 & \\
\hline
\end{tabular}

\begin{tabular}{|c|c|c|c|c|c|c|c|c|c|c|c|}
\hline \multicolumn{12}{|c|}{ EXPANSIOH } \\
\hline \multirow{2}{*}{ FECHA } & \multirow{2}{*}{ HORA } & \multirow{2}{*}{ TIENP } & \multirow{2}{*}{ DIAL } & \multicolumn{2}{|c|}{ EXPANSIOH } & \multirow{2}{*}{ DIAL } & \multicolumn{2}{|c|}{ ExPAHSIOH } & \multirow{2}{*}{ DIAL } & \multicolumn{2}{|c|}{ EXPAHSIOH } \\
\hline & & & & $=$ & $x$ & & - & x & & $\Rightarrow$ & $x$ \\
\hline & & & & & & & & & & & \\
\hline & & & & & & & & & & & \\
\hline & & & & & & & & & & & \\
\hline & & & & & & & & & & & \\
\hline & & & & & & & & & & & \\
\hline
\end{tabular}

\begin{tabular}{|c|c|c|c|c|c|c|c|c|c|c|c|c|c|}
\hline \multicolumn{14}{|c|}{ PENETRACION } \\
\hline \multirow{3}{*}{$\begin{array}{l}\text { PEHETRACIOH } \\
\qquad-\infty)\end{array}$} & \multirow{3}{*}{$\begin{array}{l}\text { CARGA } \\
\text { ESÍ́ndAB } \\
\text { (K+tC-2) }\end{array}$} & \multicolumn{4}{|c|}{ HOLDE H-22 } & \multicolumn{4}{|c|}{ HOLDE H 23} & \multicolumn{4}{|c|}{ HOLDE H-24 } \\
\hline & & \multicolumn{2}{|c|}{ CARGA } & \multicolumn{2}{|c|}{ CORRECCIÓn } & \multicolumn{2}{|c|}{ CAREA } & \multicolumn{2}{|c|}{ CORRECGIÓn } & \multicolumn{2}{|c|}{ CARGA } & \multicolumn{2}{|c|}{ CORRECCIÓn } \\
\hline & & iel (Ai) & kv & kt & $x$ & iel (di) & kt & kt & $x$ & Diel ctio) & kt & kt & x \\
\hline 0.000 & & & 0 & & & & 0 & & & & 0 & & \\
\hline 0.635 & & & 142 & & & & 122 & & & & 105 & & \\
\hline 1.270 & & & 401 & & & & 301 & & & & 201 & & \\
\hline 1.905 & & & 732 & & & & 501 & & & & 324 & & \\
\hline 2.540 & 70.5 & & 1022 & 967.5 & 70.5 & & 756 & 709.4 & 51.7 & & 456 & $43 \% 3$ & 31.4 \\
\hline 3.810 & & & 1502 & & & & 1132 & & & & 654 & & \\
\hline 5.080 & 105.7 & & 2032 & 2012.5 & 47.8 & & 1566 & 1568.6 & 76.2 & & 986 & 963.3 & 46.8 \\
\hline 6.350 & & & $23 \% 8$ & & & & 1966 & & & & 1249 & & \\
\hline 7.620 & & & 2763 & & & & 2345 & & & & 1546 & & \\
\hline 10.160 & & & 3454 & & & & 2986 & & & & 1984 & & \\
\hline 12.700 & & & 3988 & & & & 3345 & & & & 2258 & & \\
\hline
\end{tabular}




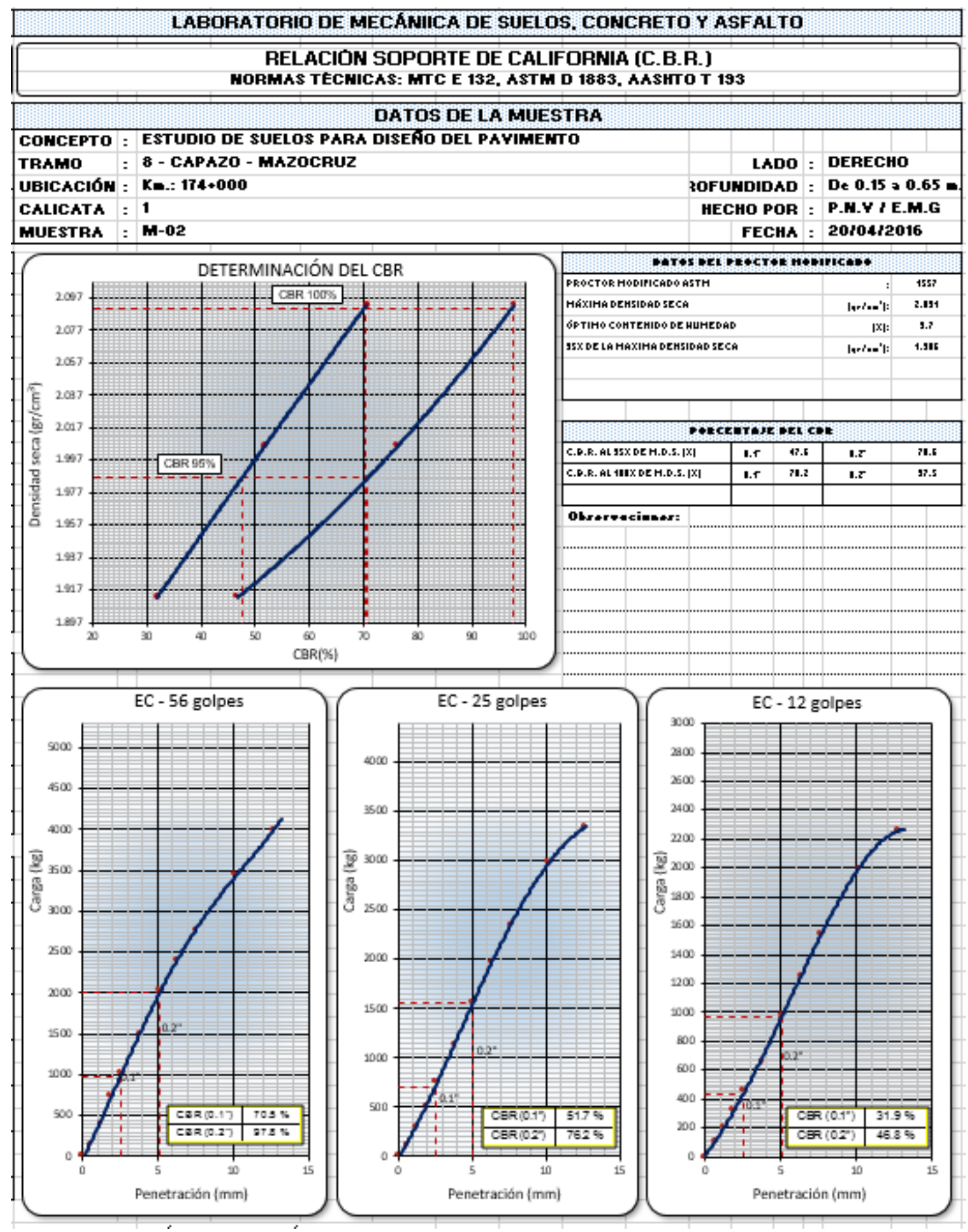


Anexo 1.7: Valores de CBR en cada progresiva y método de las diferencias acumuladas

\begin{tabular}{|c|c|c|c|c|c|c|c|c|c|}
\hline Progresiva & CBR (\%) & \# Intervalo & $\begin{array}{l}\text { Dist. Entre } \\
\text { intervalo }\end{array}$ & $\begin{array}{l}\text { Dist. Acumulada } \\
\text { entre intervalos }\end{array}$ & $\begin{array}{l}\text { Intervalo } \\
\text { promedio }\end{array}$ & $\begin{array}{l}\text { Área del } \\
\text { intervalo }\end{array}$ & $\begin{array}{c}\text { Área } \\
\text { acumulada }\end{array}$ & $Z x$ & $\begin{array}{c}\text { Sub Tramos } \\
\text { CBR prom. } \\
(\%)\end{array}$ \\
\hline $174+000$ & 49.35 & 1 & 2000 & 2000 & 49.4 & 98700 & 98700 & 24961.42 & \multirow{5}{*}{42.8} \\
\hline $176+000$ & 37 & 2 & 2000 & 4000 & 43.175 & 86350 & 185050 & 37572.85 & \\
\hline $178+000$ & 40.35 & 3 & 2000 & 6000 & 38.675 & 77350 & 262400 & 41184.27 & \\
\hline $180+000$ & 37.8 & 4 & 2000 & 8000 & 39.075 & 78150 & 340550 & 45595.69 & \\
\hline $182+000$ & 49.45 & 5 & 2000 & 10000 & 43.625 & 87250 & 427800 & 59107.12 & \\
\hline $184+000$ & 23.3 & 6 & 2000 & 12000 & 36.375 & 72750 & 500550 & 58118.54 & \multirow{4}{*}{29.8} \\
\hline $186+000$ & 31.35 & 7 & 2000 & 14000 & 27.325 & 54650 & 555200 & 39029.96 & \\
\hline $188+000$ & 27.35 & 8 & 2000 & 16000 & 29.35 & 58700 & 613900 & 23991.39 & \\
\hline $190+000$ & 37.15 & 9 & 2000 & 18000 & 32.25 & 64500 & 678400 & 14752.81 & \\
\hline $192+000$ & 43.7 & 10 & 2000 & 20000 & 40.425 & 80850 & 759250 & 21864.23 & \multirow{7}{*}{42.1} \\
\hline $194+000$ & 49.65 & 11 & 2000 & 22000 & 46.675 & 93350 & 852600 & 41475.66 & \\
\hline $196+000$ & 34.65 & 12 & 2000 & 24000 & 42.15 & 84300 & 936900 & 52037.08 & \\
\hline $198+000$ & 52.05 & 13 & 2000 & 26000 & 43.35 & 86700 & 1023600 & 64998.50 & \\
\hline $200+000$ & 40.3 & 14 & 2000 & 28000 & 46.175 & 92350 & 1115950 & 83609.93 & \\
\hline $202+000$ & 43.2 & 15 & 2000 & 30000 & 41.75 & 83500 & 1199450 & 93371.35 & \\
\hline $204+000$ & 31.1 & 16 & 2000 & 32000 & 37.15 & 74300 & 1273750 & 93932.77154 & \\
\hline $206+000$ & 27 & 17 & 2000 & 34000 & 29.05 & 58100 & 1331850 & 78294.19 & \multirow{7}{*}{27.7} \\
\hline $208+000$ & 36.65 & 18 & 2000 & 36000 & 31.825 & 63650 & 1395500 & 68205.62 & \\
\hline $210+000$ & 31 & 19 & 2000 & 38000 & 33.825 & 67650 & 1463150 & 62117.04 & \\
\hline $212+000$ & 25.6 & 20 & 2000 & 40000 & 28.3 & 56600 & 1519750 & 44978.46 & \\
\hline $214+000$ & 22.35 & 21 & 2000 & 42000 & 23.975 & 47950 & 1567700 & 19189.89 & \\
\hline $216+000$ & 28.6 & 22 & 2000 & 44000 & 25.475 & 50950 & 1618650 & -3598.69 & \\
\hline $218+000$ & 22.75 & 23 & 2000 & 46000 & 25.675 & 51350 & 1670000 & -25987.27 & \\
\hline $220+000$ & 44.3 & 24 & 2000 & 48000 & 33.525 & 67050 & 1737050 & -32675.84 & \multirow{4}{*}{43.4} \\
\hline $222+000$ & 52.7 & 25 & 2000 & 50000 & 48.5 & 97000 & 1834050 & -9414.42 & \\
\hline $224+000$ & 28.45 & 26 & 2000 & 52000 & 40.575 & 81150 & 1915200 & -2003.00 & \\
\hline $226+000$ & 48.15 & 27 & 1400 & 53400 & 38.3 & 53620 & 1968820 & 0.00 & \\
\hline \multirow[t]{3}{*}{$227+400$} & & & & & & At & 1968820 & & \\
\hline & & & & & & Lp & 53400 & & \\
\hline & & & & & & $F$ & 36.869288 & & \\
\hline
\end{tabular}

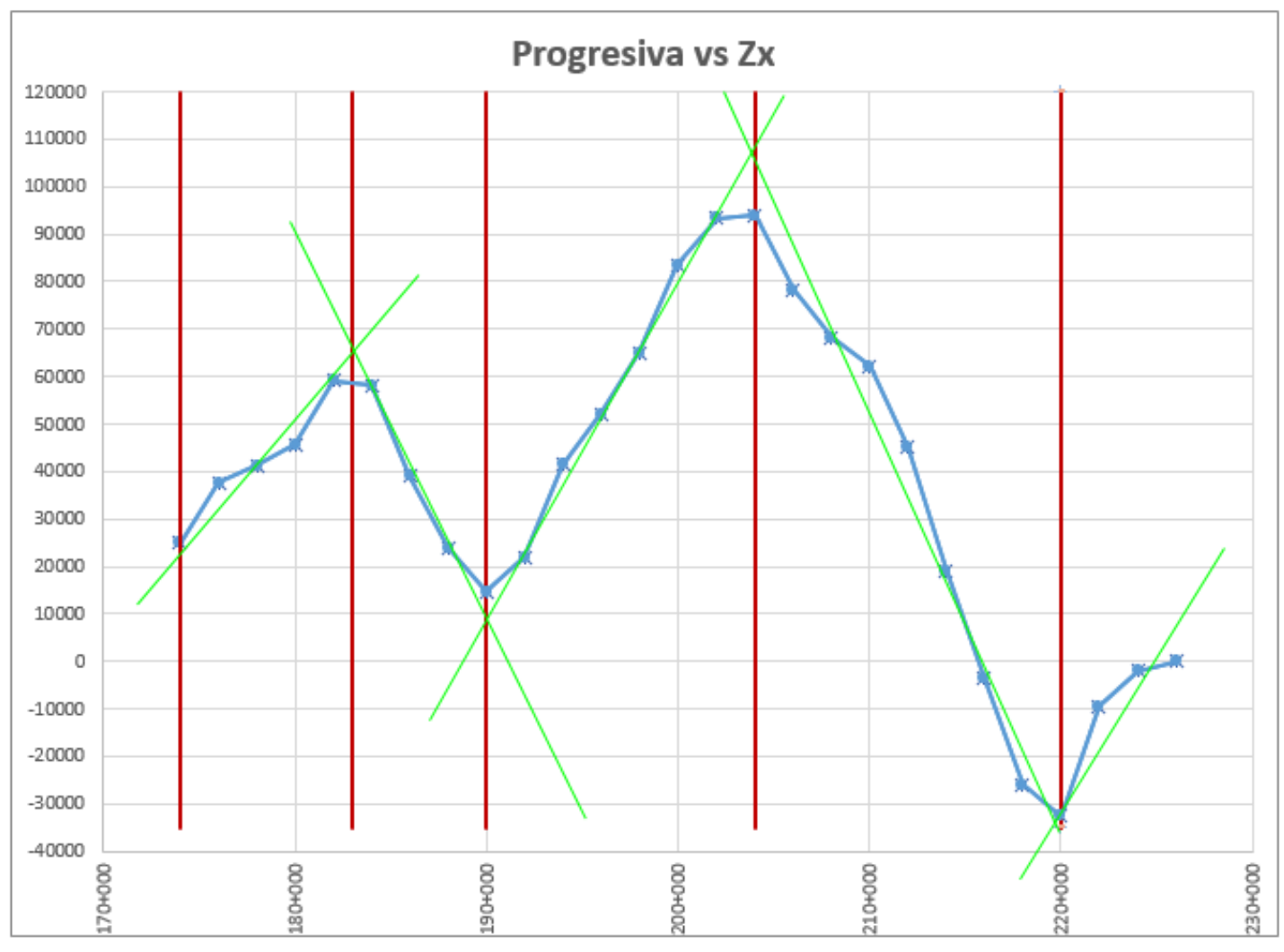




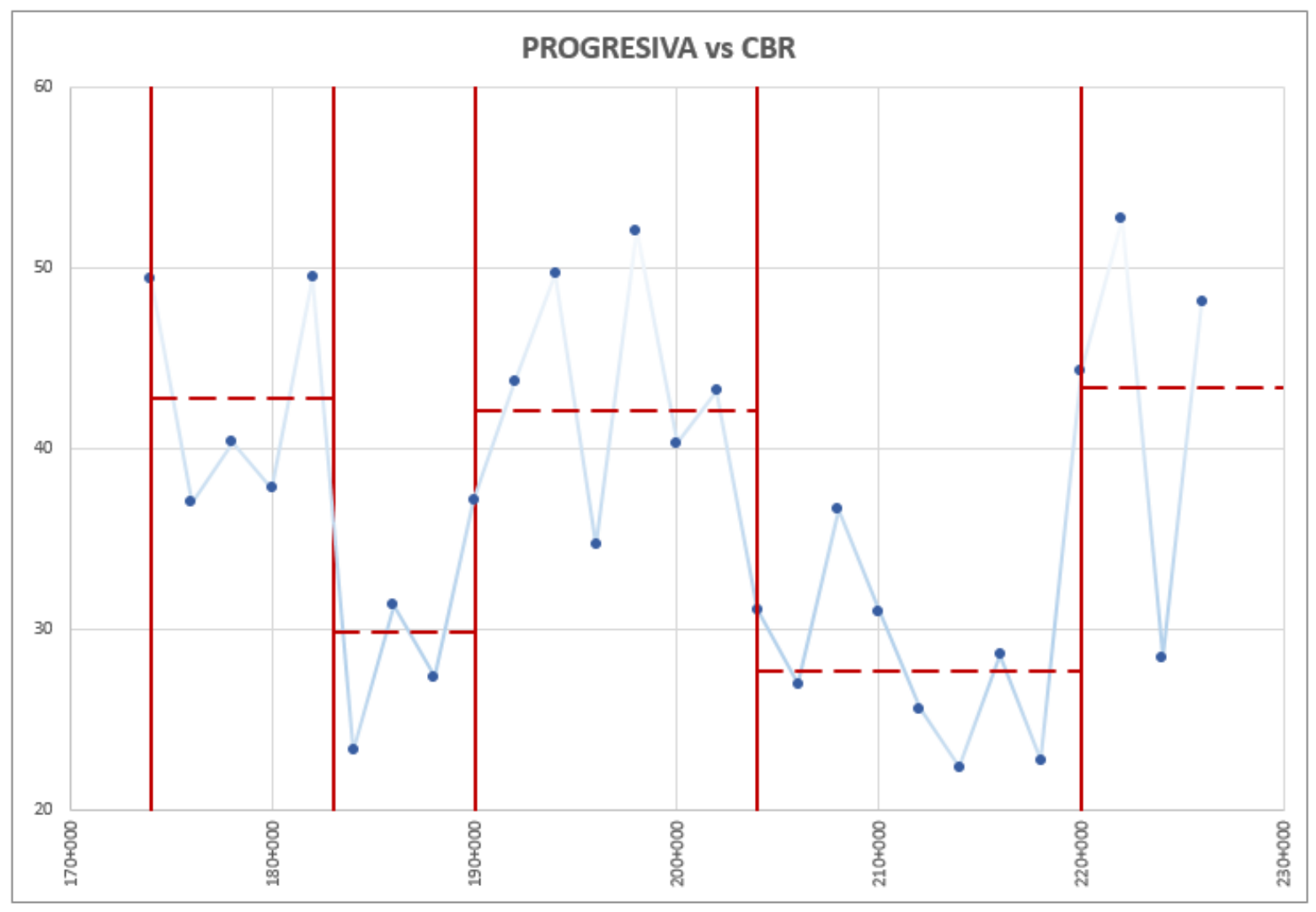

129 
Anexo 1.8: Tramos homogéneos y valores de CBR por tramo

\begin{tabular}{|c|c|c|c|}
\hline \multicolumn{2}{|c|}{ Sectores } & $\begin{array}{c}\text { CBR (\%) } \\
\text { Sectores }\end{array}$ & Sub Tramos \\
\hline $174+000$ & $184+000$ & 42.79 & Sub tramo Homogéneo 1 \\
\hline $184+000$ & $192+000$ & 29.79 & Sub tramo Homogéneo 2 \\
\hline $192+000$ & $208+000$ & 42.09 & Sub tramo Homogéneo 1 \\
\hline $208+000$ & $218+000$ & 27.71 & Sub tramo Homogéneo 2 \\
\hline $218+000$ & $226+000$ & 43.40 & Sub tramo Homogéneo 1 \\
\hline
\end{tabular}


Anexo 1.9: Características de la Cantera Mazocruz Km 225+650

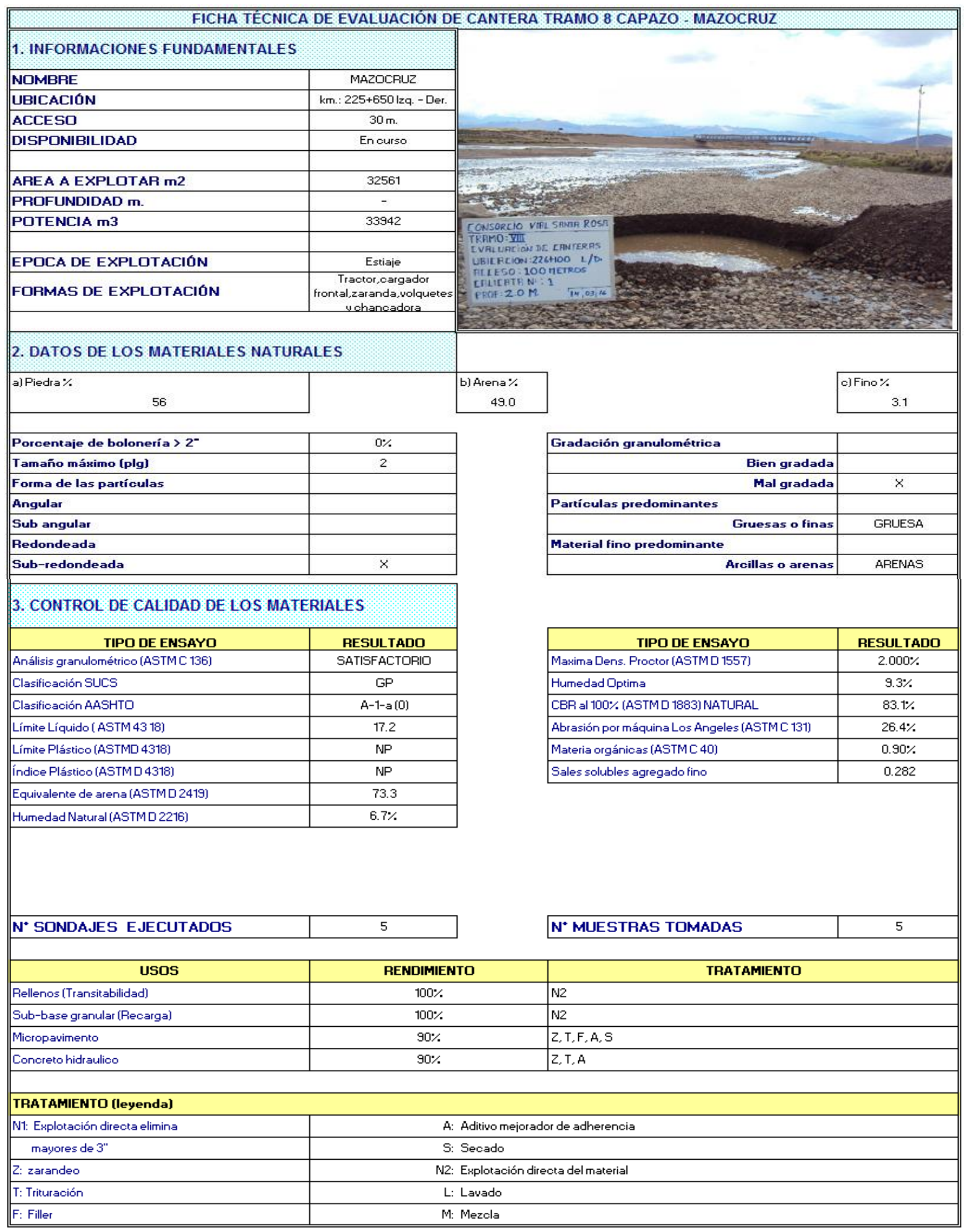




\begin{tabular}{|c|c|c|c|c|c|c|c|c|c|c|c|c|c|c|c|}
\hline \multicolumn{2}{|c|}{ 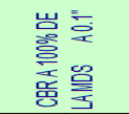 } & $\approx$ & ஐ & 局 & & r. & $m$ & $\bar{\infty}$ & ฐ & ฐี & 䂴 & 웅 & $=$ & 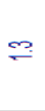 & : \\
\hline \multirow{2}{*}{$\begin{array}{l}\text { 訔 } \\
\text { 言畹 }\end{array}$} & $\begin{array}{l}\text { se } \\
\text { 홈 }\end{array}$ & 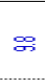 & $\bar{\sigma}$ & $\infty$ & . & . & $m$ & 8 & $\infty$ & $\infty$ & : & $\stackrel{\infty}{0}$ & $\bar{\sigma}$ & कs & \multirow{2}{*}{ : } \\
\hline & 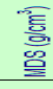 & 喛 & $\approx$ & $\approx$ & . & . & $\infty$ & ㄱ. & శి & ని & : & 8 & 8 & 8 & \\
\hline \multirow{2}{*}{ 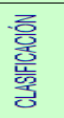 } & 울 & $\frac{\bar{p}}{\frac{7}{\dot{x}}}$ & $\frac{\bar{\sigma}}{\frac{p}{\dot{s}}}$ & $\frac{\bar{p}}{\bar{p}}$ & $\frac{\bar{p}}{\dot{p}}$ & $\frac{\overline{\frac{p}{p}}}{\dot{i}}$ & 0 & $\frac{\bar{\sigma}}{\frac{\bar{z}}{\dot{x}}}$ & ' & : & : & ' & ' & ' & \multirow[t]{2}{*}{ : } \\
\hline & 㧝 & 용 & 总 & 总 & 总 & 용 & 0 & 웅 & ! & : & : & ; & : & : & \\
\hline \multirow[t]{2}{*}{ 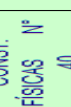 } & $\simeq$ & 9 & $\cong$ & $\because$ & 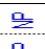 & $\cong$ & 0 & $\underline{z}$ & 8 & 8 & $\because$ & 1 & 1 & $!$ & 1 \\
\hline & ज & $=$ & $=$ & $=$ & 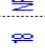 & $\begin{array}{l}2 \\
\infty\end{array}$ & W & $\cong$ & 을 & के & : & $=$ & $=$ & 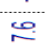 & : \\
\hline 峑 & 硠 & 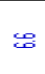 & 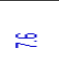 & 8 & $\cong$ & $\widetilde{\sigma}$ & is & $\overline{5}$ & 8 & $\stackrel{\circ}{=}$ & : & 8 & s & 8 & : \\
\hline \multicolumn{2}{|c|}{ 於区 } & $\mathscr{8}$ & $\vec{\omega}$ & 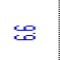 & 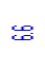 & $\stackrel{2}{2}$ & هـ & 8 & $\therefore$ & $=$ & : & 용 & 8 & $\infty$ & : \\
\hline \multirow{16}{*}{ 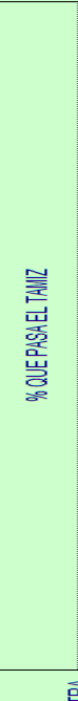 } & 离 & $\bar{\sim}$ & $\approx$ & e & 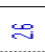 & $\Rightarrow$ & s & \& & $\bar{\sim}$ & $\bar{F}$ & : & 응 & $=$ & 象 & \multirow{16}{*}{$\begin{array}{l}\text { 訔 } \\
\text { 淁 }\end{array}$} \\
\hline & 흘 & $\approx$ & 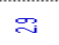 & $\overline{E s}$ & $\approx$ & $\mathbb{8}$ & Co & 8 & D & $\infty$ & : & 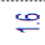 & $\vec{\sim}$ & 总 & \\
\hline & 啹 & $\bar{\infty}$ & $\infty$ & $\Xi$ & $\risingdotseq$ & $\stackrel{\rho}{\mathrm{m}}$ & 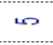 & $\stackrel{\circ}{\circ}$ & $\infty$ & के & : & $\approx$ & $\approx$ & בे & \\
\hline & $\mathrm{e}$ & $\Xi$ & $\cong$ & $\Xi$ & $\vec{E}$ & $\Phi$ & $\infty$ & $\stackrel{\infty}{=}$ & $\stackrel{\infty}{=}$ & 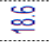 & : & $\approx$ & 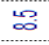 & $\bar{\rho}$ & \\
\hline & ฐ & 루 & $\bar{s}$ & 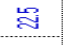 & สี & $\tilde{\Xi}$ & $\infty$ & $\overline{8}$ & 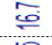 & $\tilde{\mathbb{E}}$ & $:$ & $\bar{\infty}$ & $\stackrel{8}{\infty}$ & $\stackrel{?}{=}$ & \\
\hline & $\stackrel{3}{2}$ & 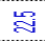 & $\bar{\Xi}$ & 票 & है & $\overline{\text { के }}$ & is & వ̊త్ & జี & $\overline{\sigma^{3}}$ & : & $\bar{\sigma}$ & $\ddot{8}$ & ळ & \\
\hline & $\vec{z}$ & 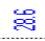 & $\stackrel{\infty}{0}$ & g & 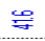 & 掌 & is & 옹 & 满 & 9 & : & $\approx$ & $\approx$ & $\Phi$ & \\
\hline & ळ & 룽 & $\bar{\exists}$ & $\widetilde{8}$ & 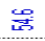 & $\vec{E}$ & 10 & \& & 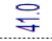 & E & $:$ & $\approx$ & $\Xi$ & $\stackrel{p}{=}$ & \\
\hline & $\triangleq$ & 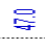 & 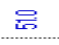 & $\$$ & $\ddot{z}$ & $\approx$ & $\infty$ & 용 & $\cong$ & $\approx$ & : & $?$ & $\overline{9}$ & $\Xi$ & \\
\hline & w & $\overline{8}$ & $\tilde{8}$ & $\approx$ & 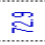 & 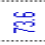 & $\infty$ & 总 & $\overline{8}$ & $\ddot{m}$ & : & 8 & $\bar{\nabla}$ & 2 & \\
\hline & $=$ & 8 & $\approx$ & $\overrightarrow{\mathbf{x}}$ & 竦 & 욣 & 10 & 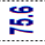 & 8 & के & : & $\vec{\sigma}$ & $\bar{E}$ & 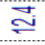 & \\
\hline & $\cong$ & 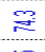 & $\vec{z}$ & $\overline{85}$ & 8 & 8 & $\infty$ & 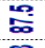 & $?$ & $\overline{8}$ & : & $\infty$ & 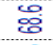 & 8 & \\
\hline & $\approx$ & $\ddot{8}$ & $\bar{\Xi}$ & $\$$ & $\overline{\$}$ & 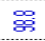 & $\infty$ & : & $\overline{8}$ & $\ddot{8}$ & : & $\bar{m}$ & $\stackrel{\infty}{\stackrel{2}{2}}$ & $\stackrel{\infty}{\infty}$ & \\
\hline & $\cong$ & 을 & 를 & ह & 을 & 을 & $\infty$ & 흘 & 8 & 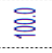 & $:$ & 8 & 8 & 8 & \\
\hline & m & 을 & @ & 을 & 을 & 을 & $\omega$ & 亏े & हे & ङ & : & 8 & 8 & 8 & \\
\hline & $\Rightarrow$ & 흘 & 흘 & 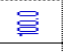 & 을 & 을 & $\infty$ & 흘 & 를 & ஓ & : & 8 & 8 & 8 & \\
\hline \multicolumn{2}{|c|}{ 蒿 } & $\bar{\Sigma}$ & $\Sigma$ & $\bar{\Sigma}$ & $\Sigma$ & $\Sigma$ & \multirow{6}{*}{$=$} & \multirow{6}{*}{$\approx$} & \multirow{6}{*}{ 즐 } & \multirow{6}{*}{ 줄 } & \multirow{6}{*}{ 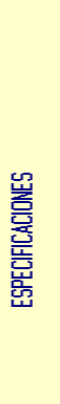 } & \multirow{6}{*}{$\begin{array}{l}\text { 譬 } \\
\text { 密 } \\
\text { 密 }\end{array}$} & \multirow{6}{*}{ 裹 } & \multirow{6}{*}{ 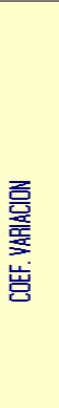 } & \\
\hline \multicolumn{2}{|c|}{ 暧 } & $\bar{\sigma}$ & $\square$ & 3 & $\Xi$ & 3 & & & & & & & & & \\
\hline \multicolumn{2}{|c|}{ 옴 } & \multicolumn{5}{|c|}{ 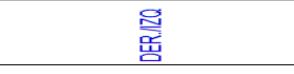 } & & & & & & & & & \\
\hline \multicolumn{2}{|c|}{ 윻를 } & & & 寝 & & & & & & & & & & & \\
\hline 要 & & & & 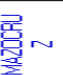 & & & & & & & & & & & \\
\hline$\overline{\overline{\underline{\underline{E}}}}$ & & - & $\sim$ & $m$ & $\theta$ & م & & & & & & & & & \\
\hline
\end{tabular}


ANEXO 2: Caracterización geotécnica de los agregados de la base espumada (Mezcla de Cantera Mazocruz y Cantera Km. 217)

Anexo 2.1: Ensayo de análisis granulométrico de la mezcla Cantera Mazocruz y Cantera Km. 217

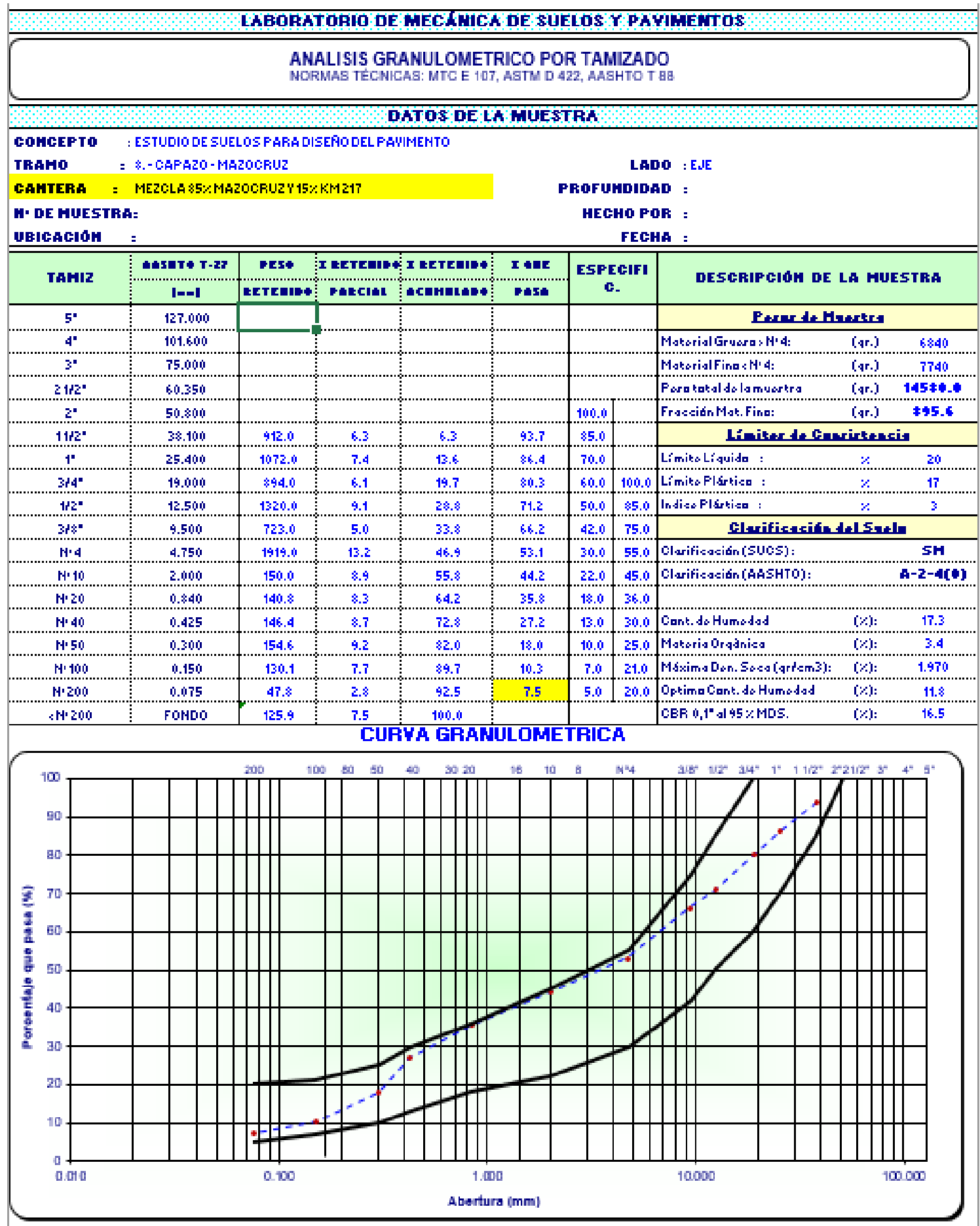


Anexo 2.2: Ensayo Proctor de la mezcla Cantera Mazocruz y Cantera Km. 217

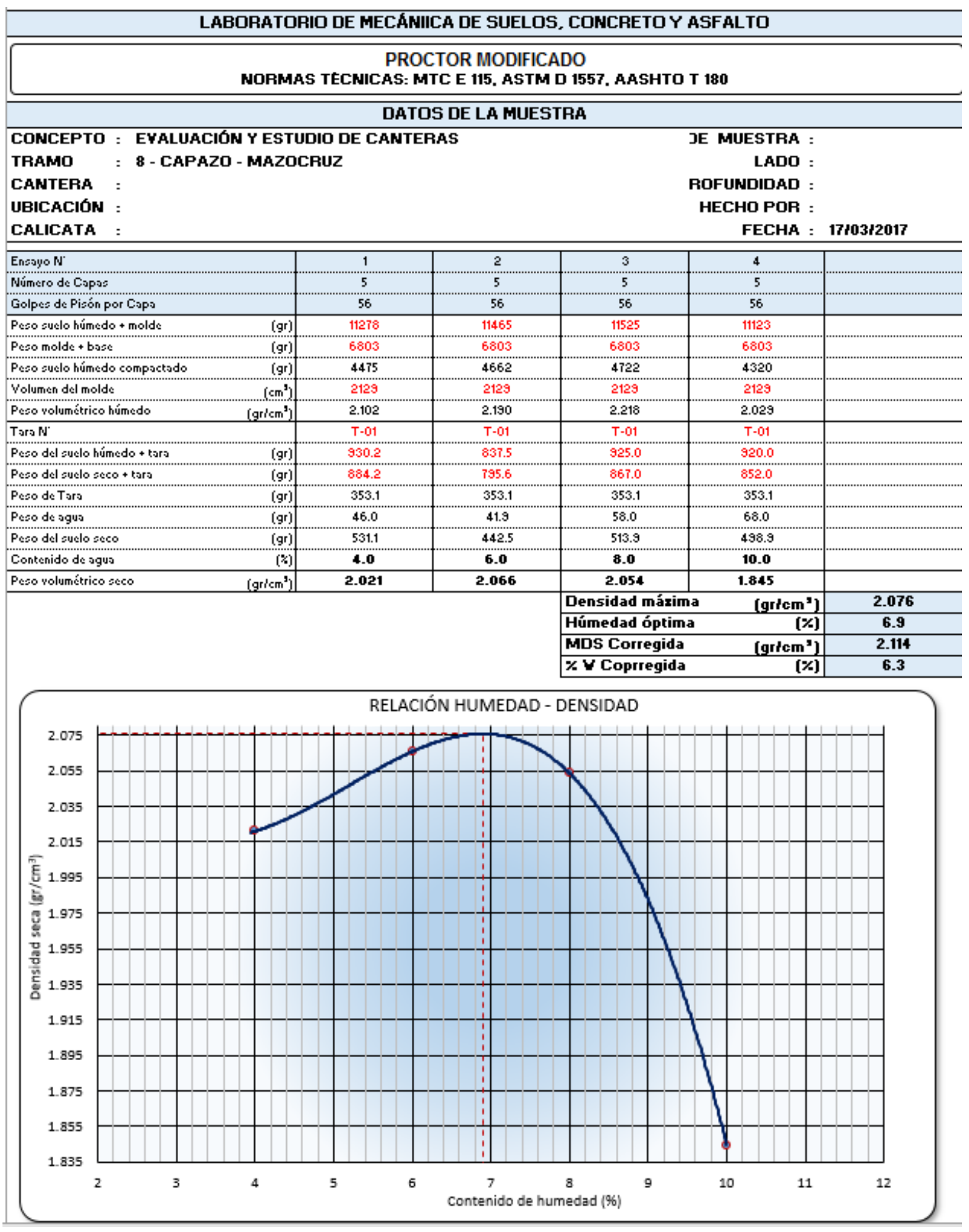


ANEXO 3: Diseño de Asfalto Espumado

Anexo 3.1: Asfalto PEN 85/100

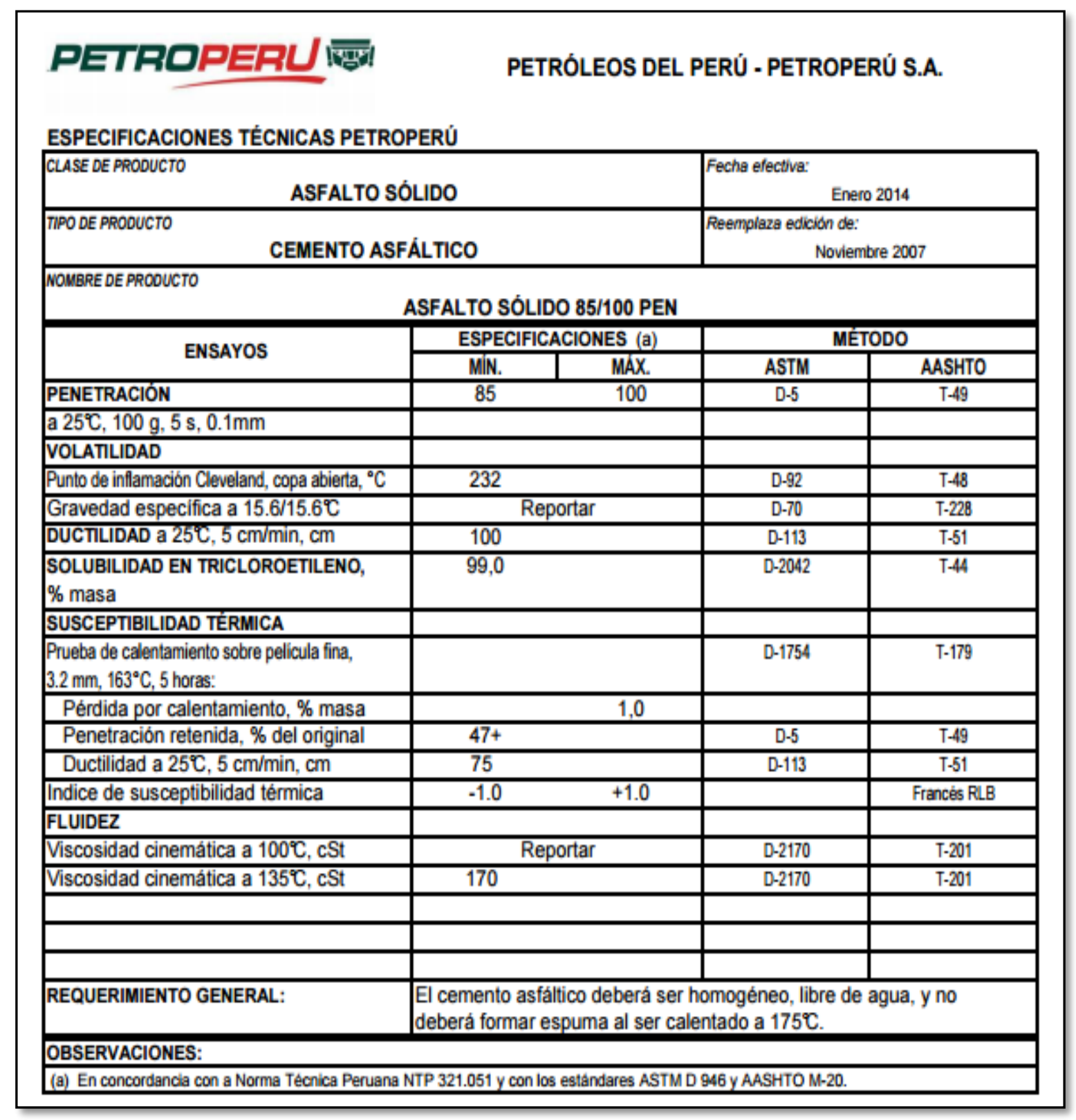


Anexo 3.2: Asfalto PEN 120/150:

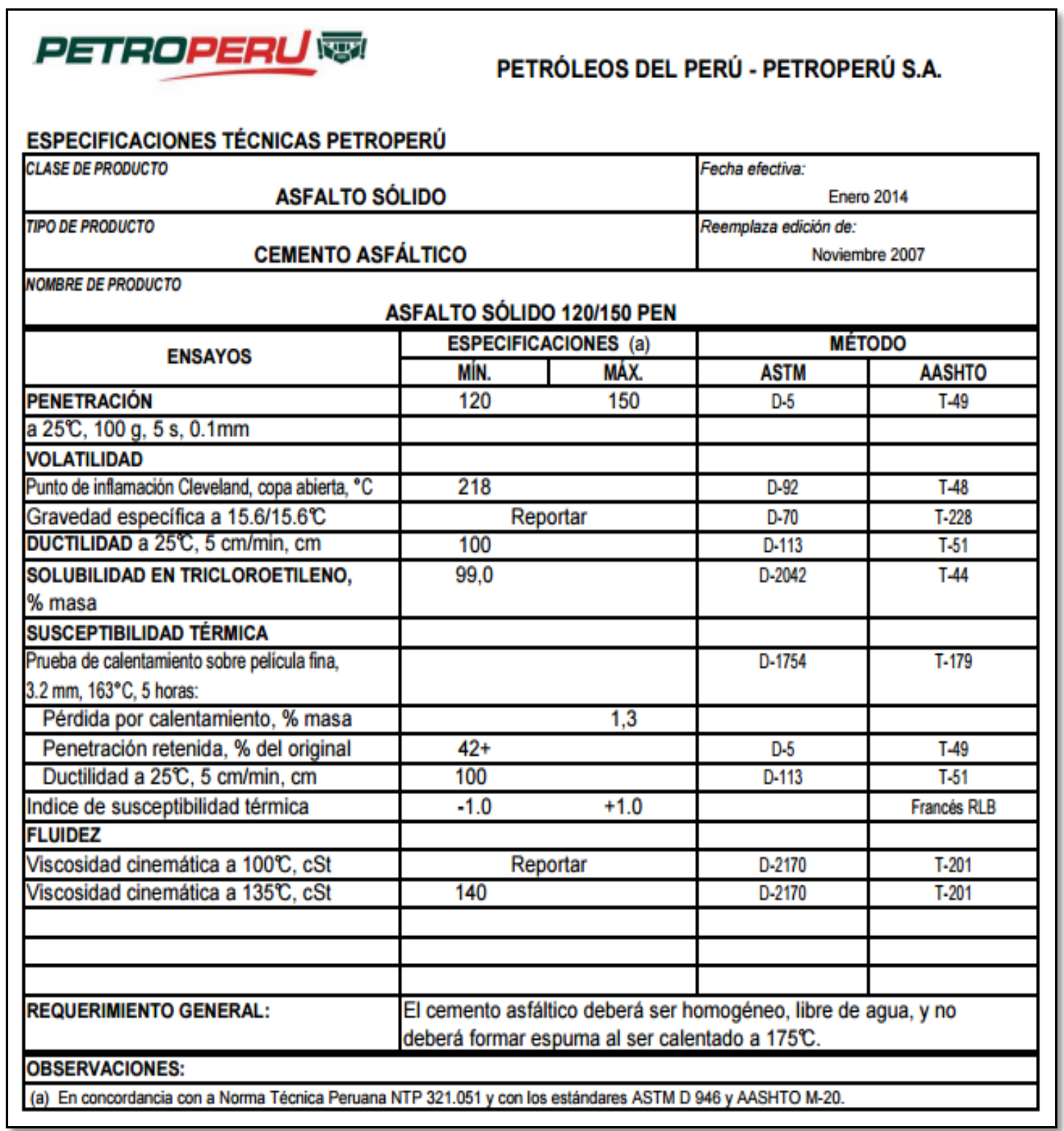


Anexo 3.3: Diagrama de ensayos realizados

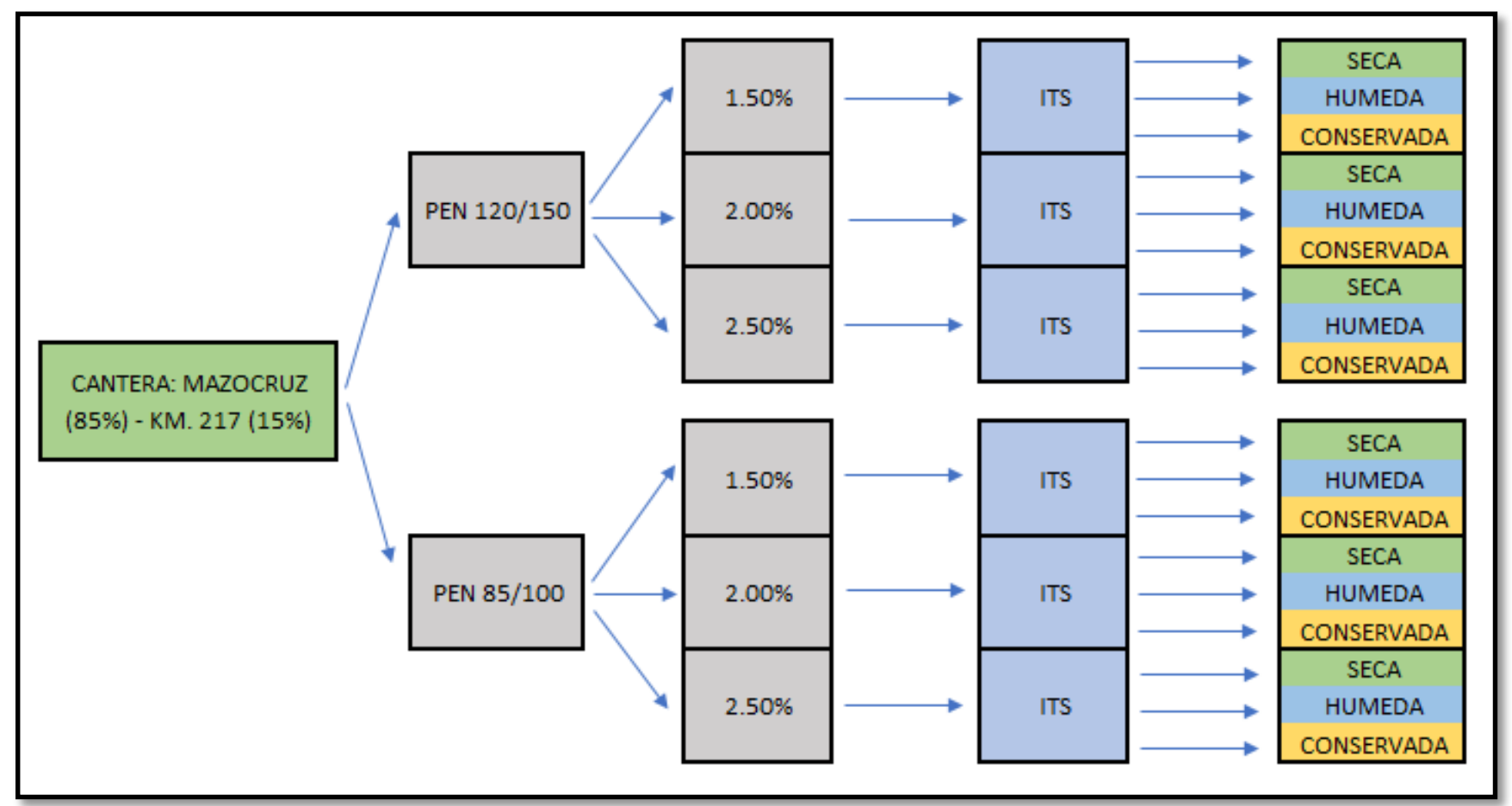


Anexo 3.4: Resultados de resistencia seca, húmeda y conservada para los distintos diseños de mezcla con cemento asfáltico PEN 120/150.

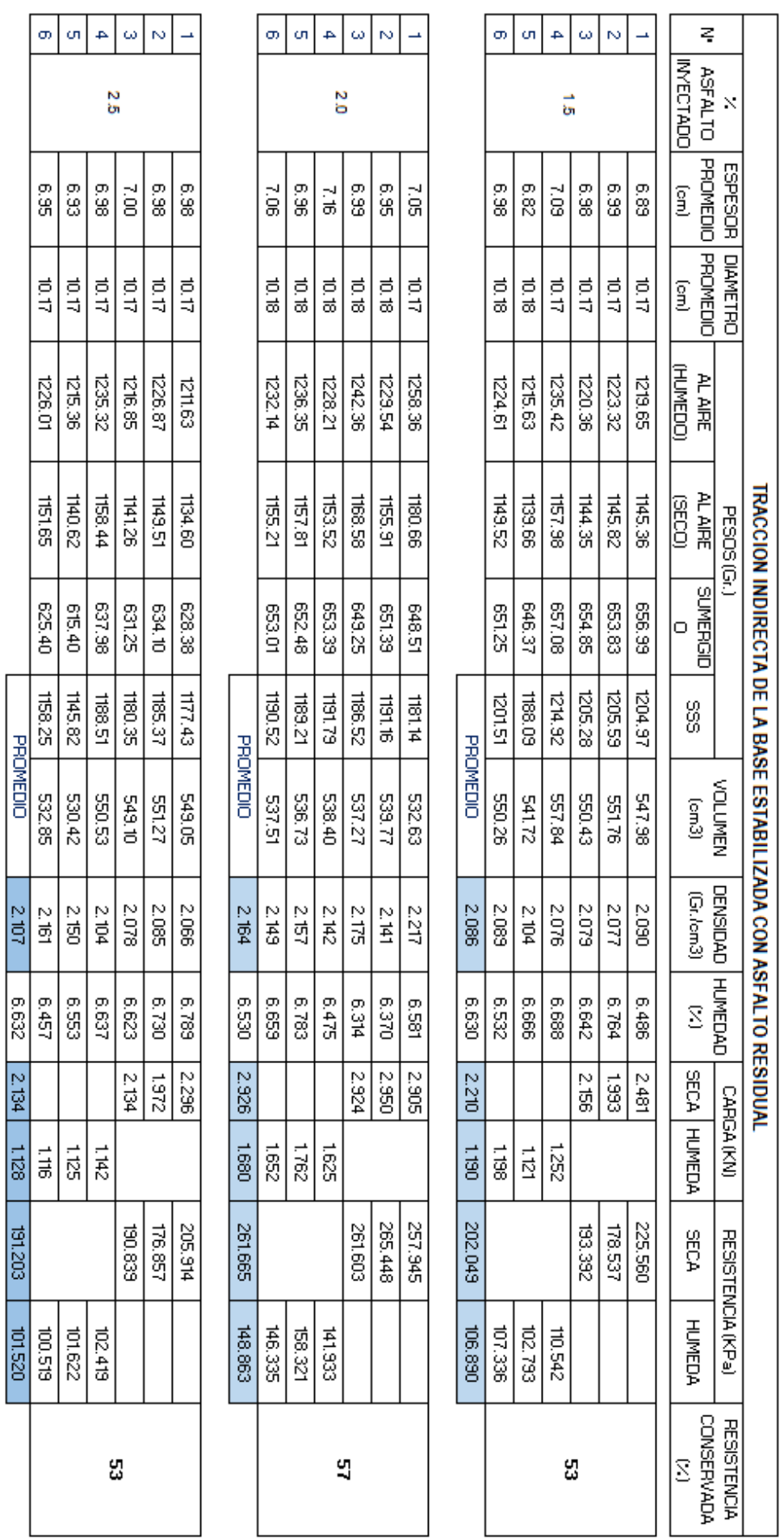


Anexo 3.5: Resultados de resistencia seca, húmeda y conservada para los distintos diseños de mezcla con cemento asfáltico PEN 85/100.

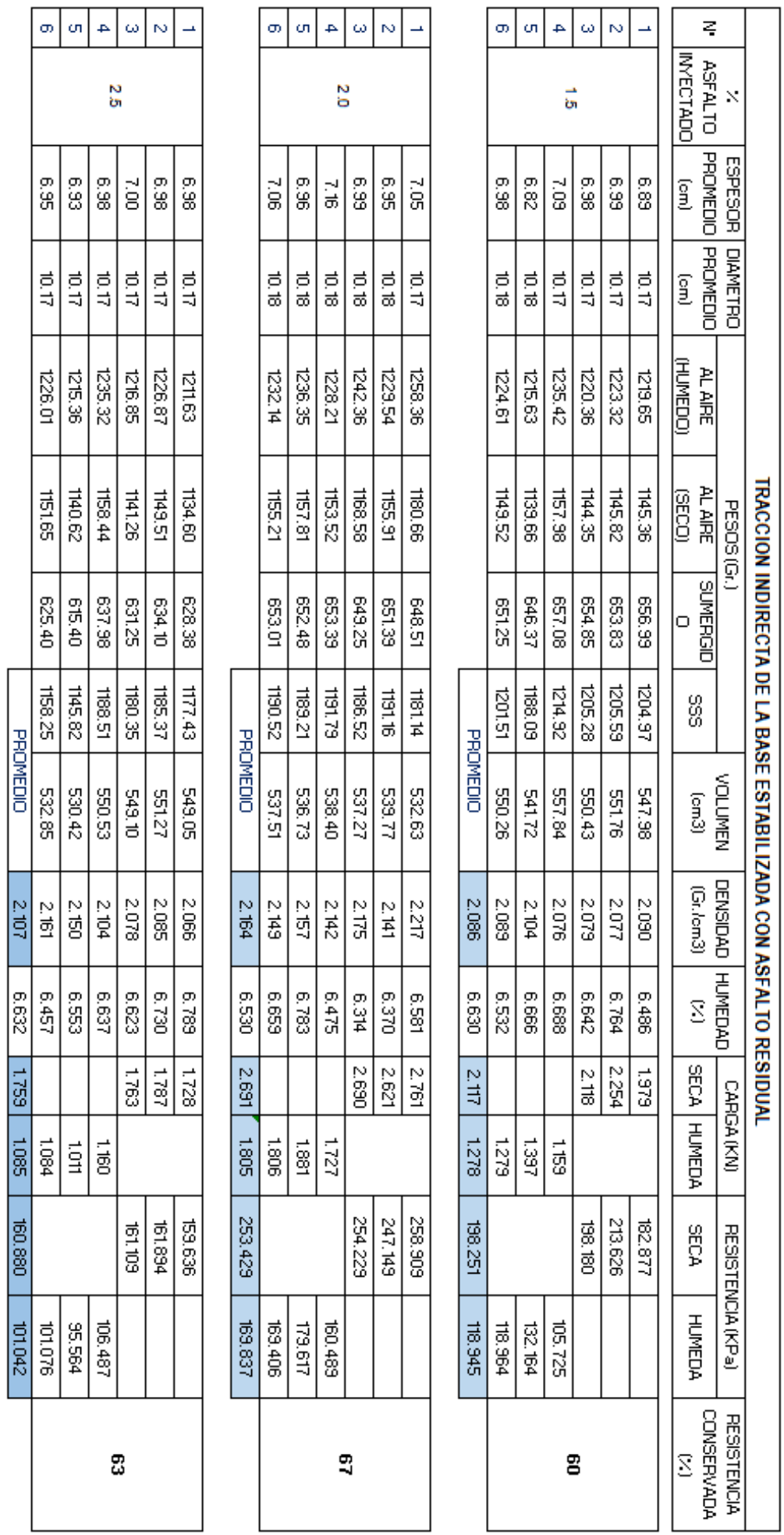


Anexo 3.6: Resultados de resistencia seca, húmeda y conservada de la capa estabilizada desarrollada en el proyecto (Asfalto inyectado 2.00\% - PEN 120/150)

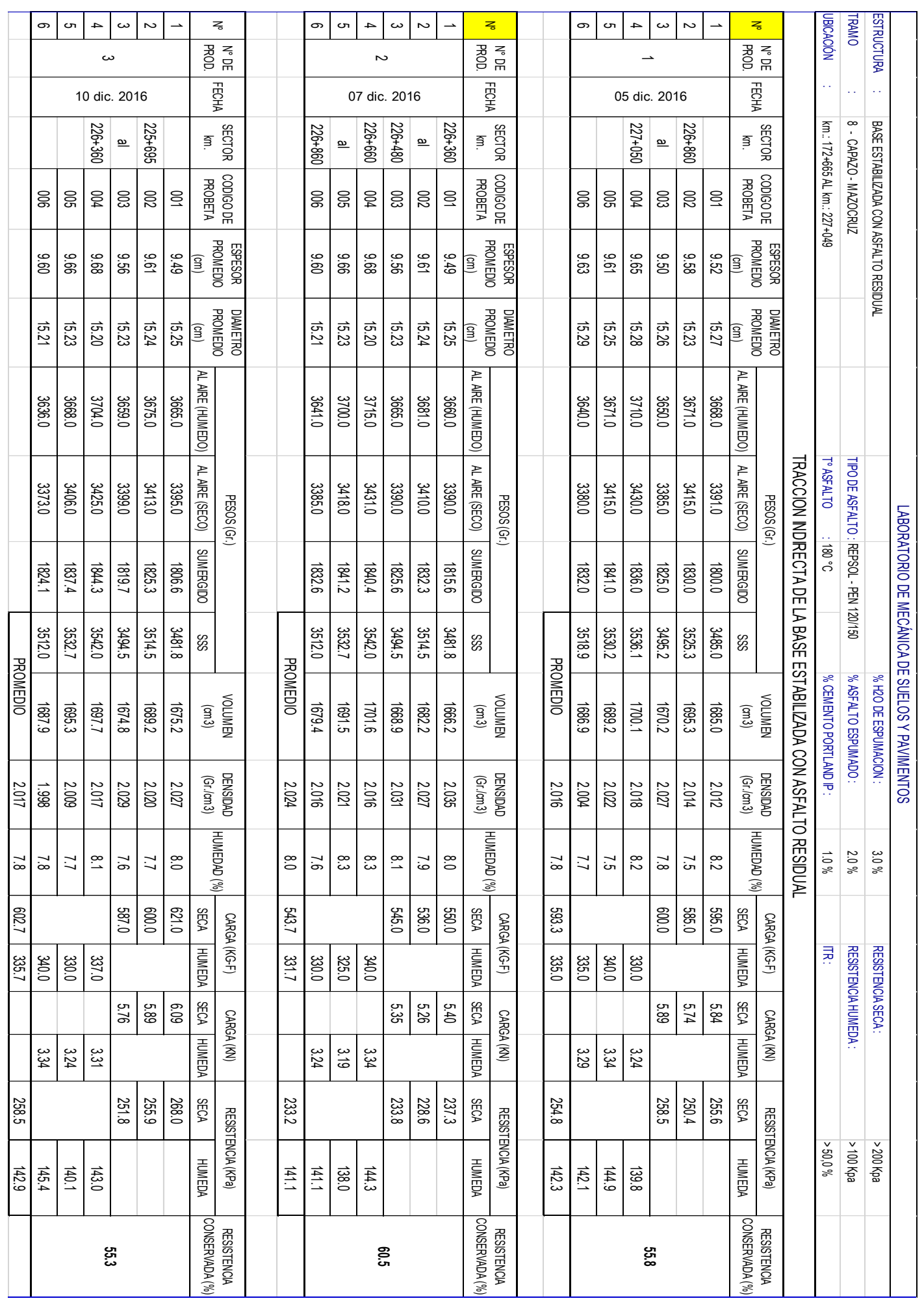




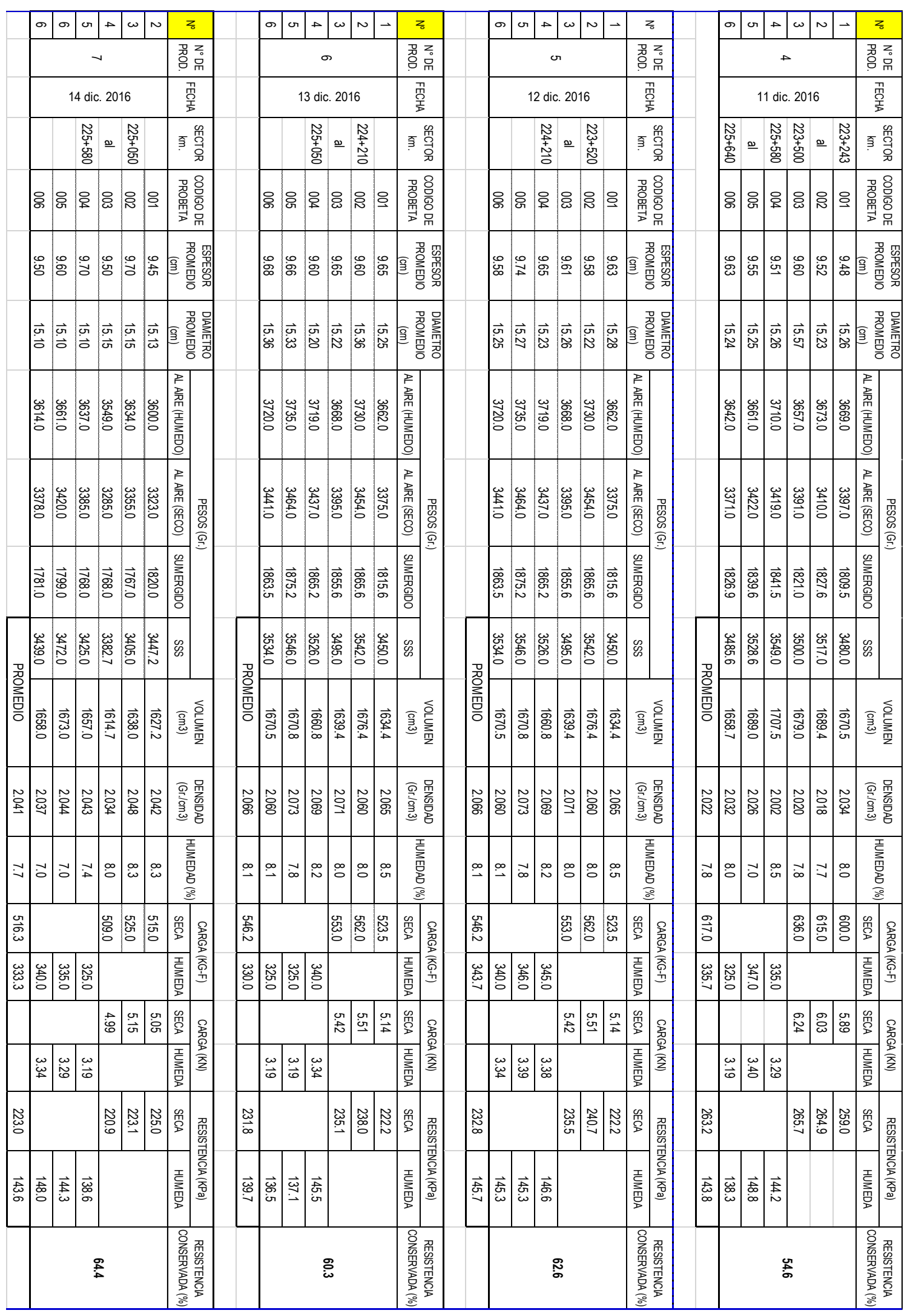

